\title{
Unpaid Work and the Economy
}

The unpaid domestic sector is surprisingly understudied in economics. In order to fully understand the functioning of the economic system, unpaid and voluntary work in the process of social reproduction needs to be taken into account and afforded the same analytical visibility as paid activities.

This book constitutes a rigorous economic analysis. Using a gender perspective to analyse standards of living and well-being it covers, in a very innovative approach, unpaid work and its major ramifications for the modern economy.

The unified vision that is offered by the leading array of contributors makes for a work of excellent quality. There is every chance that this book will become a seminal study on unpaid work and as such will provide a useful reference for students and academics involved in gender studies, wellbeing, the labour market, public policy, econometrics, and consumption studies.

Antonella Picchio is Professor at the Faculty of Economics at the University of Modena and Reggio Emilia, Italy. 


\title{
Routledge frontiers of political economy
}

\author{
1 Equilibrium Versus Understanding \\ Towards the rehumanization of economics within social theory \\ Mark Addleson \\ 2 Evolution, Order and Complexity \\ Edited by Elias L. Khalil and Kenneth E. Boulding \\ 3 Interactions in Political Economy \\ Malvern after ten years \\ Edited by Steven Pressman \\ 4 The End of Economics \\ Michael Perelman \\ 5 Probability in Economics \\ Omar F. Hamouda and Robin Rowley
}

6 Capital Controversy, Post Keynesian Economics and the History of Economics Essays in honour of Geoff Harcourt, volume one

Edited by Philip Arestis, Gabriel Palma and Malcolm Sawyer

7 Markets, Unemployment and Economic Policy

Essays in honour of Geoff Harcourt, volume two

Edited by Philip Arestis, Gabriel Palma and Malcolm Sawyer

8 Social Economy

The logic of capitalist development

Clark Everling

9 New Keynesian Economics/Post Keynesian Alternatives

Edited by Roy J. Rotheim

10 The Representative Agent in Macroeconomics

James E. Hartley

11 Borderlands of Economics

Essays in honour of Daniel R. Fusfeld

Edited by Nabid Aslanbeigui and Young Back Choi

12 Value, Distribution and Capital

Essays in honour of Pierangelo Garegnani

Edited by Gary Mongiovi and Fabio Petri

13 The Economics of Science

Methodology and epistemology as if economics really mattered

James R. Wible 
14 Competitiveness, Localised Learning and Regional Development

Specialisation and prosperity in small open economies

Peter Maskell, Heikki Eskelinen, Ingjaldur Hannibalsson, Anders Malmberg and Eirik Vatne

15 Labour Market Theory

A constructive reassessment

Ben J. Fine

16 Women and European Employment

Jill Rubery, Mark Smith, Colette Fagan, Damian Grimshaw

17 Explorations in Economic Methodology

From Lakatos to empirical philosophy of science

Roger Backhouse

18 Subjectivity in Political Economy

Essays on wanting and choosing

David P. Levine

19 The Political Economy of Middle East Peace

The impact of competing trade agendas

Edited by J.W. Wright, Jnr

20 The Active Consumer

Novelty and surprise in consumer choice

Edited by Marina Bianchi

21 Subjectivism and Economic Analysis

Essays in memory of Ludwig Lachmann

Edited by Roger Koppl and Gary Mongiovi

22 Themes in Post-Keynesian Economics

Essays in honour of Geoff Harcourt, volume three

Edited by Peter Kriesler and Claudio Sardoni

23 The Dynamics of Technological Knowledge

Cristiano Antonelli

24 The Political Economy of Diet, Health and Food Policy

Ben J. Fine

25 The End of Finance

Capital market inflation, financial derivatives and pension fun capitalism

Jan Toporowski

26 Political Economy and the New Capitalism

Edited by Jan Toporowsi

27 Growth Theory

A philosophical perspective

Patricia Northover

28 The Political Economy of the Small Firm

Edited by Charlie Dannreuther

29 Hahn and Economic Methodology

Edited by Thomas Boylan and Paschal F. O'Gorman

30 Gender, Growth and Trade

The miracle economies of the postwar years

David Kucera 
31 Normative Political Economy

Subjective freedom, the market and the state

David Levine

32 Economist with a Public Purpose

Essays in honour of John Kenneth Galbraith

Edited by Michael Keaney

33 The Theory of Unemployment

Michel De Vroey

34 The Fundamental Institutions of Capitalism

Ernesto Screpanti

35 Transcending Transaction

The search for self-generating markets

Alan Shipman

36 Power in Business and the State

An historical analysis of its concentration

Frank Bealey

37 Editing Economics

Essays in honour of Mark Perlman

Hank Lim, Ungsub K. Park and Geoff Harcourt

38 Money, Macroeconomics and Keynes

Essays in honour of Victoria Chick, volume one

Philip Arestis, Meghnad Desai and Sheila Dow

39 Methodology, Microeconomics and Keynes

Essays in honour of Victoria Chick, volume two

Philip Arestis, Meghnad Desai and Sheila Dow

40 Market Drive and Governance

Reexamining the rules for economic and commercial contest Ralf Boscheck

41 The Value of Marx

Political economy for contemporary capitalism

Alfredo Saad-Filho

42 Issues in Positive Political Economy

S. Mansoob Murshed

43 The Enigma of Globalisation

A journey to a new stage of capitalism

Robert Went

44 The Market

Equilibrium, stability, mythology

S.N. Afriat

45 The Political Economy of Rule Evasion and Policy Reform

Jim Leitzel

46 Unpaid Work and the Economy

Edited by Antonella Picchio 


\title{
Unpaid Work and the Economy
}

\author{
A gender analysis of the standards \\ of living
}

Edited by Antonella Picchio

(2) Routledge

(-) Taylor \& Francis Group LONDON AND NEW YORK 
An earlier version of Chapter 1 appeared as 'Un enfoque macroeconomico ampliado de las condiciones de vida' in Cristina Carrasco (ed.), Tiempos, Trabajos y Género, Universidad de Barcelona. An earlier version of Chapter 7 appeared as 'A nest or a golden cage: family coresidence, human capital investment and labour market decisions of young adults' in International Journal of Manpower, 21, 3 (July 2000). An earlier version of Chapter 8 appeared as 'Gender in the Italian welfare state reforms' in Southern European Policy and Society (1999).

First published 2003 by Routledge

Published 2017 by Routledge

2 Park Square, Milton Park, Abingdon, Oxon OX14 4RN

711 Third Avenue, New York, NY 10017, USA

Routledge is an imprint of the Taylor E Francis Group, an informa business

Copyright (C) 2003 Antonella Picchio; individual chapters (C) the individual contributors

Typeset in Garamond by Wearset Ltd, Boldon, Tyne and Wear

The Open Access version of this book, available at www.tandfebooks.com, has been made available under a Creative Commons Attribution-Non Commercial-No Derivatives 4.0 license.

British Library Cataloguing in Publication Data

A catalogue record for this book is available from the British Library

Library of Congress Cataloging in Publication Data

Picchio, Antonella.

Unpaid work and the economy : a gender analysis of the standards of living / Antonella Picchio.

p. cm. - (Routledge frontiers of political economy; 46)

Includes bibliographical references and index.

1. Wages-Women-Italy. 2. Wages-Women.

3. Wages-Housewives-Italy. 4. Voluntarism-Economic aspects.

5. Women-Social conditions. I. Title. II. Series.

HD6061.2.I8 P53 2003

$339.4^{\prime} 7^{\prime} 0820945-\mathrm{dc} 21$

2002036975

ISBN 978-0-415-29694-6 (hbk) 


\section{Contents}

List of illustrations $\quad$ ix

List of contributors $\quad$ xiii

Introduction 1

ANTONELLA PICCHIO

1 A macroeconomic approach to an extended standard of living

ANTONELLA PICCHIO

2 Unpaid work by gender in Italy

TINDARA ADDABBO

3 Extended income estimation and income inequality by gender

TINDARA ADDABBO AND ANTONELLA CAIUMI

4 Unpaid work and household living standards: equivalence scale estimation and intra-family distribution of resources

ANTONELLA CAIUMI

5 Unpaid work and household well-being: a non-monetary assessment

ENRICA CHIA P PERO-MARTINETTI

6 'Convenience consumption' and unpaid labour time: paradoxes or norms? 


\section{viii Contents}

7 Young people living with their parents: the gender impact of co-residence on labour supply and unpaid work

GIANNA CLAUDIA GIANNELLI AND CHIARA

MONFA R D I I

8 Unpaid and paid caring work in the reform of welfare states

ELISABETTA A D DIS

9 The gender impact of workfare policies in Italy and the effect of unpaid work

TINDARA ADDABBO AND MASSIMO BALDINI 


\section{Illustrations}

\section{Figures}

$1.1 \quad$ Co-operative flow 15

1.2 Extended living - standard flow 15

1.3 Social wealth flow 16

2.1 Allocation of time by gender on weekdays for different household types and with children $\quad 35$

2.2 Allocation of time by gender on weekdays for different household types and without children $\quad 36$

2.3 Allocation of time by gender for different household types and with children on Saturdays $\quad 37$

2.4 Allocation of time by gender for different household types and without children on Saturdays

2.5 Allocation of time by gender for different household types and with children on Sundays

2.6 Allocation of time by gender for different household types and without children on Sundays

2.7 Allocation of time by level of education and for women aged between 18 to 35 with children on weekdays 42

3.1 Extended standard of living 70

3.2 Distribution of total working time and of extended income by gender

3E.1 Allocation of time by gender - industrialised countries 98

3E.2 Allocation of time by gender - Italy 98

3F.1 Decile composition by employment condition of money income (a) and extended income evaluated at the opportunity cost (b) 99

4.1 Non-parametric Engel curves on monetary consumption 109

4.2 Non-parametric Engel curves on extended consumption 109

5.1 From resources to individual well-being in the capability approach

5.2 Household production process, individual well-being and gender inequalities 
6.1 Housewives' weekly working hours 163

6.2 Distribution of time among various kinds of household work 164

6.3 Time devoted to laundry 165

8.1 No welfare state 192

8.2 Symmetry in welfare states 194

8.3 Pathologies of the continental welfare state 198

\section{Tables}

2.1 Average weekly hours of work by gender and employment 30

2.2 Allocation of time by gender and household type households with children

2.3 Allocation of time by gender and household type households without children

2.4a Allocation of unpaid work by gender - double earners with children

2.4b Allocation of work by gender - double earners with children

2.4c Allocation of time by gender - double earners with children

2.5 Paid and unpaid work on different days of the week by gender - employed single people

2.6 Paid and unpaid work on different days of the week by gender - non-employed single people

2A.1 Descriptive analysis Indagine Multiscopo ISTAT 1989

2A.2 Allocation of time between different uses by gender and household type

2A.3 Unpaid work on average by household type

3.1a Estimated weekly working hours by gender

3.1b Unpaid versus paid work by gender - SHIW 2000

3.2 Descriptive statistics on monthly money and extended income

3.3 Income inequality by household type

$71-2$

3.4 Inequality measures of earnings, extended income and equivalent income for households and individuals

3A.1 Descriptive statistics and t-test on the SHIW and TBS (weekdays) samples and t-test

3B.1 Married women's housework equations

3B.2 Married women's care work equations

3B.3 Married women's constrained time of work equations

3B.4 Married men's housework equations

3B.6 Married men's constrained time of work equations 
3C.1 Comparison between observed and imputed values of unpaid work for couples with and without children

$91-2$

3C.2 Weekly unpaid work imputed values - samples of couples with and without children, SHIW 1995

3D.1 First step: employment probability 93

3D.2 Second step: wage equations 93

3D.3 Second step: wage equations 94

3E.1 Allocation of time by gender in one-earner households 95

3E.2 Allocation of time in one-earner households 96

3E.3 Allocation of time in double-earner households 96

3E.4 Allocation of time by women's age in households without children

3E.5 Allocation of time by women's age in households with children

3E.6 Allocation of time by women's education levels in households without children

3E.7 Allocation of time by women's education levels in households with children

4.1 Non-parametric Engel scale 110

4.2 Parametric Engel scale 111

4A.1 Descriptive statistics 118

5.1 Average membership degrees for each elementary subset 131-2

5.2 Average membership degrees for each functioning 133

5.3 Average membership degrees for each elementary subset 135-6

5.4 Average membership degrees for each functioning 137

5.5 Distribution of time by sex 138

5.6 Unpaid work - whole sample 140

5.7 Unpaid work - employed people 141

5.8 Total time - whole sample 142

5.9 Total time - employed people 143

5.10 Fathers' and mothers' unpaid work by children's age 144

7.1 Observed sample frequencies for males aged 18 to 32

7.2 Observed sample frequencies for females aged 18 to 32

$\begin{array}{lll}7.3 & \text { Reference individual characteristics } & 175\end{array}$

7.4a Marginal effects and elasticities - women 176

7.4b Marginal effects and elasticities - men 176

7.5 Effects on probabilities of variations in categorical

7.6 Average probabilities by region of residence 178

7.7 Domestic hours of work - people aged 18 to 32 with a high school diploma

7B.1 The multinomial logit regressions 183-7

8.1 Taxonomy and evaluation of welfare regimes 216

8A.1 Participation rates by sex, selected years 218

8A.2 Unemployment rates by sex, selected years 219 


\section{xii Illustrations}

8A.3 Social expenditure in the EU countries as a percentage of GNP

8A.4 Main categories of social protection expenditure in EU 12

9.1 Distribution of households by working status of partners and equivalent financial income

9.2 Households with children

9.3 Households without children

9.4 Distribution of households by area of residence and equivalent financial income

9.5 Distribution of households by educational level and equivalent financial income

9.6 Distribution of households by age of wife and equivalent financial income

9.7 Changes in financial income, unpaid work income and extended income for working wife

9.8 Changes in financial income, unpaid work income and extended income for working husband

9.9 Changes in financial income for single-earner households, not including childcare costs

9.10 Changes in financial income for single-earner households, including childcare costs

9A.1 Equations on married women's housework on different days of the week

9B.1 Employment probability (Heckman first step) 245

9B.2 Wage equations (second step, potential wage) 245 


\section{Contributors}

Tindara Addabbo Dipartimento di Economia Politica, Università degli Studi di Modena e Reggio Emilia; Research fellow of CHILD (Centre for Household, Income, Labour and Demographic Economics) and of CAPP (Centro di Analisi delle Politiche Pubbliche); e-mail: addabbo@unimore.it.

Elisabetta Addis Facoltà di Economia, Università di Sassari; e-mail: elisabetta.addis@uniroma1.it.

Massimo Baldini Dipartimento di Economia Politica, Università di Modena e Reggio Emilia, and CAPP (Centro di Analisi delle Politiche Pubbliche); e-mail: baldini@unimore.it.

Antonella Caiumi ISAE (Istituto di Studi e Analisi Economica), Rome, and CAPP (Centro di Analisi delle Politiche Pubbliche), Dipartimento di Economia Politica, Università degli Studi di Modena e Reggio Emilia; e-mail: caiumi@unimore.it.

Giuliana Campanelli Department of Economics, Finance and Global Business, William Paterson University, New Jersey; e-mail: andreopoulosg@wpunj.edu; and Dipartimento di Scienze Economiche, Università di Bologna; e-mail: campanel@spbo.unibo.it.

Enrica Chiappero-Martinetti Dipartimento Economia Pubblica e Territoriale, Università di Pavia; e-mail: enrica.chiappero@unipv.it.

Gianna Claudia Giannelli Dipartimento di Studi dello Stato, Università di Firenze, and CHILD (Centre for Household, Income, Labour and Demographic Economics); e-mail: giannelli@uniff.it.

Chiara Monfardini Università degli Studi di Bologna and CIDE (Centro Interuniversitario di Econometria); e-mail: chiaram@sun.economia.unibo.it.

Francesca Olivier CAPP (Centro di Analisi delle Politiche Pubbliche), Dipartimento di Economia Politica, Università degli Studi di Modena e Reggio Emilia; e-mail:folivier@iol.it.

Antonella Picchio Dipartimento di Economia Politica, Università degli Studi di Modena e Reggio Emilia; e-mail: picchio@unimore.it. 



\title{
Introduction
}

\author{
Antonella Picchio
}

\section{Unpaid work and living conditions}

Unpaid domestic work comprises the labour involved in maintaining living spaces, buying and transforming the commodities used in the family, supplementing services provided to family members by the public and private sectors (e.g. health, education, transport, administration), and managing social and personal relationships. To this, which represents the great bulk of unpaid work, the care of people has to be added. ${ }^{1}$ By revealing the quantity of unpaid work we bring out: (1) the extent and persistence of major inequalities between men and women in the distribution of time, activities, economic resources and social responsibilities; (2) a necessary and dynamic component of the economic system represented by the process of social reproduction of the population and of the working population in particular. ${ }^{2}$ Living conditions, however defined and measured, represent a state within the process of social reproduction.

With regard to the first point, the data show that differences between men and women in the distribution of unpaid work are in general highly significant and in Italy in particular - a great, persistent inequality that 'spreads' into the labour market and the distribution of income, affecting both the level and type of income. Because of the systematic interrelationship between paid and unpaid work, the usual analysis of the labour market, limited to activity rates, employment, sectors and so on, needs to be extended. For this purpose, in this research we introduce new concepts such as total work, i.e. the sum of paid and unpaid work, and extended income, i.e. the sum of money income and services derived from unpaid work. This extension is calculated not only to bring out crucial differences between men and women in the family and in the market, but also to deepen the analysis of the whole economic system. It is merely a first step, since much remains to be done to provide an adequate view of the economic implications of unpaid reproductive work and to acknowledge that the process of social reproduction of the population is one of the basic issues, along with the production, distribution and exchange of commodities. In particular, the reproduction of the working population has to be considered a necessary input of 


\section{Antonella Picchio}

the productive process as acknowledged in classical political economy (Picchio 1992).

The process of social reproduction is here taken to include the reproduction of bodies and minds located in historical times and geographical spaces. As such it includes the provision of material resources (food, clothing, housing, transport) and the training of individual capabilities necessary for interaction in the social context of a particular time and place. At the level of education, for instance, it includes not only formal education and vocational training, but also, with increasing visibility, the formation of individual and collective identities to carry out new tasks and take advantage of new opportunities - involving mobility, job changes and mass communication. These new tasks lead, among other things, to changes in social conventions and consumption patterns, whose stimulating and disorienting effects require continuous adaptation of individual identities and social relationships. In this process, in fact, the conditions of sustainability of the whole system have to be continuously reconstituted.

The formation of identity begins in early infancy in a personalised, multidimensional relationship in which emotions, languages (of body and mind), socialisation and vast amounts of care work are all interwoven. In addition, adults have to receive - and to some extent give - a certain amount of personal services necessary to activate capabilities and social functions. The analysis of the unpaid work of social reproduction shares problems with the concept of well-being as studied by Amartya Sen and Martha Nussbaum. ${ }^{3}$ It is a dense concept related to individual and social choices about practices of living in given social contexts. In this book the concept of well-being as capability and effective individual functioning is extended to include unpaid reproductive work that plays a fundamental role in forming capability and sustaining effective functioning. This inclusion leads to a definition of wellbeing as a state of a process of social reproduction which requires material goods and commodities, personal services provided by paid (state and market) and unpaid work (in the household and in the community). This process takes place within an institutional context, which involves families, state institutions, firms, markets and communities.

Some of the difficulties involved in developing and calibrating the empirical tools required for measuring unpaid work, and its division between men and women, arise from the analytical opacity of the whole question of social reproduction of the population. This tends to conceal the role of unpaid reproductive labour in the economic structure. The standard of living is usually conceptualised as a stock of commodities and services. In fact, a historically given bundle of commodities and services may be used as an indicator but the whole process cannot be reduced to it. That would be equivalent to analysing productive processes solely in terms of technical indicators. Without an adequate conceptualisation and analytical location of the process of social reproduction of the population as such, we lose sight of a dense and multidimensional core of the structure of any economic system, where both 
equity and efficiency are rooted. The term 'structure', although out of fashion, implies a necessary component whose changes affect the conditions of reproduction of the whole system. The living conditions of the working population, in fact, have a crucial impact on the efficiency of production, the dimension of markets and the distribution of income. ${ }^{4}$ Thus unpaid work as a major component of the process of social reproduction has a structural role which still needs to be adequately analysed and conceptualised.

In this tangle of questions, statistical language may offer a few useful signposts to avoid getting lost in complexity. When unpaid labour is revealed and quantified, it can be seen in its social and historical features. Moreover, we can escape the reductionism of a purely demographic approach that seems to take into account only sex, age, number of children and family composition, as if the position of women (young and old) and of the young and old (men and women) depended only on natural characteristics such as sex and age and not on the division of labour, income and social responsibility based on the social power of the different segments of the population, both in society and the family.

Despite historical changes in economic contexts, technologies, fertility rates, forms of sexual and generational relationships, the quantity of unpaid socially reproductive labour and its distribution on the basis of sex and age is proving slow to change. This, however, is a fact that needs to be explained; it cannot be attributed to an immutable self-sacrificing female nature. The unpaid work of reproduction bears the burden of many contradictory demands both for modernisation and the defence of tradition; for recognition of equal opportunities and for the maintenance of historical hierarchies between men and women; for the opportunity to leave home to earn an income and the stability required to manage everyday life. The tensions can be disentangled and the blob given a shape only by starting from a perspective of women's agency in disclosing real processes, setting priorities and in finding a sense in the relationship between the individual man and woman and society. Their agency defines a social space, which includes the three fundamental economic institutions - family, state and market - and both paid and unpaid work.

The necessary reductionism of statistical measurement enables us to stand back and distinguish, for example, housework from the work of personal care and the work of financial and bureaucratic management. Statistics assume, among other things, a symbolic role, which makes it possible to confront the problem in less dense and private terms. The tensions in the real world over the distribution of work and resources between production and social reproduction can lead economists to shut their eyes to the problem. The trouble is that in this defensive blindness many important questions disappear from view, so that problems which are important in economic reality drop out of the analysis, and those that remain are distorted. This has more than marginal implications for the failure of economic policies.

In the case of women, the removal of the relationship between paid and 


\section{Antonella Picchio}

unpaid work from the analysis of their position in the labour market patently lacks sense. The female labour market is marked by the very interweaving of paid and unpaid work; the distribution of time between these two kinds of work is continually adjusted in the life cycle, week and day, depending on conventions rooted in time and class and gender power relationships. This experience, largely female, has finally acquired empirical visibility in official statistics at international level; for example, the Canadian Statistical Institute has published a satellite account on 'total work' that includes all the activities, paid and unpaid, of men and women (Statistics Canada 1996).

The fact that unpaid work does not meet the golden rules of substitution between activities on the basis of relative prices given the income and time constraints, but depends instead on conventional rules, power relationships and responsibilities, is not due to backwardness. In fact, it is strongly present even in industrialised countries, as shown in the UNDP Human Development Reports. ${ }^{5}$ If one looks beyond the traditional indicators of equal opportunity (activity rates, political representation, public and health services), the contradictory link between paid and unpaid work emerges even in Sweden, where inequalities between men and women, in the labour market and in relation to the state, remain strong with regard to part-time jobs, wages and salaries, and incomes (in level and type). Even in Sweden, persistent gender differences in the distribution of unpaid work between men and women may be seen in hours of work, careers, sectors, qualifications and public transfers (Nyberg 1998). ${ }^{6}$

In Italy, in the Region of Emilia Romagna, where women's activity rates are the highest in the country and the standard of childcare services is relatively high in quality and extent, we find a persistent solid amount of unpaid work. ${ }^{7}$ The result is that Emilian women have the highest total workload in Italy, thanks also to male behaviour similar to that in the South. It is interesting to note that even the high quality of services has the effect of increasing unpaid work - on the one hand, because working time is increased, for example, by travel and school meetings, and, on the other, because when a child is at home the relationship dictates new priorities with respect to other domestic activities (Osservatorio 1997: Chapter 9).

\section{Structure of the research}

This research uses the visibility of unpaid work, made possible by the data from the Italian Statistical Service (ISTAT) Time-Use Survey, to investigate the question of the living conditions of the working population and their productive role in the functioning of the economic system. The ISTAT survey lays the groundwork for beginning to answer questions such as 'How much unpaid work is done?' and 'Who does it?' Nevertheless, there still remains the problem of where and how to use the information within the economic system to give an adequate reflection of its quantitative and qualitative importance. For this purpose, this study is based on the connec- 
tions identified between the economic system and unpaid work. On the basis of these conceptual and quantitative connections, it may be possible to start thinking of economic policies to address the problem directly, rather than continually tracking down its perverse and unexpected effects. This is a new, undeveloped field in which one can proceed only by trial and error, and hence with caution and modesty, to consolidate analytical and empirical tools that may help to yield an advance in the state of the art.

The research proceeds on three levels: (1) the conceptualisation of links between unpaid work and the structure of the economic system; (2) the formulation and calibration of some tools for bringing data on unpaid work into direct relation with incomes, consumption and the labour market; (3) the indication of possible areas in which to assess the gender impact of economic policies, focusing on total work and extended incomes.

The connection between unpaid work and the economic structure is identified in the living conditions of the working population, conceived of as a process in which goods, services and work (paid and unpaid) are used to socially reproduce the population and enable it to keep the system going. Unpaid work is inserted into a circular flow of production of goods and services in which the space for human development is defined by the living conditions and well-being of the working population. This is a macroeconomic analytical picture that goes beyond the traditional microeconomic approach of analysis of the family. However, when the compact family nucleus is opened up by the analysis of the intra-family distribution of work and the consequent extension of the economic analysis, there is a risk of dangerous economistic reductionisms. To avoid these, at least in part, we also proceed to expand the meaning of individual and collective objectives and behaviour. This expansion is tied up with the concept of well-being, understood not in the traditional utilitarian sense of individual maximisation of utility within given constraints of time and income, but as the result of individual and social real practices which develop human capabilities for the exercise of vital social functionings, expressing and shaping the quality of men's and women's lives. The multidimensionality of these functions 'expands' the analysis to a field different from that of the traditional economic analyses focused exclusively on the exchange and allocation of scarce commodities. In this way we can bring to light certain qualitative modifications in the relation between (sexed and gendered) individuals and society, and make visible certain tensions inherent in the labour market, and through it the production and exchange of social wealth.

Placing unpaid work within a macroeconomic circular flow makes it possible to raise the question of the quality and adequacy of living conditions and well-being of the working population, not as women's responsibility but as a central and general problem of the system, thus redefining the traditional view where the functioning of the economic system is reduced to monetary exchanges. The point is not to reduce the work of social reproduction to an economistic dimension by stripping it of the complexity and richness of 


\section{Antonella Picchio}

other anthropological, cultural and emotional dimensions, but to find an approach that does not relegate it to the margin of the analysis of the economic structure and its dynamics. This inclusion could lead to a different view as to what is meant by 'economic', since economic reductionism derives largely from the very removal of the many dimensions of the process of social reproduction of the population.

Traditionally in economics, conceptualisations must go hand in hand with measurements, because this makes it possible to create a ground for reasonable consensus. ${ }^{8}$ At the empirical level this study carries forward experimentally the integration of unpaid work and incomes, combining the data made available by the ISTAT Time Budget Survey with another important data-set, that of the Bank of Italy's Survey on Household Income and Wealth. The availability and adequacy of data on unpaid reproductive labour are still far from being satisfactory, but even more needs to be done to develop essential tools for empirical analysis to link the data on total labour (paid and unpaid) with data on income. This is not surprising, since even data on wages and incomes disaggregated by sex are still scarce.

In their collective research in this volume the authors of the different contributions:

- Measure the distribution of total working time and resources between men and women in Italy, by an innovative econometric model matching time-use data with other standard data-sets.

- Explore alternative ways to measure the contribution of unpaid work to welfare, using a new, fuzzy logic approach.

- Analyse the links between use of time, consumption of goods and consumption of time-saving goods.

- Link use of time in paid and unpaid work and demographic variables (fertility and presence of children in the household).

- Study how the choice between paid and unpaid work is affected by taxation and subsidies, and then assess the impact of some policy measures on this choice.

- Recommend public policies that explicitly take into account the economic value of unpaid work.

Different authors have written the following chapters, but the book is the result of a closely coordinated research effort which lasted for more than two years, focusing on unpaid work and its contribution to the economic system. Very different approaches and quantitative tools are used derived from various intellectual traditions in economics to investigate the same subject: a classical institutional circular macroeconomic approach, a microeconomic neoclassical analysis, a capability framework, econometrics and a nonstandard mathematical methodology. The result is that by making all of women's work visible, new dimensions of the economic system are disclosed such as a process of social reproduction, the role of social conventions and 
historical power relationships, and the structural interlinkage between family, state and markets. It is an advance in terms of realism, which requires further discussion to lead to a theoretical framework of relative prices and distribution of incomes and resources capable of reflecting the relevance and nature of these problems. The techniques and tools used here are different, but the choice was to allow each researcher to confront the problem of unpaid work using her or his own 'tool-box' without being constrained, in this experimental phase, by attempts at theoretical uniformity. This means that the work is not only pragmatic but also eclectic. All the contributors, however, share common objectives and focus, and all succeed in producing a shift of perspective.

Chapter 1 introduces the reader to the overall theoretical framework of the research using a circular macro framework containing unpaid work and revealing its contribution in the family, in social well-being and in the labour market. In fact, Figure 1.2 may be used as a guide to placing the various contributions of the different authors in a sequence that follows the basic functions of unpaid work. First, it starts with the process of extending standards of living from a bundle of commodities and services acquired through the paid economy into its transformation by unpaid work into an actual standard. Second, it follows the process of expanding the actual standard of living into a state of well-being which focuses on the formation of individual capabilities and their use in social functioning. Third, it shows the function of unpaid work in supporting the waged labour market in its selection of people. Finally, Figure 1.3 provides a broader picture that covers the monetary and non-monetary economy necessary to assess social policy, taking into account unpaid work. In Chapter 2 Addabbo uses ISTAT Time Budget Survey data (TBS) in order to measure the amount of unpaid work undertaken by people of different sexes in households of different composition; on different days of the week a woman's unpaid work increases in the presence of children, and also, independently, in the presence of a husband and other adult members of the household. ${ }^{9}$ In Chapter 3 Addabbo and Caiumi match two different data sources (ISTAT TBS and the Bank of Italy Survey on Household Income and Wealth, SHIW) to measure the monetary value of unpaid work, by imputing unpaid work estimated by using ISTAT TBS data to the Bank of Italy SHIW data. Addabbo and Caiumi present computations according to two leading methodologies (service price and opportunity cost). Finally, they add the monetary value of unpaid work to money income, to obtain an econometric measure of 'extended' household income. This is a better measure of total resources accruing to the family than monetary income alone, and therefore a more accurate tool in measuring welfare and its distribution. In Chapter 4, Caiumi provides some technical background on how equivalence scales change when household production is included in the selected bundle of conventional necessities. The results show that the age profile of the cost of children is significantly affected and that data on unpaid work are essential in order to analyse infra-household allocation of resources. In Chapter 5, 


\section{Antonella Picchio}

Chiappero-Martinetti takes a very innovative approach, pointing to the concept of 'capabilities and functioning' introduced by Amartya Sen, making it operational by means theory of fuzzy sets, and underlying the strong gender inequality in the provision of basic functioning found in Italian data. Campanelli (Chapter 6) studies the complicated pattern of 'convenience consumption' of time-saving commodities. The availability of such commodities does not increase leisure time, since social conventions change the normal standards of living. In Chapter 7, Giannelli and Monfardini analyse the gender impact of adult children co-residence with their family on their labour supply and on unpaid work. Addis (Chapter 8) compares the role of different welfare state 'regimes' (Nordic, Liberal and Bismarckian) in determining the amount of unpaid and paid work undertaken by men and women; she also shows how some types of welfare programme foster women's low participation rates, high unemployment rates, dependency and low fertility, while others do not. Finally, Addabbo and Baldini (Chapter 9) use the data and the econometric tools developed in Chapters 2 and 3 to measure the impact of the recent Italian minimum insertion income policy, taking into account total work and extended income.

The research proceeds by partial but significant examples, seeking, on the one hand, to conceptualise the question of living standards in terms of commodities, services and unpaid work. On the other hand, it aims to elaborate certain quantitative tools to measure the impact of unpaid work at policy level. The initial objective of extending and deepening the analysis showing the importance of unpaid work on certain important dimensions of the economic system seems to have been achieved with regard to:

- the distribution of income;

- the distribution of work and incomes within the family;

- the analysis of well-being as the generation and exercise of human capabilities and functionings;

- the elucidation of certain links between unpaid work and the consumption market;

- the importance of an extended approach for evaluating the impact of economic policies.

As the person responsible for directing this study commissioned by CNEL (Consiglio Nazionale Economia e Lavoro) from the Department of Political Economy of the University of Modena and Reggio Emilia, and as editor of this book, I must thank the whole research group. Their enthusiasm and sense of involvement has made the work very gratifying and productive for the common purpose of adapting analytical and empirical tools to reality as Keynes taught - rather than adapting reality to the tools - a practice that is currently widespread. 


\section{Acknowledgements}

This study is based on research sponsored by the CNEL (Italian National Council of Economy and Labour) on 'Unpaid work and standards of living'. The research was commissioned from the Department of Political Economy of the University of Modena and Reggio Emilia, and the research group was directed by Antonella Picchio.

I would like to thank my very dear friends Ann Johnston and Joan Hall. Ann has copyedited the whole book with her well-known competence and kindly took upon herself all the tensions arising from inaccuracies in the original; Joan has, once again, generously supported me with her expertise in languages, translating the Introduction and Chapter 1 with great improvements to my style and thoughts.

Finally, I am very grateful to Adriana Buffardi and Caterina Guarna, respectively, at the time, Counsellor and Senior Officer of CNEL, who used their influence to open an institutional space for this research and supported it warmly all the way. I also thank CNEL for having financed the research and for allowing permission for its publication.

\section{Notes}

1 To indicate the whole range of activities listed we shall often use the term 'work of social reproduction'.

2 The term 'working population' denotes that part of the population which has access to the means of subsistence through income from work, not property. Obviously this is not a clearly defined category, since the working population may also have access to some income from property (e.g. home ownership, pension funds). Nevertheless, there remains a large part of the population which depends principally on wages and other forms of paid work, either directly or indirectly as family dependants.

3 The capabilities approach is becoming a wide field of research. For some basic references see Nussbaum 2000; Sen 1987, 1993.

4 It is worth remembering that the classical political economy focused on the structural dynamics of the social system. In its analysis the questions of money, international trade, value, capital, distribution of income and, last but by no means least, the subsistence of the population are all fundamental blocks of its foundations. In the analysis of the classical economists subsistence did not mean survival, but the materially and socially sustainable conditions of life (Picchio 1998). As social theorists and economic thinkers become aware that capital is constituted essentially by waged labour, the question of subsistence - i.e. of the social and reproductive adequacy of wages - is progressively removed, reappearing later only as separate and marginal, i.e as a demographic problem, wage rigidity, poverty and social exclusion.

5 See in particular Human Development Report 1995 and the ones following.

6 Even in the case of the Swedish Institute of Statistics, definitions have a strong symbolic value. For example, the concept of 'independence' is interpreted differently for men and women: a woman is defined as 'independent' when she earns a living wage, while a man is considered 'independent' when he can live without working for a wage. For the woman, in other words, it is mainly a question of independence from men, while for a man it is independence from waged work (Nyberg 1998: 3).

7 In spite of an activity rate for women between the ages of 25 and 55 at 60 per cent, 


\section{Antonella Picchio}

and the lowest percentage of housewives in Italy at 9.1 per cent against a national average of 14.9 per cent (Osservatorio 1997: 98, 125).

8 On the question of measurements as a key to confirm theories, i.e. making them acceptable by the profession, and thus as part of a rhetorical practice in scientific language, see Kuhn (1977: 178-92).

9 The research uses the 1989 ISTAT Time-Budget Survey (TBS), because it is the most detailed, and it collects on a daily basis the allocation of time for each household member over the age of 3 . These time budget data provide more precise information on paid and unpaid work because they allow for simultaneous use of time and are less affected by recall errors than other types of data. At any rate, the imbalance in the distribution of time-use by gender is also confirmed by more recent time-budget data which report only weekly average hours of unpaid work (ISTAT Household Survey 1994, 1998; Bank of Italy Survey of Household Income and Wealth 2000). In the Bank of Italy Survey in 2000, some questions on unpaid work were inserted for the first time, following the advice of Tindara Addabbo and Enrica Chiappero-Martinetti.

\section{References}

Cagatay, N., Elson, D. and Grown, C. (eds) (1995) 'Gender adjustment and macroeconomics'. Special Issue. World Development, 23(11).

Elson, D. and Cagatay, N. (2000) 'The social content of macroeconomic policies', World Development, 28(7): 1347-64.

Goldschmidt-Clermont, L. and Pagnossin-Aligisakis, E. (1996) 'Measures of unrecorded economic activities in fourteen countries', in Background Papers, Human Development Report, 1995, New York: UNDP.

Kuhn, T. (1977) 'The function of measurement in modern physical science', in The Essential Tension, Chicago, IL: Chicago University Press.

Nussbaum, M. (2000) Women and Human Development. The Capabilities Approach, Cambridge: Cambridge University Press.

Nyberg, A. (1998) Women, Men and Incomes. Gender Equality and Economic Independence, A Report to the Commitee on the Distribution of Economic Power and Economic Resources between Women and Men, Stockholm.

Osservatorio sul mercato del lavoro (1997) Rapporto sulla situazione sociale, Regione Emilia-Romagna, Italy.

Picchio, A. (1992) Social Reproduction. The Political Economy of the Labour Market, Cambridge: Cambridge University Press.

- (1998) 'Subsistence', in H. Kurz and N. Salvadori (eds) The Elgar Dictionary of Classical Economics, Aldershot: Edward Elgar.

- (2000) 'Wages as a reflection of social embedded production and reproduction processes', in L. Clarke, P. de Gijsel and J. Janssen (eds) The Dynamics of Wage Relations in the New Europe, Boston, MA: Kluwer Academic.

Sen, A. (1987) The Standard of Living, ed. G. Hawthorn, Cambridge: Cambridge University Press.

_ (1993) 'Capability and wellbeing', in Martha Nussbaum and Amartya Sen (eds) The Quality of Life, Oxford: Clarendon Press.

Statistics Canada (1996) The Statistics Canada Total Work Account System, Ottawa.

UNDP (1995-2001) Human Development Reports, New York. 


\title{
1 A macroeconomic approach to an extended standard of living
}

\author{
Antonella Picchio
}

\section{Introduction}

The statistical quantification of the unpaid work of social reproduction requires a conceptualisation of the economic system capable of containing it, taking account of its dimensions and its quality. Unpaid work involves the upkeep of living spaces and domestic goods, care of the health, education and psychological needs of family members, and the maintenance of social relationships. According to statistical classifications, it is divided into domestic labour (transformation of goods and care of living spaces), care of persons, and work required to link the domestic and public spheres arising from family responsibilities (e.g. taking children to school, paying bills). Data show, at international level, that these three components may change in weight, but the total does not alter. For example, in some types of family less time is spent preparing meals and more time is spent on childcare and servicing (e.g. taking them to the swimming pool, to school). ${ }^{1}$ Quantitatively, unpaid work, measured in units of time, in Italy and in other countries, slightly exceeds the total amount of paid work done by men and women, while, qualitatively, it is essential for the maintenance of the system as a whole. Thus, this work constitutes one of the major aggregates of the economic system. In its specific activities and their relative weights it reflects historical and cultural changes; its basic functions, along with public services and the provision of market goods and services, are central to the process of social reproduction of the population. ${ }^{2}$ Unpaid work is essential, both for those who benefit from it and for those who do it; it is part of the basic organisation of living conditions, and it reflects historical relationships between men and women, classes and generations.

Data on the use of time show that it is simplistic to believe that children and the old are the only ones to benefit from domestic and care work. Behind these groups are stronger ones, especially adult men, for whom women's housework and care is a basic support for living, not only at times of crisis but also, and especially, in normal, everyday life. Daily reproductive activities are interwoven with the labour market which regulates mobility, times and conditions of paid and unpaid work. The division between men 


\section{Antonella Picchio}

and women of the unpaid work of social reproduction within the household constitutes the kernel of gender difference. In fact the data show a macroscopic difference in men's and women's use of time, which in Italy is greater than in other countries (Picchio 1992, 1999; Sabbadini and Palomba 1995; Addabbo, Chapter 2, this volume).

This study, while adopting gender difference as a tool of analysis, uses the experience and awareness of this difference to reveal some basic aspects of the economic system, and the persistence of certain profound tensions within it. The analytical link between gender difference and the economic system is indicated in the living conditions of the working population and in their role as social capital. The argument for integrating the unpaid work of social reproduction into the view of the system, and hence into macroeconomic analysis, is here articulated in three circular-flow diagrams linking, first, families and firms, and then families, firms, the state and civil society. ${ }^{3}$

The major functions of reproductive labour at systemic level are to ensure the quantity and quality of the population: (1) to extend income from a monetary value to a standard of living that includes the transformation of goods and services through unpaid domestic labour; (2) to expand the extended standard of living into a condition of well-being which involves the enjoyment of specific, conventionally established levels of education, health and social relations; (3) to sustain the filtering process of the labour market (young and old, women and men, able and non-able); in this case, the unpaid work done in the home serves to underpin the selection of individuals for the labour market and the personal capacities used. Thus, unpaid work both materially and psychologically facilitates the processes of adaptation to the waged labour market, absorbing its tensions.

From the statistical point of view, extending the definition of income means counting unpaid work as one of the components of wealth. A grilled steak is more enjoyable and digestible than a raw steak; how it is cooked and how it is eaten depends on the cultural and historical context, but cooking meat is as much a part of economic reality as producing and selling it, all the more so as the one who produces (the waged worker) needs to eat enough, if possible in company, to be productive. Hence the extension affects both the accounting of a contribution to the production of wealth and the accounting of a cost necessary to produce adequate living conditions for labour efficiency. The absence of a commercial exchange in the case of socially reproductive work in the family has made a basic contribution to social wealth invisible, and has also obscured an important part of the costs of production. ${ }^{4}$

Whereas extension takes account of the quantitative aspects of the unpaid work of reproduction, adding these to monetary income to define the standard of living in terms of goods and services in their effective form, the expansion of the standard of living (as an extended bundle of goods and services) to include well-being takes account of the qualitative aspects of the 
work of social reproduction, and recognises the change of priorities and direction inherent in caring for people. That is to say, the primary aim of this work is the well-being of persons in terms of their quality of life. This is a material, social and cultural process based on trust, affection, friendship and social relations, which requires a sense of responsibility in order to achieve results. The expansion of income into well-being depends on actions and practices directed towards the well-being of persons. This perspective, as in the case of the approach used by Amartya Sen and Martha Nussbaum (Sen 1987, 1993; Nussbaum 2000), involves a change of priorities and direction: instead of using human labour as a means of valuing commodities, we use commodities as means in a multidimensional process of social reproduction at individual and collective level. This reversal has been analysed by Amartya Sen in a microeconomic context focusing on the actual freedom of individual non-utilitarian choices in given social contexts.

In this study, on the one hand, we make unpaid reproductive work visible; on the other hand, we locate well-being in a macro surplus approach and see it as a state within a process of social reproduction. In this approach, the exogenous distribution between wages and profit is centred on the very tensions between the living conditions of the working population and profit accumulation (Picchio 1992, 1998, 2000). Thus we follow a macroeconomic approach in which well-being is conceived of not in terms of individual choices, but as part of a structural framework that includes the material processes of production, distribution and exchange of wealth together with the process of social reproduction of the working population. Inserting an inherently institutional, historical and symbolic process such as that of social reproduction into the basic structure leads to radical modifications in the way the whole system is conceptualised. Moreover, class tensions are seen as centred on the historical social quality of the relationship, and the interaction between working and living conditions of waged labour.

Finally, the work of reproduction - besides making the living conditions of the working population sustainable - facilitates the functioning of the filter through which the population gains access to wages through the labour market. This involves a great flexibility of adaptation. At present, for example, in a context of variable work hours, increasing geographical mobility and intermittent access to wages, the family acts more and more as a filter compensating between disposable incomes and aspirations to socially adequate standards of living and rising expectations.

Important information on current changes in the functioning of the labour market as a filter of access to income may be found in the European Community Household Panel (ECHP) in which one can study and make comparisons among European countries with regard to changing types and distribution of incomes, rates of poverty, long-term unemployment and levels of family satisfaction. Changes in access to the labour market are combined with changes in the form of labour contracts. Among other things, the Panel's data show an increasing tendency towards workers being trapped in 
low wages and a growing rate of poverty within waged labour (Lucifora 1997). There is also a rise in the rate of dependency in terms of the number of people dependent on one wage. The growing tension within the family between the distribution of income and living standards, rooted in habits, tastes and social conventions, suggests that current restructuring in the labour market and welfare systems is being translated into an increased burden of unpaid work mostly done by women within the family. Nevertheless, economic policies devote very little attention to the problem of the adequacy of income with respect to conventional living conditions, and this fact leads, in present structural adjustments, to an intensification of unpaid labour that hides a withdrawal of firms and the state from their social responsibilities towards the quality of life.

Although research on family incomes explicitly studies the contributions made by different family members, the contribution of reproductive work continues to be ignored. In its questionnaire the European Panel asks one question about the care of the respondent's own children and about the unpaid care of other people's children, and one question about the daily unpaid activity of attendance on elderly, ill or disabled people. These two questions belong to a group of seven under the title 'Responsibilities and social relations'. While recognising that the questions are burdensome in terms of survey costs, we must note that in other areas the questionnaire goes into greater detail - for example, there are twenty questions on courses of study. This difference in the amount of attention indicates that only professional training and education are considered, not the long and delicate process of formation of individual capabilities. This takes place mostly in the family, and serves increasingly as the basis of working capacities, especially in new jobs with a high relational content.

One way of beginning to break this analytical ground is to insert the great mass of unpaid labour of social reproduction into the basic analytical framework of the economic system. We can begin with a diagram, usually used in economics textbooks, here called the simple co-operative circular flow', which shows a relationship of circular interdependence between families and firms (Figure 1.1). In this circular flow are shown relations of exchange, both monetary and real: the firms buy labour and sell goods, the families provide labour and buy goods. It is assumed that this flow is reproduced on the basis of co-operation between the two institutions for the reciprocal interdependence of their interests.

The first step is, then, to extend this circular flow to include unpaid work of social reproduction, in its quantitative and qualitative aspects (Figure 1.2). Using data on unpaid work one can study the distribution of work within the family, and 'extend' the notion of living conditions now seen as the result of a process that uses market and non-market goods and services and unpaid reproductive work. This process operates in social contexts, given in historical time and geopolitical space, which define adequate standards of living, and the social norms that regulate the division of labour and 


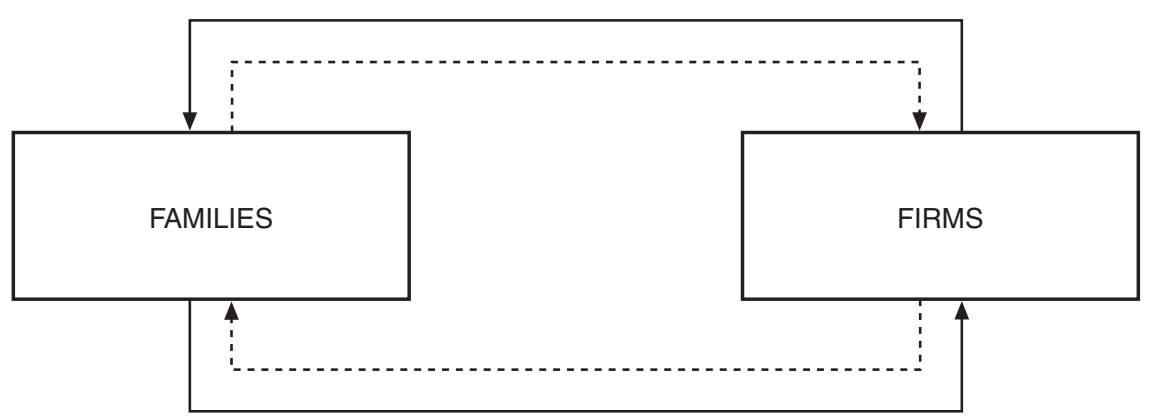

Figure 1.1 Co-operative flow.

personal responsibilities. The extension leads us into a space defined as human development (Figure 1.2). Using this concept of 'human development' one can carry out measurements which do not necessarily overlook the complexity of the process of social reproduction, and which make it possible to deal with some of its dimensions. This is done partly in the UNDP Human Development Reports, both in their indexes and in their indicators of living conditions. Here, we propose to extend the human development approach to include unpaid labour and to place it in a classical political economy macro approach. In doing so we juxtapose it to a neoclassical analytical framework that is basically ahistorical and spatially non-specific, with human subjects

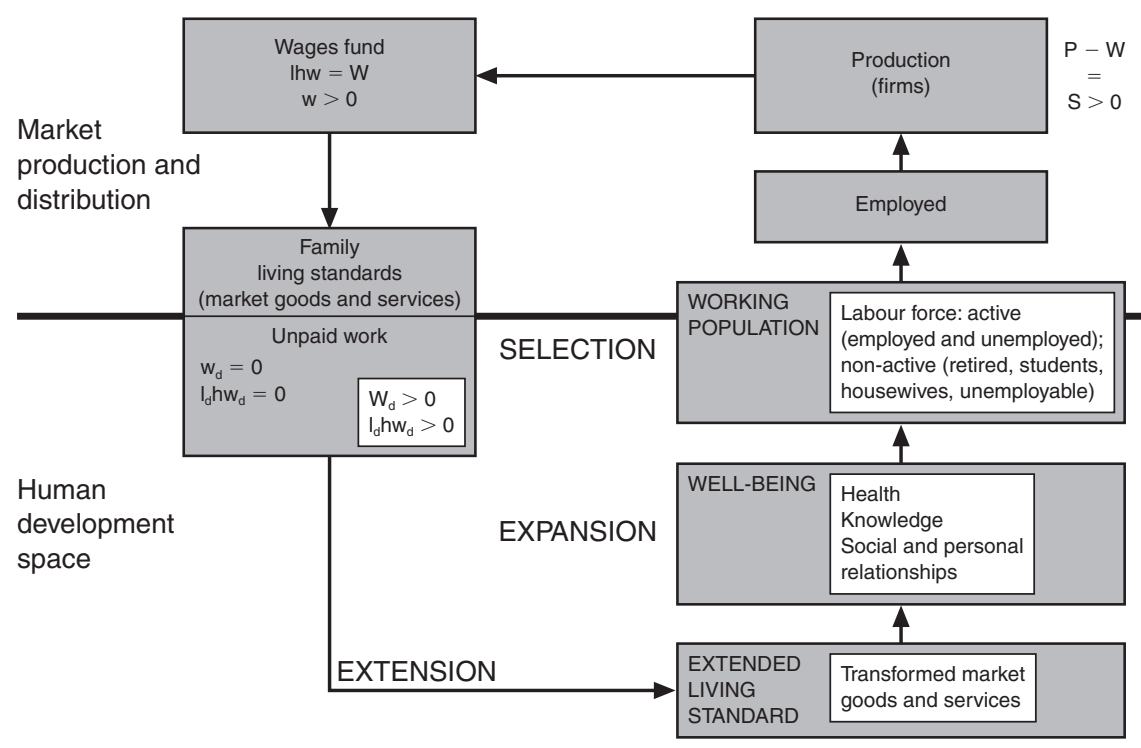

Figure 1.2 Extended living - standard flow. 


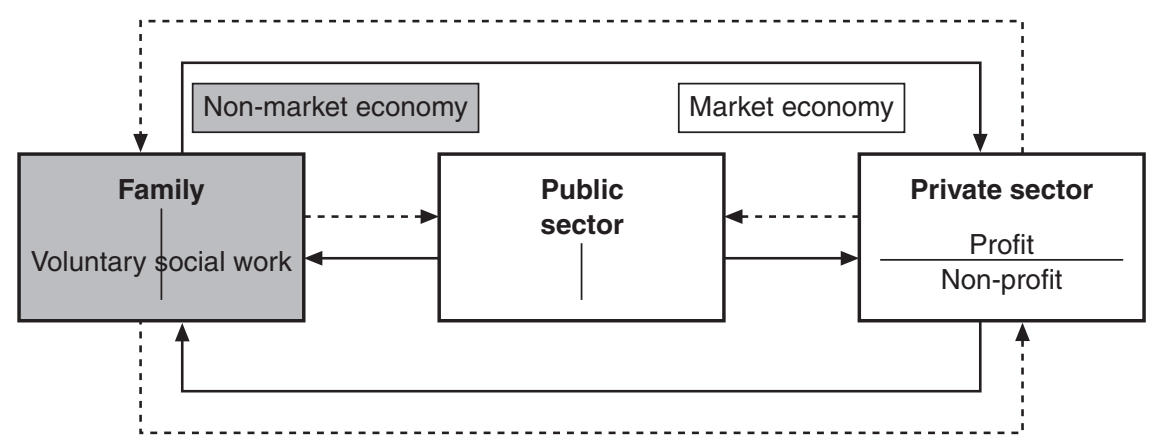

Figure 1.3 Social wealth flow.

freed from bodily needs. Thus conventional necessities are treated as simple 'frictions', i.e. non-necessities for the economic system. Moreover, in the neoclassical framework, social conventions and power relationships may be seen only as rigidities. In fact, they cannot be included as a general feature of the economic system without contradicting the basic generalisations of the theory embodied in its axioms. The problem is that in the process of social reproduction, by definition, conventions, personal interrelationships and social power relationships are fundamental persistent features. In the process of social reproduction the micro and macro aspects interact dynamically and cannot be separated, although there are many potential tensions which operate at both individual and collective level.

Finally, the potential tensions inherent in the distribution of work, resources and personal responsibilities are visualised in the third diagram entitled 'Social Wealth Flow' (Figure 1.3). This flow shows both the relations between the monetary and the non-monetary economy and their tensions with respect to aims and social practices.

\section{A simple co-operative circular flow}

The exchange relationships shown in Figure 1.1, as we said, are real and monetary: firms give money in exchange for labour, and families use the money to buy goods produced by the firms. ${ }^{5}$

The circular flow may be reproduced continuously if the reciprocity of the exchange enables the two institutions, which organise the production of goods and the reproduction of labour respectively, to have the necessary resources to carry out their functions again. This scheme indicates explicitly that the market for labour and goods is based on institutions (family/firm), but does not include the state, which enters only in Figure 1.3. However, the bipolarity between families and firms could be useful in bringing out the fact that the state, at least in part, has its origin precisely in the lack of real 
adjustments between the two institutions and the two processes - production of goods and social reproduction of the working population (Picchio $1987,1992)$. In the analytical structure of classical political economy, the lack of adjustment was considered normal, and the study of effective relations was referred to the historical and anthropological analysis of social behaviour. The classical approach to long-term positions took as given the population (in terms of quantity and living standards), production and techniques, and defined the conditions of reproducibility of the system via market exchange. ${ }^{6}$ On the basis of these data the classical economists put forward a system of relative normal prices. There are certainly links between production, distribution and exchange of wealth, on the one hand, and procreative behaviour and social and individual relationships, on the other. The question is how these relationships should be regarded: should they be seen as unidirectional, continuous, automatically interdependent and foreseeable, as the neoclassical theory would have it, or should they be studied historically, navigating between visions, conceptualisations, possible measurements and short causal chains?

If we are seeking plausible and realistic conjectures, we can proceed by looking further into some elements of the first diagram, sacrificing part of its simplicity while largely maintaining the clarity on which its effectiveness is based. First of all, note that the income of firms is different in kind from that of families. In the former case it is profit, in the latter, wages. The former derives from ownership of the means of production, the latter from labour. While certain complications are inessential and can be left out of the picture, such as the fact that incomes from labour may have different typologies, the difference between firms' income and family income is fundamental.

Given the nature of the difference between the two types of monetary income, the conditions of reproduction of the system require, as shown in Figure 1.2, that the wages fund be smaller than the value of production, so as to leave a residue for profits $(\mathrm{S}=\mathrm{P}-\mathrm{W})$. For the reproduction of capital, the wages fund must be adequate for the living conditions laid down over time and generally considered acceptable by the working population. This idea of conditions of subsistence of workers and their families as capital, which belonged to the core of the classical economists' theory, has not only been dropped by neoclassical economists who see wages merely as net wages, but also overlooked by present critical economists. None the less, this is a crucial concept in grasping the role of the living standards of the working population and disclosing some inherent tensions in the basic conditions of reproduction of economic systems. It is important to realise that what appears as a problem of basic needs of some sections of the population is, in fact, a reflection of a lack of clarity about the basic needs of the economic system. The capitalist system treats labour as a commodity and, in reality and in theory, needs to assume that it is a producible commodity, but it excludes its process of reproduction from systematic analytical scrutiny. The reason for this removal from theory of the analysis of a fundamental process 
has to be found in the deep tensions and contradictions inherent in the capitalist relationship between the process of the social reproduction of the working population, as individuals with sex and class, and the production of commodities. ${ }^{7}$ The unpaid work of social reproduction reflects all of these tensions.

Here the standard of living of the working population is studied, taking into account the household resources and the behaviour of men and women within the family with regard to the division of labour, income and reproductive responsibilities. This means that population enters not only as a quantity and a purely demographic datum, but as the result of a complex social process requiring goods and labour, a process regulated by social norms, given in historical time and bearing local characteristics. In doing so we restore to analytical attention one of the great themes of economic science, most prominent at the moment of its foundation. ${ }^{8}$

The dynamic tensions inherent in the process of human social reproduction have led historically to profound changes in production and in the use of natural resources. The very concept of nature has changed continuously. The Scottish Enlightenment theorists, including Smith, considered the forces inherent in human subsistence to be deeply dynamic and capable of determining epoch-making transformations. For a certain period a subsistence crisis can lead to destructive adjustments, but in the end insatiable wants and the survival instinct manage to find effective ways of modifying the modes of production of resources and reaching a new sustainable system (Meek 1976). In the history of these changes women have always played an important active role, though this is generally ignored and usually taken as simply adaptive.

\section{The extended income circular flow}

The process of social reproduction of the population defines what we have called, in Figure 1.2, 'human development space', characterised by individual and social action aimed directly at living conditions.

The concept of human development is different from that of "human capital', which is close but in fact is in tension with it. By human development we mean the analysis of conditions of sustainability of the process of social reproduction of the population, while the concept of 'human capital' implies an instrumental use of people as tools of production. Obviously to live one must produce, and to produce one must live; but to understand the functioning of any economic system we need to grasp the specific historical relationship between ends and means. To do that it is necessary to specify priorities and reveal the power relationships between subjects - relationships that affect what, how much, how, why and for whom production takes place.

We approach these deeper aspects by extending Figure 1.1 and converting it into an 'extended income circular flow' (Figure 1.2). Here, in quantitative and qualitative terms, the mass of unpaid reproductive labour is seen in relation to firms and the system of production. 
First of all, note that the wages fund (W) paid to workers is given by the number of labour units, workers (L), for the hours of work (h), for the average unit wage $(\mathrm{w})$. The wages fund can increase or decrease through variation of any of these variables, or, in a supply-and-demand approach, with given variable capital, these variables can change only if the wages fund changes. The question is the direction of the causal relationship. Economic theories differ on the determination of the wages fund because they disagree on the theory of wages, distribution and relative prices. The theoretical differences constitute a line of demarcation between paradigms, the line runs along the definition of wages and their position in the theory of distribution and the system of relative prices. Wages are treated either as costs of social reproduction or as marginal productivity of labour. Thus how the process of social reproduction of labour is seen becomes indeed a crucial question, for the real system as well as for the analytical vision.

When we come to the family we note some differences in the explanation of the family's role between the first and the second circular flows. In the first it is assumed, for simplicity, that the family co-operatively reproduces the right quantity and quality of labour. Theories also differ on the explanation of this matter. Classical political economists considered the reproduction of the quantity and quality of labour exogenous to the theory of relative normal prices. In the neoclassical theory, wages are determined simultaneously with profits and relative prices, and the standard of living of the working population is endogenous. The theoretical abstraction is matched by an idealisation of reality, which assumes that the daily life choices are also a continuous well-behaved function of wages and relative prices. Of course if reality does not fit the theory and changes in relative prices do not systematically change individual behaviour, the problem of adapting the reproduction of the population in quantitative and qualitative terms to numbers and characteristics required by firms becomes crucial, both for people's lives and for the efficiency of the system. This problem relates not only to formal education and training, usually acknowledged by human-capital theory, but also to the far more complex problem of social reproduction in the widest sense, taking in bodily needs and desires, expectations, culture, personal capabilities, social functioning, sense of responsibility, character and identity. ${ }^{9}$

In Figure 1.1 families are assumed to act co-operatively with firms in a natural social division of labour; this also means that internally the families are harmonious, with an equally natural division of roles between their members on the basis of sex and age. In Figure 1.2 the analytical scheme is 'extended' to include unpaid work. In this context the family becomes complicated and perhaps less harmonious, as always happens with division of labour. This may be why people try through innovative relations, escaping fixed institutional frameworks, to reduce the tensions inherent in the idealised and institutional family.

In economic analysis unpaid work disappears, partly because this aggregate counted in terms of workers and hours ( $\mathrm{Ld}$ and $\mathrm{h}$ ), does not emerge as a 
monetary transaction. If the wage for domestic work is zero, its wages fund (Wd) is also zero in spite of a large number of domestic workers (Ld) and hours (h). To work in terms of extended income we must therefore assign a monetary value to the task of social reproduction. This does not imply an actual redistribution of income - the point is merely to make visible an important component of the circular flow. Introducing a monetary element can be compared with introducing a chemical reagent which does not create a new element but makes evident one that already exists. The extended standard of living, composed of transformed goods and services, is different from the standard of living composed of a package of goods and services acquired directly in the market. To give some dimension to the extension, it is worth remembering that the extended standard incorporates a slightly greater statistical quantity of labour than the total paid work used in the production of market goods and services (see Addabbo, Chapter 2, this volume).

The extension of income has qualitative as well as quantitative dimensions. For example, a microeconometric analysis of the Italian case carried out by Addabbo and Caiumi in Chapter 3, this volume, shows that the personal distribution of extended income is less unequal than effective income. This result obtains whether the monetary value assigned to unpaid work is equated to the cost of generic domestic services, or whether the amount is differentiated according to the market-earning capacity of the person who does the work. ${ }^{10}$ Whatever monetary weight is adopted, the reduction of inequalities emerging in the analysis of extended income corresponds to a real process of absorption of the impact of inequalities made possible by unpaid domestic work. While in terms of income and wealth, inequalities are marked with clear effects on spending and social participation (Brandolini 1977), unpaid work is distributed much more evenly among classes. Part of the responsibility of caregivers is to try to counterbalance the difficulties and the frustration of a disadvantaged social situation. It is precisely the analytical recognition of needs, capabilities and expectations on the basis of common humanity that characterises what we call the process of 'expansion' of income to include well-being. Well-being is seen as a space of human development for the whole working population and not only of the wages and working conditions of those employed. Within the household it is not feasible to reproduce the pattern of exclusions typical of the labour market. Though there are hierarchies among family members, rooted in time on the basis of sex and age, given the common relationships of affection and solidarity, it becomes difficult to eliminate and abandon the family members excluded from the market. That would in any case be illegal since the law, in Italy and in other countries, fixes the degree of personal responsibility for family members and relatives. Moreover, the same normative responsibilities are referred to explicitly in the formulation and implementation of economic and social policies.

At present, access to the labour market and to employment is undergoing major restructuring, and the institutional forms that regulate it are chang- 
ing, in Italy as well as elsewhere in Europe. Hence it becomes important to keep track of functional income distribution, living standards, public services and the unpaid work of social reproduction, together with activity rates, unemployment and labour rights. ${ }^{11}$ The level of wages also has to be monitored as an increasing number of people are trapped at low wage levels, to the point where the European Commission had to refer to a 'threshold of decency' and the existence of poverty among employed people is already noticeable (OECD 1996; Lucifora 1997). However, while it is common sense that the structure of the labour market with regard to access, levels of wages, dependency rates and so on has an impact on the standard of living, data on the labour market are usually not shown in direct relation to real living conditions of the working population.

Economists take account of living conditions only in a sporadic and unfocused way. There is no explicit reference to the classical concept of a conventionally necessary standard of living that once belonged to the analysis of value, capital and income distribution. It is a dense multidimensional concept combining equity and efficiency; its material and symbolic density is a reflection of the complexity of labour as a human factor of production, necessarily relating to real people with bodies and minds, therefore located in time and space and embedded in social and personal relationships.

To guarantee the stability of the household and of the productive system the work of social reproduction needs to be very flexible, but its elasticity is not infinite, and at present it is strained to the limit by the breakdown of the old so-called Fordist social compact based, at least theoretically, on an adequate wage for the head of the family, a stable job, a wife at home and access to mass consumption (Anderson et al. 1994). That system has collapsed for various reasons, such as the restructuring of firms at global level, technological development of the communications sector, rising expectations, changing tastes and recurrent national fiscal crises. Moreover, the collapse of the Socialist bloc allowed Western countries to revise the role of the state and its agency as mediator of the class conflict. Last but not least, the old compact has also been ruled out by changes in power relationships between the sexes. The opening up of new opportunities for women, the adding together of men's and women's incomes for the maintenance of the family, an increase of consumption financed by an increase in paid work (Shor 1992), mask a degree of decline in the quality of life. The increase in total labour (paid and unpaid), the growth of job insecurity, growing poverty, are exacerbating the tense relationship between production of commodities and social reproduction of labour. Priorities are changing, placing cuts in public spending and increased labour-market flexibility at the top of the list. The result is that governments are reducing their welfare expenditure. The visibility of unpaid work could help to reveal the effects of this reduction and the real costs of structural adjustments not only in terms of poverty but also in terms of normal conditions of social sustainability and social capital. 


\section{Antonella Picchio}

Unpaid work is under continuous pressure, because it is expected to close the gap between distributed income and conventional consumption and necessities. Incomes are effectively extended through unpaid work in order to fill gaps between resources and normal expectations. Women continue to be frustrated because all the tactics used to reduce unpaid work and to shift part of their responsibilities are not effective, in spite of all the major changes occurring in society and in the relationships between sexes and generations. As a matter of fact the problem of the tensions between living and working conditions cannot be solved by urging women to make better use of their capabilities or by subsidising the family. Governments need to address the tensions and the contradictions of the whole system with respect to access to income, adequacy of resources, security, basic social services, expectations of a better quality of life, and individual and collective rights. In order to understand the labour market as a matrix of social relations that involves the different institutions in which people work and live, the differences in objectives need to be recognised. Thus we should adopt a broader view that includes the family, the state, firms and civil society in a perspective that also takes into account unpaid work. In order to do so, the first two circular flows have been broadened to include the state and civil society to complete the picture of all the institutional actors that participate in determining the quality of living conditions.

\section{The circular flow of social wealth}

Figure 1.3 comprises two sections (monetary and non-monetary) and three institutions (family, state and firms). The voluntary sector is included in the non-monetary section, and non-profit firms in the monetary section. The chart shows the interdependence of all these elements and the role of the state as mediator. It also shows two lines running vertically across the family and the state, and a horizontal line between profit and non-profit firms. These lines are meant to show the presence of unsolved tensions reflecting a basic tension inherent in the capitalist system between the production of commodities and the process of social reproduction of the working population. The institutions define a social context in which individuals, both men and women, move in order to achieve their objectives. Given their location in the social context, individuals have different and often conflicting objectives. The main division is between reproductive and profit objectives. There is space for co-operation but there are also deep tensions inherent in the system of waged labour because insecurity of subsistence is used as the key to control labour and because of the structurally endemic conflict between wages and profits.

Workers like horses and machines, are means of production in the view of classical political economists. As such, they need food to be efficient just as the other means of production need hay and fuel. The reductionism of the meaning of living inherent in the capitalist modes of production can be covered up by an increase of consumption but it cannot be solved; it re- 
emerges in the unequal income distribution, in overwork, both paid and unpaid, in interpersonal tensions and individual frustrations. From a woman's perspective the system's cracks are visible but they are too deep and complex to be faced effectively.

In the case of the family we have already seen how the division of labour creates disparities and dependencies, and how women's unpaid work is regulated by their responsibility for adapting resources to norms of consumption, development of capabilities, and expectations of family members, adult males included. For the state the role of sustaining both the interests of profit-holders and rentiers and those of the working population in terms of quality of life can become clearly contradictory, creating tensions that, at times, call for a radical restructuring of the welfare system (Picchio 1987, 1992). One way of coping with these tensions is to restructure the state itself in order to regain control. At the level of firms, the clearly emerging dynamic character of the non-profit sector has deprived profit-making firms of their monopoly of initiative and innovation, and that is no small loss at symbolic level. In fact, the quality of life and social equity have themselves both become objectives and tools for the organisation of enterprises at local and global level. This awareness stimulates enterprises - even financially viable ones - as well as an increase of social wealth.

Once the household, the state and the non-profit sector are included in the analytical framework, the relative size and relevance of the monetary profit economy is put into a different perspective. Moreover, if we were to introduce the grey area of the informal economy, we might find it difficult to define the borderline between firms operating in a market economy with the aim of providing subsistence for the family and firms integrated in production for profit. Aims and responsibilities should be indicated and subjects made accountable for the results of their social activities and individual actions. In this way the material and moral burden of women's work would also acquire a new dimension and social sense, becoming more sustainable.

\section{The assessment of economic policy}

Inserting unpaid work into a macro approach opens up new perspectives on economic policy. First of all it makes visible an area of wide inequalities between men and women with regard to responsibilities, work and incomes. In this respect it belongs to equal opportunity policy. However, when it is viewed from a macroeconomic perspective, unpaid work loses its exclusively female and familial connotation - not because it becomes neutral, but because it proves to be a question of the efficiency and sustainability of the whole economic system. For instance, in the labour market - definitely a macro market - there is no dichotomy between equity and efficiency. Equity in the sense of adequacy is a question of reproduction of human and social capital; in the sense of fairness, it is a key to efficiency because it is the basis of consent to work and trust. 


\section{Antonella Picchio}

Economic theory does not indicate mechanisms for adjustment between disposable income and living standards conventionally adequate for the social group to which the worker belongs. Real wages may prove insufficient to maintain such standards, and in that case an increase in unpaid labour is expected to bridge the gap. The flexibility of unpaid work depends on many factors: total work, social conventions, habits, power relationships within the family and in society, feminist movements and so on.

Let us now turn to some of the policy implications of the extension of the standard of living and its expansion into well-being. Expansion refers to the process of formation of individual capabilities necessary for functioning such as the enjoyment of health, knowledge, mobility, and social and interpersonal relationships. Here the problems of matching distributed resources and the conventional norms of social reproduction become even more complex. To cope with the inherent tensions between the waged labour market and effective living conditions the individual must be able to make continual adjustments in the organisation of his or her life. Nevertheless, individual flexibility is not infinite and it cannot disguise the fact that the adjustments are a structural collective problem, which need safety nets and a normal support and negotiation process as to the distribution of resources and responsibilities. It is a negotiation not only about income distribution but also about individual rights and social norms. The quality of public services and of the relationship between the individual and the state depends on what is negotiated at the level of society. For example, the tendency to undermine individual dignity, practised all too often in public and private institutions, has little to do with the scarcity of resources and much more with power relationships, which affect the distribution of income, the provision and quality of public services, individual rights and the very definition of human dignity.

As noted above, well-being has a multidimensional content that includes vital functioning conforming to social standards. Different levels of wellbeing may be measured partly by setting maximum and minimum standards given in historical time and geopolitical space. This is the method used in the construction of the human development indexes published by UNDP since 1990, in the yearly Human Development Reports. In accordance with the human development approach, social policy, including labour-market policy, should take into account objectives, concepts and indicators that try to recognise the different human dimensions. Moreover, well-being has to be defined to include the unpaid work element and should itself be included in a macro vision of the economic system that specifies the relationships between the basic processes: production, distribution, exchange of commodities and social reproduction of the working population.

The territory of well-being does not belong exclusively to the family and/or to the state. It requires an intermediate, meso level of analysis bringing out social concerns at community and local level. At this level a range of actors are involved. Besides the generally recognised ones, such as individual 
firms, business associations, state institutions, a large body of people are active in civil society who form associations, start business, build networks and so on. These activities are usually characterised by non-profit objectives, and their direct aim is often to improve the quality of living conditions, sometimes at the level of social exclusion and often at the level of recreation or art. They usually concentrate on particular segments of the population and on specific projects. Civil society activities and actors broaden the scope of negotiation on living conditions and, although they usually share the gender blindness of other agents, they do approach more directly the issue of living conditions. In this regard they could contribute by opening up some space for a more equal sharing of reproductive responsibilities, at least outside the family. In fact, while on the one hand a full recognition of women's experience and agency in daily life is crucial for complete awareness of the dimensions and inherent tensions of the process of social reproduction, on the other hand, it is only through sharing responsibility at social level for the quality of life that unpaid reproductive labour can be reduced and redistributed more equally.

For a clear picture of the impact of policies on men's and women's wellbeing, including the impact on unpaid work, it is necessary to construct analytical and institutional tools capable of handling the broadening of perspective. First of all a system of statistical sources has to be built up, capable of showing the non-monetary contribution of reproductive labour, such as the system used in Total Work, published by Statistics Canada in 1996. Moreover, it is important to formulate public budgets, as advised in the Beijing Platform, ${ }^{12}$ giving a comprehensive picture of income and expenditure that shows: (1) how much is distributed directly to men and women; (2) the different impact of policies on men and women, including unpaid work; (3) the impact on social living conditions. ${ }^{13}$ From this perspective it is also important to specify criteria of accountability, which make individual and institutional responsibilities clear and assess results. To do so, feasible indicators taking into account the adequacy of incomes, total work and social vulnerability, are needed.

At present an increasing number of public institutions, at national and local government level, are experimenting with budgets from a gender perspective. A vast literature is forming around these experiments, led especially by Diane Elson and Debbie Budlender. ${ }^{14}$ The impact of expenditure on benefits, pensions, public services and of taxes, tariffs and payment for services is very different for men and women, and this difference should be acknowledged and made clear in data and policy assessment, as is now required by the European Commission at general level. For instance, an increase of tariffs or of payment for health services may have a strong impact on women's unpaid work in the household, while a reduction of taxes may have a stronger impact on men's disposable income.

To achieve public budgets capable of including a women's perspective, much needs to be done at many levels. First of all, as noted above, we need 


\section{Antonella Picchio}

statistics that show gender differences in income, well-being and unpaid work. In this respect, there is a lot of new ground to cover as we are still lacking adequate data even on gender-based wage differentials; but, most of all, there is a lot of ground to explore at academic level. The new perspective, in fact, requires a realistic presentation of facts, the challenging of old theories, a clarification of concepts and testing of conjectural causal relationships. The challenge at theoretical and empirical level needs to spread into the teaching of new tools and the critical assessment of the old ones. Students have to be trained in universities and schools to be administrators and to wotk in civil society organisations. It is a necessary institutional step to provide the skills needed to assess the gender and social impact of policies and social projects.

Much has already been done in this direction and a new awareness of the need to take account of gender in budgets and policy has been pushed forward at various institutional levels, such as the UN and the European Commission. At academic level, new associations are being formed, such as IAFFE (International Association for Feminist Economics), which publishes the academic journal Feminist Economics. It is important to note that the advancement of knowledge about women's perspective on the economic system is taking place in a fruitful co-operative partnership among different institutions (international organisations, non-governmental organisations, women's centres, universities) and with a fruitful practice of interdisciplinarity and pragmatism.

\section{Notes}

1 The data on the unpaid work of social reproduction, divided into care and domestic work, are made available in time-use surveys carried out by National Statistical offices. For data related to various countries, see Goldschmidt-Clermont and Pagnossin-Aligisakis (1996), and UNDP (1995). The Italian data are analysed in Chapter 2, this volume. It has to be noted that, in Italy, a recent law on 'parental leave' calls for a regular time-use survey every five years.

2 Subsistence means not only a bundle of commodities that satisfy basic needs, but the state of a process of social reproduction corresponding to standards of health, education and socialisation adequate to the social conventions given in time and space (Picchio 1999).

3 For other attempts to approach macroeconomics from a gender perspective, see Cagatay et al. (1995), and Elson and Cagatay (2000).

4 New forms of national accounting are being currently tried out (Urdaneta de Ferrán 2000), and Statistics Canada produces a Total Work Account.

5 In the graph monetary exchanges are indicated by solid lines and real exchanges by dashed lines.

6 By classical economists we refer mainly to the surplus-approach theorists such as Smith, Ricardo and Marx. On the definition of long-period positions, see Garegnani (1976).

7 It has to be noted that the relationship between the social reproduction of the working population and the state production of goods and services was by no means free of deep tensions in former Socialist countries either.

8 Petty based value on the 'loaf of bread' of adult males, Ricardo defined capital as 
'that part of the wealth of a country which is employed in production, and consists of food, clothing, tools, raw materials, machinery' (Ricardo 1951: 95). In general, all the surplus theorists define the subsistence of the working population as capital. Marx centred his critique of political economy on the very tension between the value of labour and the labour value of produced commodities.

9 The multiple dimensions of the human subject were at the foundations of classical Greek philosophy and are still expressed in poetic and literary language. On these aspects the work of Martha Nussbaum is illuminating: see Nussbaum 1990. Awareness of the complexity of humanity was still colouring Smith's Wealth of Nations.

10 See Addabbo in Chapter 2, this volume. It has to be noted that in this book no particular attention is given to the growing importance of paid domestic labour. For an interesting study of paid domestic work in Italy, see Alemanni et al. (1994).

11 For an attempt to give a broader picture of the dynamics of the processes taking place in the European labour market, including also social reproduction, see Clarke et al. 2000. For a more equal opportunity perspective between men and women, see, for the European countries, Rubery et al. 1999.

12 Fourth UN Conference on Women (1975).

13 For an update of current experiences of public budgets from a gender perspective and their analysis, see the UNIFEM website: <http://www.unifem.undp.org >. For a general introduction to the subject, see UNIFEM 2000: Chapter 5; Budlender and Sharp 1998.

14 For the South African experience, see Budlender 1996, 1997, 1998; for a first assessment of the Australian experience, see Sharp and Broomhill 2002.

\section{References}

Alemanni, C. et al. (1994) Donne in frontiera. Le colf nella transizione, Milan: CENS.

Anderson, M., Bechhofer, F. and Gershuny, J. (1994) The Social and Political Economy of the Household, Oxford: Oxford University Press.

Brandolini, A. (1997) 'Andamento macroeconomico, regole di assegnazione e distribuzione personale dei redditi' (mimeo).

Budlender, D. (1996, 1997, 1998) Women's Budgets, Cape Town: Statistics South Africa.

Budlender, D. and Sharp, R. (1998) 'How to do a gender-sensitive budget analysis: contemporary research and practice', London: Commonwealth Secretariat (mimeo).

Cagatay, N., Elson, D. and Grown, C. (eds) (1995) World Development, November, 23.11.

Clarke, L., de Gijsel, P. and Janssen, J. (eds) (2000) The Dynamics of Wage Relations in the New Europe, Boston, MA: Kluwer Academic.

Elson, D. and Cagatay, N. (2000) 'The social content of macroeconomic policies', World Development, 28(7): 1347-64.

Garegnani, P. (1976) 'On a change of a notion of equilibrium in recent work on value and distribution', in M. Brown, K. Sato and P. Zarembka (eds) Essays in Modern Capital Theory, Amsterdam: North Holland.

Goldschmidt-Clermont, L. and Pagnossin-Aligisakis, E. (1996) Background Papers. Human Development Report 1995, New York: UNDP.

ISTAT (1999) Presentazione del Panel europeo, Rome.

Lucifora, C. (1997) 'Working poor? An analysis of low wage employment in Italy', in T. Asplund et al. (eds) Low-Pay and Earnings Mobility in Europe, Aldershot: Edward Elgar.

Meek, R.L. (1976) Social Science and the Ignoble Savage, Cambridge: Cambridge University Press.

Nussbaum, M. (1990) Love's Knowledge, Oxford: Oxford University Press. 


\section{Antonella Picchio}

- (2000) Women and Human Development. The Capabilities Approach, Cambridge: Cambridge University Press.

Nyberg, A. (1998) Women, Men and Incomes. Gender Equality and Economic Independence, A Report to the Committee on the Distribution of Economic Power and Economic Resources between Women and Men, Stockholm.

OECD (1996) 'Earnings inequality', OECD Employment Outlook, pp. 59-108.

Osservatorio sul mercato del lavoro (1997), Bologna: Regione Emilia-Romagna.

Picchio, A. (1987) 'Welfare', in J. Eatwell, M. Millgate and P. Newman (eds) The New Palgrave Dictionary of Political Economy, London: Macmillan.

- (1992) Social Reproduction: The Political Economy of the Labour Market, Cambridge: Cambridge University Press.

- (1996) 'The analytical and political visibility of the work of social reproduction', in Background Papers. Human Development Report 1995, New York: UNDP.

- (1998) 'Subsistence', in H. Kurz and N. Salvadori (eds) The Elgar Dictionary of Classical Economics, Aldershot: Edward Elgar.

- (1999) 'La questione del lavoro non pagato nella produzione dei servizi nel nucleo domestico (household)', Quaderni del Dipartimento di Economia Politica, Modena.

- (2000) 'Wages as a reflection of socially embedded production and reproduction processes', in L. Clarke, P. de Gijsel and J. Janssen (eds) The Dynamics of Wage Relations in the New Europe, Boston, MA: Kluwer Academic.

Ricardo, D. (1951) Principles of Political Economy and Taxation, Cambridge: Cambridge University Press.

Rubery, J., Smith, M. and Fagan, C. (1999) Women's Employment in Europe. Trends and Prospects, London: Routledge.

Sabbadini, L.L. and Palomba, R. (1995) Tempi diversi, l'uso del tempo di uomini e donne nell'Italia di oggi, Rome: ISTAT.

Sen, A. (1987) The Standard of Living, ed. by G. Hawthorn, Cambridge: Cambridge University Press.

_ (1993) 'Capability and wellbeing', in M. Nussbaum and A. Sen (eds) The Quality of Life, Oxford: Clarendon Press.

Sharp, R. and Broomhill, R. (2002) 'Budgeting for equality: the Australian experience', Feminist Economics, 8(1): 25-47.

Shor, J. (1992) Overworked America, New York: Academic Press. (1998) Overspent America, New York: Academic Press.

Statistics Canada (1996) The Statistics Canada Total Work Account System, Ottawa.

UNDP (1990-2001) Human Development Reports, New York: UNDP.

UNIFEM (2000) Report on World's Women's Progress, New York.

Urdaneta de Ferrán, L. (2000) El enfoque de género, el análisis presupuestario y las cuentas nacionales, UNIFEM Seminar and ONE (Cuban National Statistical Office), 18-20 January, Havana, Cuba. 


\title{
2 Unpaid work by gender in Italy
}

\author{
Tindara Addabbo
}

\section{Statistical sources and survey of the literature}

This chapter focuses on unpaid work (housework, care of other family members, shopping and household administration) by gender in different household types. A first source of data that may be used in order to quantify unpaid work are time-budget data. These provide direct information on unrecorded work activities and may also be used for comparative crosscountry analyses. ${ }^{1}$ The information has been recorded in Italy in the ISTAT Time Budget Survey (hereafter TBS) which records time budgets by means of interviews and daily diaries during different days of the week on a daily basis for each individual in the family more than 3 years old. The survey was conducted in 1989 on a sample of 19,728 families. ${ }^{2}$ However, the survey does not follow the same household across different days of the week (weekdays excluding Saturdays and Sundays).

TBS distinguishes among the following activities:

- personal care: personal hygiene, eating, sleeping;

- productive activities: education and training, paid and unpaid (housework, childcare, shopping) work;

- leisure (by type of activity);

- time devoted to going from one activity to another.

A revision of time-budget surveys is currently in progress in order to comply with the criteria fixed by the EUROSTAT, ETUS (European Time Use Study) project. ${ }^{3}$ A pilot survey under this project was conducted in 1998. In 1996 the research centre Eurisko carried out a time-budget survey on a sample of 3,000 individuals. ${ }^{4}$ In Law 53/2000 one states that the Italian Statistical Service (ISTAT) will carry out time-budget surveys every five years.

In analysing the allocation of unpaid work by gender in industrialised countries, a major imbalance can be noted in Italy: in fact women's unpaid work is much greater than men's unpaid work, and women's total working time is higher than men's (UNDP 1995). 
Table 2.1 Average weekly hours of work by gender and employment

\begin{tabular}{|c|c|c|c|c|}
\hline \multirow{2}{*}{$\begin{array}{l}\text { Weekly average number } \\
\text { of working hours }\end{array}$} & \multicolumn{2}{|l|}{ Men } & \multicolumn{2}{|l|}{ Women } \\
\hline & employed & total & employed & total \\
\hline Unpaid & 12.5 & 13.2 & 29.3 & 37.3 \\
\hline Paid & 43.1 & 24.9 & 35.5 & 11.6 \\
\hline Total & 55.6 & 38.1 & 64.8 & 48.9 \\
\hline \multicolumn{5}{|c|}{ Percentage of total working time } \\
\hline Unpaid working hours & 22 & 35 & 45 & 76 \\
\hline Paid working hours & 78 & 65 & 55 & 24 \\
\hline
\end{tabular}

Source: Author's calculations based on Bank of Italy 2002: 60, Table C10.

The latest data available on the average number of weekly unpaid working hours (Bank of Italy 2000) confirm the disequilibrium by gender in the distribution of total working time. On average, women (aged over 14) worked eleven hours per week more than men in the year 2000 (see Table 2.1). The difference persists even when the analysis is confined to employed people: women who are employed work on average 9.2 hours more than men (women's total working time is on average 64.8 hours, whereas employed men work on average 55.6 hours a week). The distribution of total working time confirms the lower number of hours devoted by women to paid work, for - taking all women aged over 14 - it emerges that they devote on average 76 per cent of their working time to unpaid work whereas men devote only 35 per cent of their total working time to this activity. As far as employed people are concerned, though also for employed women, paid work activities predominate in the distribution of total working time: employed women devote on average 45 per cent of their total working time to unpaid work as against only 22 per cent for men.

Analyses of the time allocation by gender for Italy based on 1989 ISTAT data have been provided by Palomba and Sabbadini (1994), Palomba (1997) and Capellari (2001). These analyses, together with Perali's (1999) analysis on EURISKO data, show a greater burden of unpaid work for women and a greater sensitivity of unpaid work supply to the presence of children for women than for men. The presence of a child in the family increases unpaid work. ${ }^{5}$ A peculiarity of the Italian family is that children tend to live with the family into adulthood, ${ }^{6}$ and this increases the unpaid work burden of their mothers (Palomba and Sabbadini 1994). The number of children rather than their age increases women's unpaid work (according to local surveys carried out in the North Central region of Italy) and decreases women's paid work. However, the presence of children does not induce women to leave the labour market but causes them to compress the time they devote to personal needs (Palomba 1997; Trifiletti 1997).

The marginal participation of men in unpaid work inside the family and 
the sharp increase (almost three hours a day) of unpaid work of women when they get married (an increase not observed for men) together mean that women's unpaid work decreases if the marriage breaks up (Vinay 1996; Palomba 1997). ${ }^{7}$

Unpaid work allocation by gender inside the couple changes depending on the area where the family lives and their level of education. Palomba (1997) finds a greater sharing of childcare by fathers living in the Northwest of Italy, and Palomba and Sabbadini (1994) find that better educated fathers tend to share housework more than less educated fathers.

It should be noted that men and women differ not only in the total amount of unpaid work provided but also in the type of unpaid work they do:

Male sharing is concentrated on the one hand in cooking and on the other in gardening and small repairs which may be more tiring but also lie between leisure and housework. Making beds, ironing and washing clothes are the exclusive responsibility of women.

(our translation from Palomba 1997: 171)

Apart from time budgeting, one can also find synthetic information on unpaid work in the ISTAT survey on the daily life characteristics of the household. ${ }^{8}$ Since 1993 this survey has contained synthetic information on the mean hours of unpaid and paid activities and information on the socioeconomic situation of the family (education, employment of each member), type of surroundings where the family lives, health and use of services. These data together with the Bank of Italy survey on household income and wealth have been used for a first evaluation of extended income in households where both partners are in work (Addabbo 1998) and have also been used by Chiappero-Martinetti in Chapter 5, this volume.

\section{The allocation of time by gender in Italian households}

The ISTAT Time Budget Survey (TBS) collects information on a sample of 19,278 households. Data were collected in June 1988 and May 1989 by asking the households to keep diaries on time use (disaggregated into 150 different activities) by each household member aged over 3. Palomba and Sabbadini (1994) carefully describe the allocation of time by people in different age groups and in different phases of their family life cycle. This chapter is devoted to an analysis of the time allocation between different types of families (with or without children; one earner or double earners; single, employed or not employed) and among men and women where the head of the family is aged between 18 and 64. We have selected people in this age group to detect the gender differences in the allocation of time between paid and unpaid activities. One problem of TBS is that it does not collect information on the same family over different days of the week but 


\section{Tindara Addabbo}

instead information on time use of different families on different days of the week. ${ }^{9}$

Descriptive statistics on the sample over the different days of the week are provided in Table 2A.1 (see Appendix). The data relate to 1,271 couples on weekdays, 1,278 on Saturdays and 1,279 on Sundays; as far as single people are concerned, we observe 88 single women and 63 single men during a weekday, 98 women and 64 men on Saturdays, 76 women and 83 men on Sundays. Women who live with a partner are on average younger than men (women 41 years, men 45) whereas among single-person households, the women's age is on average higher than the men's (women 51, men 42).

In Chapter 3 we report the results of the estimation of unpaid work equations, whereas here we report some descriptive statistics on the actual average working hours on different days of the week for men and women belonging to different family types (single, and couples with or without children) and according to spouses' employment status. Unpaid work is disaggregated into three types of activities:

1 housework

2 caring for other family members

3 shopping and house administration work (constrained time).

We find that, apart from weekdays for households without children where women are not employed, women always devote more time to total work than do men. The allocation of time by gender is shown in households with (Table 2.2) or without (Table 2.3) children.

During weekdays women's unpaid work ranges from a minimum of 4.42 hours per day in double-earner households without children (Table 2.3) to a maximum of 8.69 hours per day in one-earner households with children (Table 2.2) ${ }^{10}$ It should be noted that for employed women with children total working time is on average eleven hours per weekday.

The most relevant part of unpaid work consists of housework. The large gender imbalance in the allocation of time between paid and unpaid activities is shown clearly in Tables 2.2 and 2.3 and Figures 2.1 to 2.6.

In Table 2.4 we have analysed the allocation of time in double-earner households with children. On weekdays 57 per cent of the total working time of women is devoted to paid work and 43 per cent to unpaid work (women in this household type devote on average 4.87 hours per day to unpaid work). For a woman who lives in a double-earner family and has children, her total working hours are 71 per cent of a normal weekday, whereas men's total working time (in the same household type) amounts to 57 per cent of a normal weekday (assuming that people sleep eight hours per day but the evidence suggests that women often sleep less than eight hours per night in order to accomplish their heavy workload). On the other hand, men devote 11 per cent of their total working time to unpaid work and have more time than their partners to devote to non-work activities. Unpaid work 
Table 2.2 Allocation of time by gender and household type - households with children

\begin{tabular}{|c|c|c|c|c|c|c|c|}
\hline \multirow[t]{2}{*}{ Weekdays } & & \multicolumn{2}{|c|}{ One earner } & \multicolumn{2}{|c|}{ Double earners } & \multicolumn{2}{|c|}{ Non-earners } \\
\hline & & Mean & Variance & Mean & Variance & Mean & Variance \\
\hline \multirow[t]{2}{*}{ Housework } & Women & 6.7 & 2.5 & 3.7 & 1.8 & 6.5 & 3.0 \\
\hline & Men & 0.5 & 1.1 & 0.5 & 0.9 & 2.1 & 2.5 \\
\hline \multirow[t]{2}{*}{ Care } & Women & 1.1 & 0.2 & 0.7 & 0.9 & 0.3 & 0.7 \\
\hline & Men & 0.2 & 0.5 & 0.3 & 0.7 & 0.2 & 0.8 \\
\hline \multirow[t]{2}{*}{ Other unpaid work } & Women & 0.9 & 0.8 & 0.5 & 0.6 & 0.8 & 0.8 \\
\hline & Men & 0.2 & 0.6 & 0.2 & 0.5 & 0.6 & 0.9 \\
\hline \multirow[t]{2}{*}{ Total unpaid work } & Women & 8.7 & 2.7 & 4.9 & 2.1 & 7.5 & 3.4 \\
\hline & Men & 0.8 & 1.4 & 1.0 & 1.2 & 2.8 & 2.8 \\
\hline \multirow[t]{2}{*}{ Paid work } & Women & 0.0 & 0.0 & 6.4 & 2.3 & 0.0 & 0.0 \\
\hline & Men & 7.2 & 3.3 & 8.2 & 2.3 & 0.0 & 0.0 \\
\hline \multirow[t]{2}{*}{ Total work } & Women & 8.7 & 2.8 & 11.3 & 1.7 & 7.5 & 3.4 \\
\hline & Men & 8.0 & 3.1 & 9.2 & 2.1 & 2.8 & 2.8 \\
\hline \multirow[t]{2}{*}{ Saturdays } & & \multicolumn{2}{|c|}{ One earner } & \multicolumn{2}{|c|}{ Double earners } & \multicolumn{2}{|c|}{ Non-earners } \\
\hline & & Mean & Variance & Mean & Variance & Mean & Variance \\
\hline \multirow[t]{2}{*}{ Housework } & Women & 6.3 & 2.4 & 4.7 & 2.5 & 6.3 & 2.6 \\
\hline & Men & 1.0 & 1.7 & 1.1 & 1.6 & 2.2 & 2.6 \\
\hline \multirow[t]{2}{*}{ Care } & Women & 1.0 & 1.4 & 0.8 & 1.2 & 0.4 & 0.8 \\
\hline & Men & 0.2 & 0.6 & 0.4 & 0.8 & 0.2 & 0.7 \\
\hline \multirow[t]{2}{*}{ Other unpaid work } & Women & 1.0 & 0.9 & 0.7 & 0.9 & 0.7 & 0.6 \\
\hline & Men & 0.4 & 0.8 & 0.5 & 0.8 & 0.5 & 0.7 \\
\hline \multirow[t]{2}{*}{ Total unpaid work } & Women & 8.2 & 2.7 & 6.1 & 3.0 & 7.4 & 2.6 \\
\hline & Men & 1.7 & 2.0 & 2.0 & 2.2 & 2.9 & 2.8 \\
\hline \multirow[t]{2}{*}{ Paid work } & Women & 0.0 & 0.0 & 2.9 & 3.5 & 0.0 & 0.0 \\
\hline & Men & 4.2 & 3.8 & 4.6 & 4.1 & 0.0 & 0.0 \\
\hline \multirow[t]{2}{*}{ Total work } & Women & 8.2 & 2.7 & 9.0 & 3.1 & 7.4 & 2.6 \\
\hline & Men & 5.8 & 3.5 & 6.6 & 3.6 & 2.9 & 2.8 \\
\hline \multirow[t]{2}{*}{ Sundays } & & \multicolumn{2}{|c|}{ One earner } & \multicolumn{2}{|c|}{ Double earners } & \multicolumn{2}{|c|}{ Non-earners } \\
\hline & & Mean & Variance & Mean & Variance & Mean & Variance \\
\hline Housework & Women & 5.1 & 2.4 & 4.4 & 2.5 & 5.6 & 2.7 \\
\hline & Men & 0.9 & 1.5 & 0.9 & 1.3 & 1.2 & 2.0 \\
\hline Care & Women & 0.7 & 1.1 & 0.7 & 1.1 & 0.3 & 0.6 \\
\hline & Men & 0.3 & 0.8 & 0.4 & 1.0 & 0.1 & 0.4 \\
\hline Other unpaid work & Women & 0.1 & 0.4 & 0.1 & 0.3 & 0.0 & 0.2 \\
\hline & Men & 0.1 & 0.3 & 0.1 & 0.4 & 0.1 & 0.3 \\
\hline Total unpaid work & Women & 5.9 & 2.6 & 5.2 & 2.6 & 5.9 & 2.7 \\
\hline & Men & 1.3 & 1.7 & 1.4 & 1.7 & 1.4 & 2.0 \\
\hline Paid work & Women & 0.0 & 0.0 & 0.8 & 2.4 & 0.0 & 0.0 \\
\hline & Men & 1.1 & 2.6 & 1.2 & 2.9 & 0.0 & 0.0 \\
\hline Total work & Women & 5.9 & 2.6 & 6.0 & 2.9 & 5.8 & 2.7 \\
\hline & Men & 2.4 & 2.9 & 2.6 & 3.1 & 1.4 & 2.0 \\
\hline
\end{tabular}

Source: Author's calculations based on ISTAT 1989 Time Budget Survey. 


\section{Tindara Addabbo}

Table 2.3 Allocation of time by gender and household type - households without children

\begin{tabular}{|c|c|c|c|c|c|c|c|}
\hline \multirow[t]{2}{*}{ Weekdays } & & \multicolumn{2}{|c|}{ One earner } & \multicolumn{2}{|c|}{ Double earners } & \multicolumn{2}{|c|}{ Non-earners } \\
\hline & & Mean & Variance & Mean & Variance & Mean & Variance \\
\hline \multirow[t]{2}{*}{ Housework } & Women & 5.8 & 2.4 & 3.8 & 2.4 & 6.1 & 1.9 \\
\hline & Men & 0.5 & 1.0 & 0.6 & 0.9 & 2.0 & 2.1 \\
\hline \multirow[t]{2}{*}{ Care } & Women & 0.2 & 0.7 & 0.0 & 0.1 & 0.2 & 0.6 \\
\hline & Men & 0.1 & 0.3 & 0.1 & 0.3 & 0.2 & 0.7 \\
\hline \multirow[t]{2}{*}{ Other unpaid work } & Women & 1.0 & 0.9 & 0.6 & 0.9 & 0.9 & 0.7 \\
\hline & Men & 0.2 & 0.6 & 0.2 & 0.8 & 0.6 & 0.8 \\
\hline \multirow[t]{2}{*}{ Total unpaid work } & Women & 7.0 & 2.8 & 4.4 & 2.7 & 7.2 & 1.9 \\
\hline & Men & 0.8 & 1.3 & 0.9 & 1.3 & 2.8 & 2.5 \\
\hline \multirow[t]{2}{*}{ Paid work } & Women & 0.0 & 0.0 & 5.2 & 3.4 & 0.0 & 0.0 \\
\hline & Men & 7.0 & 3.1 & 7.0 & 3.2 & 0.0 & 0.0 \\
\hline \multirow[t]{2}{*}{ Total work } & Women & 7.0 & 2.8 & 9.7 & 2.9 & 7.2 & 1.9 \\
\hline & Men & 7.8 & 3.0 & 7.9 & 3.1 & 2.8 & 2.5 \\
\hline \multirow[t]{2}{*}{ Saturdays } & & \multicolumn{2}{|c|}{ One earner } & \multicolumn{2}{|c|}{ Double earners } & \multicolumn{2}{|c|}{ Non-earners } \\
\hline & & Mean & Variance & Mean & Variance & Mean & Variance \\
\hline \multirow[t]{2}{*}{ Housework } & Women & 5.6 & 2.1 & 4.4 & 2.5 & 5.7 & 2.4 \\
\hline & Men & 1.0 & 1.9 & 1.2 & 1.6 & 2.1 & 2.1 \\
\hline \multirow[t]{2}{*}{ Care } & Women & 0.2 & 0.6 & 0.0 & 0.2 & 0.4 & 0.8 \\
\hline & Men & 0.1 & 0.5 & 0.0 & 0.0 & 0.2 & 0.7 \\
\hline \multirow[t]{2}{*}{ Other unpaid work } & Women & 1.2 & 0.9 & 1.0 & 1.3 & 0.8 & 0.7 \\
\hline & Men & 0.5 & 0.8 & 0.9 & 1.3 & 0.6 & 0.9 \\
\hline \multirow[t]{2}{*}{ Total unpaid work } & Women & 6.7 & 2.3 & 5.4 & 2.8 & 6.9 & 2.4 \\
\hline & Men & 1.6 & 2.2 & 2.1 & 2.1 & 2.8 & 2.1 \\
\hline \multirow[t]{2}{*}{ Paid work } & Women & 0.0 & 0.0 & 2.5 & 3.2 & 0.0 & 0.0 \\
\hline & Men & 5.1 & 3.8 & 4.4 & 3.9 & 0.0 & 0.0 \\
\hline \multirow[t]{2}{*}{ Total work } & Women & 6.9 & 2.3 & 7.9 & 2.8 & 6.9 & 2.4 \\
\hline & Men & 6.7 & 3.5 & 6.5 & 2.3 & 2.8 & 2.1 \\
\hline \multirow[t]{2}{*}{ Sundays } & & \multicolumn{2}{|c|}{ One earner } & \multicolumn{2}{|c|}{ Double earners } & \multicolumn{2}{|c|}{ Non-earners } \\
\hline & & Mean & Variance & Mean & Variance & Mean & Variance \\
\hline Housework & Women & 4.7 & 2.2 & 3.5 & 2.4 & 5.5 & 2.2 \\
\hline & Men & 1.2 & 2.0 & 1.0 & 1.6 & 1.3 & 1.8 \\
\hline Care & Women & 0.1 & 0.3 & 0.1 & 0.3 & 0.1 & 0.2 \\
\hline & Men & 0.1 & 0.7 & 0.0 & 0.2 & 0.1 & 0.3 \\
\hline Other unpaid work & Women & 0.2 & 0.7 & 0.0 & 0.2 & 0.3 & 0.6 \\
\hline & Men & 0.1 & 0.2 & 0.1 & 0.1 & 0.1 & 0.3 \\
\hline Total unpaid work & Women & 4.9 & 2.3 & 3.6 & 2.5 & 5.8 & 2.2 \\
\hline & Men & 1.3 & 2.1 & 1.1 & 1.6 & 1.5 & 1.8 \\
\hline Paid work & Women & 0.0 & 0.0 & 0.5 & 2.0 & 0.0 & 0.0 \\
\hline & Men & 1.0 & 2.2 & 0.8 & 2.5 & 0.0 & 0.0 \\
\hline Total work & Women & 4.9 & 2.3 & 4.2 & 2.8 & 5.8 & 2.2 \\
\hline & Men & 2.3 & 2.7 & 1.9 & 2.7 & 1.5 & 1.8 \\
\hline
\end{tabular}

Source: Author's calculations based on ISTAT 1989 Time Budget Survey. 


\section{Women in one-earner households}

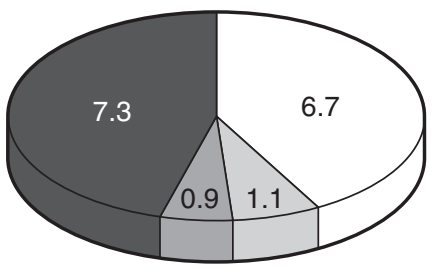

$\square$ Housework $\square$ Care

$\square$ Other unpaid work $\square$ Paid work

$\square$ Leisure

\section{Men in one-earner households}

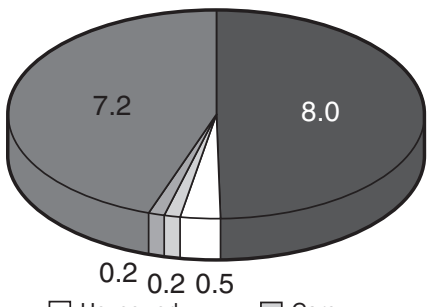

$\square$ Housework

$\square$ Other unpaid work $\square$ Paid work

$\square$ Leisure

\section{Women in double-earner households}

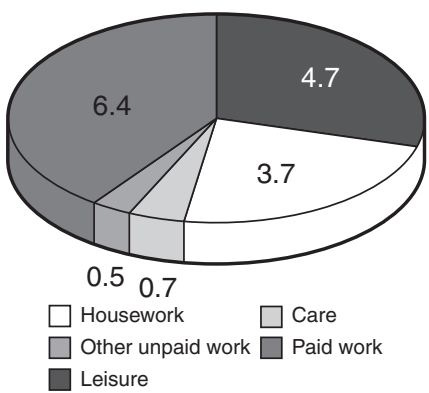

Women in non-earner households

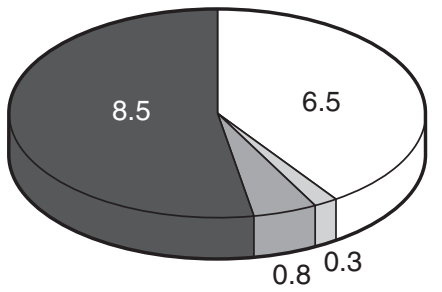

$\square$ Housework

Other unpaid work
0.8 Care

$\square$ Leisure

\section{Men in double-earner households}

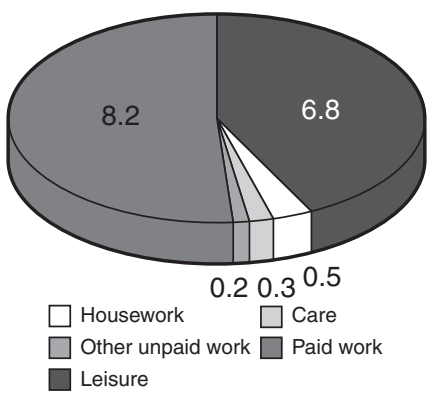

Men in non-earner households
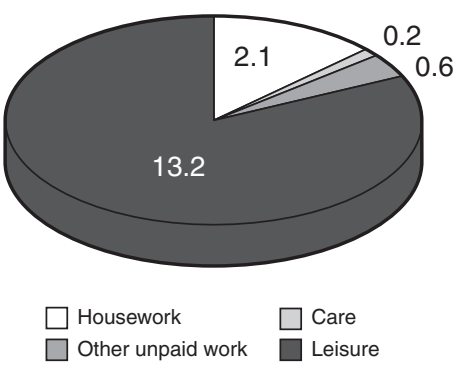

Figure 2.1 Allocation of time by gender on weekdays for different household types and with children.

Source: Author's calculations based on ISTAT 1989 Time Budget Survey. 
Women in one-earner households

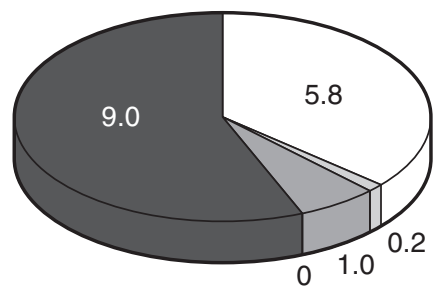

$\square$ Housework

$\square$ Other unpaid work $\square$ Paid work

$\square$ Leisure
Men in one-earner households

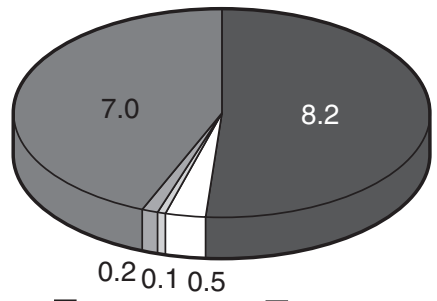

$\square$ Housework $\square$ Care

$\square$ Other unpaid work $\square$ Paid work

Leisure
Women in double-earner households

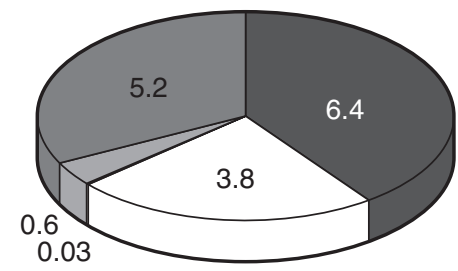

$\square$ Housework $\square$ Care

$\square$ Other unpaid work $\square$ Paid work

Leisure
Men in double-earner households

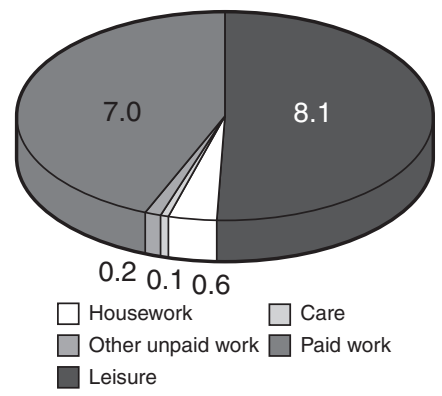

Men in non-earner households
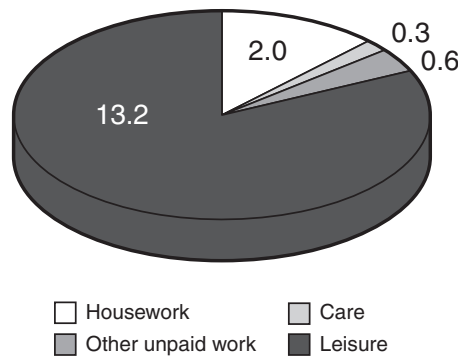

Figure 2.2 Allocation of time by gender on weekdays for different household types and without children.

Source: Author's calculations based on ISTAT 1989 Time Budget Survey. 
Women in one-earner households

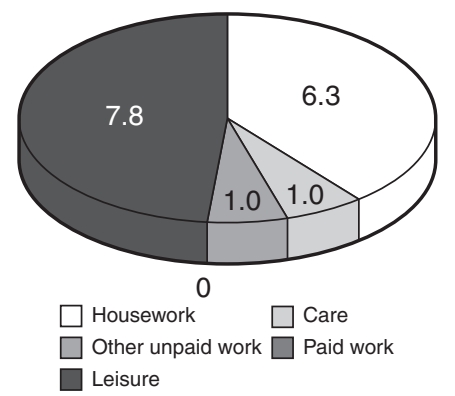

Women in double-earner households
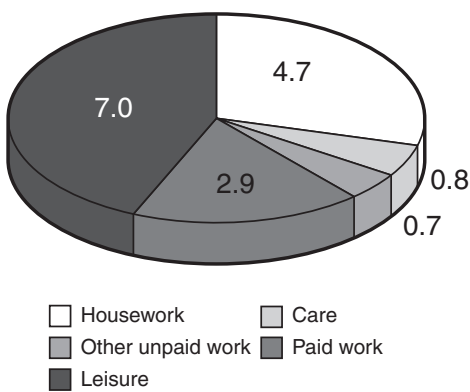

$\square$ Leisure

\section{Women in non-earner households}
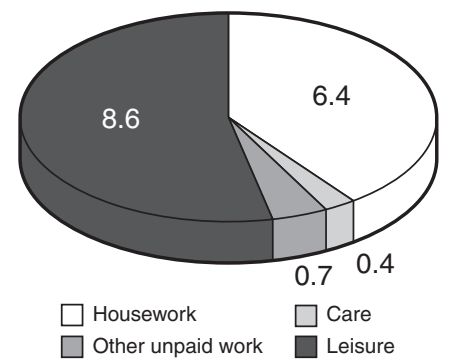

Men in one-earner households

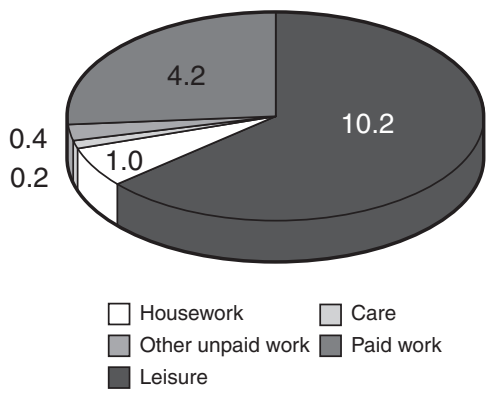

\section{Men in double-earner households}

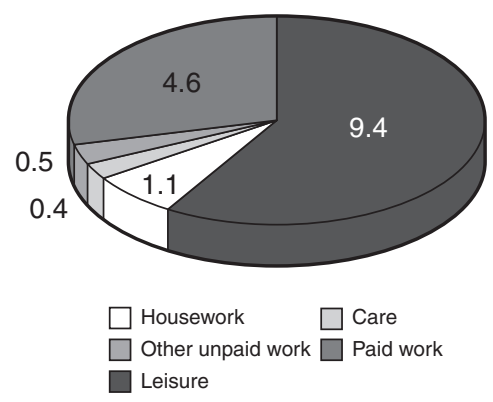

Men in non-earner households

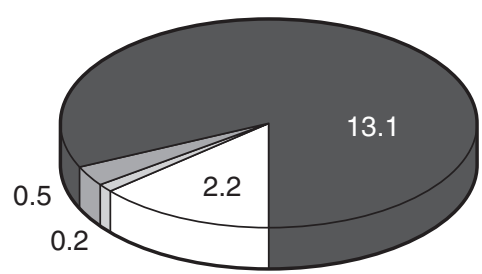

$$
\begin{array}{ll}
\square \text { Housework } & \square \text { Care } \\
\square \text { Other unpaid work } \quad \square \text { Leisure }
\end{array}
$$

Figure 2.3 Allocation of time by gender for different household types and with children on Saturdays.

Source: Author's calculations based on ISTAT 1989 Time Budget Survey. 
Women in one-earner households

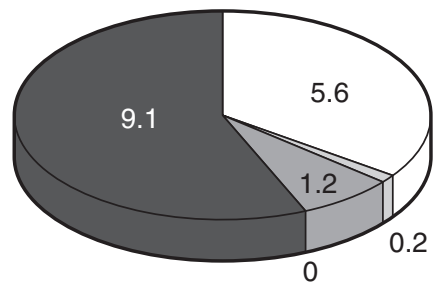

$\square$ Housework $\square$ Care

$\square$ Other unpaid work $\square$ Paid work

$\square$ Leisure

Women in double-earner households

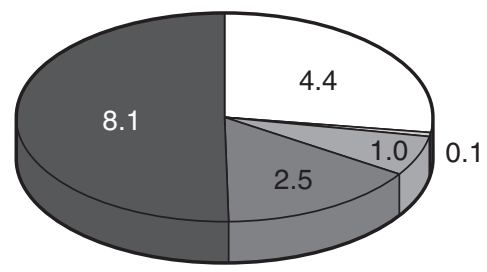

$\square$ Housework $\square$ Care

$\square$ Other unpaid work $\square$ Paid work

$\square$ Leisure

Women in non-earner households

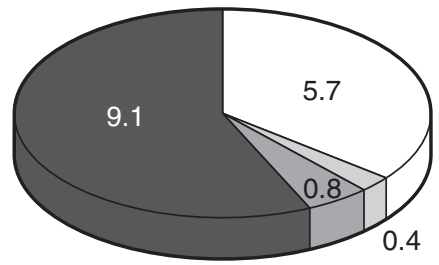

$\square$ Housework

$\square$ Other unpaid work

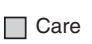

$\square$ Leisure
Men in one-earner households

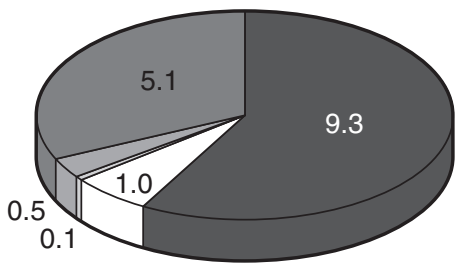

$\square$ Housework $\square$ Care

$\square$ Other unpaid work $\square$ Paid work

$\square$ Leisure
Men in double-earner households

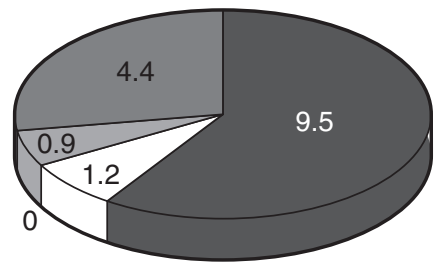

$$
\begin{aligned}
& \square \text { Housework } \square \text { Care } \\
& \square \text { Other unpaid work } \square \text { Paid work }
\end{aligned}
$$$$
\square \text { Leisure }
$$

Figure 2.4 Allocation of time by gender for different household types and without children on Saturdays.

Source: Author's calculations based on ISTAT 1989 Time Budget Survey. 
Women in one-earner households

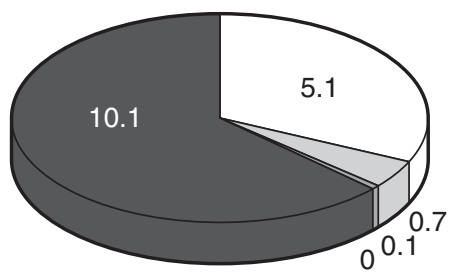

$\square$ Housework $\square$ Care
$\square$ Other unpaid work $\square$ Paid work

$\square$ Leisure

Women in double-earner households
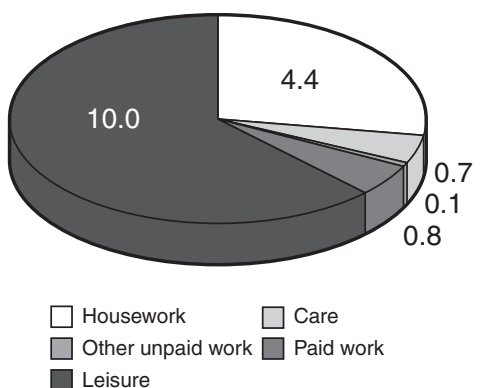

$\square$ Leisure

\section{Women in non-earner households}

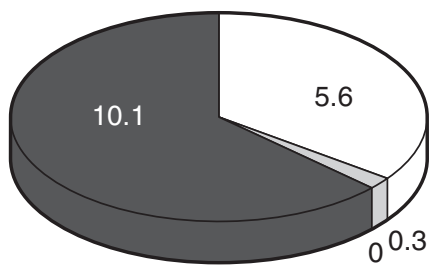

$\begin{array}{ll}\square \text { Housework } & \square \text { Care } \\ \square \text { Other unpaid work } \quad \square \text { Leisure }\end{array}$

\section{Men in one-earner households}

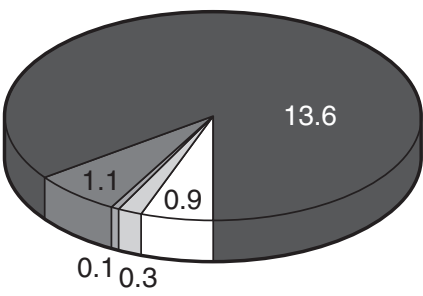

$\square$ Housework

$\square$ Other unpaid work $\square$ Paid work

$\square$ Leisure

\section{Men in double-earner households}

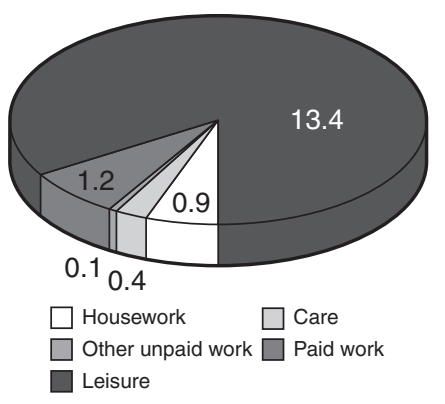

Men in non-earner households

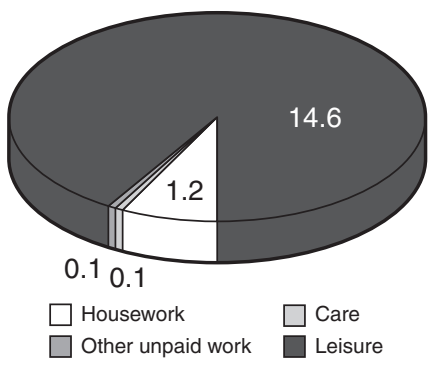

Figure 2.5 Allocation of time by gender for different household types and with children on Sundays.

Source: Author's calculations based on ISTAT 1989 Time Budget Survey. 


\section{Women in one-earner households}
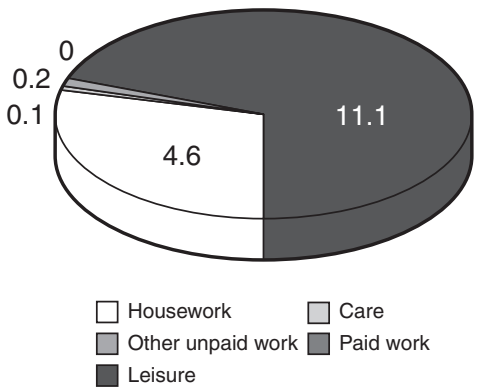

$\square$ Leisure

\section{Women in double-earner households}
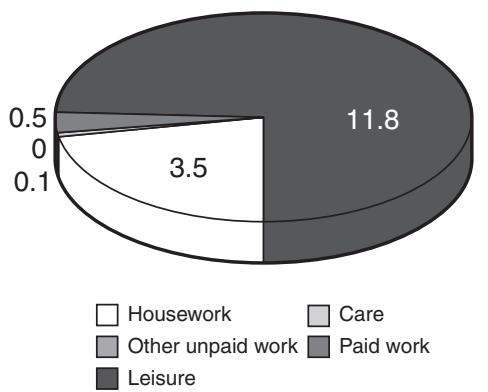

$\square$ Leisure

\section{Women in non-earner households}
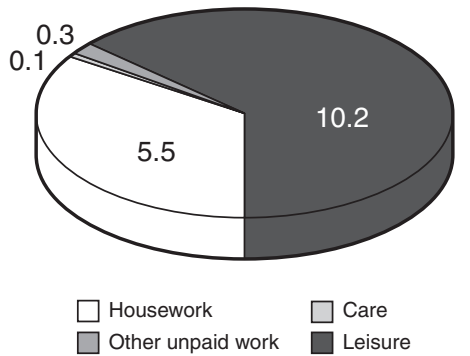

Men in one-earner households

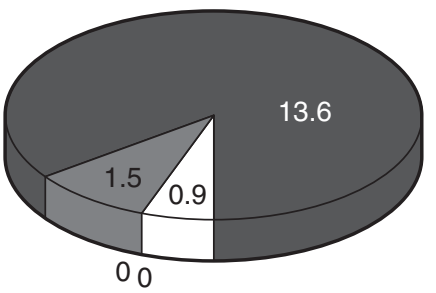

$\square$ Housework $\square$ Care

$\square$ Other unpaid work $\square$ Paid work

Leisure

Men in double-earner households

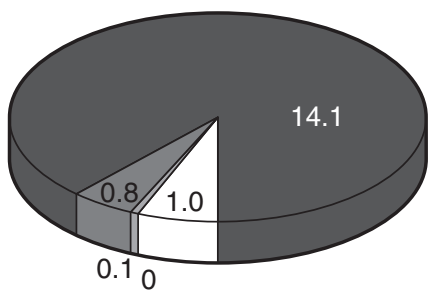

$\square$ Housework $\square$ Care

$\square$ Other unpaid work $\square$ Paid work

$\square$ Leisure

\section{Men in non-earner households}

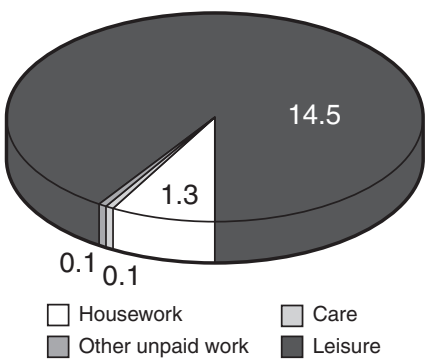

Figure 2.6 Allocation of time by gender for different household types and without children on Sundays.

Source: Author's calculations based on ISTAT 1989 Time Budget Survey. 
Table 2.4a Allocation of unpaid work by gender - double earners with children

\begin{tabular}{|c|c|c|c|c|c|c|c|}
\hline & & \multicolumn{2}{|c|}{ Weekdays } & \multicolumn{2}{|c|}{ Saturdays } & \multicolumn{2}{|c|}{ Sundays } \\
\hline & & Hours & $\%$ & Hours & $\%$ & Hours & $\%$ \\
\hline \multirow[t]{2}{*}{ Housework } & Women & 3.7 & 76 & 4.7 & 76 & 4.4 & 86 \\
\hline & Men & 0.5 & 49 & 1.1 & 56 & 0.9 & 63 \\
\hline \multirow[t]{2}{*}{ Care } & Women & 0.7 & 14 & 0.8 & 12 & 0.7 & 13 \\
\hline & Men & 0.3 & 29 & 0.4 & 20 & 0.4 & 28 \\
\hline \multirow[t]{2}{*}{ Other unpaid work } & Women & 0.5 & 10 & 0.7 & 11 & 0.1 & 1 \\
\hline & Men & 0.2 & 22 & 0.5 & 24 & 0.1 & 9 \\
\hline \multirow[t]{2}{*}{ Total unpaid work } & Women & 4.9 & 100 & 6.1 & 100 & 5.2 & 100 \\
\hline & Men & 1.0 & 100 & 2.0 & 100 & 1.4 & 100 \\
\hline
\end{tabular}

Source: Author's calculations based on ISTAT 1989 Time Budget Survey.

Table $2.4 b$ Allocation of paid work by gender - double earners with children

\begin{tabular}{|c|c|c|c|c|c|c|c|}
\hline & & \multicolumn{2}{|c|}{ Weekdays } & \multicolumn{2}{|c|}{ Saturdays } & \multicolumn{2}{|c|}{ Sundays } \\
\hline & & Hours & $\%$ & Hours & $\%$ & Hours & $\%$ \\
\hline \multirow[t]{2}{*}{ Total unpaid work } & Women & 4.9 & 43 & 6.1 & 68 & 5.2 & 87 \\
\hline & Men & 1.0 & 11 & 2.0 & 31 & 1.4 & 54 \\
\hline \multirow[t]{2}{*}{ Paid work } & Women & 6.4 & 57 & 2.9 & 32 & 0.8 & 14 \\
\hline & Men & 8.2 & 89 & 4.6 & 69 & 1.2 & 46 \\
\hline \multirow[t]{2}{*}{ Total work } & Women & 11.3 & 100 & 9.0 & 100 & 6.0 & 100 \\
\hline & Men & 9.2 & 100 & 6.6 & 100 & 2.6 & 100 \\
\hline
\end{tabular}

Source: Author's calculations based on ISTAT 1989 Time Budget Survey.

Table 2.4c Allocation of time by gender - double earners with children

\begin{tabular}{|c|c|c|c|c|c|c|c|}
\hline & & \multicolumn{2}{|c|}{ Weekdays } & \multicolumn{2}{|c|}{ Saturdays } & \multicolumn{2}{|c|}{ Sundays } \\
\hline & & Hours & $\%$ & Hours & $\%$ & Hours & $\%$ \\
\hline \multirow[t]{2}{*}{ Total work } & Women & 11.3 & 71 & 9.0 & 57 & 6.0 & 37 \\
\hline & Men & 9.2 & 57 & 6.6 & 41 & 2.6 & 17 \\
\hline \multirow[t]{2}{*}{ Total time } & Women & 16.0 & 100 & 16.0 & 100 & 16.0 & 100 \\
\hline & Men & 16.0 & 100 & 16.0 & 100 & 16.0 & 100 \\
\hline
\end{tabular}

Source: Author's calculations based on ISTAT 1989 Time Budget Survey. 


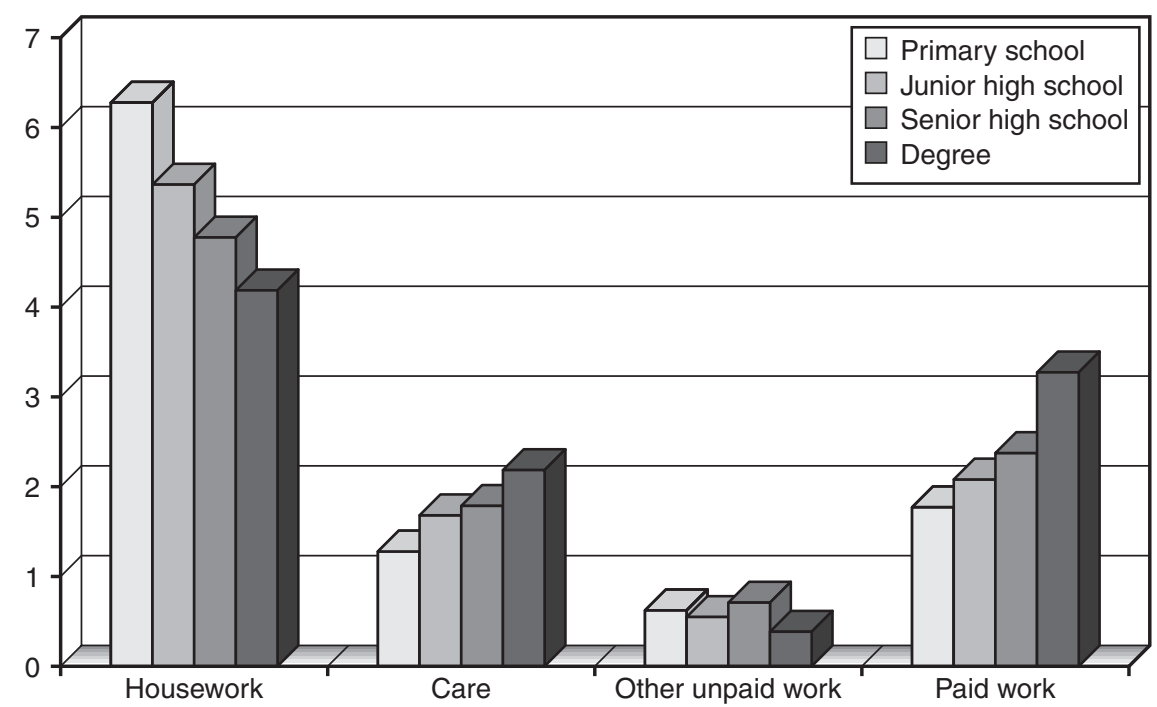

Figure 2.7 Allocation of time by level of education and for women aged between 18 to 35 with children on weekdays.

Source: Author's calculations based on ISTAT 1989 Time Budget Survey.

for men increases during the weekend but is always much less than that of their partners.

The ISTAT Time Budget Survey also contains information on education and other personal characteristics of each family member that we shall use in the unpaid work estimation carried out in Chapter 3. Here we show how the allocation of time changes according to women's educational level (see Figure 2.7) for women aged between 18 and 35 years with children. Women with different educational levels may have a different distribution of unpaid work activities (childcare versus housework). More educated women can reduce their housework (by redistributing housework inside the family or by buying market substitutes) and increase childcare.

We note that less educated women perform more unpaid work and less paid work than more educated women. More educated women in this age group undertake less housework but more childcare. Graduate women tend to do more childcare work than less educated women even when our analysis is restricted to employed women with children.

Another variable which can affect the allocation of time is age cohort. However, in order to assess its effect on the distribution of time use one would need a repeated series of cross-sections or panel data. ${ }^{11}$

Since 1989 there have been substantial changes in shop opening hours which may have changed the spread of work across the week. In addition, for single people daily unpaid work is higher for women than for men (Tables 2.5 
Table 2.5 Paid and unpaid work on different days of the week by gender - employed single people

\begin{tabular}{|c|c|c|c|c|c|c|c|}
\hline & & \multicolumn{2}{|c|}{ Weekdays } & \multicolumn{2}{|c|}{ Saturdays } & \multicolumn{2}{|l|}{ Sundays } \\
\hline & & Women & Men & Women & Men & Women & Men \\
\hline \multirow[t]{2}{*}{ Housework } & Mean & 1.7 & 0.8 & 2.7 & 1.9 & 2.3 & 1.3 \\
\hline & Variance & 1.2 & 1.1 & 2.0 & 2.6 & 2.2 & 1.5 \\
\hline \multirow[t]{2}{*}{ Care } & Mean & 0.0 & 0.0 & 0.1 & 0.8 & 0.1 & 0.0 \\
\hline & Variance & 0.2 & 0.0 & 0.7 & 0.4 & 0.6 & 0.2 \\
\hline \multirow[t]{2}{*}{ Other unpaid work } & Mean & 0.5 & 0.3 & 0.6 & 0.6 & 0.2 & 0.1 \\
\hline & Variance & 0.7 & 0.5 & 0.7 & 1.1 & 0.5 & 0.2 \\
\hline \multirow{2}{*}{ Total unpaid work } & Mean & 2.2 & 1.0 & 3.4 & 2.6 & 2.6 & 1.5 \\
\hline & Variance & 1.3 & 1.2 & 2.6 & 3.2 & 2.5 & 1.6 \\
\hline \multirow[t]{2}{*}{ Paid work } & Mean & 7.5 & 7.2 & 3.4 & 3.2 & 1.3 & 2.1 \\
\hline & Variance & 2.2 & 3.1 & 3.5 & 3.4 & 3.5 & 3.8 \\
\hline \multirow[t]{2}{*}{ Total work } & Mean & 9.7 & 8.2 & 6.8 & 5.8 & 3.9 & 3.5 \\
\hline & Variance & 1.9 & 2.6 & 3.2 & 3.9 & 3.8 & 3.8 \\
\hline
\end{tabular}

Source: Author's calculations based on ISTAT 1989 Time Budget Survey.

and 2.6). Lack of longitudinal data prevents us from testing how changes in the household composition would alter the allocation of working time. We can only observe that on average employed single women do 2.17 hours of unpaid work per weekday whereas employed wives in double-earner households without children do 4.42 hours of unpaid work per day (therefore on average women who are employed but live in couples devote more (2.25) hours to unpaid work than do single employed women). This difference in

Table 2.6 Paid and unpaid work on different days of the week by gender - nonemployed single people

\begin{tabular}{|c|c|c|c|c|c|c|c|}
\hline & & \multicolumn{2}{|c|}{ Weekdays } & \multicolumn{2}{|c|}{ Saturdays } & \multicolumn{2}{|l|}{ Sundays } \\
\hline & & Women & Men & Women & Men & Women & Men \\
\hline \multirow[t]{2}{*}{ Housework } & Mean & 5.0 & 2.0 & 4.5 & 2.1 & 4.0 & 3.5 \\
\hline & Variance & 2.2 & 1.7 & 1.6 & 1.7 & 1.5 & 4.4 \\
\hline \multirow[t]{2}{*}{ Care } & Mean & 0.2 & 0.0 & 0.2 & 0.0 & 0.2 & 0.1 \\
\hline & Variance & 0.5 & 0.0 & 0.7 & 0.1 & 0.8 & 0.3 \\
\hline \multirow[t]{2}{*}{ Other unpaid work } & Mean & 0.8 & 0.3 & 1.0 & 0.7 & 0.2 & 0.3 \\
\hline & Variance & 0.7 & 0.7 & 1.0 & 0.7 & 0.5 & 0.5 \\
\hline \multirow[t]{2}{*}{ Total unpaid work } & Mean & 6.0 & 2.4 & 5.6 & 2.8 & 4.4 & 3.8 \\
\hline & Variance & 2.4 & 2.0 & 1.8 & 2.1 & 1.9 & 4.3 \\
\hline \multirow[t]{2}{*}{ Paid work } & Mean & 0.0 & 0.0 & 0.0 & 0.0 & 0.0 & 0.0 \\
\hline & Variance & 0.0 & 0.0 & 0.0 & 0.0 & 0.0 & 0.0 \\
\hline \multirow[t]{2}{*}{ Total work } & Mean & 6.0 & 2.3 & 5.6 & 2.8 & 4.4 & 3.8 \\
\hline & Variance & 2.5 & 2.0 & 1.8 & 2.1 & 1.9 & 4.3 \\
\hline
\end{tabular}

Source: Author's calculations based on ISTAT 1989 Time Budget Survey. 


\section{Tindara Addabbo}

the number of unpaid working hours per day is greater than the difference between the unpaid work of employed women who live in double-earner households with children (whose unpaid work is 4.87 hours on average during weekdays) and employed women living in double-earner households without children (whose unpaid work is 4.42 hours on average). Therefore unpaid work for women seems to increase more when they pass from living alone to living in a couple than when they pass from living in a couple but without a child to living in a couple and having a child - evidence that having a partner increases women's unpaid work. ${ }^{12}$

The distribution of time by gender between paid and unpaid work also varies according to the area where the family lives (see Table $2 \mathrm{~A} .3$ in the Appendix). Among one-earner households with children, on weekdays we cannot find a large difference in the distribution of time according to the region where the family lives (the number of observations by cell is too low to allow for a comparison for one-earner households without children); on average in double-earner households women who live in the North do more paid work whereas women who live in the South do more unpaid work.

More recent time-budget data might allow one to see how the allocation of unpaid work has changed, especially for younger and more educated cohorts. On the whole, by comparing our results with EURISKO data analysed by Perali (1999), with ISTAT 1998 survey data (Barbagli et al. 2001) and with Bank of Italy (2000) data (Bank of Italy 2002), the persistence of a significant difference may be seen in the allocation of time by gender in Italy.

\section{Suggestions for further research and data collection}

The statistical analysis of the allocation of working time by gender has been performed by using the most recent ISTAT TBS data which, however, date from 1989 (only from 2002 will ISTAT conduct a new survey on timebudget data harmonised with surveys in other European countries). Art. 16 in Law 53 (8 March 2000) states that time-budget surveys (including gender and age disaggregation) should be performed every five years by the Italian Statistical Office. We hope that this will lead to the monitoring of allocation of time by gender, and we would recommend that longitudinal analysis on the allocation of time also be carried out in order to check, for instance, how changes in the sociodemographic structure of the family could lead to changes in the allocation of time by gender.

Time-budget surveys allow analyses of time use which are to be preferred to surveys that only give information on average working hours for a week, since the former type of analysis provides more precise information about the time devoted to different activities and also allows one to take into account activities carried out simultaneously or in the presence of different components.

By being brought into line with other European countries, the ISTAT survey will also enable a comparison of the allocation of time among different European countries and will allow us to see changes that may have 
occurred over time in the allocation of time within Italian households and among different household types.

Here we highlight a few problems faced by the ISTAT 1989 time-budget survey and make suggestions on the collection of unpaid work data. The 1989 time-budget survey did not enable collection of data on the allocation of time for the same household on different days of the week. We would suggest that the same household should be followed on different days of the week to test how unpaid work is allocated differently by the same family on days when more time is usually devoted to paid work and during the weekend; this would also avoid using estimation of unpaid work equations in order to obtain the average weekly hours of unpaid work.

The ISTAT 1989 time-budget survey did not enable the member(s) of the family cared for to be identified. The literature on unpaid work in Italy has stressed the importance of the presence of adult children in the household or the necessity to care for an elderly relative in increasing women's unpaid working time. It may be useful to have data disaggregated by the person cared for.

The difficult reconciliation between working and family time is shown clearly by different analyses of female labour supply carried out in Italy. This difficult reconciliation is evident in Colombino's (1982) analysis based on Turin data, and by Borzaga's (1994) and Giannelli's (1997) analyses based on surveys carried out in Trento and Tuscany respectively. Among the employed women interviewed in Trento, 30 per cent would prefer to work a different number of hours than they currently do (Borzaga 1994). Among underemployed women the youngest, the unmarried women and those without children are over-represented, whereas among overemployed women there are more women aged between 25 and 39 years, married and with at least one child. By using a survey of women living in Tuscany, Giannelli (1997) also shows a positive correlation between overemployment and the presence in the household of children aged under 6 .

This evidence on disequilibrium and problems of reconciling different uses of time suggests that surveys should investigate not only the actual but also the desired (paid and unpaid) working time. This would allow us to apply disequilibrium models to the family allocation of time.

The possibility of repeating the survey over time might allow one to see in which phases of the family cycle imbalances in the allocation of time occur, how long individuals bear disequilibrium, and who is most exposed inside the family to the risk of mismatches between the preferred and actual time devoted to different activities and the effect of these disequilibrium phases on the future working profile.

It is also important to measure the contribution of members who do not live in the household to unpaid activities (for instance, it is important to measure the time devoted by grandparents to caring for their grandchildren and the work done by baby-sitters or other family helpers). ${ }^{13}$ These data would enable one to see in which phases of the family life cycle and in which 
household types (by considering also the employment status of spouses) market substitutes or the time of relatives are used more frequently.

Even if time-budget data obtained by diary compilation are preferable to synthetic information on mean hours of work during a week, it might be useful to introduce the latter type of information on unpaid work into the national surveys currently carried out on household budgets and wealth: this could lead to an easier evaluation of total working time, and time-budget surveys may be used to cross-check the information on average hours of work. This suggestion has been taken into account at national level by the survey on household income and wealth carried out by the Bank of Italy in 2000 and by the local survey on the socio-economic conditions of households living in the Modena district carried out by CAPP (Centro di Analisi delle Politiche Pubbliche) in 2002. ${ }^{14}$

\section{Conclusions}

Disequilibrium in the distribution of time use in Italy by gender is shown by the analysis carried out in this chapter using the ISTAT time-budget survey. The evidence on the heavier load of unpaid work borne by women in Italy is consistent with the results of the literature surveyed.

We have shown how unpaid work changes according to household types (identified by taking into account the employment condition of the spouses, the presence of children, and whether the individuals live as a couple). Women who live in a couple perform a greater amount of unpaid work than do single women (even when couples without children are taken into account), and there are significant differences in the allocation of unpaid work among women with different levels of education. The analysis of time-budget data shows that (apart from households without children where women are not employed and on weekdays) women always devote more time to total work than do men.

Apart from a descriptive analysis of the distribution of unpaid work by gender and by type of household, this research aims to analyse the pattern of unpaid work performed by men and women who live in a couple or alone as individual and household characteristics change. The impact of variables connected with the sociodemographic structure of the family and individual characteristics are subjected to econometric analysis in Chapter 3.

We suggest changes in the design of a new time-budget survey in Italy and the inclusion of synthetic information on the desired and actual allocation of time in the surveys on households run currently in Italy.

\section{Acknowledgements}

I am grateful to the participants in the research group directed by Professor Antonella Picchio for their valuable suggestions on previous versions of this Chapter. The usual disclaimers apply. Financial support from CNEL is gratefully acknowledged. 


\section{Appendix: Descriptive statistics on ISTAT time-budget data}

Table 2A.1 Descriptive analysis Indagine Multiscopo ISTAT 1989

\begin{tabular}{|c|c|c|c|c|c|c|}
\hline & $\begin{array}{l}\text { Weekdays } \\
\text { Mean }\end{array}$ & $\begin{array}{l}\text { Weekdays } \\
\text { St. Dev. }\end{array}$ & $\begin{array}{l}\text { Saturdays } \\
\text { Mean }\end{array}$ & $\begin{array}{l}\text { Saturdays } \\
\text { St. Dev. }\end{array}$ & $\begin{array}{l}\text { Sundays } \\
\text { Mean }\end{array}$ & $\begin{array}{l}\text { Sunday. } \\
\text { St. Dev. }\end{array}$ \\
\hline Women's age & 41.10 & 18.04 & 40.77 & 8.31 & 40.97 & 8.36 \\
\hline Women's years of schooling & 8.39 & 6.47 & 8.47 & 2.98 & 8.49 & 3.03 \\
\hline North West & 0.17 & 0.61 & 0.18 & 0.29 & 0.18 & 0.29 \\
\hline North East & 0.29 & 0.73 & 0.28 & 0.34 & 0.28 & 0.34 \\
\hline Centre & 0.16 & 0.59 & 0.18 & 0.29 & 0.18 & 0.30 \\
\hline South & 0.37 & 0.80 & 0.36 & 0.36 & 0.36 & 0.37 \\
\hline Women not in labour force & 0.63 & 0.78 & 0.61 & 0.37 & 0.60 & 0.38 \\
\hline Employed women & 0.37 & 0.78 & 0.39 & 0.37 & 0.40 & 0.38 \\
\hline Housewives & 0.52 & 0.80 & 0.50 & 0.37 & 0.50 & 0.38 \\
\hline Women employees & 0.28 & 0.72 & 0.28 & 0.34 & 0.30 & 0.35 \\
\hline Self-employed women & 0.09 & 0.45 & 0.11 & 0.23 & 0.11 & 0.24 \\
\hline Women part-timers & 0.11 & 0.49 & 0.09 & 0.22 & 0.02 & 0.10 \\
\hline $\begin{array}{l}\text { Women employed in } \\
\text { agriculture }\end{array}$ & 0.03 & 0.27 & 0.04 & 0.14 & 0.03 & 0.14 \\
\hline $\begin{array}{l}\text { Women employed in } \\
\text { Services }\end{array}$ & 0.28 & 0.72 & 0.27 & 0.33 & 0.29 & 0.35 \\
\hline $\begin{array}{l}\text { Women employed in } \\
\text { manufacturing }\end{array}$ & 0.06 & 0.37 & 0.08 & 0.20 & 0.08 & 0.20 \\
\hline Number of components & 3.53 & 1.61 & 3.55 & 0.76 & 3.52 & 0.80 \\
\hline $\begin{array}{l}\text { Number of children } 0-2 \\
\text { years }\end{array}$ & 0.15 & 0.62 & 0.14 & 0.28 & 0.15 & 0.29 \\
\hline $\begin{array}{l}\text { Number of children 3-5 } \\
\text { years }\end{array}$ & 0.15 & 0.62 & 0.16 & 0.29 & 0.15 & 0.29 \\
\hline $\begin{array}{l}\text { Number of children 15-17 } \\
\text { years }\end{array}$ & 0.19 & 0.74 & 0.19 & 0.32 & 0.22 & 0.36 \\
\hline $\begin{array}{l}\text { Number of children } 18-24 \\
\text { years }\end{array}$ & 0.25 & 0.90 & 0.25 & 0.40 & 0.24 & 0.40 \\
\hline Men's age & 44.59 & 17.93 & 44.37 & 8.28 & 44.66 & 8.44 \\
\hline Men's years of schooling & 8.91 & 6.63 & 8.86 & 3.03 & 8.95 & 3.25 \\
\hline Men part-timers & 0.09 & 0.46 & 0.20 & 0.30 & 0.08 & 0.21 \\
\hline Men not in labour force & 0.19 & 0.63 & 0.17 & 0.28 & 0.16 & 0.28 \\
\hline Employed men & 0.81 & 0.63 & 0.83 & 0.28 & 0.84 & 0.28 \\
\hline Men employees & 0.56 & 0.80 & 0.58 & 0.37 & 0.58 & 0.38 \\
\hline Self-employed men & 0.23 & 0.68 & 0.24 & 0.32 & 0.24 & 0.33 \\
\hline Men employed in agriculture & 0.07 & 0.40 & 0.06 & 0.18 & 0.05 & 0.17 \\
\hline $\begin{array}{l}\text { Men employed in } \\
\text { manufacturing }\end{array}$ & 0.25 & 0.70 & 0.27 & 0.33 & 0.24 & 0.33 \\
\hline Men employed in Services & 0.48 & 0.81 & 0.49 & 0.37 & 0.54 & 0.38 \\
\hline Women’s housework & 5.66 & 4.41 & 5.46 & 1.90 & 4.78 & 1.84 \\
\hline Women's constrained time & 0.74 & 1.26 & 0.88 & 0.70 & 0.12 & 0.31 \\
\hline Women's care work & 0.80 & 2.11 & 0.70 & 0.90 & 0.51 & 0.74 \\
\hline Women's total unpaid work & 7.19 & 5.14 & 7.04 & 2.21 & 5.41 & 1.99 \\
\hline Women's paid work & 2.05 & 5.27 & 1.17 & 1.90 & 0.35 & 1.26 \\
\hline Men's housework & 0.70 & 2.31 & 1.10 & 1.29 & 0.88 & 1.11 \\
\hline Men's constrained time & 0.30 & 1.11 & 0.51 & 0.64 & 0.12 & 0.26 \\
\hline Men’s care work & 0.21 & 0.98 & 0.28 & 0.51 & 0.28 & 0.65 \\
\hline Men's total unpaid work & 1.21 & 2.96 & 1.89 & 1.59 & 1.28 & 1.30 \\
\hline Men's paid work & 6.23 & 6.33 & 3.66 & 2.93 & 0.97 & 1.90 \\
\hline Men doing unpaid work & 0.62 & \multirow{2}{*}{\multicolumn{2}{|c|}{$\begin{array}{c}0 . / 8 \quad 0.13 \\
1,278\end{array}$}} & 0.32 & 0.67 & 0.36 \\
\hline Observations & 1,271 & & & \multicolumn{2}{|c|}{1,279} & \\
\hline
\end{tabular}

Source: Author's calculations based on ISTAT 1989 Time Budget Survey. 


\section{Tindara Addabbo}

Table 2A.2 Allocation of time between different uses by gender and household type

\begin{tabular}{|c|c|c|c|c|c|c|c|}
\hline \multicolumn{2}{|l|}{ One earner with children } & \multicolumn{2}{|c|}{ Weekdays } & \multicolumn{2}{|c|}{ Saturdays } & \multicolumn{2}{|c|}{ Sundays } \\
\hline & & Hours & $\%$ & Hours & $\%$ & Hours & $\%$ \\
\hline \multirow[t]{2}{*}{ Housework } & Women & 6.7 & 77 & 6.3 & 76 & 5.1 & 86 \\
\hline & Men & 0.5 & 55 & 1.0 & 58 & 0.9 & 67 \\
\hline \multirow[t]{2}{*}{ Care } & Women & 1.1 & 13 & 1.0 & 12 & 0.7 & 12 \\
\hline & Men & 0.2 & 21 & 0.2 & 15 & 0.3 & 24 \\
\hline \multirow[t]{2}{*}{ Other unpaid work } & Women & 0.9 & 10 & 1.0 & 12 & 0.1 & 2 \\
\hline & Men & 0.2 & 24 & 0.4 & 27 & 0.1 & 9 \\
\hline \multirow[t]{4}{*}{ Total unpaid work } & Women & 8.7 & 100 & 8.2 & 100 & 5.9 & 100 \\
\hline & Men & 0.9 & 100 & 1.7 & 100 & 1.3 & 100 \\
\hline & & \multicolumn{2}{|c|}{ Weekdays } & \multicolumn{2}{|c|}{ Saturdays } & \multicolumn{2}{|c|}{ Sundays } \\
\hline & & Hours & $\%$ & Hours & $\%$ & Hours & $\%$ \\
\hline \multirow[t]{2}{*}{ Total unpaid work } & Women & 8.7 & 100 & 8.2 & 100 & 5.9 & 100 \\
\hline & Men & 0.9 & 10 & 1.7 & 29 & 1.3 & 55 \\
\hline \multirow[t]{2}{*}{ Paid work } & Women & 0.0 & 0 & 0.0 & 0 & 0.0 & 0 \\
\hline & Men & 7.2 & 90 & 4.2 & 71 & 1.1 & 45 \\
\hline \multirow[t]{4}{*}{ Total work } & Women & 8.7 & 100 & 8.2 & 100 & 5.9 & 100 \\
\hline & Men & 8.0 & 100 & 5.8 & 100 & 2.4 & 100 \\
\hline & & \multicolumn{2}{|c|}{ Weekdays } & \multicolumn{2}{|c|}{ Saturdays } & \multicolumn{2}{|c|}{ Sundays } \\
\hline & & Hours & $\%$ & Hours & $\%$ & Hours & $\%$ \\
\hline \multirow[t]{2}{*}{ Total work } & Women & 8.7 & 54 & 8.2 & 51 & 5.9 & 37 \\
\hline & Men & 8.0 & 50 & 5.8 & 36 & 2.4 & 15 \\
\hline \multirow[t]{2}{*}{ Total hours per day } & Women & 16.0 & 100 & 16.0 & 100 & 16.0 & 100 \\
\hline & Men & 16.0 & 100 & 16.0 & 100 & 16.0 & 100 \\
\hline \multicolumn{2}{|c|}{ One earner without children } & \multicolumn{2}{|c|}{ Weekdays } & \multicolumn{2}{|c|}{ Saturdays } & \multicolumn{2}{|c|}{ Sundays } \\
\hline & & Hours & $\%$ & Hours & $\%$ & Hours & $\%$ \\
\hline \multirow[t]{2}{*}{ Housework } & Women & 5.8 & 82 & 5.6 & 81 & 4.7 & 95 \\
\hline & Men & 0.5 & 65 & 1.0 & 64 & 1.2 & 88 \\
\hline \multirow[t]{2}{*}{ Care } & Women & 0.2 & 3 & 0.2 & 2 & 0.1 & 2 \\
\hline & Men & 0.1 & 10 & 0.1 & 7 & 0.1 & 7 \\
\hline \multirow[t]{2}{*}{ Other unpaid work } & Women & 1.0 & 14 & 1.2 & 17 & 0.2 & 4 \\
\hline & Men & 0.2 & 25 & 0.5 & 28 & 0.1 & 5 \\
\hline \multirow[t]{2}{*}{ Total unpaid work } & Women & 7.0 & 100 & 6.7 & 100 & 4.9 & 100 \\
\hline & Men & 0.8 & 100 & 1.6 & 100 & 1.3 & 100 \\
\hline
\end{tabular}


Table 2A.2 (cont'd)

\begin{tabular}{|c|c|c|c|c|c|c|c|}
\hline & & \multicolumn{2}{|c|}{ Weekdays } & \multicolumn{2}{|c|}{ Saturdays } & \multicolumn{2}{|c|}{ Sundays } \\
\hline & & Hours & $\%$ & Hours & $\%$ & Hours & $\%$ \\
\hline \multirow[t]{2}{*}{ Total unpaid work } & Women & 7.0 & 100 & 6.9 & 100 & 4.9 & 100 \\
\hline & Men & 0.8 & 11 & 1.6 & 24 & 1.3 & 57 \\
\hline \multirow[t]{2}{*}{ Paid work } & Women & 0.0 & 0 & 0.0 & 0 & 0.0 & 0 \\
\hline & Men & 7.0 & 89 & 5.1 & 76 & 1.0 & 43 \\
\hline \multirow[t]{4}{*}{ Total work } & Women & 7.0 & 100 & 6.9 & 100 & 2.3 & 100 \\
\hline & Men & 7.8 & 100 & 6.7 & 100 & 2.7 & 100 \\
\hline & & \multicolumn{2}{|c|}{ Weekdays } & \multicolumn{2}{|c|}{ Saturdays } & \multicolumn{2}{|c|}{ Sundays } \\
\hline & & Hours & $\%$ & Hours & $\%$ & Hours & $\%$ \\
\hline \multirow[t]{2}{*}{ Total work } & Women & 7.0 & 44 & 6.9 & 43 & 4.9 & 31 \\
\hline & Men & 7.8 & 49 & 6.7 & 42 & 1.3 & 15 \\
\hline \multirow[t]{2}{*}{ Total hours per day } & Women & 16.0 & 100 & 16.0 & 100 & 16.0 & 100 \\
\hline & Men & 16.0 & 100 & 16.0 & 100 & 16.0 & 100 \\
\hline \multicolumn{2}{|c|}{ Double earner with children } & \multicolumn{2}{|c|}{ Weekdays } & \multicolumn{2}{|c|}{ Saturdays } & \multicolumn{2}{|c|}{ Sundays } \\
\hline & & Hours & $\%$ & Hours & $\%$ & Hours & $\%$ \\
\hline \multirow[t]{2}{*}{ Housework } & Women & 3.8 & 86 & 4.4 & 81 & 3.5 & 97 \\
\hline & Men & 0.6 & 69 & 1.2 & 57 & 1.0 & 93 \\
\hline \multirow[t]{2}{*}{ Care } & Women & 0.0 & 1 & 0.0 & 1 & 0.1 & 2 \\
\hline & Men & 0.1 & 8 & 0.0 & 0 & 0.0 & 2 \\
\hline \multirow[t]{2}{*}{ Other unpaid work } & Women & 0.6 & 13 & 1.0 & 18 & 0.0 & 1 \\
\hline & Men & 0.2 & 23 & 0.9 & 43 & 0.1 & 5 \\
\hline \multirow[t]{4}{*}{ Total unpaid work } & Women & 4.4 & 100 & 5.4 & 100 & 3.6 & 100 \\
\hline & Men & 0.9 & 100 & 2.1 & 100 & 1.1 & 100 \\
\hline & & \multicolumn{2}{|c|}{ Weekdays } & \multicolumn{2}{|c|}{ Saturdays } & \multicolumn{2}{|c|}{ Sundays } \\
\hline & & Hours & $\%$ & Hours & $\%$ & Hours & $\%$ \\
\hline \multirow[t]{2}{*}{ Total unpaid work } & Women & 4.4 & 46 & 5.4 & 68 & 3.6 & 87 \\
\hline & Men & 0.9 & 11 & 2.1 & 33 & 1.1 & 59 \\
\hline \multirow[t]{2}{*}{ Paid work } & Women & 5.2 & 54 & 2.5 & 32 & 0.5 & 13 \\
\hline & Men & 7.0 & 89 & 4.4 & 67 & 0.8 & 41 \\
\hline \multirow[t]{4}{*}{ Total work } & Women & 9.7 & 100 & 7.9 & 100 & 4.2 & 100 \\
\hline & Men & 7.9 & 100 & 6.5 & 100 & 1.9 & 100 \\
\hline & & \multicolumn{2}{|c|}{ Weekdays } & Saturd & & Sunday & \\
\hline & & Hours & $\%$ & Hours & $\%$ & Hours & $\%$ \\
\hline Total work & Women & 9.7 & 60 & 7.9 & 49 & 4.2 & 26 \\
\hline & Men & 7.9 & 49 & 6.5 & 41 & 1.9 & 12 \\
\hline Total hours per day & Women & 16.0 & 100 & 16.0 & 100 & 16.0 & 100 \\
\hline & Men & 16.0 & 100 & 16.0 & 100 & 16.0 & 100 \\
\hline
\end{tabular}


50 Tindara Addabbo

Table 2A.2 (cont'd)

\begin{tabular}{|c|c|c|c|c|c|c|c|}
\hline \multicolumn{2}{|c|}{ Non-earners with children } & \multicolumn{2}{|c|}{ Weekdays } & \multicolumn{2}{|c|}{ Saturdays } & \multicolumn{2}{|c|}{ Sundays } \\
\hline & & Hours & $\%$ & Hours & $\%$ & Hours & $\%$ \\
\hline \multirow[t]{2}{*}{ Housework } & Women & 6.5 & 86 & 6.3 & 86 & 5.6 & 95 \\
\hline & Men & 2.1 & 73 & 2.2 & 77 & 1.2 & 86 \\
\hline \multirow[t]{2}{*}{ Care } & Women & 0.3 & 4 & 0.4 & 5 & 0.3 & 4 \\
\hline & Men & 0.2 & 7 & 0.2 & 7 & 0.1 & 6 \\
\hline \multirow[t]{2}{*}{ Other unpaid work } & Women & 0.8 & 10 & 0.7 & 9 & 0.0 & 1 \\
\hline & Men & 0.6 & 20 & 0.5 & 16 & 0.1 & 8 \\
\hline \multirow[t]{4}{*}{ Total unpaid work } & Women & 7.5 & 100 & 7.4 & 100 & 5.9 & 100 \\
\hline & Men & 2.8 & 100 & 2.9 & 100 & 1.4 & 100 \\
\hline & & \multicolumn{2}{|c|}{ Weekdays } & \multicolumn{2}{|c|}{ Saturdays } & \multicolumn{2}{|c|}{ Sundays } \\
\hline & & Hours & $\%$ & Hours & $\%$ & Hours & $\%$ \\
\hline \multirow[t]{2}{*}{ Total unpaid work } & Women & 7.5 & 100 & 0.7 & 100 & 0.0 & 100 \\
\hline & Men & 2.8 & 100 & 0.5 & 100 & 0.1 & 100 \\
\hline \multirow[t]{2}{*}{ Paid work } & Women & 0.0 & 0 & 0.0 & 0 & 0.0 & 0 \\
\hline & Men & 0.0 & 0 & 0.0 & 0 & 0.0 & 0 \\
\hline \multirow[t]{4}{*}{ Total work } & Women & 7.5 & 100 & 0.7 & 100 & 0.0 & 100 \\
\hline & Men & 2.8 & 100 & 0.5 & 100 & 0.1 & 100 \\
\hline & & \multicolumn{2}{|c|}{ Weekdays } & \multicolumn{2}{|c|}{ Saturdays } & \multicolumn{2}{|c|}{ Sundays } \\
\hline & & Hours & $\%$ & Hours & $\%$ & Hours & $\%$ \\
\hline \multirow[t]{2}{*}{ Total work } & Women & 7.5 & 47 & 0.7 & 46 & 0.0 & 37 \\
\hline & Men & 2.8 & 18 & 0.5 & 18 & 0.1 & 9 \\
\hline \multirow[t]{2}{*}{ Total hours per day } & Women & 16.0 & 100 & 16.0 & 100 & 16.0 & 100 \\
\hline & Men & 16.0 & 100 & 16.0 & 100 & 16.0 & 100 \\
\hline \multicolumn{2}{|c|}{ Non-earners without children } & \multicolumn{2}{|c|}{ Weekdays } & \multicolumn{2}{|c|}{ Saturdays } & \multicolumn{2}{|c|}{ Sundays } \\
\hline & & Hours & $\%$ & Hours & $\%$ & Hours & $\%$ \\
\hline \multirow[t]{2}{*}{ Housework } & Women & 6.1 & 85 & 5.7 & 83 & 5.5 & 94 \\
\hline & Men & 2.0 & 70 & 2.1 & 73 & 1.3 & 87 \\
\hline \multirow[t]{2}{*}{ Care } & Women & 0.2 & 3 & 0.4 & 5 & 0.1 & 2 \\
\hline & Men & 0.2 & 9 & 0.2 & 7 & 0.1 & 7 \\
\hline \multirow[t]{2}{*}{ Other unpaid work } & Women & 0.9 & 12 & 0.8 & 12 & 0.3 & 5 \\
\hline & Men & 0.6 & 21 & 0.6 & 20 & 0.1 & 6 \\
\hline \multirow{2}{*}{ Total unpaid work } & Women & 7.2 & 100 & 6.9 & 100 & 5.8 & 100 \\
\hline & Men & 2.8 & 100 & 2.8 & 100 & 1.5 & 100 \\
\hline
\end{tabular}


Unpaid work by gender in Italy 51

Table 2A.2 (cont'd)

\begin{tabular}{|c|c|c|c|c|c|c|c|}
\hline & & \multicolumn{2}{|c|}{ Weekdays } & \multicolumn{2}{|c|}{ Saturdays } & \multicolumn{2}{|c|}{ Sundays } \\
\hline & & Hours & $\%$ & Hours & $\%$ & Hours & $\%$ \\
\hline \multirow[t]{2}{*}{ Total unpaid work } & Women & 7.2 & 100 & 6.9 & 100 & 5.8 & 100 \\
\hline & Men & 2.8 & 100 & 2.8 & 100 & 1.5 & 100 \\
\hline \multirow[t]{2}{*}{ Paid work } & Women & 0.0 & 0 & 0.0 & 0 & 0.0 & 0 \\
\hline & Men & 0.0 & 0 & 0.0 & 0 & 0.0 & 0 \\
\hline \multirow[t]{4}{*}{ Total work } & Women & 7.2 & 100 & 6.9 & 100 & 5.8 & 100 \\
\hline & Men & 2.8 & 100 & 2.8 & 100 & 1.5 & 100 \\
\hline & & \multicolumn{2}{|c|}{ Weekdays } & \multicolumn{2}{|c|}{ Saturdays } & \multicolumn{2}{|c|}{ Sundays } \\
\hline & & Hours & $\%$ & Hours & $\%$ & Hours & $\%$ \\
\hline \multirow[t]{2}{*}{ Total work } & Women & 7.2 & 45 & 6.9 & 43 & 5.8 & 37 \\
\hline & Men & 2.8 & 18 & 2.8 & 18 & 1.5 & 9 \\
\hline \multirow[t]{2}{*}{ Total hours per day } & Women & 16.0 & 100 & 16.0 & 100 & 16.0 & 100 \\
\hline & Men & 16.0 & 100 & 16.0 & 100 & 16.0 & 100 \\
\hline
\end{tabular}

Source: Author's calculations based on ISTAT 1989 Time Budget Survey. 


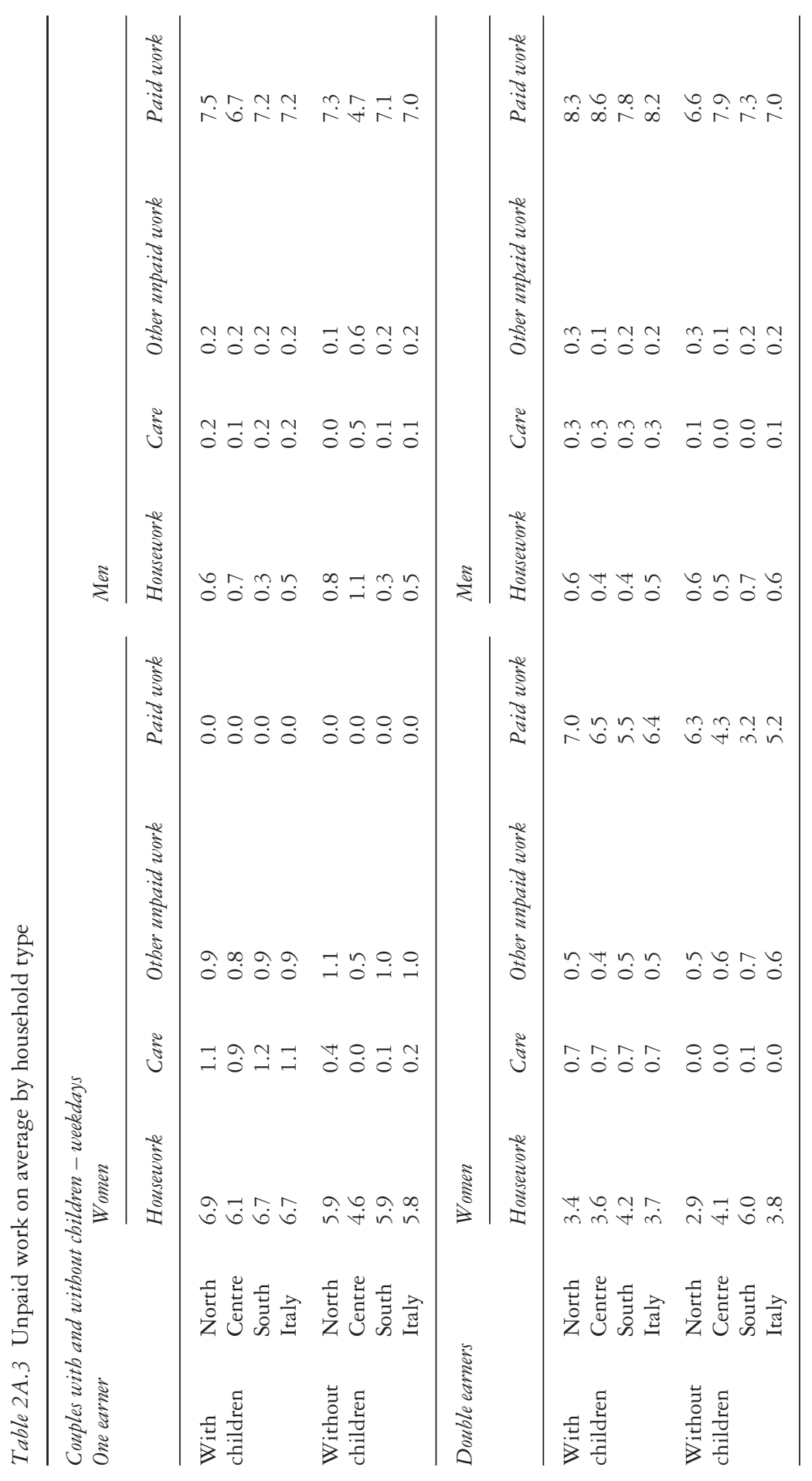




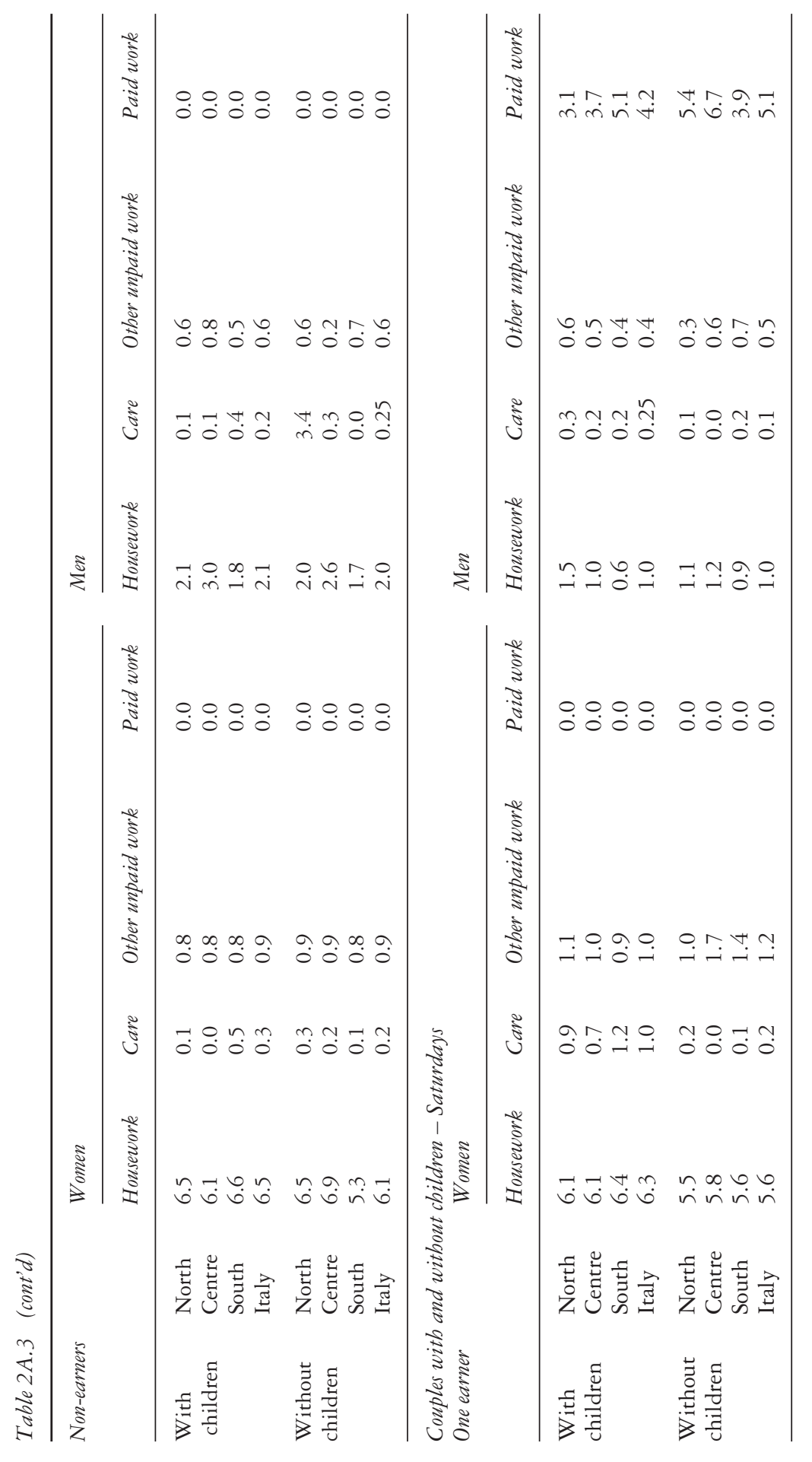




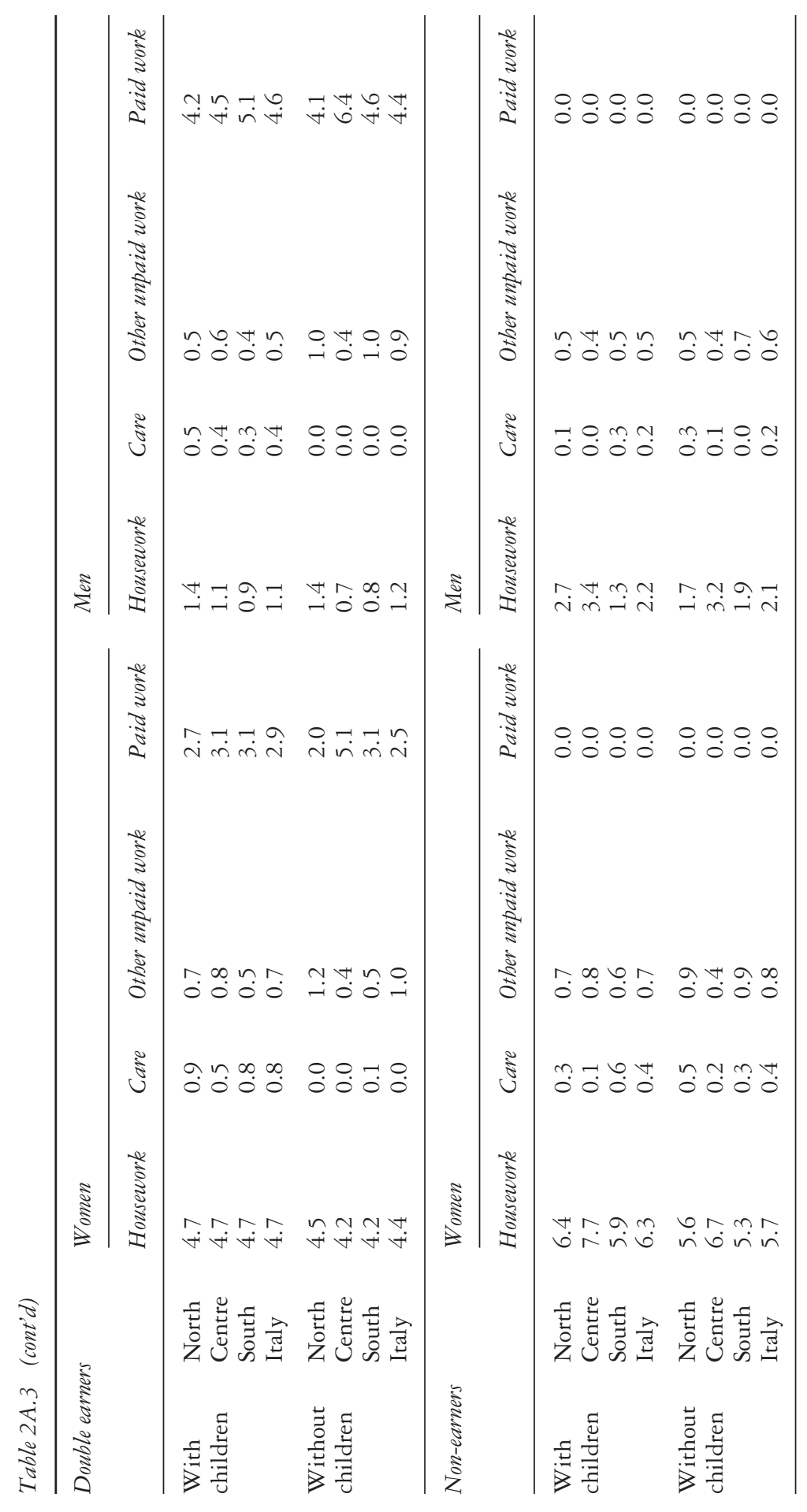




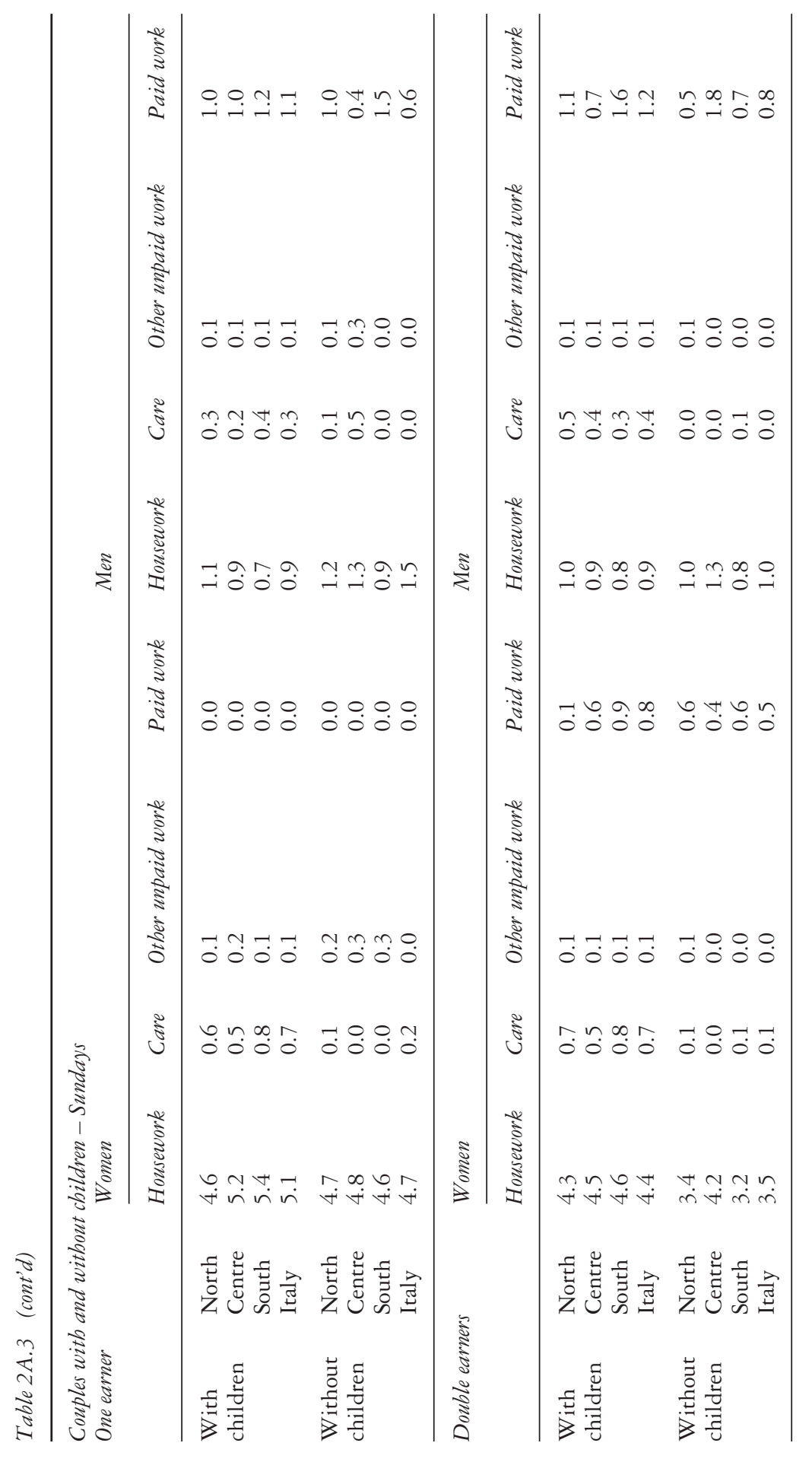




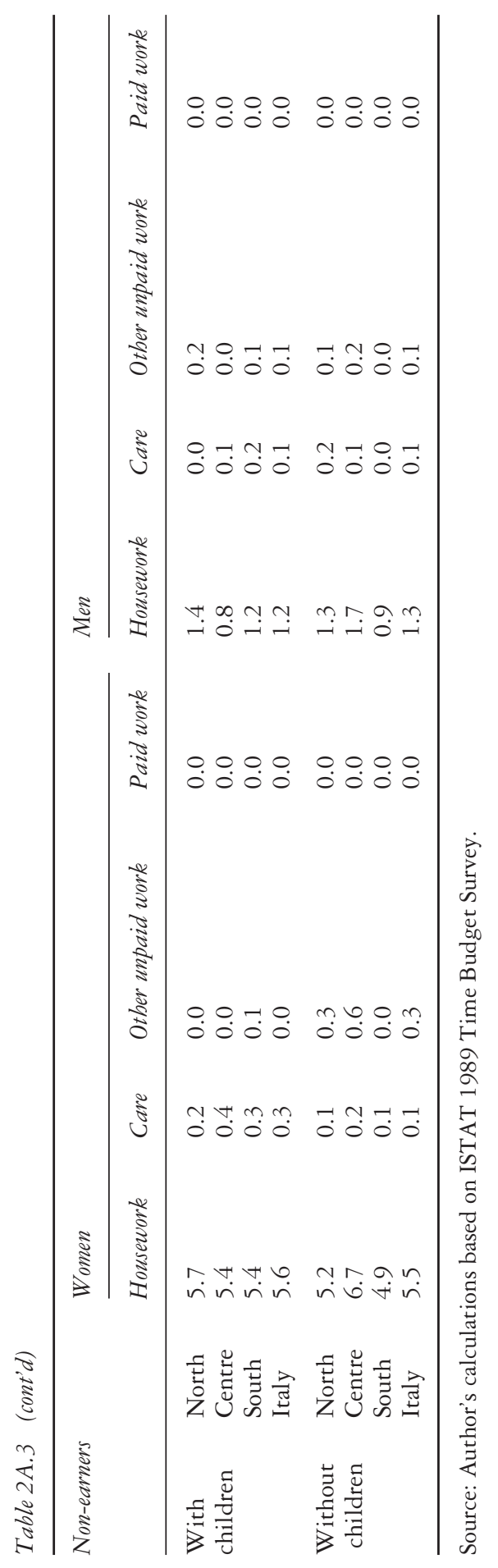




\section{Notes}

1 See Goldschmidt-Clermont and Pagnossin-Aligisakis (1996) for a comparative analysis of this type of data.

2 Capellari (2001) and Palomba and Sabbadini (1994) provide a fuller description of this time-budget survey and of the distribution of unpaid work.

3 See Zuliani 1994.

4 See Perali (1999) for data analysis.

5 Palomba (1997) estimates one hour of unpaid work for any other child.

6 See Giannelli and Monfardini, in Chapter 7, this volume.

7 The greater burden of housework which marriage brings about for women and the reduction in terms of housework for men when they get married has been found also by Duncan and Morgan (1978) by using US data.

8 The survey by ISTAT on household consumption do not contain information on unpaid work by different members of the household. The Bank of Italy survey on households' income and wealth contains information on unpaid work only in the 2000 survey.

9 The average total number of hours devoted to unpaid work over the week has been estimated by using information on time budget by different days of the week in Chapter 3, this volume.

10 Decimals are fractions of hours, not minutes.

11 It should be remembered that by using only one cross-section, the cohort effect becomes mixed with ageing effects.

12 If longitudinal data were available it would be possible to tackle the problem in greater depth, accounting also for unobserved heterogeneity among different groups of the population.

13 Surveys that account for the work of baby-sitters or family helpers show a reduction in woman's unpaid working time (Perali 1999).

14 See Bank of Italy (2002) for SHIW 2000 and <http:www.dse.unibo.it/capp > for the survey of the socio-economic conditions of households living in the district of Modena.

\section{References}

Addabbo, T. (1998) 'Lavoro non pagato e reddito esteso: un'applicazione alle famiglie italiane in cui entrambi i coniugi sono lavoratori dipendenti', Materiali di Discussione del Dipartimento di Economia Politica dell’Università degli Studi di Modena, no. 215.

Addis, E. (1997) Economia e differenze di genere, Bologna: Clueb.

Bank of Italy (2000) Survey on Households' Income and Wealth, www.bancaditalia.it.

- (2002) 'I bilanci delle famiglie italiane nell'anno 2000', Supplementi al Bollettino Statistico, no. 6.

Barbagli, M. and Saraceno, C. (eds) (1997) Lo stato delle famiglie in Italia, Bologna: Il Mulino.

Barbagli, M., Pisati, M. and Santoro, M. (2001) 'Alcuni mutamenti della società dell'Emilia-Romagna', in U. Ascoli, M. Barbagli, F. Cossentino and G. Ecchia (eds) Le politiche sociali in Emilia-Romagna, Primo Rapporto-febbraio 2001, Regione Emilia Romagna, Turin: Rosenberg \& Sellier.

Borzaga, C. (ed.) (1994) Il mercato del lavoro femminile: aspettative, preferenze e vincoli-una ricerca con microdati nel comune di Trento, Milan: Angeli.

Capellari, S. (2001) 'Lavoro per il mercato, lavoro domestico e tempo libero: le scelte di uomini e donne all'interno della famiglia', Economia E Lavoro 34(3): 15-32. 


\section{Tindara Addabbo}

Colombino, U. (1982) 'L'offerta di lavoro: prezzi e (dis)-equilibri', in G. Martinotti (ed.) La città difficile, Milan: Angeli.

Duncan, G.J. and Morgan, J.N. (eds) (1978) Five Thousand American Families: Patterns of Economic Progress, vol. 6, Ann Arbor: Survey Research Center, University of Michigan.

Giannelli, G.C. (1997) 'Squilibrio nell'offerta di lavoro e rigidità dell'orario di lavoro: Un'analisi microeconometrica su un campione nazionale e un campione regionale', Politica-Economica 13(1): 87-115.

Goldschmidt-Clermont, L. and Pagnossin-Aligisakis, E. (1996) 'Measures of unrecorded economic activities in fourteen countries', in UNDP Background Papers. Human Development Report 1995, New York.

Palomba, R. (1997) 'I tempi in famiglia', in M. Barbagli and C. Saraceno (eds) Lo stato delle famiglie in Italia, Bologna: Il Mulino.

Palomba, R. and Sabbadini, L.L. (eds) (1994) Tempi diversi. L'uso del tempo di uomini e donne nell'Italia di oggi, Rome: ISTAT.

Perali, F. (1999) 'Stima, distribuzione e decomposizione per genere del reddito esteso: metodologia ed applicazione ad un campione di individui', Economia $E$ Lavoro 33(3-4): 37-56.

Trifiletti, R. (1997) 'La famiglia e il lavoro delle donne', in M. Barbagli and C. Saraceno (eds) Lo stato delle famiglie in Italia, Bologna: Il Mulino.

UNDP (1995) Human Development Report, New York: UNDP.

Vinay, P. (1996) 'From informal flexibility to the new organization of time', in M.D. Garcia-Ramon and J. Monk (eds) Women of the European Union. The Politics of Work and Daily Life, London: Routledge.

Zuliani, A. (1994) 'L'indagine multiscopo', Quaderni di economia del lavoro 49-50: 33-42. 


\title{
3 Extended income estimation and income inequality by gender
}

\author{
Tindara Addabbo and Antonella Caiumi
}

\section{Introduction}

The evaluation of productive activities that take place within the household without involving a monetary transaction has received increasing attention in recent years in relation both to measurement issues and the theoretical implications of its inclusion in the macroeconomic framework.

Measured in hours of work in fourteen industrialised countries, the magnitude of unrecorded economic activity is as large as the recorded activity (Goldschmidt-Clermont and Pagnossin-Aligisakis 1996). In other words, neglecting the non-monetary sector means leaving out of account about half of human labour. Because of this enormous gap, social national accounting data (SNA) provide distorted figures on the resources available to households or countries to achieve their standard of living.

If non-market work is included in SNA activities, as required by the commitments made at international level in the 'Beijing Platform' (1995), the monetary value of production in the home must be compatible with measurements of SNA activities. Since there is no market, no market price for goods and services produced or transformed within the household is determined and no salaries paid, any estimation of the monetary value of home production has to be computed indirectly. However, there is no international agreement about the valuation method, and the outcome can vary considerably depending on the method used.

The problem of the visibility of domestic work has important implications besides simply broadening the definition of income, in particular for how wages are determined. ${ }^{1}$ It is evident that in the absence of household production, money income ought to be increased in order to guarantee the achievement of the same level of welfare provided by the consumption of market and non-market goods. ${ }^{2}$ It follows that the inclusion of household production in the analysis of the distribution of economic resources could have important implications in terms of redistributive economic policy, especially in light of the major changes recorded in the structure of the family in recent decades. For instance, one may argue that extended income should be taken into account in means testing access to public services or 
assessing eligibility for income support, or extended income could be used in order to analyse the gender impact of public policies (for an application of this type to the impact of minimum insertion income, see Chapter 9, this volume).

Since the distribution of household production among groups in the population is likely to vary considerably compared to the distribution of income in relation to gender, household type and composition, age, labour conditions, education and local context, it is important to provide a broader valuation of the economic welfare, accounting for extended income.

This chapter focuses on time use and aims to evaluate extended standard of living and inequality by different household types. The evaluation of standard of living requires moving from the household unit to the individual. Per capita income provides an inaccurate measurement of well-being among households of different composition. The accepted specification of income in the analysis of well-being is equivalent income (household income divided by the household equivalent scales), a measure that can be interpreted as a real value to the individual of consumption services to which each household member has access, taking into account household economies of scale and different needs. When the definition of income includes non-monetary components, the adjustment of household extended income (to control for different household composition) with the same equivalence scales usually applied to monetary income cannot be accurate (Radner 1997). The possibility that appropriate equivalence scales differ by income definition has not yet been explored (Bonke 1992; Jenkins and O'Leary 1996). In this study, we use equivalence scales estimates that are consistent with the definition of income. In particular, we obtain nonparametric estimates of Engel scales based on both monetary consumption and extended consumption in order to verify how differences in needs among household members and economies of scale that take place within the household vary in relation to the definition of consumption. ${ }^{3}$ The equivalence scales estimates used here are presented in Chapter 4.

Detailed information on household income, consumption and time use are generally not available from a single database. Only recently, with the 2000 Bank of Italy survey, has a significant achievement been made in filling this gap, by collecting information on unpaid work carried out within households on a weekly basis together with data on household income and wealth. At the time this research was carried out, the only way to perform a distributive analysis of household extended income consisted in combining information drawn from different data sources. As is well known, this requires dealing with the problem of missing data, which involves inputing missing data to records belonging to a statistical source on the basis of information drawn from other complementary sources related to other records. In this chapter, we describe a merging of statistics from the 1995 Bank of Italy Survey on Household Income and Wealth (SHIW) with the 1989 ISTAT time-budget survey (TBS). By combining information on 
hours of unpaid work with wages and monetary income data, we estimate the extended income by household. On the other hand, in order to turn to a distributive analysis, as suggested above, it is necessary to compare different households under equivalence conditions. The equivalence scales estimates are traditionally based on consumption information. As is well known, information on household consumption drawn from SHIW is underestimated. Therefore, in order to estimate the equivalence scale on market consumption goods and on extended consumption, described in Chapter 4, we use the ISTAT survey of household consumption. For this purpose we replicate the merging procedure to impute hours of unpaid work to the records of the ISTAT consumption survey in order to estimate the non-market consumption component by households.

Unpaid work is imputed by taking into account the differences in unpaid work behaviour by gender, day of the week and by type of unpaid work housework, care and constrained time. The microeconometric analysis on unpaid work is described in Section 1. The merging procedure of the different data sources is reported in Section 2. Section 3 is devoted to comparing different methods of time evaluation: the opportunity cost method and the service price method. The impact of the inclusion of household production on the distribution of resources is assessed in Section 4. Both money and extended income distributions have been analysed for different household types (one-earner, double-earner, with or without children) and according to the educational level of the family head. Inequality measures in earnings by gender are discussed in Section 5.

\section{Unpaid work: a microeconometric analysis}

Before 2002 one could not rely on the same source of data to have information on both income and unpaid work in Italy. Only the last survey on household income and wealth carried out by the Bank of Italy (SHIW 2000) contains both sets of information for a subsample of the households surveyed. ${ }^{4}$

In this chapter we have used ISTAT time-budget data (TBS) and merged them with SHIW 1995 data. Time-budget data allow us to estimate the mean number of hours worked during the week by men and women aged from 18 to 65, who live in couples or alone. The technique applied here could be used to reconstruct unpaid work and extended income distribution over time.

In Chapter 2 we provided descriptive statistics on the different allocation of time by gender, household type and region; this analysis has shown a greater unpaid workload for women in every household type and the high total number of hours worked by women. Here we use econometric models to detect the effect of individual and household variables on different types of unpaid work.

We have used Heckman's (1979) two-step estimation method to account 


\section{Tindara Addabbo and Antonella Caiumi}

for the selection bias which may occur when people do not supply any unpaid hours of work. The dependent variable is the logarithm of hours of unpaid work (housework, care and other) supplied on a weekday, on a Saturday or on a Sunday. The explanatory variables that have been introduced refer to:

- individual characteristics: age, years of education, employment condition, type of job (industry, position, hours of work)

- partner's sociodemographic characteristics

- area where the family lives

- number and presence of children in different age groups.

The estimations in Tables 3B.1-6 in Appendix B to this chapter will then be used to impute unpaid work to other sources of data (ISTAT expenditure survey data and Bank of Italy survey on household income and wealth).

\section{Unpaid work in couples by gender}

Microeconometric analysis of time budget data allows us to see the different ways in which individual and household characteristics may affect the allocation of time by gender. For instance, we investigate if, other things being equal, a better education increases or decreases different unpaid working time analysed (housework, care or other types of unpaid work), and how men and women behave differently with regard to the allocation of time when the size and composition of their household change.

Unlike men, elderly women are characterised by a heavier load of unpaid work (with regard to all types of unpaid work), whereas housework decreases as the level of education rises and less educated women devote less time to care work than do more educated women (this is consistent with the statistical analysis provided in Chapter 2).

Both the probability of care work supply and the time devoted to this activity are negatively related to children's age. The presence of children aged under 6 years significantly increases the time devoted to care work, whereas the presence of children aged over 15 years decreases care work. The larger share of unpaid work is performed by mothers, and we can see how, during the week, care work increases with the size of the household and with the presence in the household of children in the age groups where public childcare services are less widespread and more costly in Italy. ${ }^{5}$

The analysis carried out in Chapter 2 shows how the majority of unpaid work is made up of housework; here we can see that on weekdays the number of adult children increases their mothers' housework significantly. This, together with the higher and increasing probability that adult children stay longer in the household in Italy (see Chapter 7), induces us to expect an increase in the housework load for women living in Italy. The other type of unpaid work (constrained time) is related more to individual variables than to the demographic structure of the family. 
If we consider the sector in which women are employed, we can see how employment in the primary sector (compared with employment in manufacturing) increases unpaid work for reasons that may be related to the organisation of work inside the farming household. We can also see that men and women who work part-time devote more time to unpaid work.

If we consider the impact of the husband's individual characteristics on his wife's work, we can see that a more educated husband reduces his wife's care work on weekdays. The husband's care work is very low on average, but the hours devoted by husbands to care work tend to increase during the week when there are young children (though the presence of children aged between 6 and 14 lowers the number of hours devoted by their fathers to childcare). In addition, the nature of the wife's employment affects the husband's care work, for we can see how men who are married to women managers or in managerial positions tend to provide more care work. The husband's housework and constrained time tend to increase during weekdays if women are self-employed. Elderly men tend to provide less care work on weekdays and more housework or constrained time, whereas if they are white-collar or unemployed they tend to provide more care work on weekdays.

Not being in the labour force significantly increases the amount of unpaid work both for men and for women, whereas being self-employed reduces unpaid work. Having a partner in a managerial position reduces women's unpaid work and increases men's unpaid work. Having a partner who works part-time increases women's unpaid work and reduces men's unpaid work. This may imply complementarity in the use of time by women, since men who work part-time do more unpaid work.

\section{Single housebold unpaid work}

Unpaid work increases significantly with age for single women on every day of the week, and for men only on Sundays. Both for men and for women, not being in the labour force has the effect of increasing unpaid work significantly. A higher educational level reduces the unpaid work of single women, but this is so only during the weekend for men. Single women who work part-time supply more unpaid work on weekdays. Unpaid work for single self-employed women or women managers increases on weekdays (see Tables 3B.7 to 3B.9 in Appendix B).

\section{Estimating average weekly unpaid working hours}

The estimation of unpaid work for men and women interviewed on different days of the week allows us to calculate the average weekly hours of unpaid work. The technique used here consists in multiplying by five (weekdays) the estimate of unpaid work obtained by using the variables and the coefficients reported in this chapter, and by adding to this estimated average 


\section{Tindara Addabbo and Antonella Caiumi}

number of unpaid working hours for weekdays the estimated unpaid working hours for weekend days.

On average, women devote 78.5 per cent of their working time to unpaid work, whereas men devote on average 18.6 per cent of their total working time to unpaid work and 81.4 per cent to paid work (see Table 3.1a).

SHIW 2000 data based on a sample of individuals aged over 14 provides us with information on the actual number of weekly hours of unpaid work in 2000 (see Table 3.1b). The sample is different from ours (we are using TBS data in 1989 and we selected people aged 18 to 65 living in couples or alone, not including data on the other members of the family) so the information sets are not directly comparable. However, even if the samples are composed differently, one can note the similar distribution of time between paid and unpaid work activities found in 1989 with regard to women (women aged over 14 years interviewed in SHIW 2000 devoted 76 per cent of their total working time to unpaid work, while women interviewed by TBS 1989 devoted 78.5 per cent of their total working time to unpaid work activities). By comparing data on the allocation of time between paid and unpaid activities with reference to a similar sample of households (one-earner households) and by using two different sources of data (ISTAT 1994 multipurpose daily life survey data - Indagine multiscopo sugli aspetti della vita quotidiana and ISTAT 1989 TBS data), Olivier (see Appendix E) shows that the distribution of time by gender did not significantly change over time. However, the two sources of data differ since the ISTAT 1994 survey collects only the average weekly number of unpaid and paid working hours and is less precise than time-budget data. Comparison between the same data sources (ISTAT multipurpose surveys 1994 and 1998) allows Olivier (Appendix E) to show a narrowing of the gender gap in unpaid working hours over the period analysed especially for households without children. One should note that in 1998 women's total working time in double-earner households (64.5 hours in households with children and 58.3 hours in households without children) is still much higher than

Table 3.1a Estimated weekly working hours by gender

\begin{tabular}{lccccc}
\hline & \multicolumn{2}{l}{ Women } & & \multicolumn{2}{l}{ Men } \\
\cline { 2 - 3 } \cline { 6 - 6 } & hours & $\%$ & & bours & $\%$ \\
\hline Housework & 36.11 & 74.6 & & 5.56 & 61.6 \\
Care work & 5.25 & 10.8 & & 1.53 & 17.0 \\
Constrained time & 7.06 & 14.6 & & 1.94 & 21.4 \\
Unpaid work & 48.42 & 100 & & 9.03 & 100 \\
Unpaid work & 48.42 & 78.5 & & 9.03 & 18.6 \\
Paid work & 13.29 & 21.5 & & 39.45 & 81.4 \\
Total hours of work & 61.71 & 100 & & 48.48 & 100 \\
\hline
\end{tabular}

Source: Authors' calculations based on ISTAT Time Budget Survey data. 
Table 3.16 Unpaid versus paid work by gender - SHIW 2000

\begin{tabular}{lll}
\hline Weekly average number of & Women $(\%)$ & Men $(\%)$ \\
\hline unpaid working hours & 76 & 35 \\
paid work & 24 & 65 \\
\hline
\end{tabular}

Source: Authors' calculations based on Bank of Italy 2002: 60, Table C10.

men's ( 52.1 hours in households with children and 50.5 hours in households without children) (see Table 3E.3 in Appendix E).

Our estimation of average weekly hours of work can be transferred to a graph similar to UNDP (1995) to show more clearly how women's total work is higher than men's and how in Italy the disequilibrium in the type of work (paid versus unpaid work) by gender is greater than in other industrialised countries (see Appendix E). The share of women's unpaid work in their total working time is 66 per cent on average in industrialised countries according to UNDP (1995), whereas according to our estimation the share of women's unpaid work in their total working time is 78.5 per cent in Italy (see Figure 3E.2 in Appendix E).

\section{Statistical matching}

The estimates shown in Section 1 are applied in this section to impute the unpaid hours of work to individual records belonging to other surveys which did not gather this information, in particular the Bank of Italy survey of household income and wealth (SHIW) and the ISTAT survey of household consumption, by applying a statistical matching method.

The Bank of Italy survey is carried out every two years on a representative sample of about 8,000 households. Since 1987 the survey has collected information on working hours and income by each member of the household and on the wealth of the household. ${ }^{6}$ This information if combined with time use data makes possible an evaluation of the extended income by household, as we show in Section 3. The survey also contains information on household consumption, which is known to be underestimated. In order to estimate the equivalence scale on extended consumption, we need to merge the information on time use data drawn from TBS in order to predict hours in unpaid work in the ISTAT consumption survey. On the other hand, unlike the SHIW, the ISTAT consumption survey does not allow one to compute wages, which are needed to evaluate the unpaid work using the opportunity cost method (Section 3). We therefore estimate the earnings function on SHIW, which is then used to impute wages on the ISTAT consumption survey. This latter survey is carried out regularly every year. Both the SHIW and ISTAT consumption data, which we use in this chapter, were collected in 1995. 
Other studies based on the use of complementary sources of statistical information are by Angrist and Krueger (1992), Arellano and Meghir (1992), and Battistin et al. (2000). A discussion of the statistical matching procedures is provided by Rettore (1992). Some basic requirements must be met for the statistical matching to be feasible: the complementary datasets should share a common set of conditioning variables and should be drawn from the same population.

All three surveys used in this chapter contain information on sociodemographic characteristics of the households - such as household composition, age and level of education of each household member - which are used as explanatory variables in the analysis of unpaid work. As far as the second requirement is concerned, we check if the records drawn from different data sources - corresponding to the selected household types, those living alone and households with and without children - belong to the same population by testing their mean values. This provides a measure of the distance between different samples. See Appendix A, Table 3A.1 for a test on the distance between the mean of the variables used in the statistical matching, drawn from the samples based on SHIW and TBS. ${ }^{7}$ The test is rejected in many cases: the difference is often small with regard to the absolute values of means but is amplified by the standard deviation due to the small sample size. In some cases the difference can be imputed to actual differences in the variables analysed over time, given that TBS data refer to 1989 and SHIW refer to 1995; for instance, women's average years of education have increased between the late 1980s and the mid-1990s.

The statistical matching procedure applied in this chapter may be described as follows: to impute the variable of interest, $y^{\prime}$, into the survey where it is unobserved, we take the conditional mean of the regression obtained from the survey where $y$ is observed, $\mathrm{E}\left(\mathrm{y} / \mathrm{X}_{1}\right)=\beta \mathrm{X}_{1}$, and we substitute the exogenous variables drawn from the former survey, $\mathrm{X}_{0}$. Following the approach proposed by Kennedy (1983), we add the standard error of the regression, $\sigma_{\epsilon}$ in order to reproduce as far as possible the observed heterogeneity not captured by the conditional mean of the regression. The variable of interest is then computed as $y^{\prime}=\beta X_{0}+\sigma_{\epsilon}$. In a first step, a comparison between the estimated hours of work - devoted to childcare, domestic activities and constrained time - and the observed data are obtained for the selected TBS subsample in order to test the method applied. As Table 3C.1 (Appendix C) shows, the simulated distribution is close to the observed one on the basis of the first and second moments. We then apply the merging procedure on the SHIW and ISTAT consumption surveys. In both cases, the distribution parameters of the estimated unpaid hours of work - the first and second moments - are similar to the ones observed for the TBS 1989 survey (Table 3C.2 in Appendix C provides results for the SHIW data). 


\section{Evaluating unpaid work}

We now turn to the issue of time evaluation in order to assess its impact on household welfare and inequality. Two different methods have been proposed in the literature to evaluate unpaid work:

- The opportunity cost method: the individual chooses how to allocate her time, taking into account the marginal net wage she would receive in paid work.

- The service price method: unpaid work is evaluated at its market price. One can use a single market price applied to a general housekeeper (replacement cost) or one can distinguish different types of unpaid work and evaluate each according to the corresponding price of market specialists (service cost). ${ }^{8}$

The first evaluation method has been criticised on the grounds that an individual's marginal net wage in paid work may differ from an individual's marginal productivity in unpaid work (Gronau 1986). Moreover, given the greater specialisation in paid work, average productivity in paid work should be higher than average productivity in unpaid work (Bruyn-Hundt 1996). Another problem connected with this method of evaluation is how to evaluate unpaid work for unemployed people or people who are outside the labour force whose market wage is unknown.

The second way to evaluate unpaid work can also be criticised. The service cost method of evaluation could overestimate unpaid work given the higher productivity of market-trained workers; on the other hand, it might be difficult to disaggregate unpaid work into all its different components. The replacement cost, on the other hand, may underestimate the quality of the services provided at home, and some types of unpaid work may not find a similar substitute in the market. ${ }^{9}$

In this chapter we use both methods of time evaluation and assess the sensitiveness of welfare inequality to different methods of time evaluation. Following the replacement cost method we evaluate unpaid work at the mean bargained wage for a general housekeeper in 1995. We do not distinguish among the costs of the different types of unpaid work provided.

Turning to the opportunity cost method of evaluating unpaid work, owing to our sample composition we have to solve the problem of defining a wage for those people who are outside the labour force or unemployed. The opportunity cost is given by:

- the actual wage that the employed individual earns (SHIW provides this information while the ISTAT consumption survey does not provide detailed information on current labour income);

- or the reservation wage estimated by using Heckman's selection model (Appendix D). The right-hand side variables we have included are 


\section{Tindara Addabbo and Antonella Caiumi}

justified in terms of human capital theory and we have also introduced regional dummies to take into account the effect of the labour market situation on wages.

The wage equations reported in Appendix D are the result of a wider set of regressions we have run. The return of education (years of schooling) is 8 per cent for women and 7 per cent for men, age having no significant effect on women's wage. Past work experience increases the women's wage by 6 per cent and the men's wage by 8 per cent. Wages are clearly lower for women living in the South-west (16 per cent less with respect to those living in the North), in the South-east (10 per cent less) and those living in Central Italy (11 per cent). Wages decrease by 15 per cent if men live in the South and by 4 per cent if they live in Central Italy. Heckman's selection term has the positive and significant effect on wages, meaning that those who are more likely to work are also more likely to earn higher wages.

\section{Extended income distribution}

In this section we present the results of the extension of income to include unpaid work evaluated by following the methods described in Section 3. A household's extended income (yex) is defined as the sum of money income plus the evaluation of unpaid working time for each member of the household:

$$
\begin{aligned}
& \text { yex }=\mathrm{y}+\gamma_{\mathrm{w}}(\mathrm{UNP} 2)+\gamma_{\mathrm{h}}(\mathrm{UNP} 1) \\
& \mathrm{y}=\text { household net money income, } \\
& \text { UNP1 = men's unpaid working time, } \\
& \text { UNP2 }=\text { women's unpaid working time, } \\
& \gamma_{\mathrm{w}}=\text { evaluation of wife's unpaid work, } \\
& \gamma_{\mathrm{h}}=\text { evaluation of husband's unpaid work. }
\end{aligned}
$$

This extended income definition has been used among others by Bonke (1992), Bryant and Zyck (1985) and by Jenkins and O'Leary (1996). Table 3.2 presents the descriptive statistics on the money and extended income distributions at the level of the household, per capita and adult equivalent by using the opportunity cost (o.c.) and the service price (s.p. $)^{10}$ methods. Equivalent income corresponds to the adjusted income obtained by using the appropriate estimates of equivalence scales for each definition of income (money and extended). The cost of children index applied to money (extended) income is $0.40(0.96)$ for a baby under 2 years old, 0.48 (0.94) for a child between 3 and 5 years old, $0.48(0.48)$ for a child between the ages of 6 and 17, and 0.74 $(0.74)$ for a young dependent between the ages of 18 and 24.

The average monthly extended income of married couples is around $6,000,000$ lire $(€ 3,100)$ when evaluated by using the opportunity cost prin- 
Table 3.2 Descriptive statistics on monthly money and extended income

\begin{tabular}{lllc}
\hline & Median & Mean & Std dev. \\
\hline Household money income & 3485.917 & 4027.921 & 2373.027 \\
Extended household income (o.c.) & 5301.472 & 6070.504 & 2913.722 \\
Extended household income (s.p.) & 4915.19 & 5470.094 & 2194.293 \\
Per capita money income & 1040.861 & 1273.618 & 900.1993 \\
Per capita extended income (o.c.) & 1617.759 & 1898.097 & 1103.97 \\
Per capita extended income (s.p.) & 1471.834 & 1713.083 & 904.9367 \\
Equivalent money income & 1491.214 & 1719.914 & 1043.114 \\
Equivalent extended income (o.c.) & 2310.201 & 2617.939 & 1276.056 \\
Equivalent extended income (s.p.) & 2121.673 & 2359.977 & 982.1832 \\
\hline
\end{tabular}

Source: Authors' calculations based on 1995 SHIW matched with 1989 TBS data (thousand lire).

Notes

Sample: number of observations 2,013 (couples only).

o.c. = opportunity cost method; s.p. = service price method.

ciple and 5,470,000 lire when evaluated by using the service price method, whereas average money income is 4,000,000 lire (Table 3.2).

To evaluate the standard of living at the individual level we have compared the distribution of equivalent and per capita money and extended income (extended income has been evaluated by using both the opportunity cost and the service price methods) (Figure 3.1). The increase observed in the median of the extended income is by over 40 per cent, with nonsignificant differences between various definitions of income, suggesting that significant differences between household economies are not apparent when different consumption definitions are used. However, when we use equivalent income, the extended standard of living increases significantly for households (ranging from 42 per cent to 55 per cent depending on the method used to evaluate unpaid work). Extended income distribution is more concentrated around the mean when unpaid work is evaluated at service price rather than at opportunity cost. Next we analyse how inequality changes with the inclusion of household production in the definition of income for the whole sample and for significant groups of households.

By using different indicators of income inequality (Gini, Theil and Log of variance), we find that extended income is characterised by a lower inequality than money income and that extended income valued at opportunity cost (o.c.) is characterised by greater inequality than extended income valued at service price (s.p.) (Table 3.3). ${ }^{11}$ This result holds for different types of families: one-earner, double-earner, childless or with children, and for different levels of education of the head of the family. The reduction in income inequality is greater in one-earner households than in double-earner households. Income distribution for childless households and for households with children is similar, owing probably to a similar distribution, within these groups of families, of one-earner and double-earner households. In general, 
Dn of per capita money income

$\triangle \mathrm{Dn}$ of equivalent money income

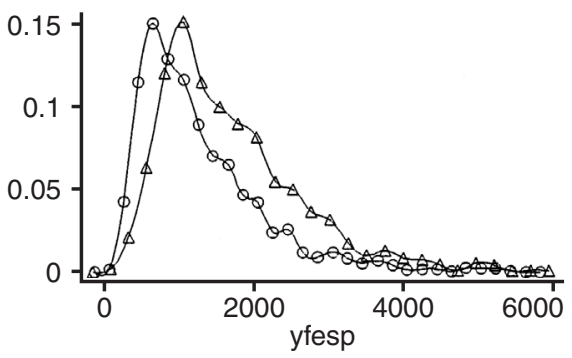

Dn. of PC. and Eq. Money Income

$\bigcirc$ Dn of PC extended income - spp

$\triangle \mathrm{Dn}$ of equivalent extended income

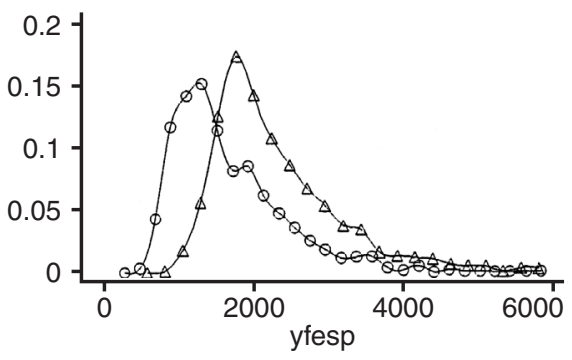

Dn. of PC. and Eq. Ext. Income - SPP
Dn of PC extended income - ocp

$\triangle \mathrm{Dn}$ of equivalent extended income

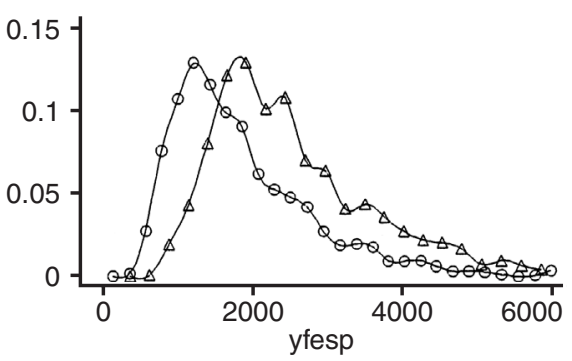

Dn. of PC. and Eq. Ext. Income - OCP

Dn of equiv. money income

$\square$ Dn of equiv. ext. income - SPP

$\triangle \mathrm{Dn}$ of equiv. ext. income - OCP

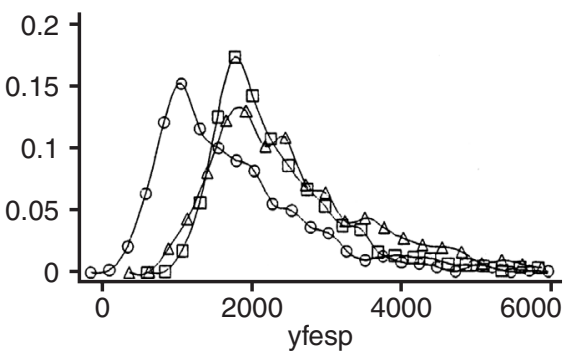

Extended standard of living

Figure 3.1 Extended standard of living.

Source: Author's calculations on 1995 SHIW matched with TBS data (thousand lire).

inequality in the distribution of resources is reduced when we use equivalent income instead of per capita income as a measure of welfare.

The decrease in income inequality that we obtain by widening the income definition to include unpaid work is found for different household types and with different inequality indicators. This equalisation result is consistent with Jenkins and O'Leary's (1996) analysis of UK data and in contrast with the mixed evidence provided by other studies such as those by Bonke (1992) and by Bryant and Zyck (1985). ${ }^{12}$ Jenkins and O'Leary's (1996) analysis is based on personal equivalent income (rather than on household income, like most of the previous literature on this topic). We find that equalisation in extended income distribution does not depend on the unit of analysis, since it holds for household income, per capita and equivalent income.

Note that the inequality measurements for the whole sample are higher than intra-group inequality in the case of households distinguished by economic status (for instance, the Theil index for extended income evaluated at 
Table 3.3 Income inequality by household type

\begin{tabular}{|c|c|c|c|c|c|c|}
\hline & \multicolumn{6}{|c|}{ Whole sample } \\
\hline & Gini & Theil & \multicolumn{4}{|l|}{ Log Var } \\
\hline Household money income & 0.30 & 0.15 & 0.33 & & & \\
\hline Extended household income (o.c.) & 0.24 & 0.10 & 0.18 & & & \\
\hline Extended household income (s.p.) & 0.20 & 0.07 & 0.12 & & & \\
\hline Per capita money income & 0.27 & 0.12 & 0.23 & & & \\
\hline Equivalent money income & 0.31 & 0.16 & 0.35 & & & \\
\hline Per capita extended income (o.c.) & 0.29 & 0.14 & 0.26 & & & \\
\hline Equivalent extended income (o.c.) & 0.25 & 0.10 & 0.19 & & & \\
\hline Per capita extended income (s.p.) & 0.26 & 0.11 & 0.20 & & & \\
\hline \multirow[t]{3}{*}{ Equivalent extended income (s.p.) } & 0.20 & 0.07 & 0.12 & & & \\
\hline & \multicolumn{3}{|c|}{ Double-earners } & \multicolumn{3}{|c|}{ One-earner } \\
\hline & Gini & Theil & Log Var & Gini & Theil & Log Var \\
\hline Household money income & 0.23 & 0.09 & 0.17 & 0.28 & 0.14 & 0.29 \\
\hline Extended household income (o.c.) & 0.22 & 0.08 & 0.15 & 0.20 & 0.08 & 0.12 \\
\hline Extended household income (s.p.) & 0.18 & 0.06 & 0.10 & 0.16 & 0.05 & 0.08 \\
\hline Per capita money income & 0.27 & 0.13 & 0.24 & 0.33 & 0.20 & 0.37 \\
\hline Equivalent money income & 0.23 & 0.09 & 0.18 & 0.28 & 0.15 & 0.30 \\
\hline Per capita extended income (o.c.) & 0.25 & 0.10 & 0.19 & 0.26 & 0.13 & 0.20 \\
\hline Equivalent extended income (o.c.) & 0.21 & 0.08 & 0.14 & 0.21 & 0.08 & 0.13 \\
\hline Per capita extended income (s.p.) & 0.23 & 0.09 & 0.16 & 0.23 & 0.10 & 0.15 \\
\hline Equivalent extended income (s.p.) & 0.18 & 0.06 & 0.10 & 0.17 & 0.06 & 0.09 \\
\hline \multirow[t]{3}{*}{ Obs } & 1,008 & & & 1,005 & & \\
\hline & \multicolumn{3}{|c|}{ No children } & \multicolumn{3}{|c|}{ With children } \\
\hline & Gini & Theil & Log Var & Gini & Theil & Log Var \\
\hline Household money income & 0.31 & 0.16 & 0.36 & 0.30 & 0.15 & 0.32 \\
\hline Extended household income (o.c.) & 0.25 & 0.11 & 0.20 & 0.24 & 0.10 & 0.18 \\
\hline Extended household income (s.p.) & 0.22 & 0.08 & 0.14 & 0.19 & 0.07 & 0.11 \\
\hline Per capita money income & 0.31 & 0.16 & 0.36 & 0.32 & 0.17 & 0.38 \\
\hline Equivalent money income & 0.31 & 0.16 & 0.36 & 0.30 & 0.15 & 0.34 \\
\hline Per capita extended income (o.c.) & 0.25 & 0.11 & 0.20 & 0.27 & 0.12 & 0.22 \\
\hline Equivalent extended income (o.c.) & 0.25 & 0.11 & 0.20 & 0.25 & 0.10 & 0.19 \\
\hline Per capita extended income (s.p.) & 0.22 & 0.08 & 0.14 & 0.22 & 0.09 & 0.15 \\
\hline Equivalent extended income (s.p.) & 0.22 & 0.08 & 0.14 & 0.20 & 0.07 & 0.12 \\
\hline Obs & 370 & & & 1,643 & & \\
\hline
\end{tabular}

Source: Authors' calculations based on 1995 SHIW matched with 1989 TBS data. 
72 Tindara Addabbo and Antonella Caiumi

Table 3.3 (cont'd) Income inequality by household type

\begin{tabular}{|c|c|c|c|c|c|c|}
\hline & \multicolumn{3}{|c|}{$\begin{array}{l}\text { Years of education } \\
\text { under } 8\end{array}$} & \multicolumn{3}{|c|}{$\begin{array}{l}\text { Years of education } \\
8-13\end{array}$} \\
\hline & Gini & Theil & Log Var & Gini & Theil & Log $\operatorname{Var}$ \\
\hline Household money income & 0.26 & 0.11 & 0.28 & 0.26 & 0.11 & 0.24 \\
\hline Extended household income (o.c.) & 0.20 & 0.07 & 0.12 & 0.21 & 0.08 & 0.14 \\
\hline Extended household income (s.p.) & 0.15 & 0.04 & 0.07 & 0.18 & 0.06 & 0.10 \\
\hline Per capita money income & 0.42 & 0.30 & 0.73 & 0.32 & 0.17 & 0.39 \\
\hline Equivalent money income & 0.27 & 0.12 & 0.30 & 0.27 & 0.12 & 0.25 \\
\hline Per capita extended income (o.c.) & 0.26 & 0.11 & 0.21 & 0.27 & 0.13 & 0.22 \\
\hline Equivalent extended income (o.c.) & 0.20 & 0.07 & 0.13 & 0.22 & 0.08 & 0.15 \\
\hline Per capita extended income (s.p.) & 0.22 & 0.08 & 0.15 & 0.25 & 0.11 & 0.19 \\
\hline Equivalent extended income (s.p.) & 0.16 & 0.04 & 0.08 & 0.19 & 0.06 & 0.11 \\
\hline \multirow[t]{3}{*}{ Obs } & 973 & & & 795 & & \\
\hline & \multicolumn{6}{|c|}{ Years of education 13-18 } \\
\hline & Gini & Theil & Log Var & & & \\
\hline Household money income & 0.24 & 0.10 & 0.19 & & & \\
\hline Extended household income (o.c.) & 0.21 & 0.07 & 0.14 & & & \\
\hline Extended household income (s.p.) & 0.20 & 0.07 & 0.13 & & & \\
\hline Per capita money income & 0.32 & 0.17 & 0.34 & & & \\
\hline Equivalent money income & 0.24 & 0.10 & 0.19 & & & \\
\hline Per capita extended income (o.c.) & 0.23 & 0.09 & 0.17 & & & \\
\hline Equivalent extended income (o.c.) & 0.20 & 0.07 & 0.13 & & & \\
\hline Per capita extended income (s.p.) & 0.24 & 0.09 & 0.17 & & & \\
\hline Equivalent extended income (s.p.) & 0.20 & 0.07 & 0.12 & & & \\
\hline Obs & 238 & & & & & \\
\hline
\end{tabular}

Source: Authors' calculations based on 1995 SHIW matched with 1989 TBS data.

opportunity cost is 7.5 per cent for double earners and 8.1 per cent for oneearner families, whereas for the whole sample it is 10 per cent). This suggests the presence of inter-group inequality. What is interesting to note is that inter-group inequality remains even after allowing for household production. This result is emphasised in Figure 3F.1 (in Appendix F) where subgroup decile decomposition for one-earner and double-earner households is reported.

In sum, income inequality decreases and the standard of living increases when one considers unpaid work as part of the household's standard of living. However, it is important to bear in mind that the production of unpaid work is mainly a result of women's work, as was shown in Chapter 2. It follows that it is women's unpaid work that sustains a higher standard of living. The object of Section 5 is to evaluate gender inequality in earnings both in traditional and non-traditional households. 


\section{Gender inequality in earnings}

This section focuses on gender inequality in earnings. While the entire approach to inequality has recently been based on identifying what people get out of the means they can use rather than on the means they earn, the traditional approach of relying on earnings as a welfare indicator is useful in highlighting an important asymmetry between women and men still existing in our society. Women often work as hard as, or harder than, men, while their earnings are much lower. As shown in Figure 3.2, more than 50 per cent of the total time devoted to work by a married couple, including the unpaid kind, is done by women, whose contribution to household extended income is less than 50 per cent. This holds both for traditional households where the women's share of working time is 52 per cent, while their contribution to household extended income is 36 per cent, and for non-traditional households where women share the 58 per cent of total working time to which about 48
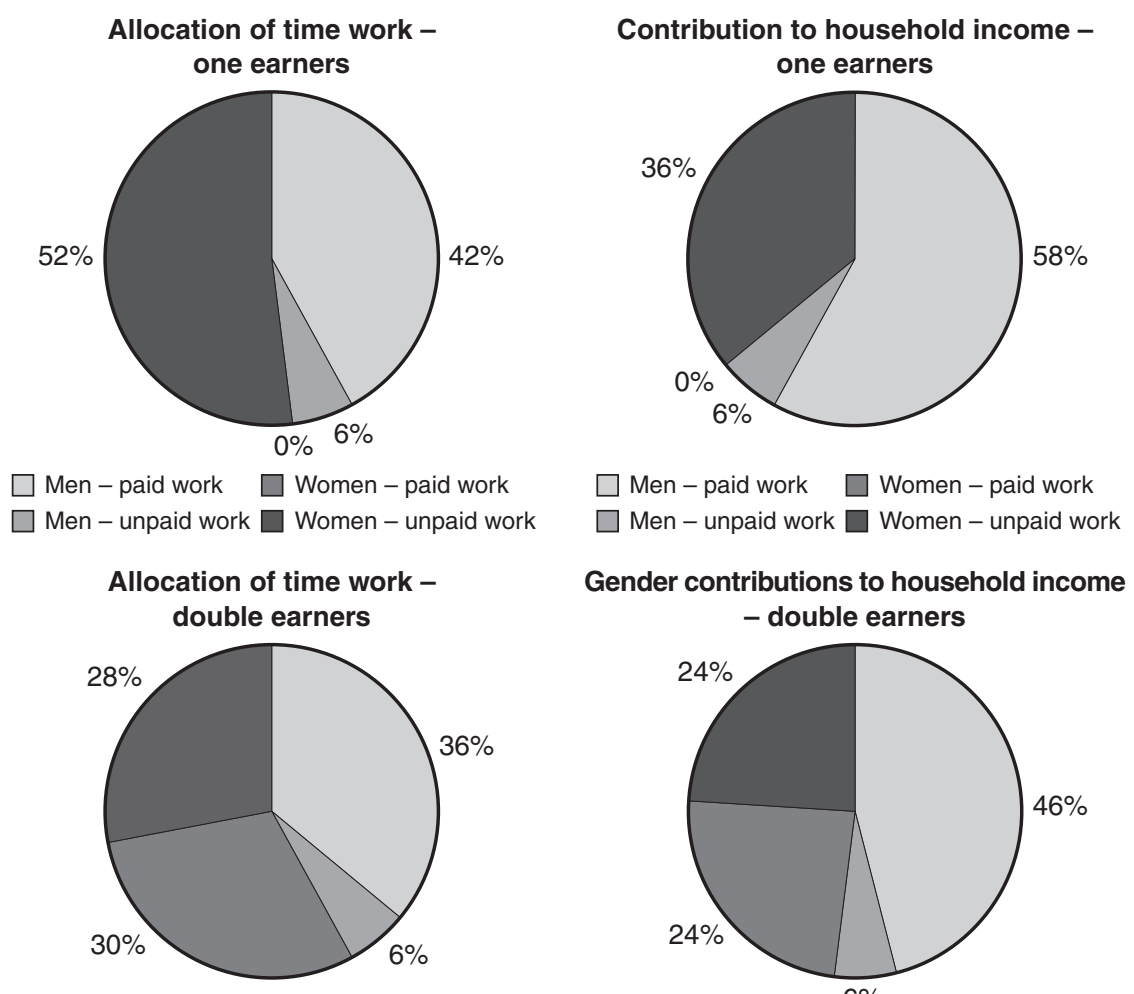

$\square$ Men - paid work $\square$ Women - paid work
Men - unpaid work $\square$ Women - unpaid work

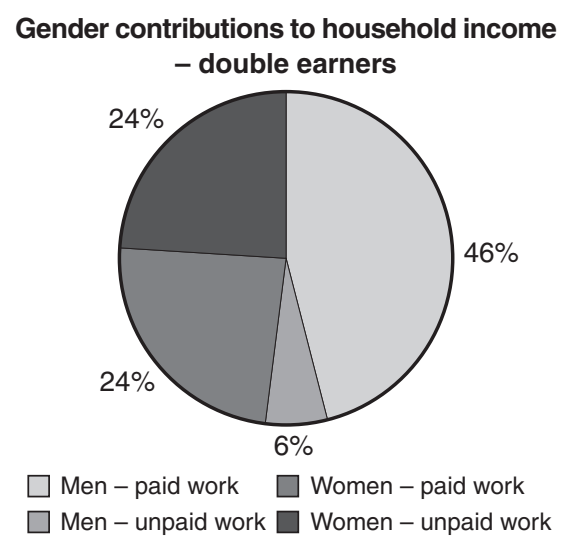

Figure 3.2 Distribution of total working time and of extended income by gender.

Source: Author's calculations based on 1995 SHIW matched with 1989 TBS data. 


\section{Tindara Addabbo and Antonella Caiumi}

per cent of household extended income corresponds. This is due to the presence of a consistent wage differential by gender in the labour market. ${ }^{13}$

The assessment of gender inequality in achievement can be evaluated by comparing the amount of inequality in the distribution of household income and the amount of inequality in the distribution of individual income. The larger the gender gap, the larger the inequality as measured by any inequality indices. The difference between the inequality measures in the two distributions provides an indirect measure of the extent of the intra-household inequality.

As far as the earnings aspect is concerned, Table 3.4 shows that income inequality is greater among individuals than among households. As expected, the distance between individual and household income inequality decreases when we extend income to include unpaid work, especially in oneearner households, suggesting that allowing for unpaid work reduces the gender gap. As noted in Section 4, inequality is lower when unpaid work is evaluated at the service price rather than using the opportunity cost method, even if the evaluation method used does not affect the distance in terms of inequality between households and individuals.

\section{Conclusions}

In this chapter we have analysed the pattern of unpaid work supply as households and individual characteristics change, and we have used the estimated equations to impute unpaid work in SHIW and ISTAT surveys. This analysis shows that household composition and individual characteristics affect unpaid work by gender differently. As expected, women's unpaid work increases significantly with the presence of children consistently with the type of childcare services available in Italy. We have also found that not only young dependants but also older ones increase significantly women's unpaid work.

We focus on the assessment of extended standard of living and inequality by gender in one-family households. Extended income distribution has been analysed for couples with or without children by using equivalence scales consistent with the definition of income used. ${ }^{14}$ The non-monetary income component is almost 40 per cent of money income. Extended income distribution is more concentrated around the mean when unpaid work is evaluated by using the replacement cost rather than the opportunity cost method. As expected, extended income valued at opportunity cost is characterised by greater inequality than extended income valued at service price, while both are more equally distributed than money income. This result holds also at a disaggregated level, by disaggregating the sample according to the number of earners in the family and the presence of children. The reduction in inequality passing from money to extended income is greater for one-earner than for double-earner households.

More than 50 per cent of a couple's total working time (computed by also 


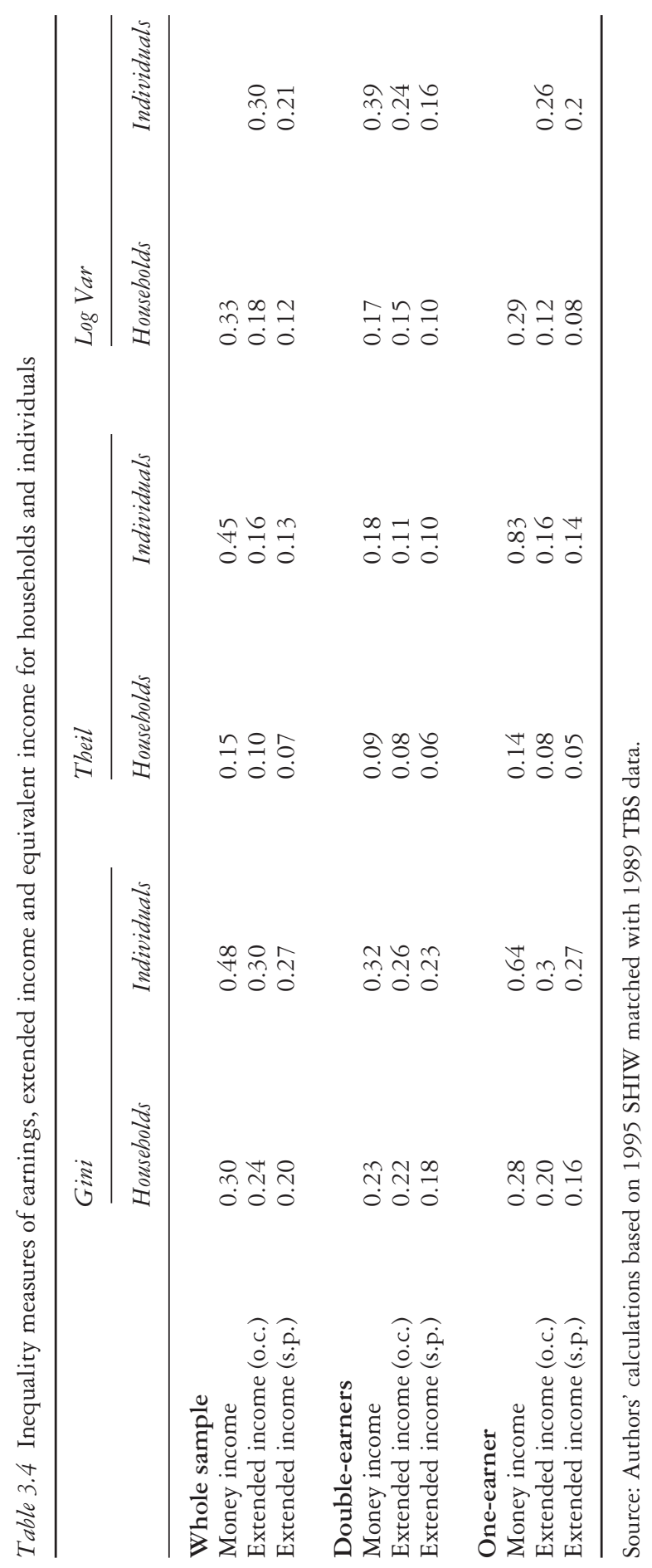




\section{Tindara Addabbo and Antonella Caiumi}

including unpaid work) is performed by women, but their share of extended income is less than 50 per cent. This disparity is observed both in one-earner households (where women's share of total working time is 52 per cent, whereas their share of extended income is 36 per cent) and in double-earner households (where women's share of total working time is 58 per cent, whereas their share of extended income is 48 per cent). Therefore one can note, together with a disequilibrium in the distribution of total working time, a disequilibrium in household income distribution in its extended def-

inition. This uneven distribution of working time and income by gender should be taken into account in the assessment of welfare policies. 


\section{Appendix 3A Descriptive statistics and t-test on the SHIW and TBS (weekdays) samples and t-test}

Table 3A.1 Descriptive statistics and t-test on the SHIW and TBS (weekdays) samples and t-test

Observations

SHIW 3,858

ISTAT 1,532

\begin{tabular}{|c|c|c|c|c|c|}
\hline \multirow[b]{2}{*}{ Variables } & \multicolumn{2}{|l|}{ SHIW } & \multicolumn{2}{|l|}{ ISTAT } & \multirow[b]{2}{*}{$t$-test } \\
\hline & mean & std dev. & mean & std dev. & \\
\hline Women's age & 42.48 & 9.95 & 41.1 & 18.04 & -3.75 \\
\hline Women's years of education & 8.88 & 4.12 & 8.39 & 6.47 & -3.61 \\
\hline North-west & 0.28 & 0.44 & 0.17 & 0.61 & -8.34 \\
\hline North-east & 0.2 & 0.39 & 0.29 & 0.73 & 6.08 \\
\hline Centre & 0.18 & 0.38 & 0.16 & 0.59 & -1.61 \\
\hline South & 0.34 & 0.47 & 0.37 & 0.8 & 1.82 \\
\hline Women not in labour force & 0.58 & 0.49 & 0.63 & 0.78 & 3.07 \\
\hline Employed women & 0.42 & 0.49 & 0.37 & 0.78 & -3.07 \\
\hline Housewives & 0.47 & 0.49 & 0.52 & 0.8 & 3.00 \\
\hline Women employees & 0.32 & 0.46 & 0.28 & 0.72 & -2.65 \\
\hline Women self-employed & 0.1 & 0.3 & 0.09 & 0.45 & -1.05 \\
\hline Women employed in agriculture & 0.02 & 0.14 & 0.03 & 0.27 & 1.84 \\
\hline Women employed part-time & 0.11 & 0.3 & 0.11 & 0.49 & 0.00 \\
\hline Women employed in service & 0.3 & 0.45 & 0.28 & 0.72 & -1.33 \\
\hline Women employed in manufacturing & 0.09 & 0.3 & 0.06 & 0.37 & -3.63 \\
\hline No. of members & 3.56 & 0.98 & 3.53 & 1.61 & -0.90 \\
\hline No. of children aged $0-2$ & 0.08 & 0.27 & 0.15 & 0.62 & 5.73 \\
\hline No. of children aged 3-5 & 0.15 & 0.38 & 0.15 & 0.62 & 0.00 \\
\hline No. of children aged 6-17 & 0.63 & 0.82 & 0.19 & 0.74 & -23.58 \\
\hline No. of children aged $18-24$ & 0.43 & 0.69 & 0.25 & 0.9 & -9.10 \\
\hline Men's age & 46.04 & 10.04 & 44.59 & 17.93 & -3.96 \\
\hline Men's years of education & 9.33 & 4 & 8.91 & 6.63 & -3.06 \\
\hline Men employed part-time & 0.04 & 0.2 & 0.09 & 0.46 & 5.52 \\
\hline Men not in the labour force & 0.23 & 0.41 & 0.19 & 0.63 & -3.01 \\
\hline Men employed & 0.77 & 0.41 & 0.81 & 0.63 & 3.01 \\
\hline Men employees & 0.56 & 0.49 & 0.56 & 0.8 & 0.00 \\
\hline Men self-employed & 0.21 & 0.4 & 0.23 & 0.68 & 1.43 \\
\hline Men employed in agriculture & 0.04 & 0.19 & 0.07 & 0.4 & 3.76 \\
\hline Men employed in manufacturing & 0.31 & 0.46 & 0.25 & 0.7 & -4.06 \\
\hline Men employed in the service sector & 0.44 & 0.49 & 0.48 & 0.81 & 2.38 \\
\hline
\end{tabular}




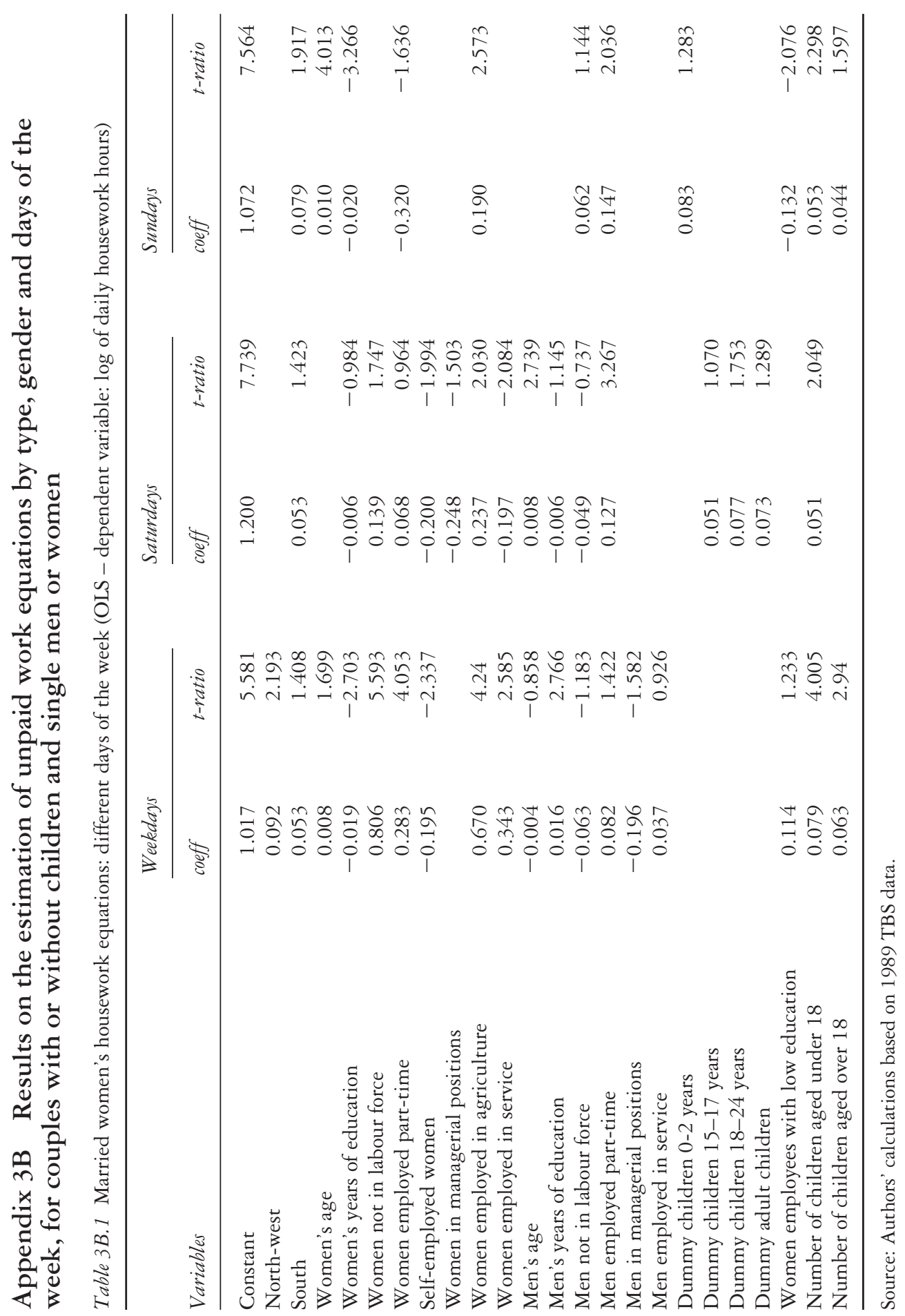




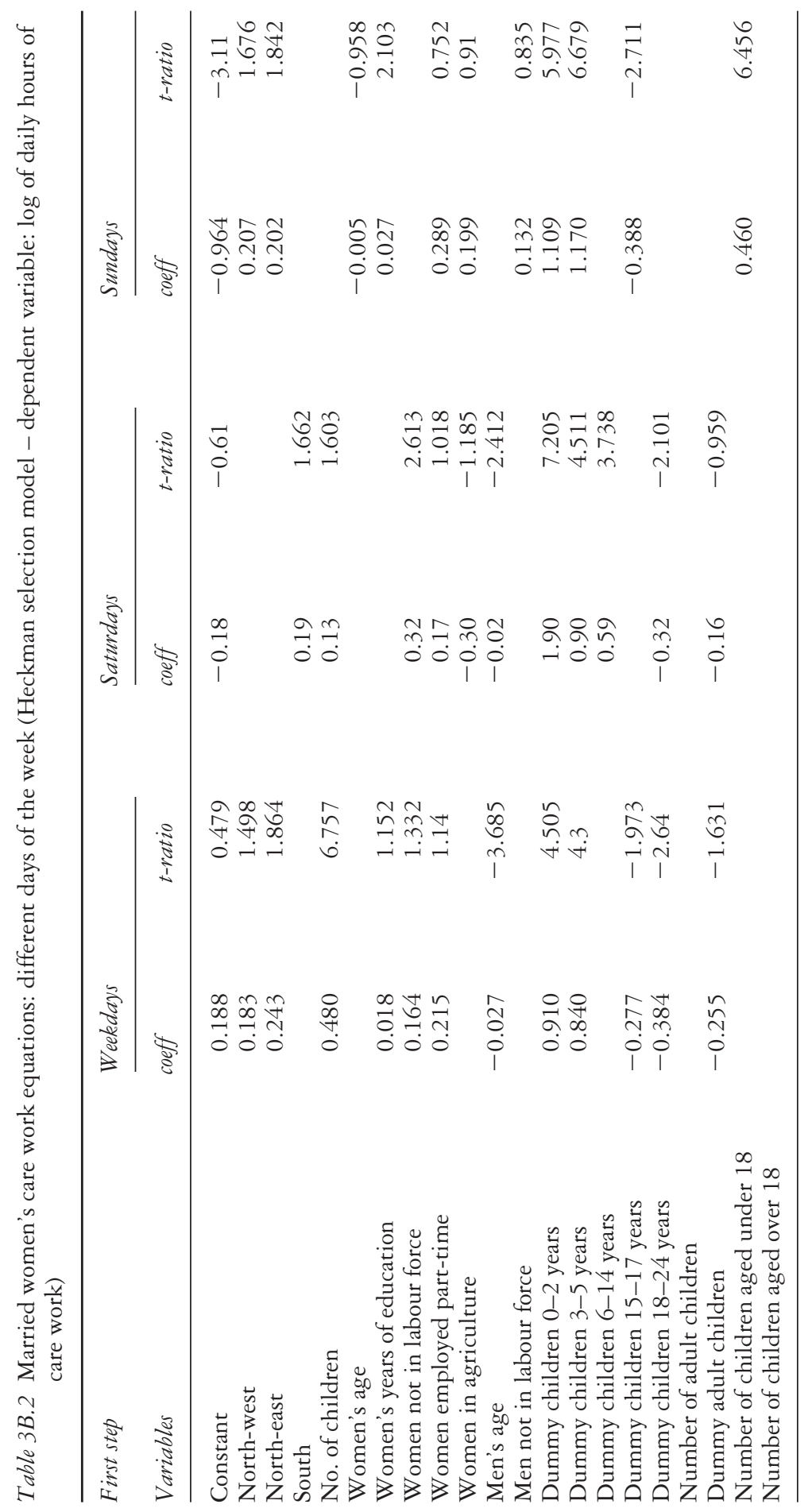




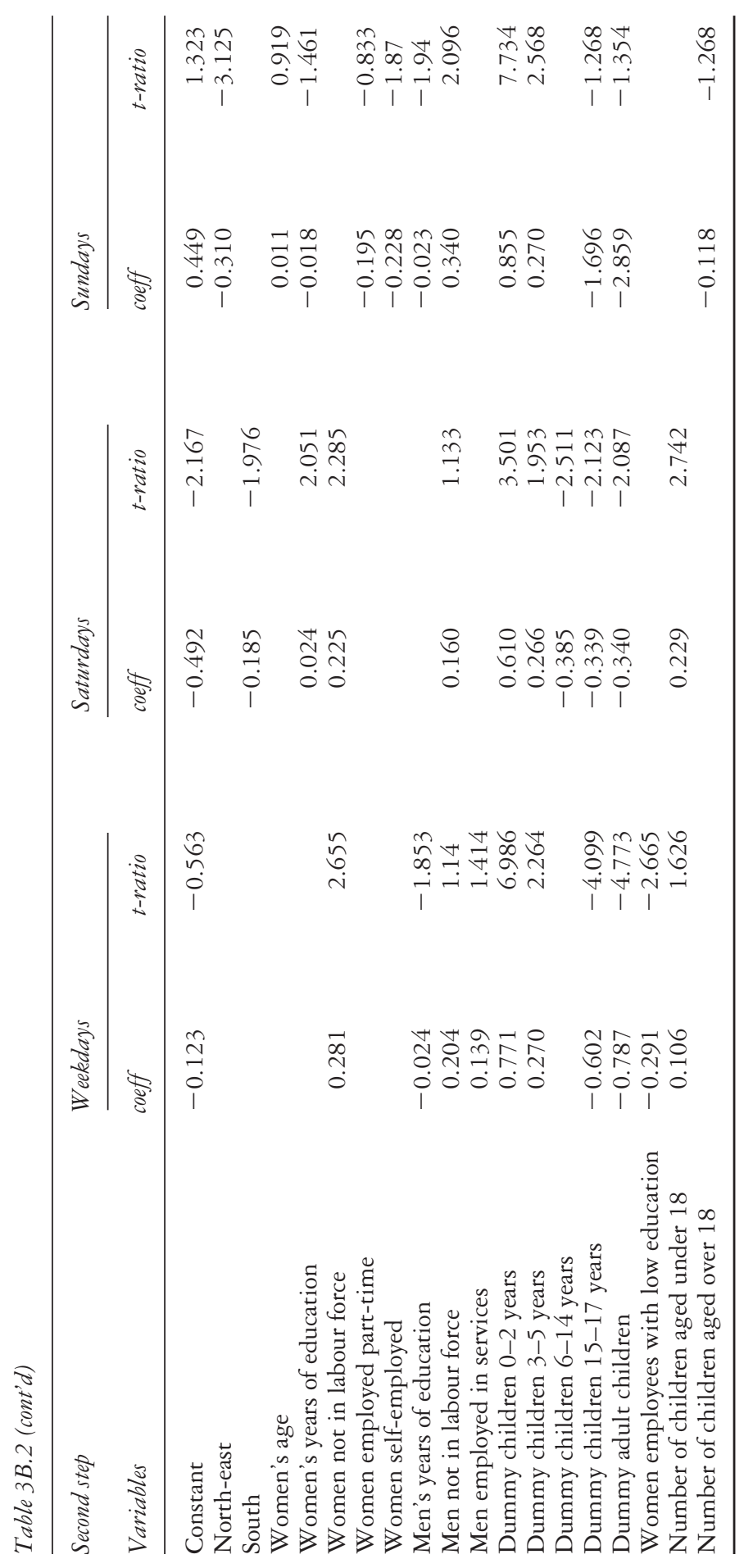


Table 3B.3 Married women's constrained time of work equations: different days of the week (Heckman selection model - dependent variable: log of daily hours of constrained work)

\begin{tabular}{|c|c|c|c|c|}
\hline \multirow{2}{*}{$\begin{array}{l}\text { First step } \\
\text { Variables }\end{array}$} & \multicolumn{2}{|l|}{ Weekdays } & \multicolumn{2}{|l|}{ Saturdays } \\
\hline & coeff & t-ratio & coeff & t-ratio \\
\hline Constant & 0.744 & 2.857 & 1.127 & 5.167 \\
\hline South & -0.209 & -2.44 & -0.214 & -2.399 \\
\hline Women's years of education & 0.030 & 2.796 & & \\
\hline Women employed part-time & 0.173 & 1.18 & -0.141 & -0.812 \\
\hline Women self-employed & -0.530 & -3.769 & & \\
\hline Women employed in agriculture & & & -0.171 & -0.513 \\
\hline Women employed in service & -0.359 & -3.91 & -0.242 & -1.993 \\
\hline Men's age & -0.005 & -1.068 & -0.010 & -2.207 \\
\hline Dummy children $0-2$ years & -0.404 & -2.906 & -0.197 & -1.862 \\
\hline Dummy children $3-5$ years & -0.310 & -2.461 & & \\
\hline Dummy children $6-14$ years & & & -0.034 & -0.446 \\
\hline Dummy children $15-17$ years & & & -0.178 & -1.903 \\
\hline \multicolumn{5}{|l|}{ Second step } \\
\hline Constant & -0.403 & -2.19 & -0.247 & -0.126 \\
\hline South & 0.331 & 4.824 & 0.097 & 1.313 \\
\hline Women's age & 0.009 & 2.332 & 0.009 & 2.306 \\
\hline Women's years of education & & & 0.016 & 2.026 \\
\hline Women employed part-time & -0.166 & -1.538 & -0.280 & 1.739 \\
\hline Women employed in agriculture & 0.224 & 1.822 & & \\
\hline Men not in labour force & & & -0.219 & -2.96 \\
\hline Men employed in service & 0.099 & 1.722 & & \\
\hline Dummy children $0-2$ years & 0.130 & 1.139 & & \\
\hline Dummy children $3-5$ years & 0.105 & 0.972 & & \\
\hline Dummy children $18-24$ years & 0.151 & 2.101 & -0.215 & -1.851 \\
\hline Dummy adult children & -0.139 & -1.748 & -0.208 & -1.415 \\
\hline Women employees with low education & 0.138 & 1.793 & 0.302 & 3.051 \\
\hline Number of children aged over 18 & & & 0.190 & 2.142 \\
\hline
\end{tabular}




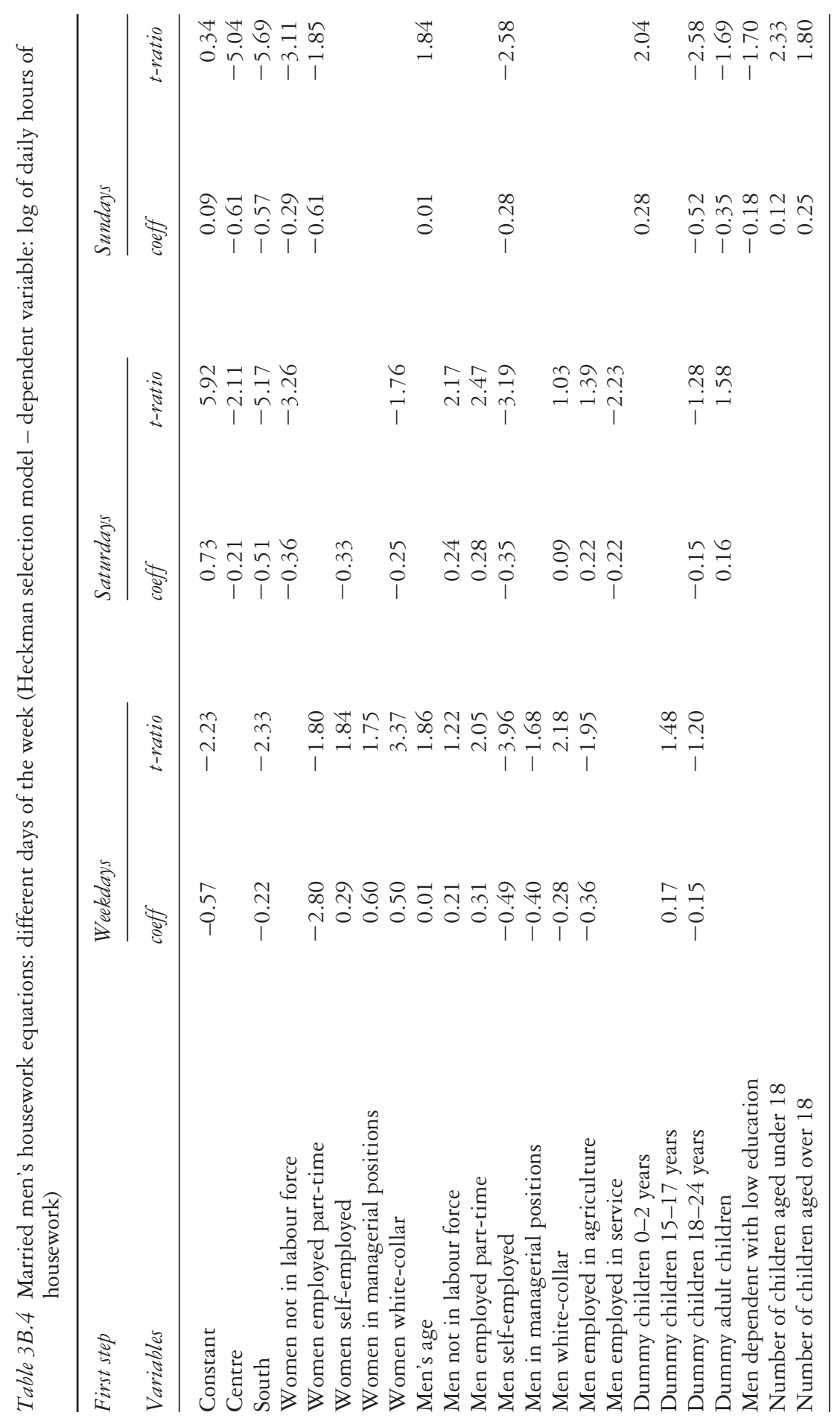




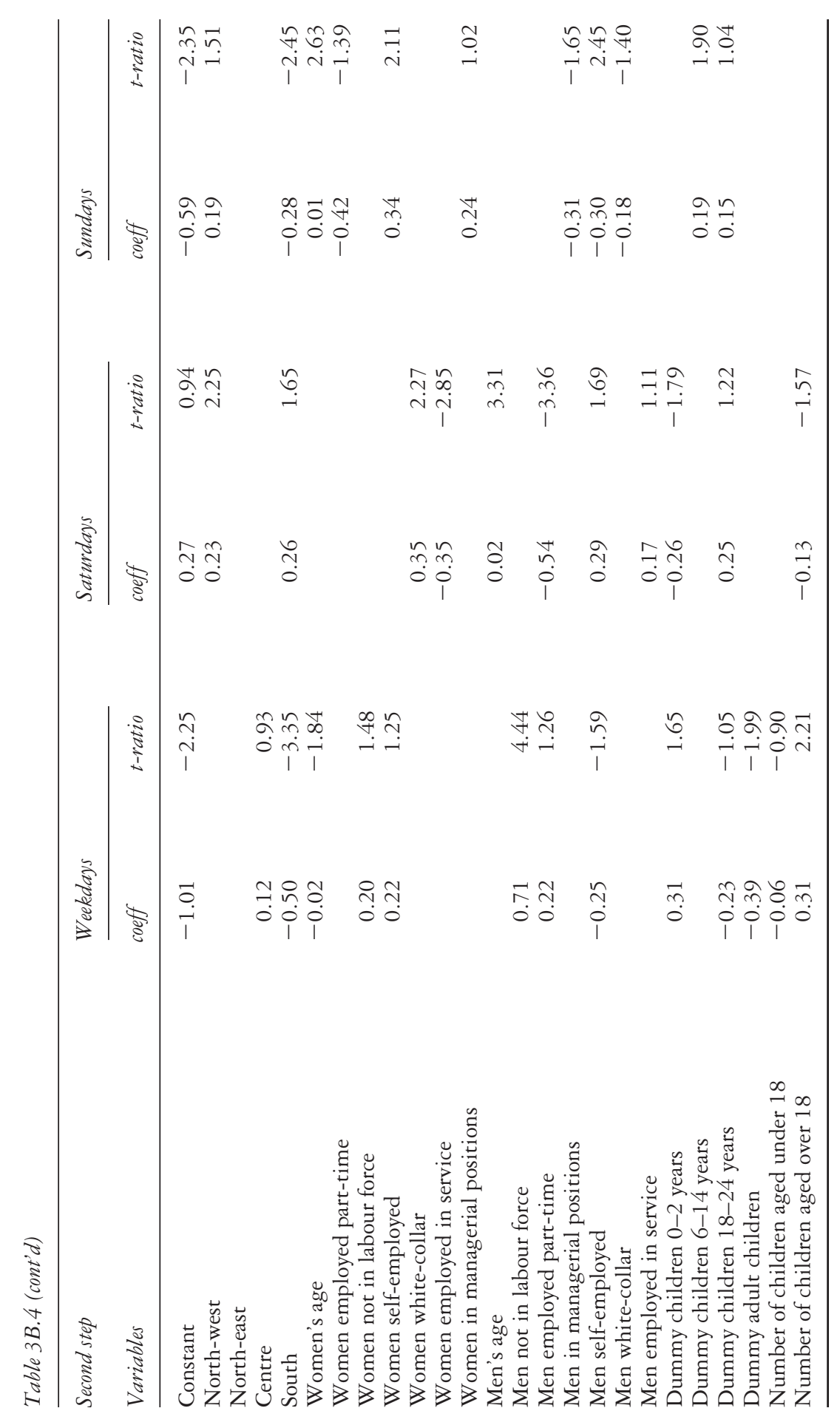




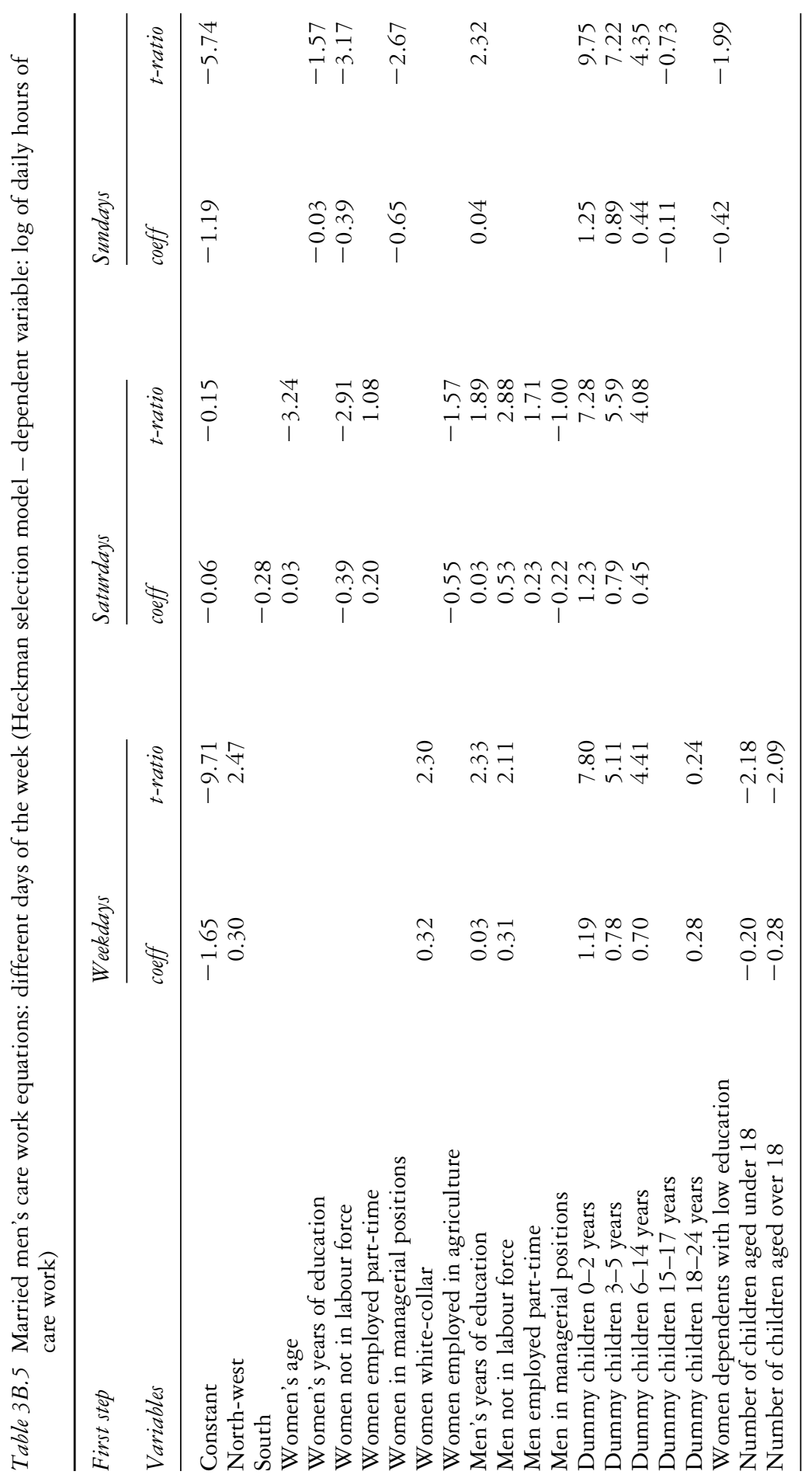




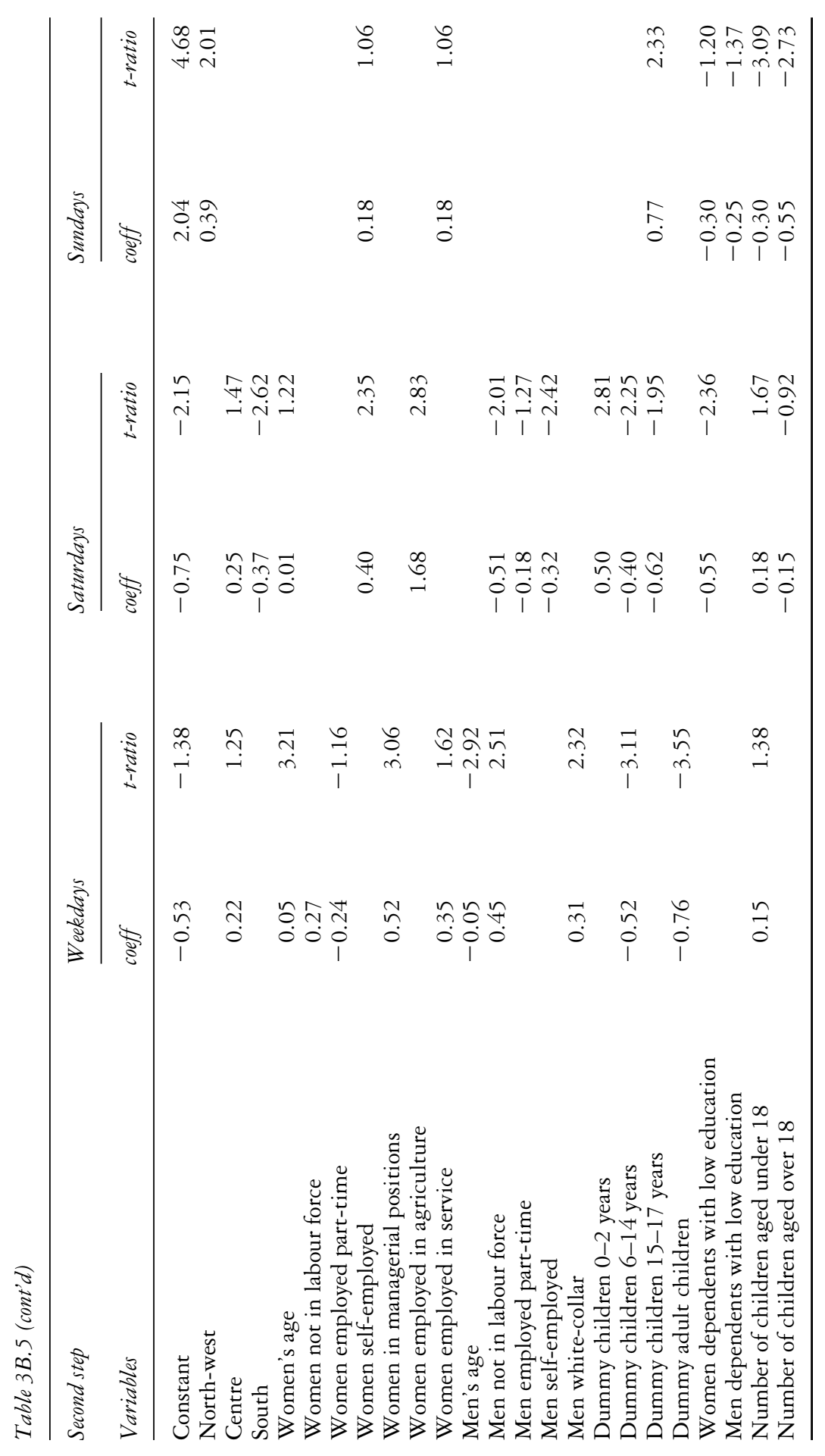




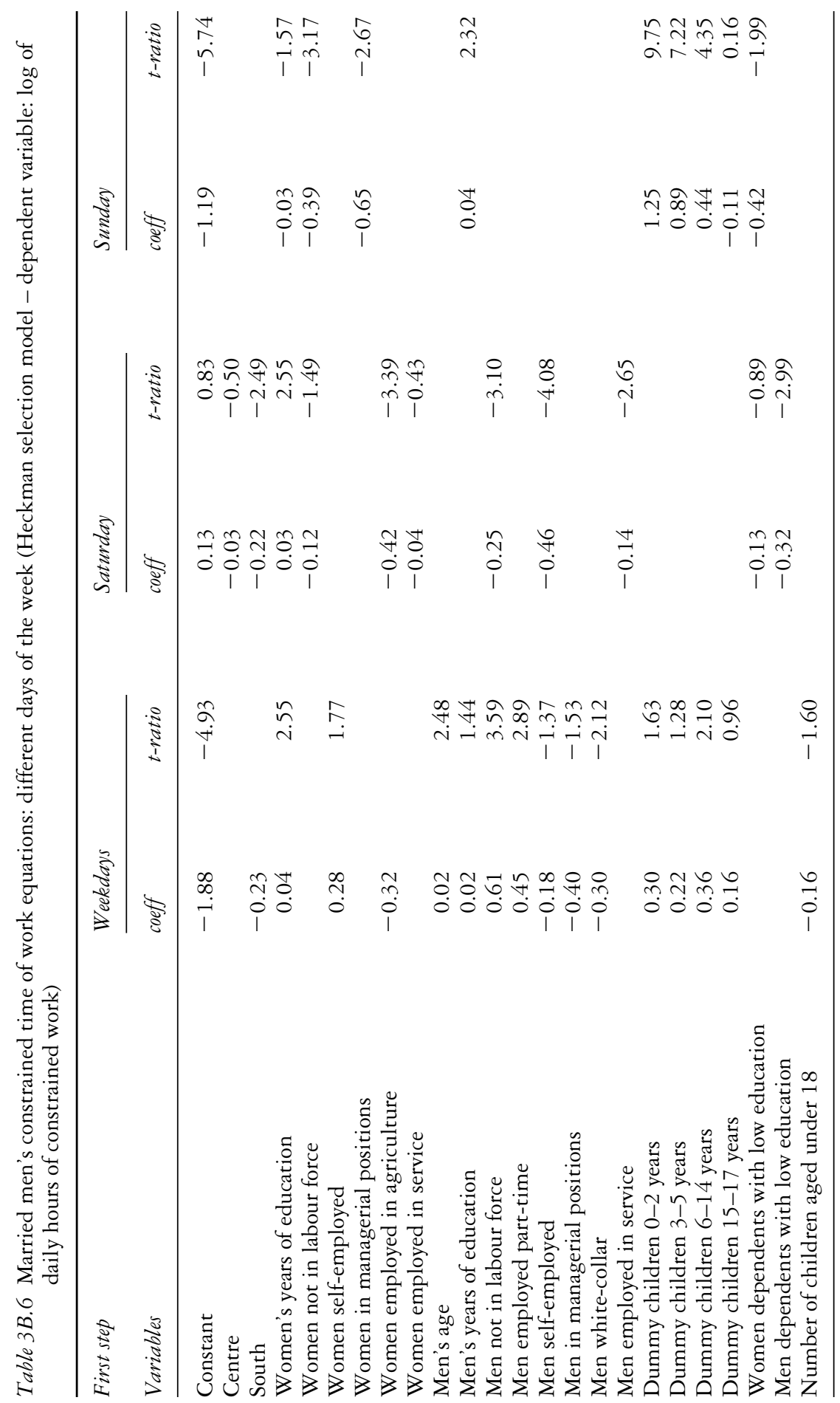




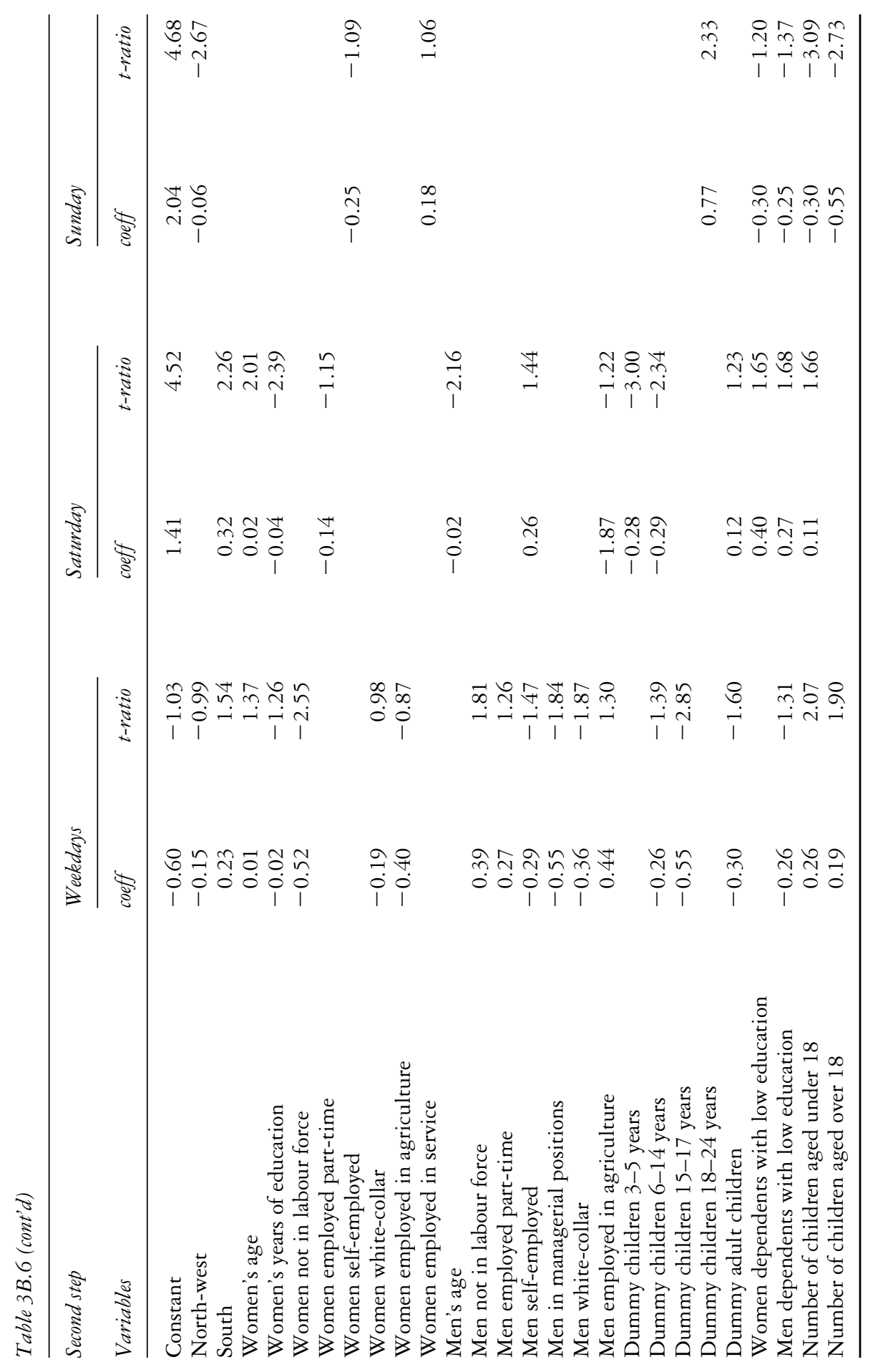




\section{Tindara Addabbo and Antonella Caiumi}

Table 3B.7 Unpaid work of single men and women - weekdays

(a) Single women - weekdays

(OLS - dependent variable: log of daily hours of unpaid work)

\begin{tabular}{lrlrcc}
\hline Variables & Coeff. & Std. error & t-ratio & $\begin{array}{l}\text { Variable } \\
\text { mean }\end{array}$ & Std. dev. \\
\hline Constant & -0.93 & 0.31 & -2.99 & & \\
Age & 0.03 & 0.01 & 4.86 & 50.87 & 11.88 \\
Not employed & 0.91 & 0.23 & 3.98 & 0.46 & 0.5 \\
South & -0.67 & 0.14 & -4.68 & 0.28 & 0.45 \\
Employed in agriculture & 0.74 & 0.58 & 1.29 & 0.01 & 0.11 \\
Employed in services & -0.41 & 0.21 & -1.94 & 0.4 & 0.49 \\
Self-employed & 1.05 & 0.21 & 5 & 0.16 & 0.37 \\
Part-time employed & 0.99 & 0.25 & 3.94 & 0.1 & 0.3 \\
Manager & 0.91 & 0.26 & 3.51 & 0.08 & 0.28 \\
\hline
\end{tabular}

(b) Single men - weekdays (Heckman selection model)

(First step of Heckman model: Unpaid work probability)

\begin{tabular}{lrlrcr}
\hline Variables & Coeff. & Std. error & t-ratio & $\begin{array}{c}\text { Variable } \\
\text { mean }\end{array}$ & Std. dev. \\
\hline Constant & -0.55 & 0.84 & -0.65 & & \\
Age & 0.02 & 0.01 & 1.25 & 41.64 & 13.82 \\
Years of education & 0.07 & 0.05 & 1.47 & 9.6 & 4.04 \\
Centre & -0.68 & 0.49 & -1.39 & 0.13 & 0.34
\end{tabular}

(Second step: Dependent variable log of men's unpaid working hours)

\begin{tabular}{lccrrr} 
Constant & -2.1 & 1.13 & -1.85 & & \\
Age & 0.02 & 0.02 & 1.26 & 42.15 & 13.88 \\
Not employed & 1.15 & 0.46 & 2.51 & 0.23 & 0.43 \\
Self-employed & 0.95 & 0.46 & 2.05 & 0.19 & 0.39 \\
Part-time employed & -0.89 & 0.49 & -1.83 & 0.14 & 0.35 \\
Heckman's lambda & 1.9 & 1.67 & 1.14 & 0.39 & 0.13 \\
\hline
\end{tabular}


Table 3B.8 Unpaid work of single men and women - Saturdays

(a) Single women - Saturdays

(OLS - dependent variable: log of daily hours of unpaid work)

\begin{tabular}{lrlrrl}
\hline Variables & Coeff. & Std. error & t-ratio & $\begin{array}{l}\text { Variable } \\
\text { mean }\end{array}$ & Std. dev. \\
\hline Constant & 0.24 & 0.42 & 0.58 & & \\
Age & 0.02 & 0.01 & 3.25 & 52.43 & 9.14 \\
Years of study & -0.03 & 0.01 & -1.98 & 8.15 & 5 \\
Not employed & 0.21 & 0.15 & 1.42 & 0.56 & 0.5 \\
Self-employed & -1.12 & 0.57 & -1.97 & 0.01 & 0.11 \\
\hline
\end{tabular}

(b) Single men - Saturdays (Heckman selection model) (First step of Heckman model: Unpaid work probability)

\begin{tabular}{lccccc}
\hline Variables & Coeff. & Std. error & t-ratio & $\begin{array}{c}\text { Variable } \\
\text { mean }\end{array}$ & Std. dev. \\
\hline Constant & 1.33 & 1.58 & 0.84 & & \\
Age & 0.04 & 0.03 & 1.55 & 43.51 & 11.79 \\
Years of study & -0.14 & 0.07 & -1.92 & 9.32 & 4.05 \\
North-west & -1.13 & 0.65 & -1.74 & 0.19 & 0.4 \\
South & -1.91 & 0.56 & -3.4 & 0.21 & 0.41 \\
$\quad$ (Second step: Dependent variable log of men's unpaid working hours) & \\
\hline Constant & 3.22 & 0.49 & 6.56 & & \\
Years of study & -0.13 & 0.05 & -2.85 & 8.47 & 3.85 \\
Not employed & -1.34 & 0.45 & -2.97 & 0.26 & 0.44 \\
Employed in services & -0.6 & 0.37 & -1.64 & 0.6 & 0.5 \\
Self-employed & -1.21 & 0.33 & -3.62 & 0.26 & 0.44 \\
White-collar & -0.98 & 0.4 & -2.43 & 0.2 & 0.4 \\
Heckman's lambda & -0.37 & 0.46 & -0.8 & 0.2 & 0.31 \\
\hline
\end{tabular}




\section{Tindara Addabbo and Antonella Caiumi}

Table 3B.9 Unpaid work of single men and women - Sundays

(a) Single women - Sundays

(OLS - dependent variable: log of daily hours of unpaid work)

\begin{tabular}{lccccc}
\hline Variables & Coeff. & Std. error & t-ratio & $\begin{array}{l}\text { Variable } \\
\text { mean }\end{array}$ & Std. dev. \\
\hline Constant & 0.81 & 0.43 & 1.88 & & \\
Age & 0.02 & 0.01 & 2.69 & 52.27 & 11.65 \\
Years of study & -0.1 & 0.02 & -4.75 & 8.4 & 4.2 \\
Centre & 0.34 & 0.17 & 1.99 & 0.25 & 0.44 \\
South & 0.53 & 0.19 & 2.78 & 0.13 & 0.34 \\
Self-employed & 0.42 & 0.24 & 1.7 & 0.1 & 0.3 \\
White-collar & 0.53 & 0.22 & 2.38 & 0.27 & 0.45 \\
Manager & 0.52 & 0.45 & 1.16 & 0.03 & 0.17 \\
\hline
\end{tabular}

(b) Single men - Sundays - Heckman selection model (First step of Heckman model: Unpaid work probability)

\begin{tabular}{lrlrrr}
\hline Variables & Coeff. & Std. error & t-ratio & $\begin{array}{l}\text { Variable } \\
\text { mean }\end{array}$ & Std. dev. \\
\hline Constant & 0.81 & 0.88 & 0.92 & & \\
Age & 0.02 & 0.02 & 1.33 & 38.03 & 12.27 \\
Years of study & -0.09 & 0.04 & -2.31 & 10.82 & 4.53
\end{tabular}

(Second step: Dependent variable log of men's unpaid work hours)

\begin{tabular}{lrlccc}
\hline Constant & -0.9 & 0.86 & -1.04 & & \\
Age & 0.03 & 0.02 & 1.86 & 40.25 & 13.38 \\
Not employed & 0.43 & 0.37 & 1.16 & 0.2 & 0.4 \\
Employed in services & -0.49 & 0.29 & -1.71 & 0.52 & 0.5 \\
Self-employed & 0.65 & 0.31 & 2.1 & 0.26 & 0.44 \\
White-collar & 0.56 & 0.31 & 1.82 & 0.27 & 0.45 \\
Heckman's lambda & 0.31 & 0.82 & 0.37 & 0.42 & 0.25 \\
\hline
\end{tabular}




\section{Appendix 3C Results of the statistical matching: comparison between actual and imputed values in ISTAT TBS 1989 and SHIW 1995 survey}

Table 3C.1 Comparison between observed and imputed values of unpaid work for the sample of couples with and without children belonging to the 1989 TBS

\begin{tabular}{|c|c|c|c|c|c|c|}
\hline \multicolumn{2}{|c|}{ (a) Women: weekdays } & \multirow{2}{*}{$\begin{array}{l}\text { Obs. } \\
1532\end{array}$} & \multirow{2}{*}{$\frac{\text { Mean }}{5.56}$} & \multirow{2}{*}{$\begin{array}{l}\text { Std. dev. } \\
2.72\end{array}$} & \multirow{2}{*}{$\frac{\text { Min. }}{0}$} & \multirow{2}{*}{$\frac{M a x}{14.67}$} \\
\hline Housework & Observed & & & & & \\
\hline & Imputed & 1532 & 5.32 & 2.8 & 0 & 13.85 \\
\hline \multirow[t]{2}{*}{ Care work } & Observed & 1532 & 0.8 & 1.27 & 0 & 9.5 \\
\hline & Imputed & 1532 & 0.81 & 1.08 & 0 & 6.44 \\
\hline \multirow[t]{2}{*}{ Constrained } & Observed & 1532 & 0.7 & 0.79 & 0 & 6 \\
\hline & Imputed & 1532 & 1.23 & 0.74 & 0 & 3.63 \\
\hline \multirow[t]{2}{*}{ Unpaid work } & Observed & 1532 & 7.07 & 3.16 & 0 & 16 \\
\hline & Imputed & 1532 & 7.36 & 3.18 & 0 & 16 \\
\hline \multirow{2}{*}{\multicolumn{2}{|c|}{ (b) Men: weekdays }} & & & & & \\
\hline & & Obs. & Mean & Std. dev. & Min. & Max. \\
\hline \multirow[t]{2}{*}{ Housework } & Observed & 1532 & 0.73 & 1.44 & 0 & 11.59 \\
\hline & Imputed & 1532 & 0.67 & 1.04 & 0 & 6.47 \\
\hline \multirow[t]{2}{*}{ Care work } & Observed & 1532 & 0.23 & 0.66 & 0 & 6.5 \\
\hline & Imputed & 1532 & 0.20 & 0.52 & 0 & 3.42 \\
\hline \multirow[t]{2}{*}{ Constrained } & Observed & 1532 & 0.27 & 0.66 & 0 & 6.08 \\
\hline & Imputed & 1532 & 0.31 & 0.64 & 0 & 3.62 \\
\hline \multirow{2}{*}{ Unpaid work } & Observed & 1532 & 1.23 & 1.82 & 0 & 11.67 \\
\hline & Imputed & 1532 & 1.19 & 1.43 & 0 & 7.56 \\
\hline \multirow{2}{*}{\multicolumn{2}{|c|}{ (c) Women: Saturdays }} & & & & & \\
\hline & & Obs. & Mean & Std. dev. & Min. & Max. \\
\hline \multirow[t]{2}{*}{ Housework } & Observed & 1395 & 5.59 & 2.57 & 0 & 17.86 \\
\hline & Imputed & 1395 & 5.14 & 1.46 & 1.01 & 9.97 \\
\hline \multirow[t]{2}{*}{ Care work } & Observed & 1395 & 0.72 & 1.24 & 0 & 13.5 \\
\hline & Imputed & 1395 & 0.76 & 0.99 & 0 & 5.38 \\
\hline \multirow[t]{2}{*}{ Constrained } & Observed & 1395 & 0.84 & 0.90 & 0 & 5.5 \\
\hline & Imputed & 1395 & 1.49 & 0.84 & 0 & 3.83 \\
\hline \multirow[t]{2}{*}{ Unpaid work } & Observed & 1395 & 7.15 & 2.93 & 0 & 17.86 \\
\hline & Imputed & 1395 & 7.4 & 1.93 & 1.25 & 14.52 \\
\hline
\end{tabular}


92 Tindara Addabbo and Antonella Caiumi

Table 3C.1 (cont'd)

\begin{tabular}{|c|c|c|c|c|c|c|}
\hline \multicolumn{2}{|c|}{ (d) Men: Saturdays } & \multirow{2}{*}{$\frac{\text { Obs. }}{1395}$} & \multirow{2}{*}{$\frac{\text { Mean }}{1.19}$} & \multirow{2}{*}{$\frac{\text { Std. dev. }}{1.84}$} & \multirow{2}{*}{$\frac{M i n .}{0}$} & \multirow{2}{*}{$\frac{\text { Max. }}{12.58}$} \\
\hline Housework & Observed & & & & & \\
\hline & Imputed & 1395 & 1.38 & 1.69 & 0 & 7.37 \\
\hline \multirow[t]{2}{*}{ Care work } & Observed & 1395 & 0.27 & 0.68 & 0 & 5.58 \\
\hline & Imputed & 1395 & 0.26 & 0.58 & 0 & 6 \\
\hline \multirow[t]{2}{*}{ Constrained } & Observed & 1395 & 0.49 & 0.85 & 0 & 4.92 \\
\hline & Imputed & 1395 & 0.38 & 0.71 & 0 & 4.62 \\
\hline \multirow[t]{2}{*}{ Unpaid work } & Observed & 1395 & 1.95 & 2.20 & 0 & 13.08 \\
\hline & Imputed & 1395 & 2.03 & 2.05 & 0 & 10.36 \\
\hline \multirow{2}{*}{\multicolumn{2}{|c|}{ (e) Women: Sundays }} & & & & & \\
\hline & & Obs. & Mean & Std. dev. & Min. & Max. \\
\hline \multirow[t]{2}{*}{ Housework } & Observed & 1371 & 4.78 & 2.47 & 0 & 17.08 \\
\hline & Imputed & 1371 & 4.37 & 1.36 & 0.25 & 9.01 \\
\hline \multirow[t]{2}{*}{ Care work } & Observed & 1371 & 0.54 & 0.98 & 0 & 7 \\
\hline & Imputed & 1371 & 0.63 & 0.91 & 0 & 4.39 \\
\hline \multirow[t]{2}{*}{ Unpaid work } & Observed & 1371 & 5.42 & 2.65 & 0 & 17.58 \\
\hline & Imputed & 1371 & 5.00 & 1.53 & 0.25 & 10.39 \\
\hline \multirow{2}{*}{\multicolumn{2}{|c|}{ (f) Men: Sundays }} & & & & & \\
\hline & & Obs. & Mean & Std. dev. & Min. & Max. \\
\hline \multirow[t]{2}{*}{ Housework } & Observed & 1371 & 0.96 & 1.55 & 0 & 12.33 \\
\hline & Imputed & 1371 & 0.79 & 0.91 & 0 & 4.24 \\
\hline \multirow[t]{2}{*}{ Care work } & Observed & 1371 & 0.28 & 0.82 & 0 & 8.08 \\
\hline & Imputed & 1371 & 0.26 & 0.62 & 0 & 3.45 \\
\hline \multirow[t]{2}{*}{ Unpaid work } & Observed & 1371 & 1.35 & 1.75 & 0 & 14.25 \\
\hline & Imputed & 1371 & 1.05 & 1.11 & 0 & 5.46 \\
\hline
\end{tabular}

Table 3C.2 Weekly unpaid work imputed values - samples of couples with and without children, SHIW 1995

\begin{tabular}{lcr}
\hline Observations: & $3,858$. & \\
\hline & Mean & Std. dev. \\
\hline Women & & \\
Housework & 34.8 & 14.94 \\
Care work & 8.44 & 5.50 \\
Constrained & 6.30 & 4.83 \\
Unpaid work & 49.54 & 25.27 \\
Men & & \\
Housework & 7.76 & 8.16 \\
Care work & 4.10 & 4.19 \\
Constrained & 3.15 & 3.87 \\
Unpaid work & 15.01 & 16.21 \\
\hline
\end{tabular}




\section{Appendix 3D Estimation of the potential wage equations for men and women}

Table 3D.1 First step: employment probability

\begin{tabular}{|c|c|c|c|c|c|c|}
\hline \multirow[b]{2}{*}{ Variable } & \multicolumn{3}{|l|}{ Women } & \multicolumn{3}{|l|}{ Men } \\
\hline & Coeff. & Std. error & t-ratio & Coeff. & Std. error & t-ratio \\
\hline Constant & -5.177 & 0.538 & -9.621 & -4.800 & 0.632 & -7.599 \\
\hline Household income & -0.001 & 0.002 & -0.625 & -0.014 & 0.002 & -8.248 \\
\hline Age & 0.238 & 0.028 & 8.638 & 0.308 & 0.030 & 10.364 \\
\hline Age square & -0.003 & 0.000 & -9.095 & -0.004 & 0.000 & -11.927 \\
\hline Years of education & 0.134 & 0.007 & 18.407 & 0.082 & 0.008 & 10.302 \\
\hline $\begin{array}{l}\text { Number of children } \\
\text { aged under } 3\end{array}$ & -0.343 & 0.088 & -3.905 & 0.107 & 0.111 & 0.958 \\
\hline $\begin{array}{l}\text { Number of children } \\
\text { aged } 3-5\end{array}$ & -0.231 & 0.064 & -3.602 & 0.019 & 0.080 & 0.234 \\
\hline $\begin{array}{l}\text { Number of children } \\
\text { aged } 6-17\end{array}$ & -0.183 & 0.036 & -5.136 & -0.141 & 0.038 & -3.681 \\
\hline $\begin{array}{l}\text { Number of children } \\
\text { aged } 18-24\end{array}$ & -0.157 & 0.044 & -3.550 & 0.088 & 0.045 & 1.951 \\
\hline $\begin{array}{l}\text { Regional } \\
\text { unemployment rate }\end{array}$ & -0.049 & 0.006 & -8.735 & -0.040 & 0.006 & -6.601 \\
\hline Chronic disease & -0.270 & 0.087 & -3.103 & -0.119 & 0.084 & -1.423 \\
\hline Partners not employed & 0.156 & 0.106 & 1.465 & -0.159 & 0.170 & -0.934 \\
\hline
\end{tabular}

Table 3D.2. Second step: wage equations

\begin{tabular}{lccrrrr}
\hline & Women & \multicolumn{5}{c}{ Men } \\
\cline { 2 - 7 } Variable & Coeff. & Std. error & t-ratio & Coeff. & Std. error & t-ratio \\
\hline Constant & 0.504 & 0.470 & 1.072 & -0.237 & 0.302 & -0.783 \\
Years of education & 0.084 & 0.009 & 9.411 & 0.072 & 0.003 & 24.272 \\
Age & 0.030 & 0.019 & 1.556 & 0.089 & 0.014 & 6.249 \\
Age square & -0.000 & 0.000 & -0.982 & -0.001 & 0.000 & -6.042 \\
Past work experience & 0.064 & 0.019 & 3.373 & 0.078 & 0.011 & 6.824 \\
South-east & -0.103 & 0.057 & -1.812 & -0.152 & 0.026 & -5.792 \\
South-west & -0.164 & 0.057 & -2.855 & -0.155 & 0.029 & -5.287 \\
Centre & -0.109 & 0.038 & -2.880 & -0.043 & 0.023 & -1.848 \\
Heckman's lambda & 0.175 & 0.106 & 1.649 & 0.449 & 0.073 & 6.111 \\
Observations & 1,290 & & & 2,455 & & \\
$\mathrm{R}^{2}$ & 0.27 & & & 0.30 & & \\
\hline
\end{tabular}




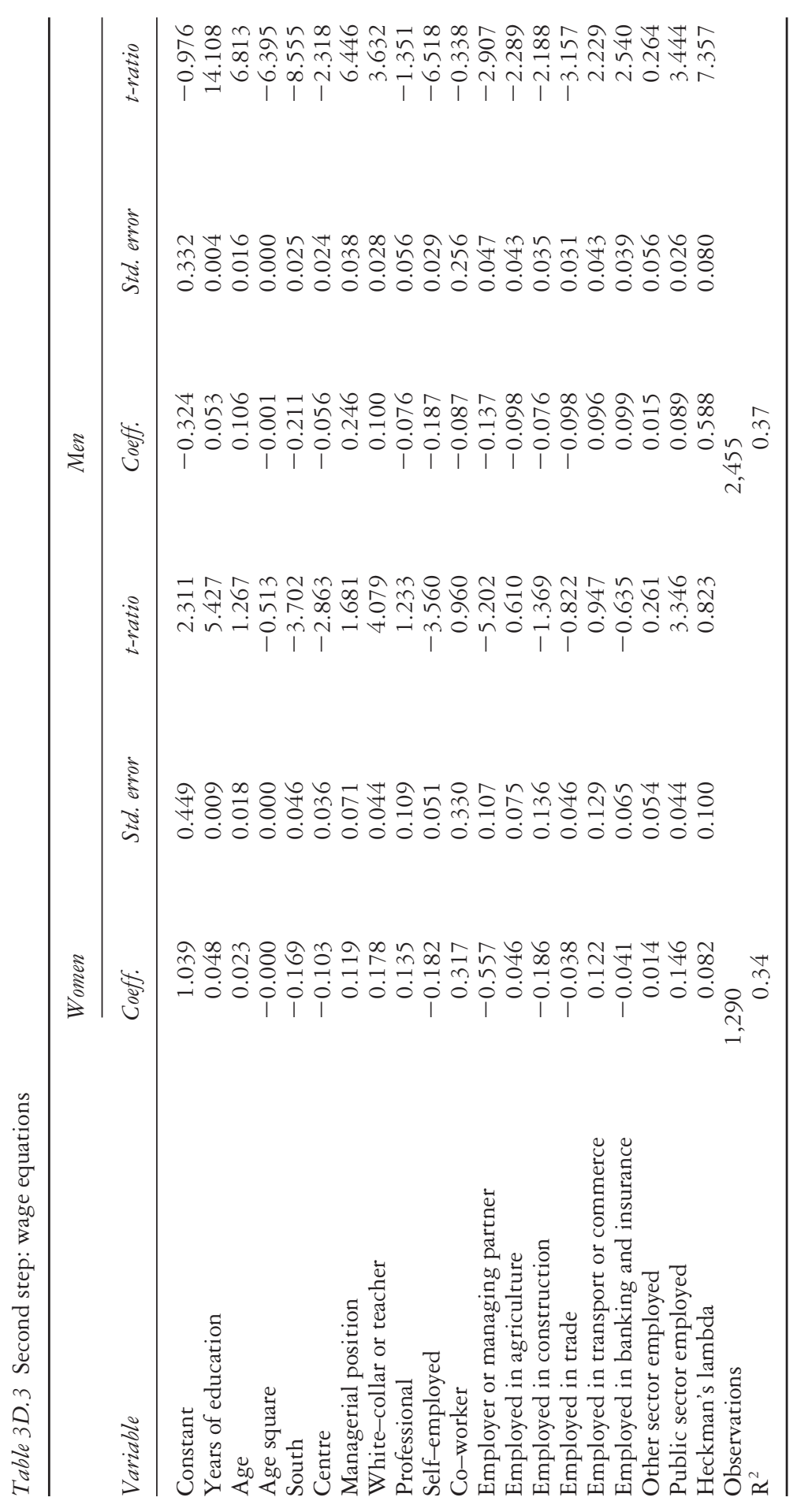




\section{Appendix 3E Unpaid work by gender over time and across countries}

\section{Francesca Olivier}

In this Appendix a comparison among different surveys which record information on unpaid work in Italy over different years will be carried out together with a comparison among data from other countries.

I shall compare TBS time budget data with the information on unpaid hours of work taken from the ISTAT 1994 multipurpose survey on daily life (Indagine multiscopo sugli aspetti di vita quotidiana). The latter data are less precise than the TBS data for the following reasons:

- ISTAT 1994 data do not allow us to distinguish between housework, care and shopping and house administration, but collect total average unpaid work time carried out by each family member.

- This total time does not refer to a specific day, nor does it come from a diary, but is a weekly mean; hence it is not possible to account for simultaneous activities and average weekly data are more exposed to the risk of recall errors.

For the comparison I have used a subsample: only one-earner couples. Despite the different statistical sources and the different years, the data shown in this Appendix confirm what has been found by using the 1989 ISTAT time budget survey: in 1989 women devoted 79 per cent of their total working time to unpaid work (according to time budget data) and 75 per cent according to survey data.

However, the differences in the distribution of time arising in this comparison may be due to the different sources of data analysed. To see how total work distribution has changed over time in Italy I have therefore

Table 3E.1 Allocation of time by gender in one-earner households: ISTAT TBS 1989 versus ISTAT 1994 Survey

\begin{tabular}{lcc}
\hline & $1989(\%)$ & $1994(\%)$ \\
\hline Women & & \\
Unpaid work & 79 & 75 \\
Paid work & 21 & 25 \\
Total working time & 100 & 100 \\
\hline Men & & \\
Unpaid work & 18 & 20 \\
Paid work & 82 & 80 \\
Total working time & 100 & 100 \\
\hline
\end{tabular}

Sources: Author's calculations based on ISTAT TBS 1989 and ISTAT 1994 data. 


\section{Tindara Addabbo and Antonella Caiumi}

compared the same sources of data (ISTAT multipurpose surveys 1994 and 1998) distinguishing by different household types. As Tables 3E.2 and 3E.3 show, the average time spent on unpaid work by women without children decreased between 1994 and 1998 both in one-earner (where only the husband was employed) and double-earner households. On the other hand, women's unpaid work in households with children decreased only in oneearner households. There was a narrowing of the gap in total working time by gender between 1994 and 1998 .

By looking at the distribution of time by type of household (with or without children) and by women's age (Tables 3E.4 and 3E.5) one can see that women aged under 50 have reduced significantly unpaid work activities in households without children (Table 3E.4), whereas the decrease in

Table 3E.2 Allocation of time (hours) in one-earner households: comparison between 1994 and 1998 ISTAT household surveys

\begin{tabular}{|c|c|c|c|c|}
\hline & \multicolumn{2}{|c|}{ With children } & \multicolumn{2}{|c|}{ Without children } \\
\hline & 1994 & 1998 & 1994 & 1998 \\
\hline \multicolumn{5}{|l|}{ Women } \\
\hline Unpaid work & 50.5 & 48.9 & 44.0 & 38.9 \\
\hline Paid work & 0 & 0 & 0 & 0 \\
\hline Total working time & 50.7 & 48.9 & 44.0 & 38.9 \\
\hline \multicolumn{5}{|l|}{ Men } \\
\hline Unpaid work & 4.9 & 5.3 & 4.4 & 4.5 \\
\hline Paid work & 43.6 & 43.9 & 42.5 & 43.8 \\
\hline Total working time & 48.5 & 49.2 & 46.9 & 48.3 \\
\hline
\end{tabular}

Table 3E.3 Allocation of time (hours) in double-earner households: comparison between 1994 and 1998 ISTAT household surveys

\begin{tabular}{lccccc}
\hline & \multicolumn{2}{l}{ With children } & & & \multicolumn{2}{l}{ Without children } \\
& 1994 & & & 1994 & 1998 \\
\hline Women & & & & \\
Unpaid work & 30.4 & 30.2 & & 24.5 & 20.9 \\
Paid work & 34.5 & 34.3 & & 37.3 & 37.5 \\
Total working time & 64.9 & 64.5 & & 61.8 & 58.3 \\
Men & & & & \\
Unpaid work & 6.5 & 7.9 & & 5.5 & 6.0 \\
Paid work & 43.6 & 44.2 & & 45.1 & 4.5 \\
Total working time & 50.1 & 52.1 & & 50.6 & 50.5 \\
\hline
\end{tabular}


Table 3E.4 Allocation of time (hours) by women's age in households without children: comparison between 1994 and 1998 ISTAT household surveys

\begin{tabular}{|c|c|c|c|c|c|c|}
\hline & \multicolumn{2}{|c|}{$18-35$ years } & \multicolumn{2}{|c|}{$35-50$ years } & \multicolumn{2}{|c|}{ 50-65 years } \\
\hline & 1994 & 1998 & 1994 & 1998 & 1994 & 1998 \\
\hline Unpaid work & 31.1 & 24.4 & 32.8 & 26.8 & 36.5 & 34.1 \\
\hline Paid work & 28.9 & 32.9 & 29.5 & 31.4 & 25.1 & 27.4 \\
\hline
\end{tabular}

Table 3E.5 Allocation of time (hours) by women's age in households with children: comparison between 1994 and 1998 ISTAT household surveys

\begin{tabular}{|c|c|c|c|c|c|c|}
\hline & \multicolumn{2}{|c|}{$18-35$ years } & \multicolumn{2}{|c|}{$35-50$ years } & \multicolumn{2}{|c|}{$50-65$ years } \\
\hline & 1994 & 1998 & 1994 & 1998 & 1994 & 1998 \\
\hline Unpaid work & 41.7 & 41.3 & 40.6 & 39.2 & 40.8 & 38.9 \\
\hline Paid work & 21.4 & 23.7 & 24.0 & 25.8 & 21.0 & 23.8 \\
\hline
\end{tabular}

women's unpaid work for households with children occurs only when women are older.

By analysing women's level of education (Tables 3E.6 and 3E.7) one can see that women's unpaid work in households without children (Table 3E.6) decreased, especially for women with medium or high levels of education, whereas the reduction in unpaid working time was much lower for women in households with children, while unpaid work of graduate women even increased. Note the net increase in women's total working time in households with children and (for graduate women) in households without children.

I then carried out a comparison between UNDP (1995) data on the allocation of time in industrialised countries and data on the allocation of time estimated by using ISTAT TBS data for Italy. This comparison (made by using a graph similar to the one proposed by UNDP 1995) shows a greater

Table 3E.6 Allocation of time (hours) by women's education levels in households without children: comparison between 1994 and 1998 ISTAT household surveys

\begin{tabular}{|c|c|c|c|c|c|c|c|c|}
\hline & \multicolumn{2}{|c|}{ Primary } & \multicolumn{2}{|c|}{ Lower secondary } & \multicolumn{2}{|c|}{ Upper secondary } & \multicolumn{2}{|l|}{ Degree } \\
\hline & 1994 & 1998 & 1994 & 1998 & 1994 & 1998 & 1994 & 1998 \\
\hline Unpaid work & 38.5 & 36.5 & 35.3 & 30.6 & 29.3 & 24.0 & 22.8 & 21.7 \\
\hline Paid work & 23.8 & 26.0 & 27.7 & 30.5 & 30.1 & 32.1 & 27.3 & 33.2 \\
\hline Total working time & 62.3 & 62.5 & 63.0 & 61.1 & 59.4 & 56.1 & 50.1 & 54.9 \\
\hline
\end{tabular}


98 Tindara Addabbo and Antonella Caiumi

Table 3E.7 Allocation of time (hours) by women's education levels in households with children: comparison between 1994 and 1998 ISTAT household surveys

\begin{tabular}{|c|c|c|c|c|c|c|c|c|}
\hline & \multicolumn{2}{|c|}{ Primary } & \multicolumn{2}{|c|}{ Lower secondary } & \multicolumn{2}{|c|}{ Upper secondary } & \multicolumn{2}{|l|}{ Degree } \\
\hline & 1994 & 1998 & 1994 & 1998 & 1994 & 1998 & 1994 & 1998 \\
\hline Unpaid work & 44.7 & 43.8 & 42.7 & 42.2 & 38.3 & 37.1 & 30.0 & 31.6 \\
\hline Paid work & 18.6 & 20.1 & 21.0 & 22.8 & 26.2 & 27.8 & 27.7 & 28.1 \\
\hline Total working time & 63.3 & 63.9 & 63.7 & 65.0 & 64.5 & 64.9 & 57.7 & 59.7 \\
\hline
\end{tabular}

disequilibrium by gender in the allocation of time in Italy (Figure 3E.2) than in all the industrialised countries analysed in UNDP 1995 (Figure 3E.1).

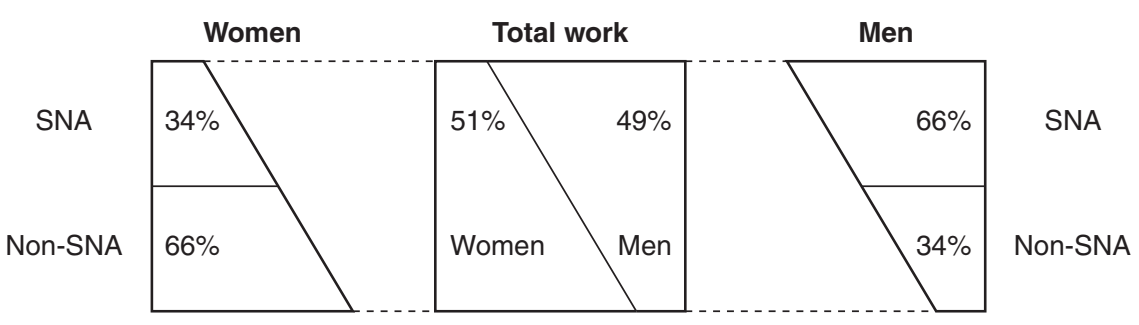

Figure 3E.1 Allocation of time by gender - industrialised countries.

Source: UNDP (1995).

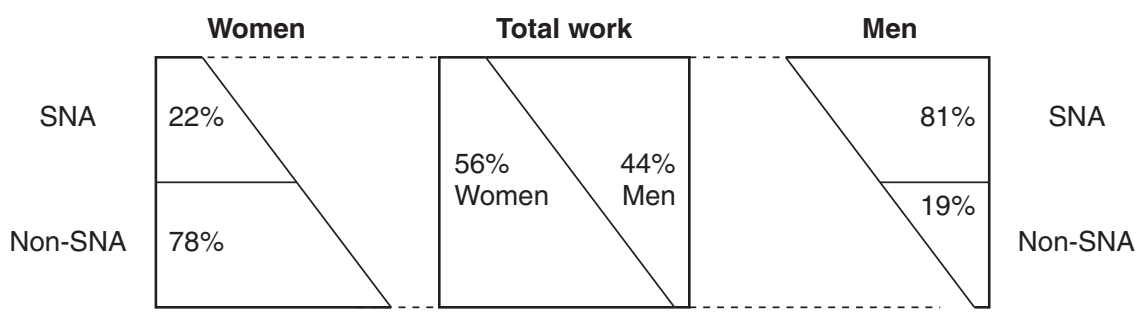

Figure 3E.2 Allocation of time by gender - Italy.

Source: Authors' calculations based on SHIW 1995 data matched with ISTAT TBS.

Notes

SNA, recorded in the system of national accounts.

Non-SNA, unrecorded in the system of national accounts. 
Appendix 3F Decile distribution of money and extended income by gender and different household types
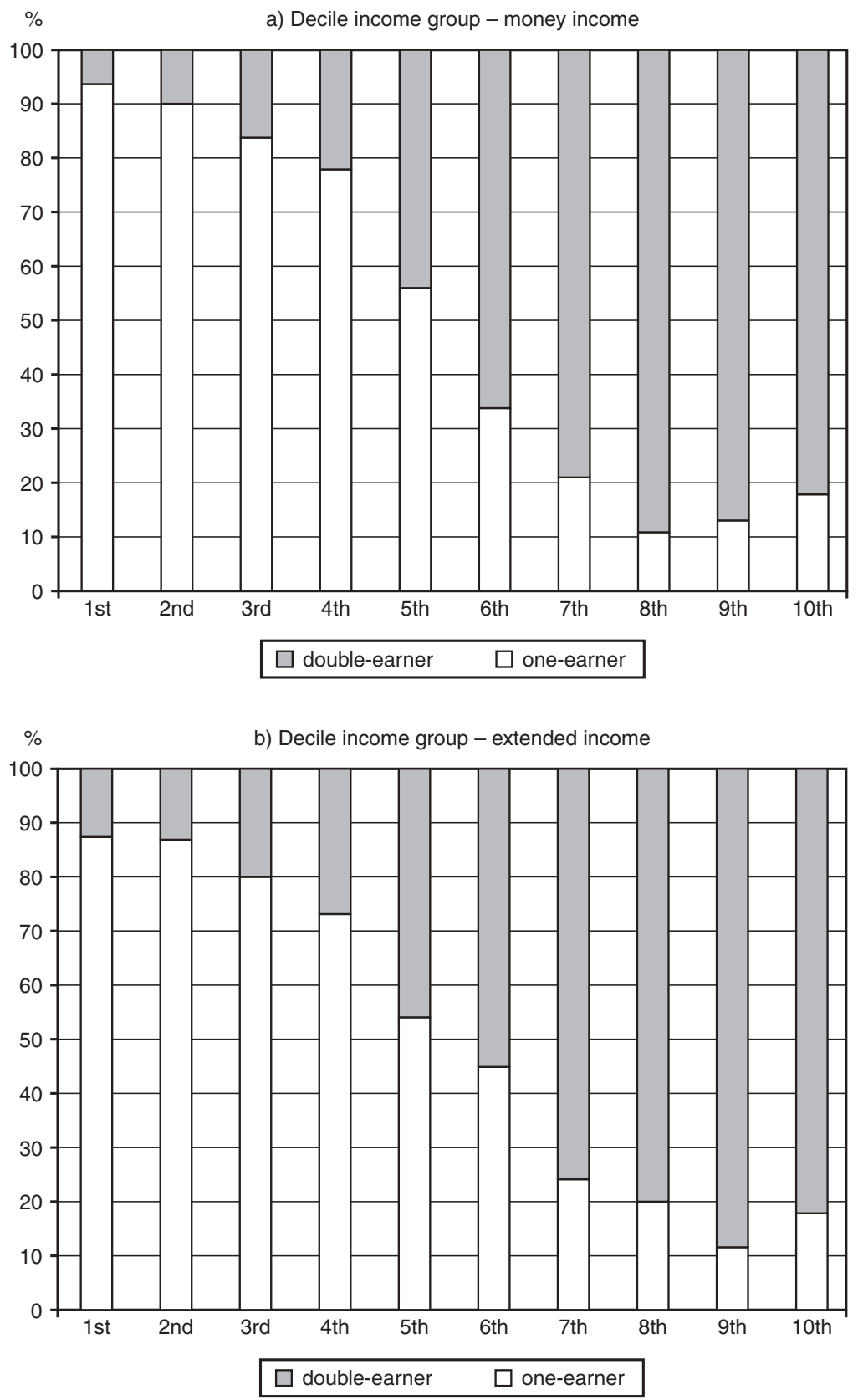

Figure 3F.1 Decile composition by employment condition of money income (a) and extended income evaluated at the opportunity cost (b). 


\section{Tindara Addabbo and Antonella Caiumi}

\section{Acknowledgements}

We thank the research group directed by Professor Antonella Picchio and the participants in the session on 'The Changing Relationship Between the Distribution of Work and the Distribution of Family Income' of the 25th General Conference of the International Association for Research in Income and Wealth for the stimulating comments received. Financial support from CNEL is gratefully acknowledged.

\section{Notes}

1 Analyses on the implications of the inclusion of unpaid work in the economic analysis are provided in Chapters 1,8 and 9 of this book.

2 'Domestic work is hidden because it sustains other types of work, formal and informal, waged and unwaged. The difficulties of measurement are partly related to the problem of placing this work and the whole process of the reproduction of people within the analytical framework of basic economic processes, and within the scheme of the social relationships that link different kinds of work, social subjects and economic processes' (Picchio 1996: 90).

3 Household activities contribute to household consumption by combining market goods and household time into commodities. By the term 'extended consumption' we mean the consumption of market and non-market goods.

4 See Bank of Italy (2002) for a first analysis of the 2000 survey. The survey includes synthetic information on household members' weekly hours of unpaid work together with information on household income and wealth.

5 Analyses of the presence of childcare services for children in different age groups are provided by Moss (1990), ISTAT (1997), Saraceno (1997) and OECD (2001). In addition, women's paid work is affected significantly by the presence and number of children in different age groups depending on the system of childcare services (Addabbo 1999).

6 See Brandolini and Cannari (1994) and Cannari and Gavosto (1994) for more details on SHIW.

7 If the two samples are drawn from the same population one can show that the two instrumental variables estimator suggested by Angrist and Krueger (1992) (and applied, among others, by Lusardi 1996) provides consistent estimates for the moments of the population even if computed on two different samples.

8 Chadeau (1985), Perali (1999) and Murphy (1982).

9 Bruyn-Hundt (1996).

10 We use as service price method the replacement cost

11 This result has also been obtained by Jenkins and O'Leary (1996).

12 Bonke (1992) finds that the result on equalisation depends on the type of inequality index and the type of household analysed, whereas Bryant and Zyck (1985), by using US data, found that income inequality decreased by extending income to include unpaid work between 1979 and 1980 and increased between 1975 and 1976.

13 The wage differential by gender in Italy was 22 per cent in 1995 and has increased over the past decade (ITER 2001; Rossi 1998).

14 See Chapter 4 for an analysis of the equivalence scales used here. 


\section{References}

Addabbo, T. (1999) 'Labour supply and employment probabilities in Italy: a gender analysis in a regional perspective', Economia E Lavoro, 33(3-4): 189-207.

Angrist, J. and Krueger, A. (1992) 'The effect of age at school entry on education attainment: an application of instrumental variables with moments from two samples', Journal of the American Statistical Association, 87: 328-36.

Arellano, M. and Meghir, C. (1992) 'Female labor supply and on-the-job search: an empirical model estimated using complementary data sets', Review of Economic Studies, 59: 537-57.

Bank of Italy (2002) 'I bilanci delle famiglie italiane nell'anno 2000', Supplementi al Bollettino Statistico, 6.

Banks, J. and Johnson, P. (1993) 'Children and household living standards', The Institute for Fiscal Studies, London.

Battistin, E., Miniaci, R. and Weber, G. (2000) 'What do we learn from recall consumption data?', The Institute for Fiscal Studies, London, Working Paper 00/10.

Bonke, J. (1992) 'Distributions of economic resources: implications of including household production', The Review of Income and Wealth, 38: 281-93.

Brandolini, A. and Cannari, L. (1994) 'The Bank of Italy's Survey of Household Income and Wealth', in A. Ando, L. Guiso and I. Visco (eds) Saving and the Accumulation of Wealth. Essay on Italian Household and Government Saving Behaviour, Cambridge: Cambridge University Press.

Bruyn-Hundt, M. (1996) The Economics of Unpaid Work, Amsterdam: Thesis Publishers.

Bryant, K.W. and Zyck, C.D. (1985) 'Income distribution implications of rural household production', American Journal of Agricultural Economics, 67: 1100-4.

Cannari, L. and Gavosto, A. (1994) 'L'Indagine della Banca d'Italia sui bilanci delle famiglie: una descrizione dei dati sul mercato del lavoro', Economia E Lavoro, 28(1): 63-79.

Chadeau, A. (1985) 'Measuring household activities: some international comparisons', The Review of Income and Wealth, 31(3): 237-53.

Goldschmidt-Clermont, L. and Pagnossin-Aligisakis, E. (1996) 'Measures of unrecorded economic activities in fourteen countries', in UNDP Background Papers. Human Development Report 1995, New York: UNDP.

Gronau, R. (1986) 'Home productivity: a survey', in O.C. Ashenfelter and R. Layard (eds) Handbook of Labor Economics, Amsterdam: North-Holland.

Heckman, J. (1979) 'Sample selection bias as a specification error', Econometrica, 47: 153-61. ISTAT (1997) Rapporto Annuale. La situazione del paese nel 1996, Rome.

ITER (2001) I differenziali salariali per sesso in Italia, Research Report of Ministero del Lavoro, Comitato Nazionale di Parità e Pari Opportunità, Rome: Istituto Poligrafico dello Stato.

Jenkins, S.P. and O'Leary, N.G. (1996) 'Household income plus household production: the distribution of extended income in the UK', The Review of Income and Wealth, 42(4): 401-19.

Kennedy, P. (1983) 'Logarithmic dependent variables and prediction bias', Oxford Bulletin of Economics and Statistics, 45(4): 389-92.

Lusardi, A. (1996) 'Permanent income, current income and consumption: evidence from two panel data sets', Journal of Business and Economic Statistics 14(1): 81-90.

Moss, P. (1990) 'I servizi per l'infanzia nella Comunità Europea 1985-1990', Quaderni di Donne d'Europa, 31, Brussels: European Commission. 


\section{Tindara Addabbo and Antonella Caiumi}

Murphy, M. (1982) 'Comparative estimates of the value of household work in the United States for 1976', The Review of Income and Wealth, March 28(1): 29-43.

OECD (2001) Starting Strong: Early Childhood Education and Care, Paris: OECD.

Perali, F. (1999) 'Stima, distribuzione e dieomiposizione per geuere del reddito esteso: metodologia ed applicazione ad un campione di individui' Economia E Lavoro 33(3-4): 37-56.

Picchio, A. (1996) 'The analytical and political visibility of the work of social reproduction', in UNDP Background Papers. Human Development Report 1995, New York.

Radner, D.B. (1997) 'Noncash income, equivalence scales and the measurement of economic well-being', The Review of Income and Wealth, 43: 71-88.

Rettore, E. (1992) 'L'integrazione di fonti di informazioni individuali complementari nella stima di modelli di comportamento economico', Atti della XXXVI Riunione Scientifica SIS, 2: 21-4.

Rossi, N. (ed.) (1998) Il lavoro e la 'souranità sociale', Quarto rapporto CNEL sulla distribuzione e redistribuzione del reddito in Italia, 1996-7, Bologna: Il Mulino.

Saraceno, C. (1997) 'Le politiche per la famiglia', in M. Barbagli and C. Saraceno (eds) Lo stato delle famiglie in Italia, Bologna: Il Mulino.

UNDP (1995) Human Development Report, New York: Oxford University Press. 


\title{
$4 \quad$ Unpaid work and household living standards
}

\author{
Equivalence scale estimation and \\ intra-family distribution of \\ resources
}

Antonella Caiumi

\section{Introduction}

The aim of this chapter is to provide some measures of how equivalence scales change when household production is included in a broader definition of consumption. In Chapter 3 we stressed the importance of extending the definition of income to measure economic well-being. Traditionally, in welfare analysis the money income of a household is treated as a proxy for its level of welfare on the grounds that income is the means to achieve welfare. Defined in this way, income represents the value of consumption that can be undertaken. However, it may be observed that household activities contribute to household consumption by combining market goods and labour time of household members, as input to a household production process, into household commodities as output. The evaluation of the 'value added' to household consumption through domestic activities and the extent to which broadening the definition of income may affect the distribution of welfare was the object of Chapter 3. For this purpose, we pointed out that the fact that households differ in terms of their size, composition and other demographic characteristics implies that if we wish to compare the welfare level of two households it is not sufficient simply to compare their income levels. For example, families with children need more income than families without children to achieve the same living standard. The question is: How much more income?

A household equivalence scale is a measure of the adjustment required to compare income and expenditure of different household types, by taking account of demographic variables. For instance, suppose that a household of two adults and two children has an equivalence scale of 1.5 where the reference household type is the childless couple. If a family of the former type has $€ 3,000$ of total monthly expenditure, it follows that the same level of utility may be achieved by a childless couple with $€ 2,000$ income per month. This chapter aims to analyse whether equivalence scales vary with the definition of income. As shown in Chapter 2, time spent on household activities depends largely on household composition. It is likely that household 
equivalence scales associated with the non-monetary component of consumption are different from those usually estimated on market consumption goods. To our knowledge, the possibility that appropriate equivalence scales differ with the definition of income has not yet been explored.

Since our purpose is to perform interpersonal welfare comparisons from cross-sectional data and not, for instance, to measure the cost of raising children over the parents' life cycle, the approach adopted in order to estimate equivalence scales is based on needs. We apply Engel's approach to compute, parametrically and non-parametrically, the compensating variation required in order to restore household welfare to its level prior to the change in family composition. In particular, this study provides the cost associated with the presence of children by different age groups and the cost of a single adult as a percentage of the cost of a childless couple. The inclusion of household commodities in the bundle of necessities increases significantly the cost of pre-school children.

Equivalence scales make it possible to convert household income into equivalent quantities, based on the assumption of equal treatment of family members. In terms of interpersonal welfare comparison, focusing only on inter-household distribution and disregarding questions related to intrahousehold inequality implies that measures of poverty and inequality may be grossly underestimated.

The question of how resources are allocated within the household is crucial in behavioural analysis related to the household decision-making process. It is also relevant in the context of the design of household policies; for example, to devise eligibility rules for benefit schemes targeted at a specific household member or to rank households in terms of the equality of the intra-household distribution process. Besides, the distributive effects of alternative tax/benefit schemes should take into account their impact on individual behaviour and welfare.

One method of estimating the extent of inequality within the household is based on labour supply data. Chiappori (1992) argues that by observing how leisure is shared between the individual partners, it is possible to infer (up to a certain constant) how resources are shared between spouses and how the household's 'sharing rule' alters in response to changes in income or prices. Since time spent outside the labour market is not just pure leisure because it is often spent in household production and domestic work it is usually unequally distributed by gender - accounting for household production allows one to avoid misleading results concerning the intra-household resource allocation (Apps and Rees 1996).

The analysis of the behaviour of household members and their interactions through the sharing rule is central in the measurement of equivalence scales since utility is ultimately experienced by individuals.

After reviewing the literature on intra-household allocation of resources and the inclusion of household production, we summarise some results on the estimation of the sharing rule for Italian households and the implication 
related to the presence of children within a collective representation of the household, based on the data described in Chapter 3.

The chapter is organised as follows. Section 1 introduces the conventional method of estimating equivalence scales. Section 2 provides estimation results obtained using data on extended consumption. Section 3 is devoted to discussing issues related to the intra-household decision-making process and domestic production. Section 4 deals with the challenges implied by moving from inter-household comparison to interpersonal comparisons.

\section{Equivalence scales: definitions}

Equivalence scales attempt to measure the proportionate increase (or decrease) in income necessary to maintain a certain level of welfare given some changes in household composition. By analogy with the theory of cost of living indices, equivalence scales are expressed as a ratio between the cost of reaching a given standard of living for different types of households. Let us define the cost or expenditure function $C(u, p, d)=x$ as the minimum cost $x$ necessary to reach the utility level $u$ at prices $p$ for a household with characteristics $d$.

If $d^{1}$ denotes a family of two adults and a child, and $d^{0}$ a reference family usually composed of a childless couple, the additional cost of choosing $d^{1}$ over $d^{0}$ may be expressed as a consumer surplus measure, by

$$
D\left(p, d^{1}, d^{0} ; u\right)=C\left(p, d^{1} ; u\right)-C\left(p, d^{0} ; u\right) .
$$

For a given utility level of the reference household $u$ and current prices, (4.1) corresponds to the monetary compensation required to restore the utility level of the household before the change.

An equivalence scale compares two households with different demographic composition, in the same way that a cost of living index number compares two price levels, and can be written as

$$
E S\left(p, d^{1}, d^{0} ; u\right)=\frac{C\left(p, d^{1} ; u\right)}{C\left(p, d^{0} ; u\right)} .
$$

Following the previous example, the ratio (4.2) corresponds to an index of child cost. Analogously, if $d^{1}$ differs from $d^{0}$ for only one element, the equivalence scale corresponds to an index of cost associated with a specific demographic attribute, say, the cost of an elderly or disabled person, or the cost of living in a specific region. The difference between (4.2) and unity determines the compensating variation as a percentage of total household expenditure.

An equivalence scale (ES) may be considered exact if it is independent of the utility level or the income level chosen as the base of comparison among different households. This property of the ES is called base independence (BI), and implies a restriction on the form of the cost function. It has been shown (Lewbel 1989; Blackorby and Donaldson 1993) that a base-independent 
equivalence scale requires the cost function to be separable in the demographic function which includes only prices $p$ and demographic characteristics $d$ as arguments, $m(p, d)$, and in the cost function independent from $d$, $G\left(u, p, d^{0}\right)$. If $C(u, p, d)=G\left(u, p, d^{0}\right) m(p, d)$, it follows that $m(p, d)$ corresponds to a base-independent equivalence scale, which is independent from $u$, $E S(p, d)=m(p, d)$.

In this context, if preferences are represented in terms of the dual indirect utility function, $V(p, y, d)$, the level of welfare of a family with total expenditure $x$ and prices $p$ is given by $V(p, y, d)=V\left(p, x / m(p, d), d^{0}\right)$, where $x / m(p, d)$ represents the equivalent expenditure. It follows that if two households facing the same prices are endowed with the same amount of equivalent expenditure, they are equally well-off.

In order to calculate equivalence scales, the cost function $C(u, p, d)$ has to be recovered from expenditure surveys. However, household characteristics $d$ is exogenous in demand equations; thus it is not possible to identify from consumption data alone all the parameters required for modelling explicitly how households choose their characteristics. In other words, demand data reveal only conditional preference ordering regardless of whether households choose consumption and demographic characteristics simultaneously, subsequently or independently (Blundell 1998). This is the root of the fundamental identification problem of equivalence scales (Pollak and Wales 1979). Nevertheless, consumption data can be used to recover the conditional cost of attaining each indifference curve in consumption space, i.e. conditional preferences, and therefore provide some information on relative costs (Blundell and Lewbel 1991).

Another shortcoming associated with this approach of equivalence scales measurement is that the cost function $C(u, p, d)$ is specified at the household level, while the utility derived from consumption is experienced by individual members. This implies that welfare comparisons are only allowed across households rather than individuals (see Section 4).

The literature on equivalence scales has also been criticised because it has been observed that the cost of children, measured as a utility loss, is only distantly related to the total cost that parents sustain to raise their children, which should include the actual outlays and losses of earnings (Cigno 1996). In particular, Cigno suggests that the expenditure function of the household should be replaced by the cost of children function, where the minimand is the opportunity cost of having children (given by the amount of expenditure plus income forgone for raising children) while the utility held constant is that of children, or, more concretely, the quality of life offered to them.

In our view, this approach can provide useful insights for the analysis of fertility choices and design of family policies. In the context of welfare analysis, we observe that, measured in this way, the cost of children is subject to wide variability in relation to preferences expressed by parents in terms of the quantity - that is, the number - and quality - in the sense of 
quality of life - of children, to the household production technology and, obviously, to time and budget constraints. This implies that the estimate of the cost of children would not be exact, or, that is, the same, not independent, of the level of income or utility chosen as reference. It follows that if the estimation of the cost of children is motivated by the aim of making interpersonal welfare comparisons, as in this study, a more appropriate method would rely on needs; that is to say, the method should be empirically consistent with the property of equivalence scale exactness.

In this study, we adopt the compensating variation method to compute equivalence scales, but unlike the traditional approach which is based only on market consumption goods, we widen the class of goods on which interpersonal comparisons are usually based.

\section{Estimation and results}

In this section, we present our estimation results of equivalence scales on extended consumption by applying the Engel method, which is based on the assumption that the welfare of adults is inversely related to the proportion of the household budget spent on food. This leads to the hypothesis that adults in two households with different numbers of children enjoy the same level of welfare if these households have the same food share. The Engel equivalence scale, then, may be defined as the ratio of household expenditure that implies an identical budget share for food in these demographically different households.

The Engel method is also known in the literature as the iso-prop method. This term is more general since it allows one to choose as an indirect indicator of welfare any number of necessities, such as food, clothing, education or household commodities, which we consider in this study. The Engel curve may be linear or non-linear depending on the nature of the product. In particular, for a necessity such as food, the relationship between the associated expenditure share and the logarithm of income is linear.

One method to estimate Engel curves without imposing parametric restriction on the shape of the function to be estimated is based on kernel regression methods. This approach offers the advantage that it does not require us to assume any particular function in order to estimate the unknown conditional expectation function. The conditional expectation function of the Engel relationship is given by:

$$
m_{m}^{b}(x)=E\left[W_{m i} \mid X_{i}=x, d_{i}=d^{b}\right]
$$

where $W_{m i}$ is the consumption budget share of good $m, X_{i}$ denotes income (total expenditure) and $d_{i}$ is a vector of variables representing household characteristics, and we allow $d_{i}$ to assume a number of discrete values identifying $H$ household groups, $b=1, \ldots, H$. 


\section{Antonella Caiumi}

The Engel curve in (4.3) is estimated using kernel techniques (see e.g. Hardle 1990) by

$$
\hat{m}_{m}^{b}(x)=\frac{\sum_{n=1}^{N} w_{m i} K\left(\left(X_{i}-x\right) / b\right) I\left(d_{i}=d^{b}\right)}{\sum_{n=1}^{N} K\left(\left(X_{i}-x\right) / b\right) I\left(d_{i}=d^{b}\right)}
$$

where $\mathrm{I}(\mathrm{A})$ is the indicator function of the event $\mathrm{A}$ and $\mathrm{K}($.$) is a kernel func-$ tion (we chose the Gaussian density).

Alternatively, the Engel curve can be estimated parametrically by choosing a specific function. In comparing non-parametric results, we estimate the budget share function proposed by Working (1943) and Leser (1963) that takes the form:

$$
w_{i}=\alpha_{i}+\beta_{i} \ln y+\ln \mu(d)
$$

where it is assumed that the function of demographic characteristics $\ln \mu(d)$ is separable analogously to the cost function from which it is derived, $\ln C(u, p$, $d)=\ln \left(G\left(u, p, d^{0}\right) m(p, d)\right)$. In particular, $\ln \mathrm{m}(d)=\ln \mu^{\prime}(p, d)$ is the first derivative with respect to prices of the demographic function $\ln \mu(p, d){ }^{1}$

Data on extended consumption have been drawn by matching the survey of Italian household consumption (1995) carried out by ISTAT with data on time use (ISTAT Multiscopo (TBS) described in Chapter 3).

We consider the following types of household: single adults, childless couples, and couples with one child and couples with two children. These latter two categories are also distinguished by the children's age group (under 2 , between 3 and 5, between 6 and 17, between 18 and 24 years old). All subsamples are selected in order to exclude adults over 65 years old since expenditure patterns are likely to differ for the elderly. In terms of expenditure categories we consider only non-durable consumption, in particular food consumed at home, clothing, transport, recreation and personal care. Table 4.1 shows summary statistics about the data for some household types.

Within the categories of these market goods, only food may be classified as a necessity according to the shape of related expenditure shares (Figure 4.1). As far as household commodities are concerned, only domestic activities and personal care provided by the woman seem to correspond to the requirement that the share computed in terms of extended consumption is downward-sloping (Figure 4.2). Extended consumption is obtained as the sum of the expenditure for goods purchased in the market, in this case only non-durable goods, and the imputed value of household production.

Including household commodities in the selected bundle of necessities changes significantly the index of cost of children. At the median, the cost of a child under 6 years old rises to 48 per cent of the figure for a childless couple, which means it almost equals the cost of an equivalent adult. For an older child, the compensating variation converges to conventional measures based on market consumption goods. In particular, it turns out that the cost 


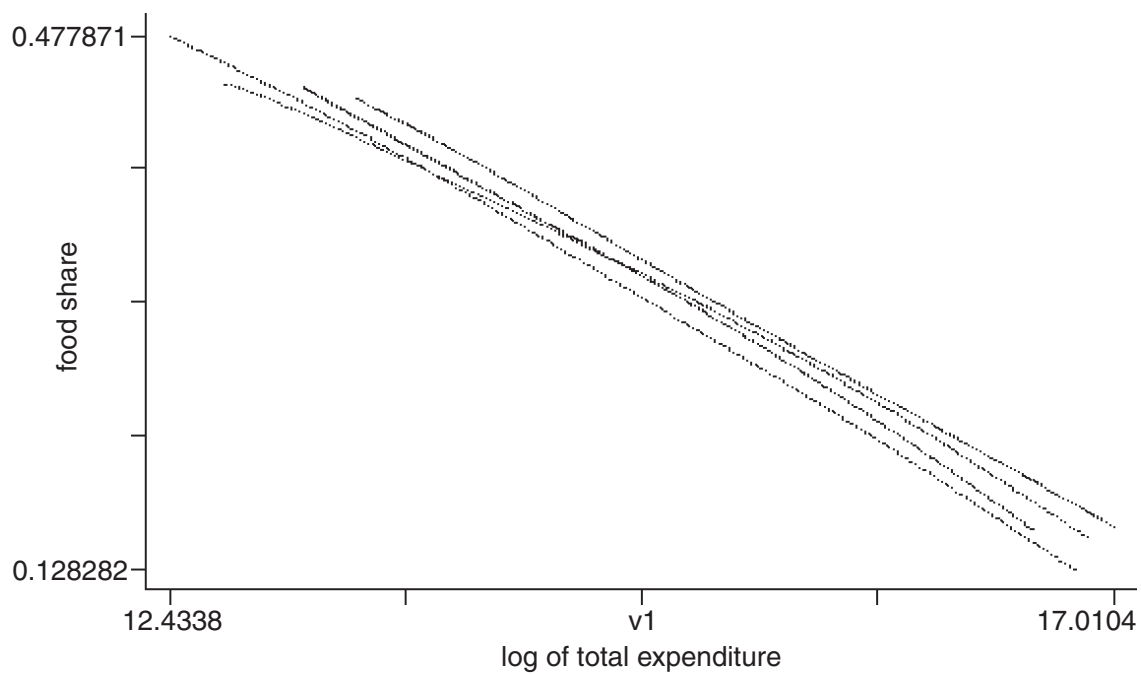

Figure 4.1 Non-parametric Engel curves on monetary consumption for different household types.

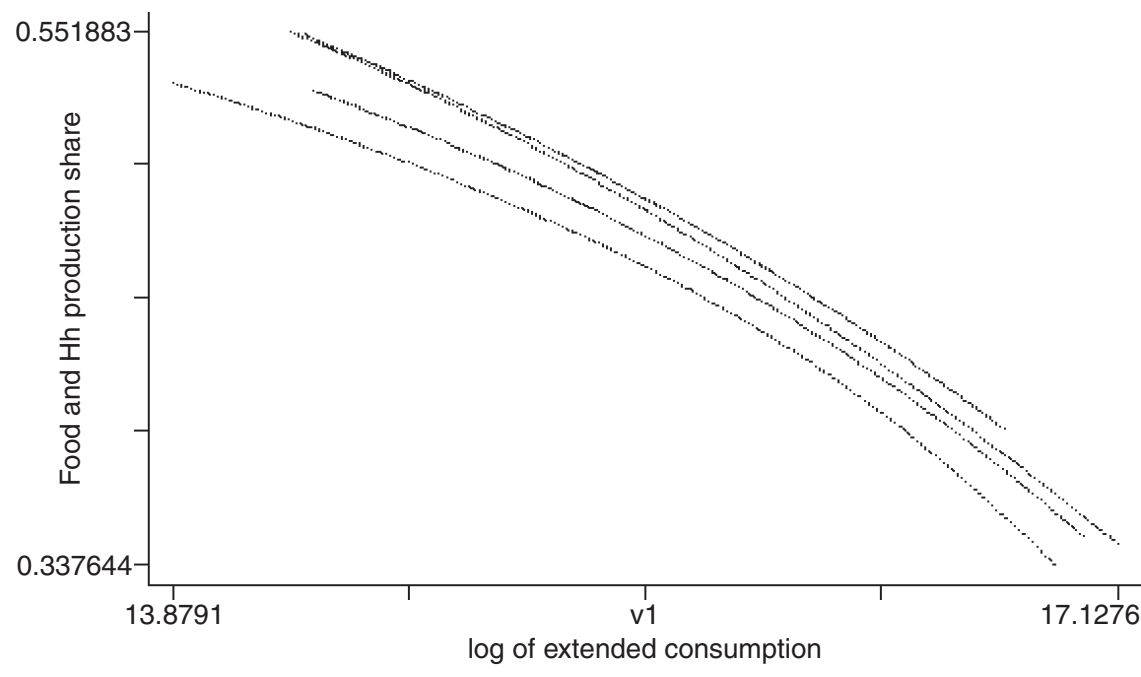

Figure 4.2 Non-parametric Engel curves on extended consumption for different household types.

of a young child is higher than the cost of a dependent adult in terms of extended consumption. This result also holds according to parametric estimates even if the distance between the two age groups is smaller, probably because the functional form needed to fit the Engel curve is less flexible than non-parametric regression (Table 4.2). 
110 Antonella Caiumi

Table 4.1 Non-parametric Engel scale

\begin{tabular}{|c|c|c|c|c|c|}
\hline \multirow[t]{2}{*}{ Quantile } & \multirow{2}{*}{$\begin{array}{l}\text { No. } \\
\text { adults }\end{array}$} & \multirow{2}{*}{$\begin{array}{l}\text { No. } \\
\text { children }\end{array}$} & \multirow{2}{*}{$\begin{array}{l}\text { Children } \\
\text { age group }\end{array}$} & \multicolumn{2}{|c|}{ Engel equivalence scale } \\
\hline & & & & Food & $\begin{array}{l}\text { Food and household } \\
\text { production }\end{array}$ \\
\hline \multirow[t]{7}{*}{40 per cent } & 1 & 0 & - & 0.60 & 0.48 \\
\hline & 2 & 1 & $<2$ & 1.14 & 1.50 \\
\hline & 2 & 1 & $3-5$ & 1.20 & 1.49 \\
\hline & 2 & 1 & $6-17$ & 1.23 & 1.25 \\
\hline & 2 & 2 & $6-17$ & 1.40 & 1.44 \\
\hline & 2 & 1 & $18-24$ & 1.35 & 1.38 \\
\hline & 2 & 2 & $18-24$ & 1.60 & 1.55 \\
\hline \multirow[t]{7}{*}{ Median } & 1 & 0 & - & 0.60 & 0.47 \\
\hline & 2 & 1 & $<2$ & 1.20 & 1.48 \\
\hline & 2 & 1 & $3-5$ & 1.24 & 1.47 \\
\hline & 2 & 1 & $6-17$ & 1.24 & 1.24 \\
\hline & 2 & 2 & $6-17$ & 1.35 & 1.32 \\
\hline & 2 & 1 & $18-24$ & 1.37 & 1.37 \\
\hline & 2 & 2 & $18-24$ & 1.51 & 1.52 \\
\hline \multirow[t]{7}{*}{60 per cent } & 1 & 0 & - & 0.61 & 0.47 \\
\hline & 2 & 1 & $<2$ & 1.20 & 1.46 \\
\hline & 2 & 1 & $3-5$ & 1.28 & 1.46 \\
\hline & 2 & 1 & $6-17$ & 1.30 & 1.25 \\
\hline & 2 & 2 & $6-17$ & 1.45 & 1.41 \\
\hline & 2 & 1 & $18-24$ & 1.39 & 1.37 \\
\hline & 2 & 2 & $18-24$ & 1.50 & 1.51 \\
\hline
\end{tabular}

Source: Author's calculations based on ISTAT Consumption Survey (1995) matched with ISTAT TBS Indagine Multiscopo (1989).

Note also that at a lower welfare level (corresponding to the fourth quintile of the budget share distribution) the costs associated with a child under 2 years old falls to 14 per cent of the reference household, according to the equivalence scales based on food, whereas it rises to 50 per cent when the basket of necessities includes parents' time devoted to household production. On the other hand, this index remains stable at 20 per cent at a higher welfare level for a household with a small child as at the median level, while it falls to 46 per cent in the case of extended consumption, implying that some substitutions between purchasing market goods and household production occur in relation to earning capacities, especially when the child is very young.

As far as economies of scale are concerned, it seems that the cost of two children in the same age group increases the costs of the reference household less than proportionally. In particular, economies of scale seem higher within extended consumption also according to parametric estimates (Table 4.2), with the exception of the cost of a single adult compared to the cost of a couple. Family formation is associated with a higher level of needs than living alone when household production is considered. 
Table 4.2 Parametric Engel scale

\begin{tabular}{lccll}
\hline No. adults & No. children & Children age group & \multicolumn{2}{l}{\begin{tabular}{l} 
Engel equivalence scale \\
\cline { 3 - 4 }
\end{tabular}} \\
\cline { 3 - 5 } & & Food & $\begin{array}{l}\text { Food and bousehold } \\
\text { production }\end{array}$ \\
\hline 1 & 0 & - & 0.59 & 0.53 \\
2 & 1 & $<2$ & 1.13 & 1.30 \\
2 & 1 & $3-5$ & 1.16 & 1.21 \\
2 & 2 & $6-17$ & 1.30 & 1.45 \\
2 & 1 & $6-17$ & 1.19 & 1.22 \\
2 & 2 & $18-24$ & 1.40 & 1.40 \\
2 & 1 & $18-24$ & 1.28 & 1.28 \\
2 & 2 & & 1.55 & 1.50 \\
\hline
\end{tabular}

Source: Author's calculations based on ISTAT Consumption Survey (1995) matched with ISTAT TBS Indagine Multiscopo (1989).

It should be noted that even the same value of the equivalence scale associated with a given household implies a very different amount of compensation needed to restore the same standard of living of the reference household depending on consumption definitions, as the median of the household expenditure distribution is about $€ 1,550$, whereas the extended consumption median is approximately $€ 2,580$.

\section{Intra-household allocation of resources, household production...}

The recent literature on the models of household-level analysis is increasingly critical of those describing household decisions in a unitary fashion, from both a theoretical and an empirical viewpoint. To be consistent with methodological individualism, the basic unit of microeconomic analysis should be the individual rather than the household. Within the unitary model, individual preferences of household members are aggregated so that it is not possible to recover the parameters characterising the internal decision-making process that determines observed outcomes. Put more simply, a preference ordering defined at the household level presupposes a common preference among family members or that consensus is reached by the dominance of a benevolent dictator. Family behaviour is described as the outcome of the maximisation of a single utility function subject to a pooled income constraint, implying that family demand for goods, leisure and commodities (such as children) are independent of which individuals in the family receive income or control resources. The reservations advanced by Samuelson (1956) on the empirical validity of the unitary approach have been endorsed in numerous studies (Manser and Brown 1980; McElroy and Horney 1981; Chiappori 1988; Horney and McElroy 1988; Notburga 1992; Del Boca 1997; Perali 1999). 


\section{Antonella Caiumi}

As a consequence, collective models of household behaviour have been developed. These studies describe the household decision-making process as the outcome of a strategic game. Bargaining theory represents the household as a group of individuals, each of whom is characterised by specific preferences, and provides tools to recognise explicitly the existence of several decision-making units. Within this setting, the rules underlying the intrahousehold allocation of individual consumption, time use and welfare can be investigated, as well as issues such as household formation and divorce. This approach relies on a specific class of collective models, namely the cooperative ones, based on the Nash bargaining scheme.

The condition of Pareto-efficient resource allocation is central in the literature on household behaviour, both in the common preferences and bargaining models. That is to say, households will never adopt Pareto-dominated decisions. Chiappori $(1988,1992)$ proposes a more general collective representation of household behaviour than the bargaining ones. Starting from the sole Pareto-efficiency assumption without requiring the choice of a specific bargaining model, the collective model nests the co-operative models and the unitary approach as specific cases, making it possible to derive testable restrictions upon behaviour. Chiappori shows under which conditions it is possible to recover a sharing rule (up to a certain constant) and a pair of individual preferences in the limited case where only one private or assignable product is observed.

In most household surveys, consumption and expenditure data are collected at household rather than individual level, so individual consumption is not observed directly. Moreover, few goods are consumed by only one member of the household. Therefore, most empirical analyses of intra-household allocation models have focused on leisure demand (Chiappori 1992; Browning et al. 1994; Fortin and Lacroix 1997). It has then been shown that the use of exogenous information affecting only the distribution process, but not preferences in the standard collective model, is helpful in improving the identification of the sharing rule (Chiappori et al. 2002). Focusing on labour supply, Blundell et al. (1998) and Donni (2002) analyse decisions (not to) participate in the labour market and the impact of income tax.

While it has been recognised since the work of Becker (1965) that a significant proportion of time not allocated to paid labour supply is spent in producing goods and services within the household, up to now few papers have focused on the implications of including household production on the estimates of intra-household resource allocation. Apps and Rees (1996, 1997) emphasise the importance of incorporating household production in collective models of household behaviour in order to better describe the intra-household resource allocation process and obtain more precise estimates of individuals' responses to policies. They point out that the absence of domestic production leads to misleading results for welfare analysis, especially in households where the allocation of time to domestic activities results from high specialisation of labour between domestic and market pro- 
duction (see also Chapter 3 for a distributional analysis of extended income). On the other hand, they argue that in the collective model with household production, the partial derivatives of the share function can only be recovered completely at the cost of imposing some specific restrictions.

Chiappori (1997) shows that when collective models are extended to include household production of a tradable product, which implies that the price of the domestic product is exogenously determined in an outside market, then previous results hold, namely the sharing rule can be identified up to an additive constant. In the alternative situation considered by Apps and Rees, where households cannot buy or sell domestic products, endogeneity of the household product price to household decisions is crucial. Functionally different parametric structural models may be consistent with the same reduced form, thus revealing a fundamental identification problem giving rise to sharing rules identifiable only up to an additive function of wages.

We often experience situations where the same goods or services produced within the household may also be bought on outside markets. For instance, eating out can substitute for meals prepared at home, household members may choose to do the ironing themselves or hire someone else to do it and so on. On the other hand, there are domestic goods that can be produced only within the household. Examples of household commodities include 'children, prestige and envy, health and pleasure of the senses' (Becker 1965). If the case of a tradable domestic product is likely to prevail. One may test it empirically.

Arosson and colleagues (2001) provide estimates of individual demand for leisure in a collective model with household production based on a model specification derived for the case of a non-tradable domestic product without explicitly modelling the related price. They also consider the case of a marketable household product and the unitary model as nested versions. The evidence drawn from Swedish cross-sectional data in terms of models comparison is not univocal across different years. Even if this attempt empirically to validate the assumption incorporated into the household model is useful, the specification adopted in this chapter does not take into account explicitly the fact that production and consumption in the household model cannot be separated when there are missing markets. It follows that household decisions cannot be modelled recursively as in the case of a marketable domestic product, and the decentralised solution of the collective model should be redefined accordingly.

While recently empirical studies have shown the advantages offered by the collective approach in evaluating the economic effect of public policies, ${ }^{2}$ it is to be hoped that further research efforts are made to address the issues involved in modelling household decisions including domestic production. None the less, significant progress in the identification of the share function is connected unavoidably with the availability of survey data on individual consumption of market and non-market goods and time use, even in stylised form (Perali 2002a). 


\section{Antonella Caiumi}

\section{$4 \ldots$ and children}

Further extensions of the collective approach should examine modelling family decisions concerning children to analyse the linkage between labour supply, fertility and consumption. Applying the tools of household production, Picard and Ekert-Jaffe (2002) consider children as goods both produced and publicly consumed by household members, and they explore the consequences implied by the non-separability of the production and consumption sides of the model on the Pareto-optimal solution of the collective framework.

Another promising field concerns the reconciliation of the literature on the collective analysis of household behaviour with the literature on equivalence scales measurement, in line with Phipps' exhortation (1997). Traditionally, equivalence scales measure the income or expenditure adjustment required to perform interpersonal welfare comparisons across households on the assumption that everyone in the household shares the same level of welfare. 'However, there are cases in which such an assumption would clearly be inappropriate' (Deaton and Muellbauer 1986). Several studies have shown that unequal distribution of resources within the household - between men and women, between adults and children and so on can increase inequality (Haddad and Kanbur 1990; Lazear and Michael 1988; Borooah and McKee 1994; Davies and Joshi 1994; Woolley and Marshall 1994). Inequality measurement among individuals requires converting household well-being into individual well-being. This may involve two measurement adjustments: an adjustment for economies of scale across households of different size, and an adjustment for the distribution of resources that occurs within the household (Johnson 1998). Indices of intrahousehold inequality resulting from the household bargaining process may be considered as household attributes directly affecting the measurement of the scales and enhancing the informational basis on which inter-household comparisons are made (Perali 2002b). This kind of information would also be useful in designing an optimal in-kind benefit. Taking account of who exactly in the household receives the benefits is essential, for instance, to target income support for children. Clearly, the provision would be meaningless if the increase in family disposable income were followed by a reduction in the child's share of resources.

While intra-household inequality cannot be inferred directly on the basis of the available household expenditure surveys, the collective approach developed through the works of Bourguignon et al. (1993), Browning et al. (1994) and Browning and Chiappori (1998) offers a tool to estimate the sharing rule within the household in quite general situations, namely without requiring the notion of private goods, on the basis of observations of aggregate household consumption behaviour and bargaining power of household members, as well as to recover individual utility functions. The underlying idea is that observing an exclusive product enables something to 
be inferred about the allocation of consumption among family members. Analogously, observing how the aggregate consumption of goods depends on the various income sources in the household is sufficient to identify the share of the budget allocated to household members up to a certain constant.

One of the main advantages of this approach consists in the possibility of evaluating how intra-household distribution of welfare varies in relation to any variable that may affect the decision-making process and the bargaining power of each household member, such as his or her wage or non-labour income, regulation of minimum wages, legislation on divorce, the marriage market and so on. For instance, a change in the minimum wage is likely to modify the threat point of non-working spouses according to the bargaining theory, which in turn would affect the amount of income shared with the partner. Accordingly, any variable that is correlated positively with the bargaining power of one spouse should have a positive effect on his or her own share, while negative effects should result from any increase in the partner's threat point.

It is even more important to explore the possibility that the collective approach provides an alternative to traditional equivalence scales methods for interpersonal welfare comparisons. The individual utility function may be recovered from the representation of the process of intra-household allocation of goods and services, thus making it possible to derive welfare functions at the level of every individual in the family based on what each individual actually receives. By splitting the household expenditure into costs attributable, for instance, to adults and children separately would allow one to compute a measure of the standard of living of the adults based on the adults' expenditure level and the compensation needed to restore the pre-child utility level, as advocated by Deaton and Muellbauer (1986).

Bourguignon (1999) investigates extensions of earlier work (Bourguignon et al. 1993; Browning et al. 1994) which make it possible to identify a twodimensional sharing rule, by distinguishing the resources allocated to children from those shared between husband and wife. In contrast to conventional methods, this approach avoids the need to rely on any comparability assumption of family behaviour among households of different composition - say, demographic separability - so that the associated measures of the cost of children can be derived under less restrictive assumptions. None the less, it is worth mentioning several limitations. First, Bourguignon considers children as a household public product, and therefore with no decision-making power, while the intra-household allocation game is played by only the two parents. This assumption seems reasonable until the child grows older and can choose to leave his family. Thus the challenging issue remains to extend the collective framework to admit several decisionmaking units beyond the couple, so that households may be followed through the life cycle. This will be helpful also in disentangling intergenerational issues, allowing dynamic models of generational accounts to be developed. Second, this approach allows one to analyse the allocation of 


\section{Antonella Caiumi}

resources among family members only in terms of differentials rather than in absolute terms, since the sharing rule can be identified only up to a constant. Identifying fully the sharing rule requires resorting to arbitrary allocation for some reference couple. Third, this chapter disregards costs associated with parents' time spent in childcare and other domestic activities, and so is subject to the shortcomings highlighted in Section 3.

A different attempt to reconcile the literature on decision-making units within the family and the literature on the estimation of equivalence scales is suggested by Caiumi and Perali (1999). Borrowing from the literature on modifying functions used to incorporate demographic or other exogenous effects into demand systems and from studies estimating household technologies (Bollino et al. 2000), they specify a gender-specific demand system incorporating a sharing rule in structural form $^{3}$ with the aim of learning about the intra-household distribution process of goods and time, including household production. The main purpose of this study is not to perform interpersonal comparisons, but rather to illustrate how the presence of children affects the allocation of time and other resources within the household, and to examine the implications related to the estimation of the cost of children on the basis of a collective model that considers full-time labour supply as endogenous. In particular, this chapter provides measures of the extent to which the full cost of a child is shared between the mother and father. An analogous perspective is adopted in the analysis developed by Apps and Rees (2001) to derive the intra-household distribution of resources and implied child-rearing costs.

The paper by Caiumi and Perali (1999) draws statistical data from the matched data-set on individual earnings and time use described in Chapter 3, so it is worth summarising the main results of this chapter after a brief discussion of the model's specification. Individual utility functions are defined for leisure, a composite domestic product and a composite market product, and are maximised with respect to an individual budget constraint. The allocation process depends on individual market wages and non-labour income. The model specification requires an a priori assumption about the sharing of market and domestic goods between the partners since information on individuals is lacking. This implies that estimates of both preferences and the sharing rule may be driven by priors. Specifically, assuming that a large share of both goods is public and accessible to both members without restrictions, individual budget shares are computed imposing that both composite market and domestic goods are assigned fairly between the couple. It follows that the inference on the sharing rule (up to a constant) relies on observations of leisure demand and how the combination of market and domestic goods varies in relation to different income sources of the household. Provided that the assumption mentioned above is not too far from reality, the authors argue that estimating a joint system of equations is more informative than a single equation approach based on a private product, since it takes into account the full set of constraints faced by the consumer. 
When we look at demand elasticities, in double-earner households the husband's behaviour is not affected by the presence of children, while the wife reacts by becoming significantly unresponsive to wage changes. This suggests that when a child is born, a woman in a non-traditional household spends more time in the home, while the husband's time allocation remains almost unchanged. Furthermore, estimates of the share function suggest that in double-earner families an increase in each member's labour income is not shared with the spouse, while an increase in non-labour income raises the transfer to the other partner. The presence of children seems to motivate transfers from the husband to the wife. By contrast, single-earner households behave in a more altruistic manner. For both household types, at lower income levels the actual and predicted values of the male share of total income show a more egalitarian distribution as a result of a more equal distribution of power. The patterns of relative contributions to the full cost of a child are only slightly affected by the different organisation in traditional and non-traditional households. In both situations, the parental investment in household production is supported mainly by the mother at the expense of the consumption of leisure, especially when the child is very young.

\section{Conclusions}

In this chapter we show that equivalence scales change significantly, especially for young children when household commodities are taken into account. Although the importance of incorporating household production into models of household analysis has been recognised, there are still few studies that address this issue.

Further progress should be made to redefine equivalence scales more correctly in terms of individual welfare instead of household welfare. Distributional analyses, such as the one described in Chapter 3, could then benefit from a better inequality assessment by gender.

As suggested also by others (Apps and Rees 1997), we emphasise that significant improvement in empirical application requires household consumption data to be collected jointly with information on time use and on individual consumption of market and domestic goods. Stylised time use information is very effective and may be added to household surveys at very low administrative cost. 


\section{Antonella Caiumi}

\section{Appendix Descriptive statistics}

Table 4A.1 Descriptive statistics

\begin{tabular}{|c|c|c|c|c|c|}
\hline \multirow[b]{2}{*}{ Obs. } & \multicolumn{5}{|c|}{ Housebold types } \\
\hline & $\begin{array}{l}\text { Single } \\
(3,014)\end{array}$ & $\begin{array}{l}\text { Couple, } \\
\text { O children } \\
(2,818)\end{array}$ & $\begin{array}{l}\text { Couple, } \\
1 \text { child } \\
(3,174)\end{array}$ & $\begin{array}{l}\text { Couple, } \\
2 \text { children } \\
(3,291)\end{array}$ & $\begin{array}{l}\text { All } \\
\text { families } \\
(19,947)\end{array}$ \\
\hline Food & 0.29 & 0.31 & 0.32 & 0.35 & 0.33 \\
\hline Clothing & 0.09 & 0.09 & 0.09 & 0.09 & 0.09 \\
\hline Transportation & 0.24 & 0.26 & 0.27 & 0.25 & 0.25 \\
\hline Recreation & 0.27 & 0.23 & 0.22 & 0.21 & 0.23 \\
\hline Personal care & 0.11 & 0.11 & 0.10 & 0.10 & 0.10 \\
\hline \multicolumn{6}{|c|}{ Extended consumption (average shares) } \\
\hline & \multicolumn{5}{|c|}{ Housebold types } \\
\hline Obs. & $\begin{array}{l}\text { Single } \\
(3,014)\end{array}$ & $\begin{array}{l}\text { Couple, } \\
\text { O children } \\
(2,818)\end{array}$ & $\begin{array}{l}\text { Couple, } \\
1 \text { child } \\
(3,174)\end{array}$ & $\begin{array}{l}\text { Couple, } \\
2 \text { children } \\
(3,291)\end{array}$ & $\begin{array}{l}\text { All } \\
\text { families } \\
(19,947)\end{array}$ \\
\hline Food & 0.20 & 0.16 & 0.16 & 0.18 & 0.18 \\
\hline Household production & 0.27 & 0.46 & 0.47 & 0.46 & 0.42 \\
\hline Clothing & 0.07 & 0.05 & 0.05 & 0.05 & 0.05 \\
\hline Transportation & 0.18 & 0.14 & 0.14 & 0.14 & 0.15 \\
\hline Recreation & 0.20 & 0.13 & 0.12 & 0.12 & 0.14 \\
\hline Personal care & 0.08 & 0.06 & 0.06 & 0.05 & 0.06 \\
\hline
\end{tabular}

Source: Author's calculations based on ISTAT Consumption Survey (1995) matched with ISTAT Indagine Multiscopo (1989).

\section{Acknowledgements}

I wish to thank S.P. Jenkins and F. Perali for helpful comments on an earlier version of this chapter.

\section{Notes}

1 For an application to Italian data, see Perali (1999).

2 In particular, empirical evidence of the distortions produced in the analysis of a tax reform based on traditional household models instead of collective models is already available for several European countries (Berninger et al. 2001; Chiuri and Longobardi 2002).

3 Similar to sharing rules, demographic functions are not observable. However, when demographically modifying functions interact with exogenous prices or income, it is possible to identify the demographic parameters of interest provided that there is 
sufficient information on the data. Analogously, in order to achieve identification from a structural specification, the sharing rule interacts with individual incomes. This approach, when practicable, is simpler than a reduced form approach such as the one carried out by Chiappori et al. (2002).

\section{References}

Apps, P.F. and Rees, R. (1996) 'Labor supply, household production and intra-family welfare distribution', Journal of Public Economics, 60: 199-219.

- (1997) 'Collective labor supply and household production', Journal of Political Economy, 105: 178-90.

- (2001) 'Household production, full consumption and the costs of children', Labor Economics, 242: 8(6), 621-48.

Arosson, T., Dounfeld, A.O. and Wikstrom, M. (2001) 'Estimating intrahoushold allocation in a collective model with household production', Journal of Population Economics, 14: 569-84.

Becker, G. (1965) 'A theory of the allocation of time', Economic Journal, 75: 493-517.

Berninger D., Laisney, F. and Beblo, M. (2001) 'Welfare analysis of fiscal reforms in Europe: does the representation of family decision processes matter? Evidence from Germany', Mannheim: ZEW (mimeo).

Blackorby, C. and Donaldson, D. (1993) 'Adult equivalence scales and the economic implementation of interpersonal comparisons of well-being', Social Choice and Welfare, 10: 335-61.

Blundell, R. (1998) 'Equivalence scales and household welfare: what can be learned from household budget data?', in S.P. Jenkins, A. Kapteyn and B.M.S. Van Praag (eds) The Distribution of Welfare and Household Production, Cambridge: Cambridge University Press, pp. 364-80.

Blundell, R. and Lewbel, A. (1991) 'The information content of equivalence scales', Journal of Econometrics, 150: 49-68.

Blundell, R., Chiappori, P.A., Magnac, T. and Meghir, C. (1998) 'Collective labor supply: heterogeneity and nonparticipation', London: Institute for Fiscal Studies (mimeo).

Bollino, A., Perali, F. and Rossi, N. (2000) 'Linear household technologies', Journal of Applied Econometrics, 15: 275-87.

Borooah, V.K. and McKee, P.M. (1994) 'Intra-household income transfers and implications for poverty and inequalities in the U.K.', in J. Creedy (ed.) Taxation, Poverty and Income Distribution, Aldershot: Edward Elgar, pp. 69-86.

Bourguignon, F. (1999) 'The cost of children: may the collective approach to household behavior help?', Journal of Population Economics, 12: 503-21.

Bourguignon, F., Browning, M. and Chiappori, P.A. (1995) 'The collective approach to household behavior', Working Paper 95-04, Paris: DELTA.

Bourguignon, F., Browning, M., Chiappori, P.A. and Lechene, V. (1993) 'Intrahousehold allocation of consumption: a model and some evidence from French data', Annales d'Economie et de Statistiques, 29: 137-56.

Browning, M. and Chiappori, P.A. (1998) 'Efficient intrahousehold allocations: a general characterization and empirical tests', Econometrica, 66: 1241-78.

Browning, M., Bourguignon, F., Chiappori, P.A. and Lechene, V. (1994) 'Income and outcomes: a structural model of intrahousehold allocation', Journal of Political Economy, 102: 1067-96. 


\section{Antonella Caiumi}

Caiumi, A. and Perali, F. (1999) 'Children and intrahousehold distribution of resources: an estimate of the sharing rule of Italian households', CHILD Working Papers, no. 2, $<$ http://www.child-centre.it >.

Chiappori, P.A. (1988) 'Rational household labor supply', Econometrica, 56: 63-90.

- (1992) 'Collective labor supply and welfare', Journal of Political Economy, 100: 437-67.

- (1997) 'Introducing household production in collective models of labor supply', Journal of Political Economy, 105: 191-209.

Chiappori, P.A., Fortin, B. and Lacroix, G. (2002) 'Household labor supply, sharing rule and the marriage market', Journal of Political Economy (forthcoming).

Chiuri, M.E. and Longobardi, E. (2002) 'Welfare analysis of fiscal reforms in Europe: does the representation of family decision processes matter? Evidence from Italy', CHILD Working Papers, no. 3,< http://www.child-centre.it $>$.

Cigno, A. (1996) 'Cost of children, parental decisions and family policy', Labor, 10: 461-74.

Davies, H. and Joshi, H. (1994) 'Sex, sharing and the distribution of income', Journal of Social Policy, 23: 301-40.

Deaton, A.S. and Muellbauer, J. (1986) 'On measuring child costs: with applications to poor countries', Journal of Political Economy, 94: 720-44.

Del Boca, D. (1997) 'Intra-household distribution in families with and without children', in I. Persson and C. Jonung (eds) The Economics of the Family, London: Routledge.

Donni, O. (2003) 'Collective household labor supply: nonparticipation and income taxation', Journal of Public Economics, forthcoming.

Fortin, B. and Lacroix, G. (1997) 'A test of the unitary and collective models of household labor supply', Economic Journal, 107: 33-55.

Haddad, L. and Kanbur, R. (1990) 'How serious is the neglect of intra-household inequality?', Economic Journal, 100: 866-81.

Hardle, W. (1990) Applied Nonparametric Regression, Cambridge: Cambridge University Press.

Horney, M.J. and McElroy, M.B. (1988) 'The household allocation problem: empirical results from a bargaining model', Research in Population Economics, 6: 15-38.

Johnson, D. (1998) 'Equivalence scales and the distribution of well-being across and within households', in S.P. Jenkins, A. Kapteyn and B.M.S. Van Praag (eds) The Distribution of Welfare and Household Production, Cambridge: Cambridge University Press.

Lazear, E. and Michael, R. (1988) Allocation of Income Within the Housebold, Chicago, IL, and London: University of Chicago Press.

Leser, C. (1963) 'Forms of Engel functions', Econometrica, 31: 694-703.

Lewbel, A. (1989) 'Household equivalence scales and welfare comparisons', Journal of Public Economics, 39: 377-91.

McElroy, M.B. and Horney, M.J. (1981) 'Nash bargained household decisions: toward a generalization of the theory of demand', International Economic Review, 22: 333-49.

Manser, M. and Brown, M. (1980) 'Marriage and household decision making: a bargaining analysis', International Economic Review, 21: 31-45.

Notburga, O. (1992) Intrafamily Bargaining and Household Decisions, Berlin: SpringerVerlag.

Perali, F. (1999) 'An econometric comparison of household models: full income, gender and labor issues of a sample of Italian farm-households', University of Verona (mimeo). 
(2002a) 'Basing typologies on farm and household behavior: the ISMEA experience', University of Verona, paper presented at the International Workshop on 'The Farm-Household Firm Unit: Its Importance in Agriculture and Implications for Statistics', Imperial College, University of London, Wye, 12-13 April.

(2002b) 'The behavioral and welfare analysis of consumption', $<$ http://pilar.univr.it/personal_homepage/book.html>.

Phipps, S.H. (1997) 'What is the income "cost of a child"? Exact equivalence scales for Canadian two parent family', The Review of Economics and Statistics, 80: 157-64.

Picard, N. and Ekert-Jaffe, O. (2002) 'Children in a collective framework: public good and household production', paper presented at the International Workshop on 'Consumption Behaviour and Welfare Measurement at the Individual and Household Level', University of Verona, 15-16 March.

Pollak, R.A. and Wales, T.J. (1979) 'Welfare comparisons and equivalence scales', American Economic Review, 69: 216-21.

Samuelson, P.A. (1956) 'Social indifference curve', Quarterly Journal of Economics, 10: $1-22$.

Woolley, F.R. and Marshall, J. (1994) 'Measuring inequality within the household', Review of Income and Wealth, 40: 415-31.

Working, H. (1943) 'Statistical laws of family expenditure', Journal of the American Statistical Association, 38: 43-56. 


\title{
5 Unpaid work and household well-being
}

\author{
A non-monetary assessment
}

Enrica Chiappero-Martinetti

\section{Introduction}

The increasing attention devoted to unpaid work is concentrated mainly on the economic role it plays in the process of income production and wealth. Some of the main issues debated during recent years in many international conferences are: how, and if, unpaid work can be measured; how, and if, it can be valued and included in the systems of national accounts (SNA); and how the unpaid provision of care relates both to the market and to the state, affecting women's economic position. There are no unique and unquestionable solutions to these issues; different approaches have been suggested on how domestic work may be measured and evaluated, and the results in terms of its monetary value are strongly dependent on the chosen method. However, there is a general consensus that if non-market work was included in SNA a totally different picture would emerge. ${ }^{1}$

The monetary evaluation of unpaid work represents an essential step towards a broader assessment of economic well-being and is also the main aim of this book; but other useful perspectives may be undertaken to complement this point of view. To bring out the centrality of care work in every society requires enlarging the analysis and including those effects on personal well-being that cannot (or must not necessarily) be converted into monetary terms. The possibility of receiving care, assistance and support for practical as well as for psychological and emotional needs is one of the most important ways to achieve personal well-being, yet most of these social reproduction activities are not adequately supplied by the private or public sectors. Moreover, these activities, which take up a large amount of time and energy, are traditionally distributed unevenly between men and women with inescapable consequences for the well-being of whoever provides and whoever benefits from this care work.

The aim of this chapter is to complement the general goal of this book by investigating, from a gender point of view, the relationship between unpaid work and well-being, the latter conceived as a multidimensional and complex concept described in Sen's capability approach. First, I shall debate some theoretical issues related to this relationship and focus on how house- 
hold production, and therefore social reproduction activities, may be conceived of within this framework. Second, I shall present the main results of an empirical analysis that draws on ISTAT micro-data with the aim of answering the following questions: (1) Is there a gender inequality in the multidimensional well-being distribution? (2) Is there a gender inequality in the use of time? and (3) Is there a relationship between these two potential sources of gender inequality?

Section 1 shows how the process of 'well-being production' that occurs within the family and the relationship between unpaid work and well-being can be depicted in general terms and, in particular, through the adoption of Sen's capability framework. Section 2 describes both the methodological approach followed here and the data-set employed for the multidimensional assessment of well-being, while Section 3 presents the main empirical results obtained. The final two sections are devoted to describing how paid and unpaid work are distributed between men and women in Italy (Section 4) and to trying to define what kind of relationship may be deduced between individual well-being and unpaid work from this empirical analysis (Section 5). Some concluding remarks will follow.

\section{Some theoretical issues about the relationship between unpaid work and well-being}

The mainstream approach to welfare economics defines the individual's wellbeing in terms of available income and/or the value of the consumption to which he or she has access. The supremacy of the material dimension of well-being as the only evaluation space in which to judge standard of living, inequality and poverty has been seriously questioned in the past two decades. Among the authors who contributed to this debate a prominent role has been played by Amartya Sen (1987, 1992, 1997, 1999), who has associated a well-argued criticism of the utilitarian theory and its interpretive limits with an innovative, persuasive 'way of thinking' that leads to a broader concept of well-being. To limit one's attention to the total amount of economic resources available can lead to a partial and unsatisfying picture of an individual's standard of living. Incomes and commodities reflect the material dimension of well-being, and their influence on what people can or cannot do is crucial: however, they represent means and not ultimate goals for human life. Amartya Sen's proposal is to shift the attention towards a broader space that includes 'the substantive freedoms - the capabilities - to choose a life one has reason to value' (Sen 1999: 74).

Figure 5.1 summarises the process of well-being as conceived of in the capability approach and outlines some of the main explanatory factors that, at three different levels (individual, household and society in a broad sense), can affect the process of converting resources into capabilities and achieved functionings. A person's standard of living should be assessed on the basis of this broader scheme of well-being. 


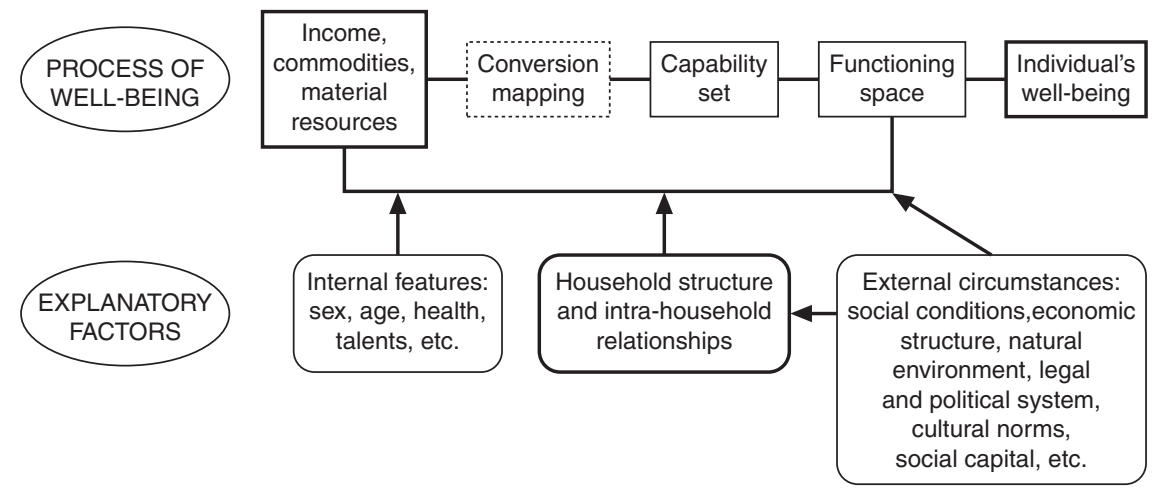

Figure 5.1 From resources to individual well-being in the capability approach.

The capability space reflects the individual's real freedom to pursue her ends, to do (or be) things that she has reason to value. These valuable things may vary from basic aspects of human life (such as being adequately nourished, enjoying a good state of health, avoiding disease, having adequate housing and having access to all levels of education) to other personal states such as taking part in social life, fulfilling one's own goals and aims, and using to their full the talents and abilities which everyone has. The possibility for the individual to accomplish these functions depends on the availability of economic resources, but also on the person's own ability to convert commodities and resources into functions and results, through what can be defined as a 'conversion mapping'. The extension of the capability set is, in its turn, linked to a variety of personal characteristics, such as age, sex, state of health, abilities and talents, but it is also positively and negatively influenced by external circumstances, including the structure and characteristics of the family, the socio-economic environment in which individuals and families are located, the social and cultural norms, the availability of social services, access to public supports and benefits and so on.

But how can unpaid work and social reproduction activities be included within this scheme? What are the costs and benefits of unpaid work in terms of well-being for whoever provides it and benefits from it, respectively?

Before discussing these issues I want briefly to describe, with diagrams, the various phases that constitute the intra-household production and distribution process, with the aim of comparing how domestic work is conceived in the new home economics and how it can be included in the capability framework.

Some general observations can be made with reference to Figure 5.2:

1 The standard approach to welfare analysis, which focuses on the income and commodities space and assumes a direct and unambiguous relation- 


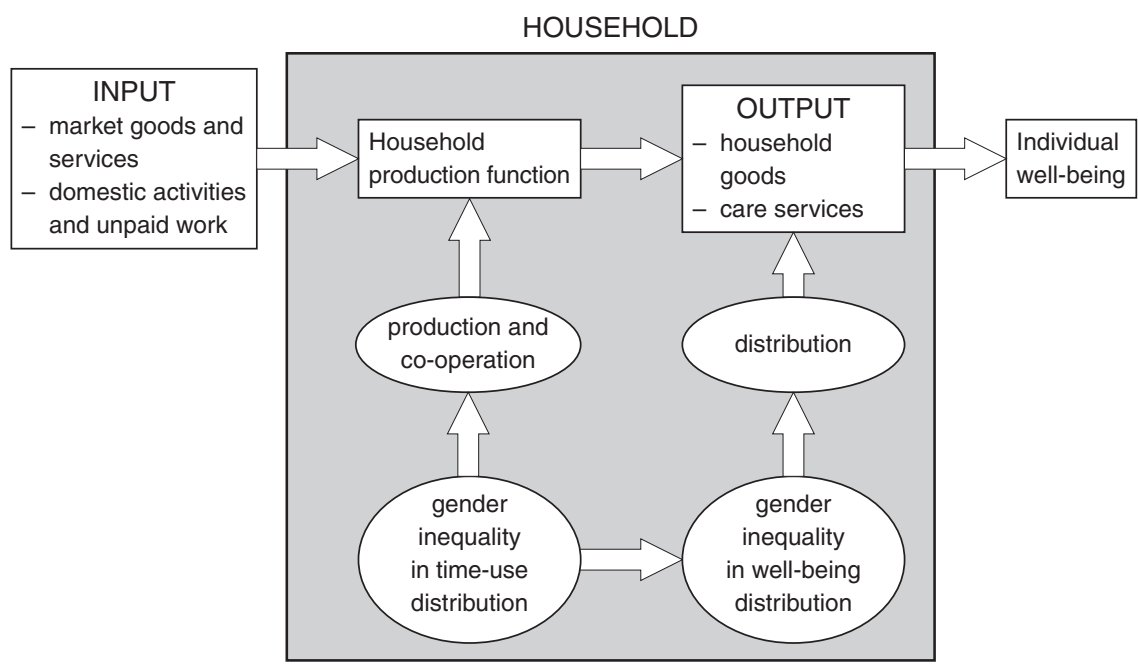

Figure 5.2 Household production process, individual well-being and gender inequalities.

ship between the amount of available economic resources and individual well-being, ${ }^{2}$ undervalues the aggregate welfare. The passage from the initial stage (market goods and services) to the final stage of this process (individual well-being) creates added value in society, so that social well-being is greater than the value of the available goods purchased on the market. It is the households, through social reproduction activities, that generate most of this added value but this is not taken into account.

2 As outlined by Ringen (1996), between the initial and final phase, there are intermediate stages that involve intra-household production, cooperation and distribution activities. The process of household production transforms raw materials (purchased goods, available services) and (unpaid) labour into household goods and services (i.e. caring, cooking, cleaning, maintenance) that are consumed by household members. Through co-operation the family takes advantage of the economies of scales and generates 'public family goods', i.e. goods (such as house, telephone, many durable goods) that do not have an exclusive and rival consumption but that can be used jointly by all the components. Finally, the distribution phase concerns the way in which goods and services are allocated among household members in relation to each individual's needs or following some other distributive rule. While the production process involves all types of household, the co-operation and distribution phases play a role only in multi-person households.

3 The way in which production and co-operation operate is linked to 


\section{Enrica Chiappero-Martinetti}

questions of efficiency and depends on the size, composition and behaviour of the household. Families who are more efficient in combining work, time and goods bought on the market produce more, and this outcome is substantially dependent on the quantity as well as the quality of the social reproduction activities. Larger families or those better at collaborating may be more efficient in producing added value and consequently the household welfare level will be higher; by contrast, unco-operative behaviour within a household can negatively affect production and consumption efficiency.

4 If production and co-operation relate mainly to efficiency, then distribution concerns equity. How needs are satisfied and well-being is allocated within the family is not easy to observe, and strong presumptive assumptions are usually made. The most frequent assumption is that intra-household distribution is, by definition, fair and all the components are able to satisfy their own needs to the same extent or proportion. This means accepting implicitly another hypothesis: either this egalitarian result is due to the presence of a head of the family who, in some way, represents a kind of 'non-despotic dictator' in that he or she chooses and distributes according to his or her own preferences, which one assumes respect individual needs; or it is the result of a real democratic process of choice that occurs within the family. However, it has been argued by many authors that neither of the hypotheses may be plausible, especially in those socio-economic contexts in which discrimination and inequality are the rule. ${ }^{3}$

5 But there is another space where distributive issues are important and this concerns the way in which time use and domestic work are distributed within the family, and how gender inequalities in this space can affect household efficiency and individual well-being. The questions are: Does a higher (lower) inequality in the distribution of unpaid work imply more (less) efficiency in terms of household production? What are the consequences of a gender inequality in the use of time on individual well-being? As we shall see below, the answers may be controversial and depend on how well-being is conceived and how its production process is postulated.

The research programme formulated by the new home economics in the early 1960s, which started with Gary Becker's seminal contribution, represents the first and most famous attempt to deal with household decisions in many fields of human life; analysing productive, co-operative and distributive questions within the family, stressing the role of unpaid work. ${ }^{4}$ The Becker approach has received wide and justified support, but several aspects of this research programme have also been strongly criticised. Namely: (1) the mainstream assumptions of rationality and maximising behaviour seem to be even more 'heroic' when applied to household decisions; (2) the decision-making process that occurs within the family is undefined or inade- 
quate to depict conflict and interdependence relationships; and, (3) more important for our aims, the way in which care work and domestic activities are taken into account can be criticised. First, in the Becker model the economic value of unpaid work is expressed in terms of opportunity cost and represents a sort of lost opportunity of participating in the labour market; but in this way it is depicted as a residual and second-best choice. Second, if the allocation of time depends on the real wage in the labour market, a low real wage rate reduces the opportunity cost of unpaid work and its economic value. Third, individuals who are relatively more 'efficient' in market activities - that is, they have a higher wage rate and or/more opportunities - will devote less time to domestic activities; but in this way, the unequal distribution of unpaid work will add to the traditional gender inequality in the labour market.

The holistic perspective suggested by Sen can offer fruitful possibilities for understanding more about the role of social reproduction activities and does not suffer from the limits that characterised the Beckerian approach. As we have already seen, in Sen's scheme the relationship between goods and well-being is not direct and immediate either, but proceeds through intermediate stages, and once again the role the family plays within this process is crucial. However, compared to Becker's household production model there are some radical changes: (1) the meaning of well-being is much broader in the capability approach and not just materialistic; (2) the relationship between means (e.g. goods and services supplied to the market or produced by the household) and ends (i.e. well-being). In this case, too, Sen's scheme is much more complex and complete, and includes the capability to convert the available resources into constitutive elements of wellbeing.

With reference to Figure 5.2, if we neglect fundamental aspects such as internal features and external circumstances and focus our attention only on the links between the bold blocks depicted in Figure 5.1, it is easy to see that social reproduction activities play an important role at three different levels:

1 They affect significantly, and in some cases contribute directly to, the determination of personal capabilities. This is quite obvious for many dimensions of human life such as education and health; but, generally speaking, the family environment is a fundamental source for the development of individual capabilities and for the attainment of psychological and physical well-being. ${ }^{5}$

2 They make it possible to realise most of the fundamental functionings of human life previously referred to: to nourish, dress and educate oneself but also to enjoy an independent life, to avoid disease and to participate in social life - all functions that are based substantially on the contribution of unpaid work.

3 They compensate for conditions of disadvantage and restrictions on 


\section{Enrica Chiappero-Martinetti}

capabilities for which there are no or only partial solutions. This refers in particular to people who have some handicap or suffer from poor health and who find the primary and sometimes unique answer to their needs within the family.

From this point of view, restricting the evaluation of the economic weight of unpaid work would perhaps risk leaving in the shadows what it really means at an individual, household and social level. This is particularly evident for the weaker members of the family - children, the elderly, the sick - for whom the absence of these activities would mean not achieving most of the fundamental functions, but it is equally true for the adult, 'stronger' component: in many societies, and certainly in Italy, the greater career opportunities for men, and therefore the different possibilities to achieve professional and personal goals, are often a consequence of an unequal distribution of domestic roles and activities within the family.

These issues, and in particular the gender inequalities in the distribution of the use of time and well-being, are the main topic of the following sections.

\section{The empirical analysis: aims, data-set and methodology}

The empirical analysis carried out in this part of the chapter is drawn from micro-data taken from a large national survey on daily household life conducted in 1994 by the Italian Statistical Office (hereafter ISTAT). ${ }^{6}$ This survey records a large amount of information (more than 350 relevant variables) on a sample of over 61,000 individuals corresponding to 21,000 households. It collects information about housing, education, employment, health, social life, opinions on many aspects of daily life as well as the weekly amount of unpaid and paid activities carried out by each member of the household.

The features of this data-set have enabled the interpretive richness of Sen's approach to be preserved to a large extent, in spite of unavoidable compromises between theoretical prescriptions and constraints faced in terms of available data. Thus, for example, I focused my attention on the achieved functionings space instead of on the capability set, for although this latter may seem more suitable for a well-being analysis, it is also more difficult to assess. The choice of the functionings is based on similar grounds. Five dimensions of well-being are included in this empirical analysis: housing conditions, health, education and knowledge, social interaction and psychological state. This choice is in line with current literature regarding the aspects of human life that should not be left out of a well-being analysis and, as such, can be considered sufficiently exhaustive. ${ }^{7}$ Corresponding to these five well-being dimensions there is a broad spectrum of elementary indicators, principally qualitative, sometimes dichotomous but more often distributed on an ordinal scale (see Appendix 5A for a more detailed list of the indicators used). 
Let us look briefly at what these indicators comprise. Housing conditions (the only material dimension of well-being considered here) is the synthesis of two elementary indicators: the first is a crowding index calculated by dividing the number of rooms available to the family by an equivalence coefficient that takes into account the economies of scale. ${ }^{8}$ The second refers to several essential aspects of living standards such as the availability of a telephone, water and adequate heating.

Health is covered by a single indicator which refers to chronic diseases; the diseases are ranked on the basis of seriousness and the restrictions they impose on a person's ability to lead a completely independent life. ${ }^{9}$ For the 'education and knowledge' functioning three variables are included relating to the level of education reached and the frequency with which books are read per year and newspapers per week.

Social interactions are measured by clusters of indicators which refer to the frequency of meeting friends and participation in social and political life. For the latter category a distinction was made between 'passive' and 'active' participation. The former, represented by a group of eight variables, is linked to the frequency with which someone participates in political, cultural and associative manifestations and events. The latter assumes instead a more direct form of participation, for example, through active membership, registration or the carrying out of activities within associative bodies, parties, unions and voluntary organisations. ${ }^{10}$ There is also a social participation indicator relating to the level of interest in political matters shown by those interviewed.

The latter refers to the psychological state and is described through a large number of indicators that express levels of satisfaction in several personal spheres: from economic conditions to personal and social relationships, from state of health to working conditions and leisure time. Some of these overlap with other dimensions (for example, those relating to health and social relationships) and in this sense they might appear redundant. However, it seemed interesting to place the objective and subjective spheres side by side since the concept of 'well-being' in the sense of being happy, having respect for oneself and satisfying one's desires plays an important role. $^{11}$

The ISTAT survey does not contain information about income or individual and family wealth, although it does consider several variables linked to consumer habits (i.e. eating and drinking habits as well as leisure time activities). However, for the purposes of this analysis, the exclusion of any monetary dimension cannot be considered a limit, since income, wealth and available resources play only an indirect role in the assessment of well-being. An inadequate level of income can certainly help to explain why, among other factors, a given functioning (for example, housing or education) is not fully achieved, but there are no particular reasons why they must be directly included in the evaluation space. The information regarding consumer habits could have been interesting for our purpose, but the impossibility of 
distinguishing the role of constraints and preferences in the observed consumption led us to omit these variables. ${ }^{12}$

The methodological tool used here is based on fuzzy set theory, which seems particularly suitable for capturing and describing the complexity associated with the capability approach. ${ }^{13}$ In brief, fuzzy set theory replaces the characteristic function of a crisp set that assigns a value of either 1 or 0 to each element in the universal set (with a clear distinction between full membership or non-membership) with a generalised characteristic function (called membership function) that varies uniformly between 0 and 1: larger values denote higher degrees of membership. Membership functions can vary from the simplest linear functions to other, more complex functions; they can either be chosen in an arbitrary way or based on empirical evidence to avoid a priori choices and to connect the analytical description to the observed reality. In this chapter I have tried to use the latter solution whenever possible (see Appendices 5B and 5C for more details on the fuzzy methodology and the way in which it has been applied).

\section{Gender inequality in multidimensional well-being}

Tables 5.1 and 5.2 show the average values of the membership degrees for the whole sample with reference to the fifteen elementary indicators and the five functionings considered, respectively. The interpretation of these indices is very simple: low values of membership degrees are a clear sign of disadvantage or of difficulty in achieving a satisfying standard of living while values close to 1 define the almost full realisation of these goals.

With reference to Table 5.1, two general remarks may be made: (1) for the total of the sample units ${ }^{14}$ high average values are registered with reference to some indicators of material life, such as the availability of essential living services $\mu_{12}$ (the average membership degree is around 0,900) and the health indicator $\mu_{21}$ (a little less than 0,800 ) as well as for some aspects of the psychological dimensions such as level of satisfaction linked to health status (this seems fairly obvious), and personal and social relationships; (2) on the other hand, the membership degrees relating to knowledge in a broad sense (in particular as regards reading) as well as to forms of participation in social life are much lower.

The distinction by population groups allows the differences to be highlighted. The values are systematically below the average for women, with the one significant exception of the indicator $\mu_{32}$ which concerns reading books. Very low levels are also recorded for the older subjects, not only with regard to health, as one would expect, but also to education and knowledge, participation and social relations. A relative disadvantage is shown for the regions of the South and the Islands as regards the housing and essential living standards indicators, as well as for education and knowledge. However, this disadvantage is not present for the indicators referring to health, social interaction and psychological state. Predictable indications 


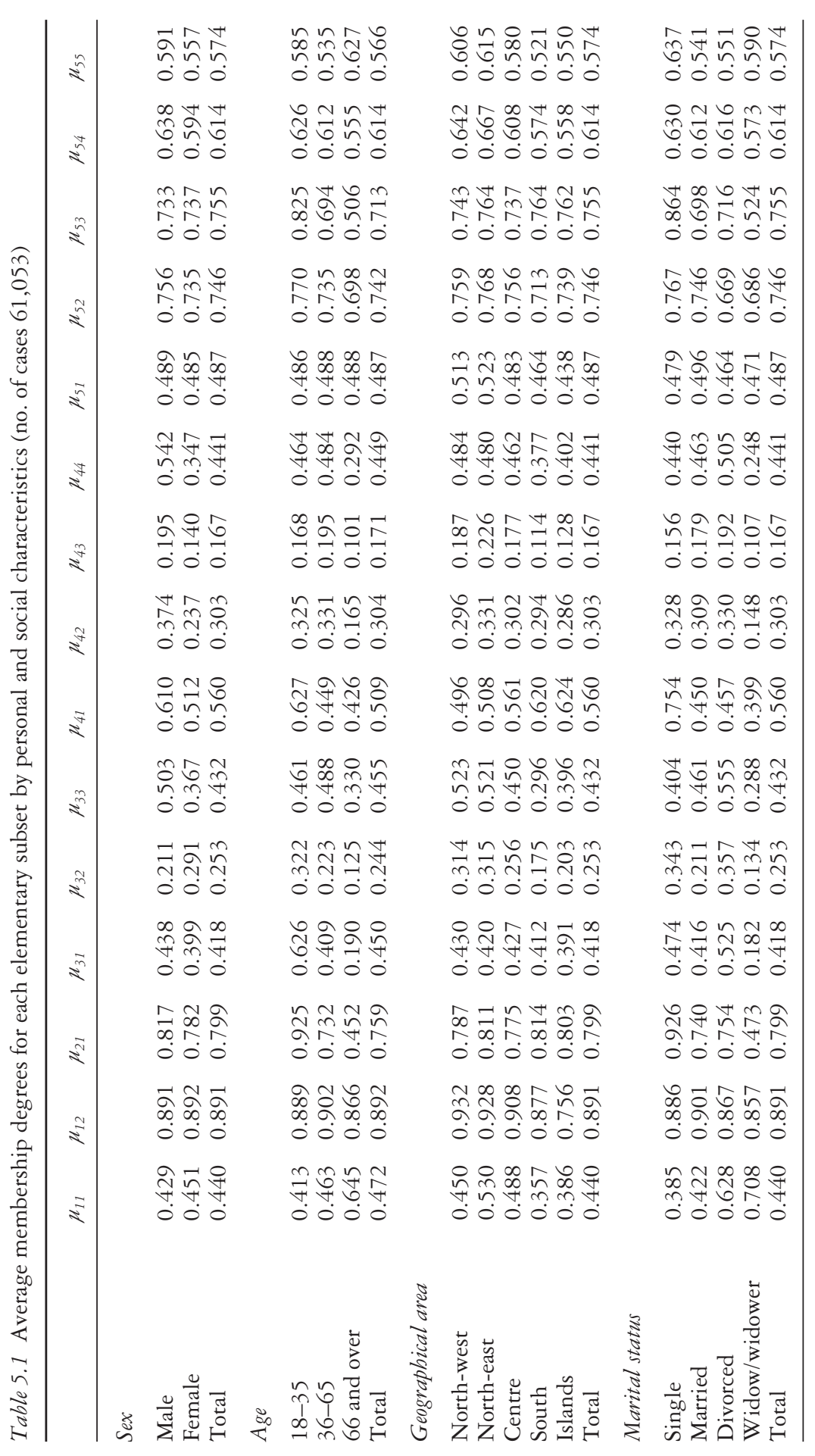




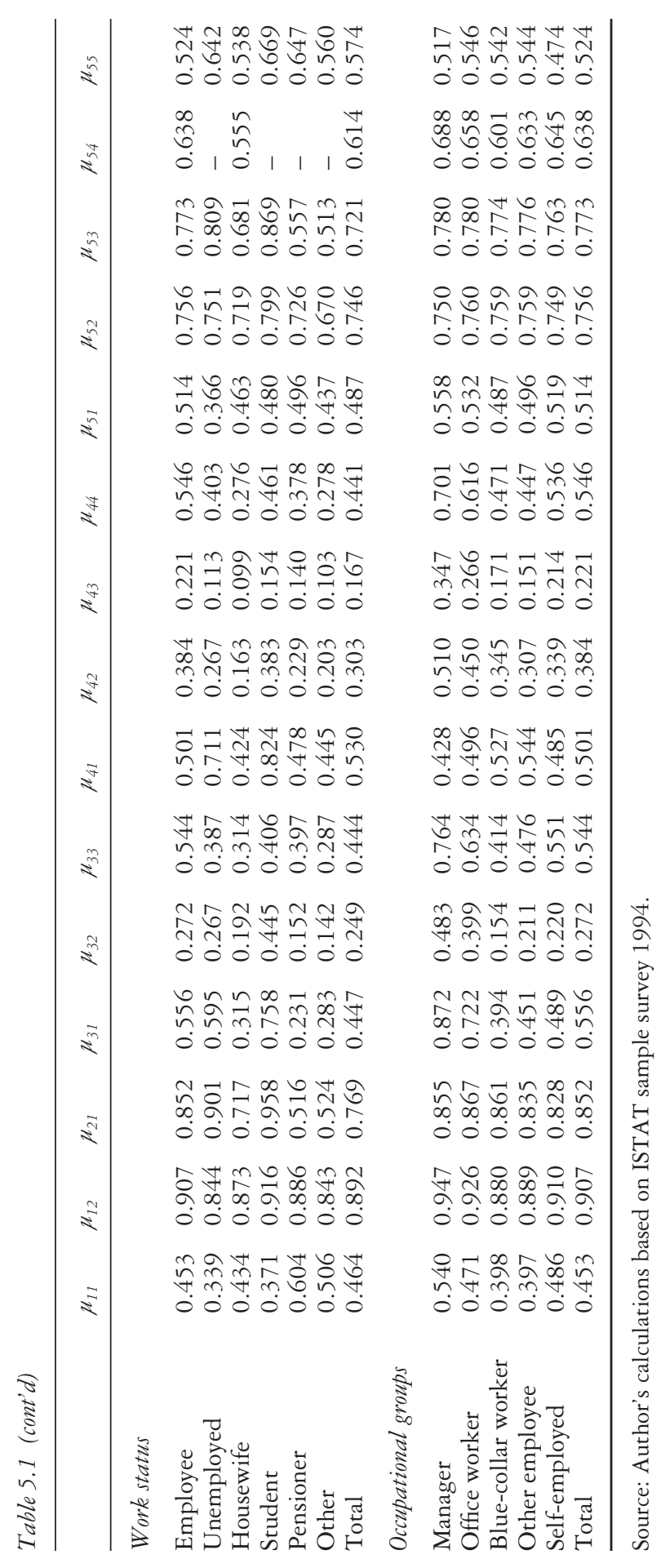


Unpaid work and well-being 133

Table 5.2 Average membership degrees for each functioning by personal and social characteristics (no. of cases 61,053)

\begin{tabular}{|c|c|c|c|c|c|}
\hline & Housing & Health & $\begin{array}{l}\text { Education } \\
\text { knowledge }\end{array}$ & $\begin{array}{l}\text { Social } \\
\text { interactions }\end{array}$ & $\begin{array}{l}\text { Psychological } \\
\text { state }\end{array}$ \\
\hline \multicolumn{6}{|l|}{ Sex } \\
\hline Male & 0.486 & 0.817 & 0.369 & 0.360 & 0.601 \\
\hline Female & 0.506 & 0.782 & 0.347 & 0.251 & 0.580 \\
\hline Total & 0.496 & 0.799 & 0.358 & 0.304 & 0.590 \\
\hline \multicolumn{6}{|l|}{ Age } \\
\hline $18-35$ & 0.472 & 0.925 & 0.448 & 0.327 & 0.612 \\
\hline $36-65$ & 0.518 & 0.732 & 0.348 & 0.320 & 0.573 \\
\hline 66 and over & 0.672 & 0.452 & 0.199 & 0.198 & 0.566 \\
\hline Total & 0.524 & 0.759 & 0.359 & 0.304 & 0.586 \\
\hline \multicolumn{6}{|l|}{ Geographical area } \\
\hline North-west & 0.509 & 0.787 & 0.411 & 0.310 & 0.611 \\
\hline North-east & 0.580 & 0.811 & 0.406 & 0.336 & 0.623 \\
\hline Centre & 0.540 & 0.775 & 0.364 & 0.312 & 0.589 \\
\hline South & 0.421 & 0.814 & 0.284 & 0.275 & 0.559 \\
\hline Islands & 0.431 & 0.803 & 0.321 & 0.284 & 0.561 \\
\hline Total & 0.496 & 0.799 & 0.358 & 0.304 & 0.590 \\
\hline \multicolumn{6}{|l|}{ Marital status } \\
\hline Single & 0.447 & 0.926 & 0.455 & 0.331 & 0.622 \\
\hline Married & 0.498 & 0.740 & 0.337 & 0.304 & 0.580 \\
\hline Divorced & 0.659 & 0.754 & 0.459 & 0.324 & 0.561 \\
\hline Widow/widower & 0.726 & 0.473 & 0.189 & 0.183 & 0.549 \\
\hline Total & 0.496 & 0.799 & 0.358 & 0.304 & 0.590 \\
\hline \multicolumn{6}{|l|}{ Work status } \\
\hline Employee & 0.509 & 0.852 & 0.428 & 0.364 & 0.595 \\
\hline Unemployed & 0.402 & 0.901 & 0.404 & 0.289 & 0.577 \\
\hline Housewife & 0.488 & 0.717 & 0.260 & 0.193 & 0.560 \\
\hline Student & 0.439 & 0.958 & 0.585 & 0.363 & 0.647 \\
\hline Pensioner & 0.639 & 0.516 & 0.241 & 0.254 & 0.587 \\
\hline Other & 0.549 & 0.524 & 0.220 & 0.209 & 0.523 \\
\hline Total & 0.517 & 0.769 & 0.358 & 0.304 & 0.590 \\
\hline \multicolumn{6}{|l|}{ Occupational groups } \\
\hline Manager & 0.591 & 0.855 & 0.669 & 0.469 & 0.610 \\
\hline Office worker & 0.527 & 0.867 & 0.554 & 0.412 & 0.610 \\
\hline Blue-collar worker & 0.458 & 0.861 & 0.294 & 0.322 & 0.591 \\
\hline Other employee & 0.459 & 0.835 & 0.360 & 0.302 & 0.595 \\
\hline Self-employed & 0.538 & 0.828 & 0.387 & 0.344 & 0.579 \\
\hline Total & 0.509 & 0.852 & 0.428 & 0.364 & 0.595 \\
\hline
\end{tabular}

Source: Author's calculations based on ISTAT sample survey, 1994. 


\section{Enrica Chiappero-Martinetti}

come from the distinctions based on civil and work status as well as for occupational groups. Of particular note is the clear disadvantage of housewives with regard to most of the well-being dimensions: the social interaction is extremely low, the same is true for education and knowledge and also, even though with smaller differentials, for subjective perception.

The same conclusions may be drawn from Table 5.2, where the average membership degrees for the five dimensions of well-being are summarised. Tables 5.3 and 5.4 show the gender inequalities in the well-being more clearly. They refer to the same indicators and the same subgroups of popu-

lation as Tables 5.1 and 5.2, but make a distinction between males and females. The results appear quite interesting. The disadvantage relating to women remains and, with reference to functionings such as social interactions and psychological conditions, does not seem to depend on age. Even young women seem to participate in social life less than do young men. As far as the subjective evaluation is concerned, women are relatively less satisfied than men, in particular with regard to personal relations, work, leisure time and health. Concerning this latter aspect, the position of women is systematically lower compared to men even if, for obvious reasons, the differential widens with increase in age. The only favourable dimension for young women is that connected with education and knowledge, while for those belonging to middle and older age groups, comparatively higher values are recorded only for housing.

If one looks at the geographical area of residence, the unfavourable differentials for women remain and are generally accentuated, with housing again being the only exception. Even the relative educational advantage noted above is now apparent only for women who live in Northern Italy while it is falling in other Italian regions.

The discrimination remains even when we look at individual groups distinguished by civil status. Unmarried and divorced women are in a more favourable position compared to men with regard to education, and widows with regard to housing, but in general women's conditions are always much worse if one looks at both the dimensions of well-being and the elementary indicators that determine them.

\section{Gender inequality in the use of time}

In this section I describe briefly the time allocated to paid and unpaid work by the socio-economic groups previously analysed, with the aim of understanding whether the differences in well-being which have emerged can be better interpreted in light of the existing disparities in the use of time. ${ }^{15}$

In Table 5.5 the time distribution between paid and unpaid work for males and females is presented for a subsample of heads of family and spouses. On average, about 80 per cent of men spend less than ten hours a week on domestic activities compared with only 11 per cent of women. By contrast, almost 70 per cent of women dedicate between twenty and fifty 


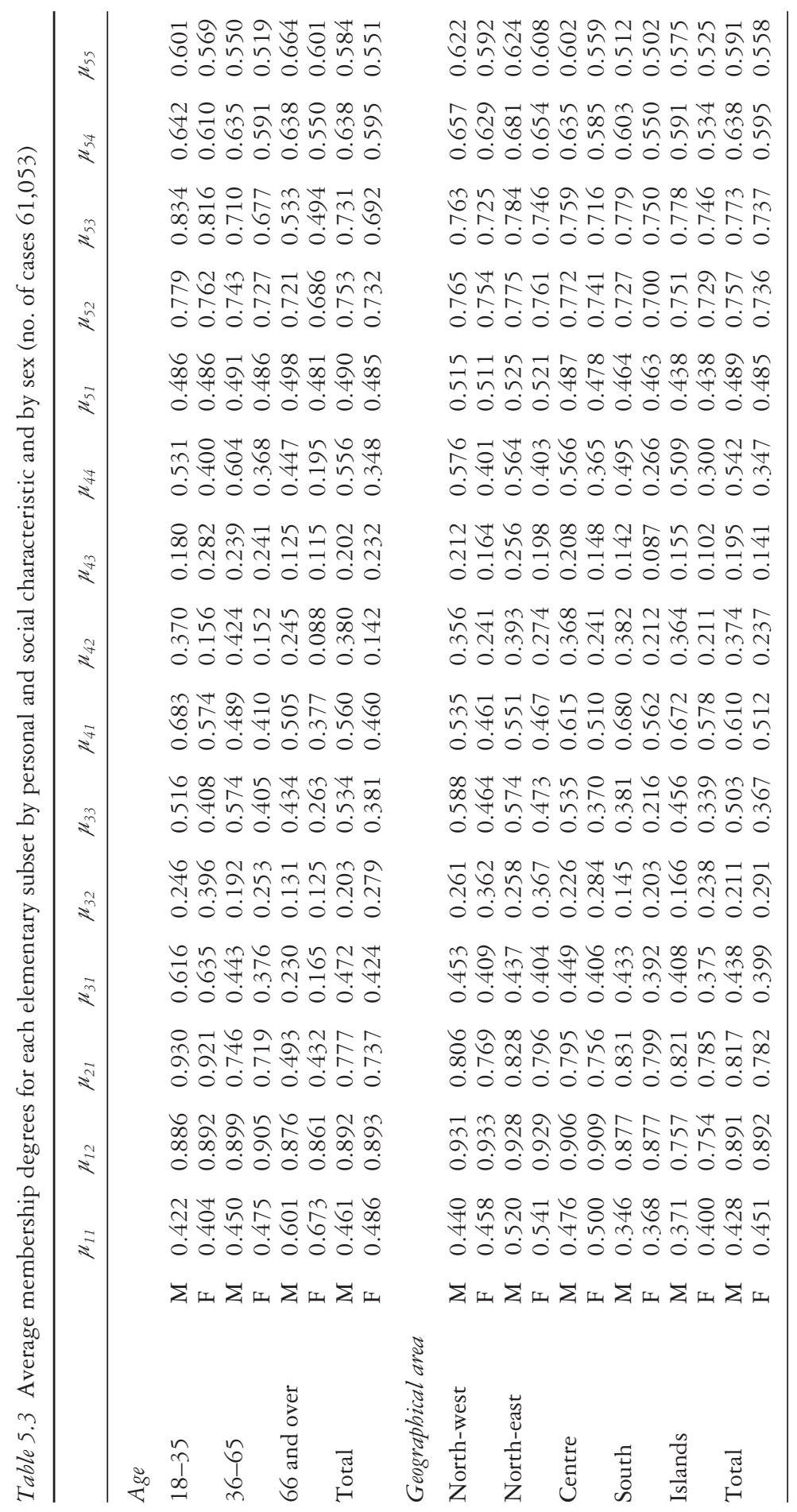




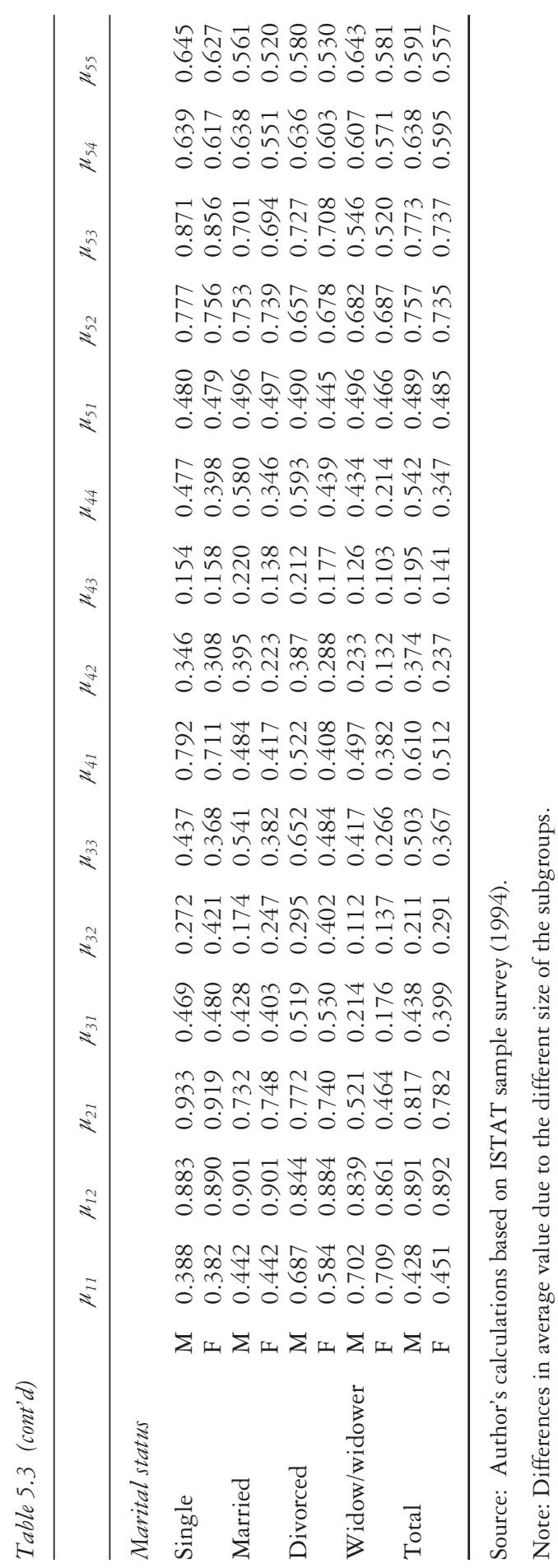


Unpaid work and well-being 137

Table 5.4 Average membership degrees for each functioning by personal and social characteristics and by sex (no. of cases 61,053)

\begin{tabular}{|c|c|c|c|c|c|c|}
\hline & & Housing & Health* & $\begin{array}{l}\text { Education } \\
\text { knowledge }\end{array}$ & $\begin{array}{l}\text { Social } \\
\text { interactions }\end{array}$ & $\begin{array}{l}\text { Psychological } \\
\text { state }\end{array}$ \\
\hline \multicolumn{7}{|l|}{ Age } \\
\hline \multirow[t]{2}{*}{$18-35$} & M & 0.480 & 0.930 & 0.427 & 0.365 & 0.620 \\
\hline & $\mathrm{F}$ & 0.464 & 0.921 & 0.468 & 0.292 & 0.605 \\
\hline \multirow[t]{2}{*}{$36-65$} & M & 0.506 & 0.746 & 0.367 & 0.391 & 0.582 \\
\hline & $\mathrm{F}$ & 0.529 & 0.719 & 0.329 & 0.251 & 0.564 \\
\hline \multirow[t]{2}{*}{66 and over } & M & 0.635 & 0.493 & 0.242 & 0.269 & 0.583 \\
\hline & $\mathrm{F}$ & 0.695 & 0.432 & 0.174 & 0.153 & 0.551 \\
\hline \multirow[t]{2}{*}{ Total } & M & 0.514 & 0.777 & 0.370 & 0.365 & 0.593 \\
\hline & $\mathrm{F}$ & 0.536 & 0.737 & 0.347 & 0.248 & 0.576 \\
\hline \multicolumn{7}{|l|}{ Geographical area } \\
\hline \multirow[t]{2}{*}{ North-west } & M & 0.500 & 0.806 & 0.415 & 0.359 & 0.621 \\
\hline & $\mathrm{F}$ & 0.517 & 0.769 & 0.407 & 0.265 & 0.602 \\
\hline \multirow[t]{2}{*}{ North-east } & M & 0.571 & 0.828 & 0.405 & 0.387 & 0.631 \\
\hline & $\mathrm{F}$ & 0.589 & 0.796 & 0.408 & 0.290 & 0.615 \\
\hline \multirow[t]{2}{*}{ Centre } & M & 0.529 & 0.795 & 0.384 & 0.369 & 0.604 \\
\hline & $\mathrm{F}$ & 0.550 & 0.756 & 0.345 & 0.258 & 0.575 \\
\hline \multirow[t]{2}{*}{ South } & M & 0.411 & 0.831 & 0.308 & 0.342 & 0.570 \\
\hline & $\mathrm{F}$ & 0.431 & 0.799 & 0.262 & 0.213 & 0.549 \\
\hline \multirow[t]{2}{*}{ Islands } & M & 0.418 & 0.821 & 0.331 & 0.343 & 0.573 \\
\hline & $\mathrm{F}$ & 0.443 & 0.785 & 0.312 & 0.228 & 0.550 \\
\hline \multirow[t]{2}{*}{ Total } & M & 0.486 & 0.817 & 0.369 & 0.360 & 0.600 \\
\hline & $\mathrm{F}$ & 0.506 & 0.782 & 0.347 & 0.251 & 0.580 \\
\hline \multicolumn{7}{|l|}{ Marital status } \\
\hline \multirow[t]{2}{*}{ Single } & M & 0.449 & 0.933 & 0.432 & 0.349 & 0.628 \\
\hline & $\mathrm{F}$ & 0.445 & 0.919 & 0.480 & 0.312 & 0.614 \\
\hline \multirow[t]{2}{*}{ Married } & M & 0.498 & 0.732 & 0.346 & 0.370 & 0.587 \\
\hline & $\mathrm{F}$ & 0.498 & 0.748 & 0.328 & 0.237 & 0.573 \\
\hline \multirow[t]{2}{*}{ Divorced } & M & 0.708 & 0.772 & 0.455 & 0.372 & 0.579 \\
\hline & $\mathrm{F}$ & 0.622 & 0.740 & 0.462 & 0.288 & 0.548 \\
\hline \multirow[t]{2}{*}{ Widow/widower } & M & 0.719 & 0.521 & 0.224 & 0.262 & 0.577 \\
\hline & $\mathrm{F}$ & 0.727 & 0.464 & 0.183 & 0.169 & 0.544 \\
\hline \multirow[t]{2}{*}{ Total } & M & 0.486 & 0.817 & 0.369 & 0.360 & 0.600 \\
\hline & $\mathrm{F}$ & 0.506 & 0.782 & 0.347 & 0.251 & 0.580 \\
\hline
\end{tabular}

Source: Own elaboration on ISTAT sample survey 1994.

Notes

Differences in average value due to the different size of the subgroups.

*Only one elementary indicator. 


\section{Enrica Chiappero-Martinetti}

Table 5.5 Distribution of time (hours of paid and unpaid work) by sex (head of family and spouses)

\begin{tabular}{|c|c|c|c|c|}
\hline & \multicolumn{2}{|c|}{ Total sample } & \multicolumn{2}{|c|}{ Employed people } \\
\hline & Male & Female & Male & Female \\
\hline \multicolumn{5}{|l|}{ Unpaid work } \\
\hline 0 & 32.8 & 2.9 & 37.2 & 2.6 \\
\hline $1-10$ & 46.3 & 8.1 & 48.0 & 10.8 \\
\hline $11-20$ & 14.2 & 14.5 & 11.5 & 25.0 \\
\hline $21-30$ & 3.8 & 18.9 & 1.9 & 27.7 \\
\hline $31-40$ & 1.4 & 18.5 & 0.8 & 18.9 \\
\hline $41-50$ & 0.7 & 15.4 & 0.4 & 9.4 \\
\hline $51-60$ & 0.2 & 9.3 & 0.1 & 3.1 \\
\hline $61+$ & 0.2 & 12.4 & 0.1 & 2.5 \\
\hline Total & 100 & 100 & 100 & 100 \\
\hline (no. of cases) & 15,970 & 18,472 & 10,812 & 5,710 \\
\hline \multicolumn{5}{|l|}{ Paid work } \\
\hline 0 & 18.9 & 47.1 & 0.4 & 0.6 \\
\hline $1-10$ & 2.1 & 2.6 & 1.2 & 1.9 \\
\hline $11-20$ & 2.4 & 6.3 & 1.6 & 10.8 \\
\hline $21-30$ & 2.5 & 8.4 & 2.6 & 16.2 \\
\hline $31-40$ & 40.8 & 26.2 & 52.0 & 52.8 \\
\hline $41-50$ & 20.8 & 6.9 & 26.3 & 13.3 \\
\hline $51-60$ & 8.1 & 1.6 & 10.3 & 3.0 \\
\hline $61+$ & 4.4 & 0.9 & 5.6 & 1.4 \\
\hline Total & 100 & 100 & 100 & 100 \\
\hline (no. of cases) & 14,031 & 12,198 & 10,851 & 5,927 \\
\hline \multicolumn{5}{|l|}{ Total time } \\
\hline 0 & 6.3 & 1.6 & 0.1 & 0.0 \\
\hline $1-10$ & 8.4 & 3.5 & 0.9 & 0.3 \\
\hline $11-20$ & 5.2 & 5.1 & 1.1 & 0.6 \\
\hline $21-30$ & 3.4 & 7.9 & 1.8 & 1.6 \\
\hline $31-40$ & 17.9 & 12.1 & 21.9 & 5.9 \\
\hline $41-50$ & 31.1 & 17.2 & 39.2 & 14.9 \\
\hline $51-60$ & 16.6 & 18.8 & 21.0 & 25.1 \\
\hline $61-70$ & 6.6 & 16.4 & 8.4 & 23.2 \\
\hline $71-80$ & 2.5 & 9.2 & 3.2 & 15.6 \\
\hline $80+$ & 2.0 & 8.2 & 2.4 & 12.8 \\
\hline Total & 100 & 100 & 100 & 100 \\
\hline (no. of cases) & 13,462 & 11,762 & 10,357 & 5,611 \\
\hline
\end{tabular}

Source: Author's calculations based on ISTAT sample survey, 1994. 
hours a week to domestic work. Figures do not really change if instead of looking at the whole sample we look only at those individuals who are in paid employment, the only significant difference being that the male load is reduced even further.

These gender differences could be explained by the fact that, in general, women dedicate less time to work outside the home. In part this is what effectively takes place, even if, when we look at the typical full-time job (thirty-one to forty hours per week), the percentage of women and men is the same whereas more men spend longer hours in paid employment (fortyone to fifty hours). However, the differences between men and women are fairly apparent if we look at the overall time dedicated to both domestic and paid work. Seventy women out of a hundred work for a minimum of forty and a maximum of eighty or more hours per week: this share is higher than 90 per cent if we consider only the women employed outside the home. The corresponding values for the male population are lower and equal to 58 and 74 per cent, respectively.

More detailed information is given in the following tables, which show the average time spent on domestic work (Tables 5.6 and 5.7) and total work (Tables 5.8 and 5.9) by men and women. Generally speaking, Italian men contribute no more than seven hours per week to domestic work: a very small contribution when compared with the thirty-seven hours spent by women. Once again this disproportion cannot be explained entirely by the presence of housewives: this is shown by the fact that differences remain even if we look at the group of employed people (Table 5.7), where five hours per week of male unpaid work correspond to twenty-seven hours of female unpaid work. Moreover, if we consider the total time dedicated to both paid and unpaid work, the average values are forty-one hours for men and fifty-two hours for women (Table 5.8) but these figures rise respectively to forty-nine and sixty-three for the subsample of employed people (Table 5.9). If we look at this subgroup of the population and focus our attention on unpaid work distribution by personal and household characteristics (Table 5.7), we will see that the low contribution of men to domestic activities (5.7 hours on average) does not seem to change. ${ }^{16}$ Men spend less time on domestic activities when their age increases, when they marry, when they have a low level of education and when they come from a large family. The situation for women is obviously the opposite and the variability is greater: getting married means increasing the time spent on domestic work by almost eleven hours a week, and with a larger family the burden of unpaid work becomes increasingly heavy. If we look at the overall time (paid and unpaid), there is not a single case in which male work is greater than female work, clear evidence that the increasing participation of women in the labour market has simply meant that the domestic workload has been added to the non-domestic workload and time devoted to personal needs has been compressed.

The last topic that I want to examine briefly is whether or not this great 


\section{Enrica Chiappero-Martinetti}

Table 5.6 Unpaid work by sex and by personal and household characteristics - whole sample (no. of cases 35,235)

\begin{tabular}{|c|c|c|c|c|}
\hline & \multicolumn{2}{|c|}{ Hours (means) } & & $\%$ cases \\
\hline Male & \multicolumn{2}{|c|}{7.3} & & 46.0 \\
\hline Female & \multicolumn{2}{|c|}{36.9} & & 54.0 \\
\hline \multirow[t]{2}{*}{ Total } & \multicolumn{2}{|c|}{23.3} & & 100.0 \\
\hline & \multicolumn{2}{|l|}{ Male } & \multicolumn{2}{|l|}{ Female } \\
\hline \multicolumn{5}{|l|}{ Age } \\
\hline $18-35$ & 6.8 & 18.0 & 37.3 & 21.6 \\
\hline $36-65$ & 6.8 & 65.7 & 39.5 & 59.2 \\
\hline 66 and over & 9.7 & 16.3 & 28.4 & 19.2 \\
\hline \multicolumn{5}{|l|}{ Work status } \\
\hline Employee & 5.7 & 67.4 & 27.6 & 31.6 \\
\hline Unemployed & 11.7 & 2.7 & 43.2 & 2.0 \\
\hline Pensioner & 10.6 & 27.7 & 33.7 & 20.2 \\
\hline Housewife & - & - & 45.6 & 43.4 \\
\hline Other & 9.2 & 2.2 & 26.7 & 2.7 \\
\hline \multicolumn{5}{|l|}{ Marital status } \\
\hline Single & 10.1 & 6.1 & 22.1 & 5.3 \\
\hline Married & 6.8 & 88.0 & 39.9 & 77.2 \\
\hline Divorced & 9.5 & 3.0 & 27.8 & 3.5 \\
\hline Widow/widower & 14.0 & 2.8 & 28.2 & 14.0 \\
\hline \multicolumn{5}{|l|}{ Education } \\
\hline University degree & 5.9 & 7.6 & 27.0 & 7.6 \\
\hline Upper secondary school & 7.2 & 25.8 & 34.4 & 25.8 \\
\hline Lower secondary school & 6.8 & 29.3 & 39.6 & 29.3 \\
\hline Primary school & 7.9 & 31.3 & 39.3 & 31.3 \\
\hline No education & 8.5 & 6.0 & 32.9 & 6.0 \\
\hline \multicolumn{5}{|l|}{ Geographical area } \\
\hline North-west & 7.7 & 22.5 & 35.0 & 22.8 \\
\hline North-east & 8.0 & 21.6 & 38.1 & 21.4 \\
\hline Centre & 6.9 & 18.8 & 35.5 & 18.9 \\
\hline South & 6.5 & 26.5 & 37.2 & 26.3 \\
\hline Islands & 7.5 & 10.6 & 40.5 & 10.5 \\
\hline \multicolumn{5}{|l|}{ Type of family } \\
\hline Single & 11.3 & 8.0 & 23.3 & 13.5 \\
\hline Couple & 7.9 & 21.6 & 33.7 & 19.3 \\
\hline Couple with children & 6.4 & 62.5 & 42.0 & 53.9 \\
\hline Lone parent & 14.3 & 1.3 & 33.3 & 6.5 \\
\hline Other & 7.2 & 6.5 & 36.6 & 6.8 \\
\hline \multicolumn{5}{|l|}{ No. of components } \\
\hline 1 & 11.3 & 8.0 & 23.3 & 13.5 \\
\hline 2 & 8.3 & 23.5 & 33.0 & 24.4 \\
\hline 3 & 6.9 & 27.4 & 38.7 & 25.7 \\
\hline 4 & 6.3 & 29.5 & 42.3 & 25.9 \\
\hline 5 & 5.8 & 8.7 & 45.0 & 7.9 \\
\hline 6 or more & 6.5 & 2.9 & 47.8 & 2.6 \\
\hline
\end{tabular}

Source: Author's calculations based on ISTAT sample survey, 1994. 
Unpaid work and well-being 141

Table 5.7 Unpaid work by sex and by personal and household characteristics - employed people (no. of cases 16,947)

\begin{tabular}{|c|c|c|c|c|}
\hline & \multicolumn{2}{|c|}{ Hours (means) } & & $\%$ cases \\
\hline Male & 5. & & & 64.4 \\
\hline Female & 27. & & & 35.6 \\
\hline \multirow[t]{2}{*}{ Total } & 13. & & & 100.0 \\
\hline & Male & & Female & \\
\hline \multicolumn{5}{|l|}{ Age } \\
\hline $18-35$ & 6.4 & 24.9 & 26.6 & 33.5 \\
\hline $36-65$ & 5.4 & 73.9 & 28.1 & 65.9 \\
\hline 66 and over & 5.0 & 1.2 & 20.9 & 0.6 \\
\hline \multicolumn{5}{|l|}{ Marital status } \\
\hline Single & 8.0 & 6.3 & 18.0 & 7.7 \\
\hline Married & 5.4 & 89.8 & 28.9 & 81.9 \\
\hline Divorced & 8.5 & 3.3 & 22.9 & 6.5 \\
\hline Widow/widower & 10.8 & 0.6 & 26.7 & 3.9 \\
\hline \multicolumn{5}{|l|}{ Education } \\
\hline University degree & 5.3 & 9.6 & 24.3 & 12.6 \\
\hline Upper secondary school & 6.5 & 32.4 & 27.6 & 41.0 \\
\hline Lower secondary school & 5.8 & 34.8 & 28.2 & 28.2 \\
\hline Primary school & 4.6 & 21.8 & 28.7 & 16.9 \\
\hline No education & 4.0 & 1.4 & 29.1 & 1.3 \\
\hline \multicolumn{5}{|l|}{ Geographical area } \\
\hline North-west & 5.7 & 21.8 & 25.8 & 25.0 \\
\hline North-east & 6.2 & 20.9 & 27.6 & 22.8 \\
\hline Centre & 5.6 & 18.7 & 27.7 & 21.3 \\
\hline South & 5.2 & 27.9 & 28.9 & 23.8 \\
\hline Islands & 5.9 & 10.7 & 28.4 & $\begin{array}{r}25.0 \\
7.1\end{array}$ \\
\hline \multicolumn{5}{|l|}{ Type of family } \\
\hline Single & 8.7 & 6.8 & 17.8 & 8.7 \\
\hline Couple & 5.2 & 12.8 & 22.3 & 14.6 \\
\hline Couple with children & 5.5 & 74.0 & 30.2 & 63.7 \\
\hline Lone parent & 10.1 & 0.8 & 26.1 & 7.1 \\
\hline Other & 4.8 & 5.6 & 26.9 & 5.9 \\
\hline \multicolumn{5}{|l|}{ No. of components } \\
\hline 1 & 8.7 & 6.8 & 17.7 & 8.8 \\
\hline 2 & 5.4 & 14.0 & 22.7 & 19.3 \\
\hline 3 & 5.6 & 29.0 & 28.2 & 31.1 \\
\hline 4 & 5.5 & 36.5 & 31.4 & 31.1 \\
\hline 5 & 4.9 & 10.5 & 31.2 & 7.7 \\
\hline 6 or more & 5.1 & 3.2 & 33.0 & 2.1 \\
\hline
\end{tabular}

Source: Author's calculations based on ISTAT sample survey, 1994. 


\section{Enrica Chiappero-Martinetti}

Table 5.8 Total time (paid and unpaid work) by sex and by personal and household characteristics - whole sample (no. of cases 26,304)

\begin{tabular}{|c|c|c|c|c|}
\hline & \multicolumn{2}{|c|}{ Hours (means) } & & $\%$ cases \\
\hline Male & 41.2 & & & 53.4 \\
\hline Female & 52.3 & & & 46.6 \\
\hline \multirow[t]{2}{*}{ Total } & \multicolumn{2}{|c|}{46.4} & & 100.0 \\
\hline & \multicolumn{2}{|l|}{ Male } & \multicolumn{2}{|l|}{ Female } \\
\hline \multicolumn{5}{|l|}{ Age } \\
\hline $18-35$ & 49.3 & 20.3 & 57.7 & 25.0 \\
\hline $36-65$ & 43.5 & 68.1 & 55.7 & 60.2 \\
\hline 66 and over & 13.7 & 11.6 & 29.5 & 14.8 \\
\hline \multicolumn{5}{|l|}{ Work status } \\
\hline Employee & 49.3 & 77.4 & 62.9 & 48.7 \\
\hline Unemployed & 19.9 & 1.9 & 46.7 & 1.7 \\
\hline Pensioner & 12.2 & 19.0 & 34.2 & 15.1 \\
\hline Housewife & - & - & 46.8 & 32.1 \\
\hline Other & 19.3 & 1.7 & 29.1 & 2.4 \\
\hline \multicolumn{5}{|l|}{ Marital status } \\
\hline Single & 43.5 & 6.2 & 44.3 & 6.1 \\
\hline Married & 41.3 & 88.7 & 55.4 & 78.3 \\
\hline Divorced & 45.8 & 3.1 & 53.3 & 4.3 \\
\hline Widow/widower & 23.2 & 2.0 & 34.6 & 11.3 \\
\hline \multicolumn{5}{|l|}{ Education } \\
\hline University degree & 43.5 & 8.3 & 52.3 & 7.3 \\
\hline Upper secondary school & 45.8 & 27.9 & 57.6 & 28.0 \\
\hline Lower secondary school & 45.2 & 30.7 & 56.7 & 25.8 \\
\hline Primary school & 35.2 & 28.2 & 48.3 & 30.9 \\
\hline No education & 21.1 & 4.9 & 35.3 & 8.0 \\
\hline \multicolumn{5}{|l|}{ Geographical area } \\
\hline North-west & 41.7 & 21.7 & 51.6 & 22.3 \\
\hline North-east & 40.9 & 22.1 & 52.8 & 24.2 \\
\hline Centre & 41.1 & 18.5 & 53.8 & 18.7 \\
\hline South & 40.3 & 27.4 & 51.0 & 26.2 \\
\hline Islands & 43.1 & 10.3 & 53.3 & 8.6 \\
\hline \multicolumn{5}{|l|}{ Type of family } \\
\hline Single & 40.9 & 7.6 & 35.9 & 12.1 \\
\hline Couple & 30.8 & 18.8 & 46.3 & 18.3 \\
\hline Couple with children & 44.6 & 66.2 & 58.3 & 56.2 \\
\hline Lone parent & 37.9 & 1.1 & 50.9 & 6.6 \\
\hline Other & 38.0 & 6.3 & 50.2 & 6.8 \\
\hline \multicolumn{5}{|l|}{ No. of components } \\
\hline 1 & 40.9 & 7.6 & 35.9 & 12.1 \\
\hline 2 & 31.3 & 20.5 & 46.0 & 23.4 \\
\hline 3 & 42.3 & 27.9 & 55.8 & 26.9 \\
\hline 4 & 45.3 & 31.7 & 59.0 & 27.2 \\
\hline 5 & 44.9 & 9.3 & 58.7 & 7.9 \\
\hline 6 or more & 43.5 & 3.0 & 60.3 & 2.5 \\
\hline
\end{tabular}

Source: Author's calculations based on ISTAT sample survey, 1994. 
Table 5.9 Total time (paid and unpaid work) by sex and by personal and household characteristics - employed people (no. of cases 16,839)

\begin{tabular}{|c|c|c|c|c|}
\hline & \multicolumn{2}{|c|}{ Hours (means) } & & $\%$ cases \\
\hline Male & 49. & & & 64.5 \\
\hline Female & 62. & & & 35.5 \\
\hline \multirow[t]{2}{*}{ Total } & \multicolumn{2}{|c|}{54.2} & & 100.0 \\
\hline & Male & & Female & \\
\hline \multicolumn{5}{|l|}{ Age } \\
\hline $18-35$ & 50.4 & 24.9 & 62.1 & 33.5 \\
\hline $36-65$ & 49.0 & 73.9 & 63.4 & 66.0 \\
\hline 66 and over & 47.2 & 1.1 & 53.9 & 0.5 \\
\hline \multicolumn{5}{|l|}{ Marital status } \\
\hline Single & 50.4 & 6.2 & 55.9 & 7.8 \\
\hline Married & 49.1 & 89.8 & 63.9 & 81.7 \\
\hline Divorced & 51.5 & 3.4 & 59.0 & 6.6 \\
\hline Widow/widower & 53.6 & 0.6 & 62.8 & 3.9 \\
\hline \multicolumn{5}{|l|}{ Education } \\
\hline University degree & 46.7 & 9.6 & 54.8 & 12.6 \\
\hline Upper secondary school & 49.3 & 32.5 & 62.9 & 41.1 \\
\hline Lower secondary school & 49.6 & 34.7 & 65.2 & 28.1 \\
\hline Primary school & 50.2 & 21.8 & 65.7 & 16.8 \\
\hline No education & 49.2 & 1.4 & 60.0 & 1.3 \\
\hline \multicolumn{5}{|l|}{ Geographical area } \\
\hline North-west & 50.1 & 21.7 & 61.9 & 25.0 \\
\hline North-east & 50.0 & 21.0 & 63.6 & 22.9 \\
\hline Centre & 49.3 & 18.7 & 63.8 & 21.3 \\
\hline South & 47.4 & 28.0 & 62.8 & 23.6 \\
\hline Islands & 49.7 & 10.7 & 62.1 & 7.1 \\
\hline \multicolumn{5}{|l|}{ Type of family } \\
\hline Single & 50.8 & 6.9 & 55.3 & 8.8 \\
\hline Couple & 48.7 & 12.7 & 59.4 & 14.6 \\
\hline Couple with children & 49.2 & 74.1 & 64.8 & 63.6 \\
\hline Lone parent & 54.1 & 0.8 & 62.2 & 7.1 \\
\hline Other & 49.6 & 5.6 & 63.8 & 5.8 \\
\hline \multicolumn{5}{|l|}{ No. of components } \\
\hline 1 & 50.8 & 6.9 & 55.3 & 8.8 \\
\hline 2 & 48.9 & 14.0 & 59.7 & 19.3 \\
\hline 3 & 49.5 & 29.0 & 63.5 & 31.0 \\
\hline 4 & 49.0 & 36.5 & 65.5 & 31.2 \\
\hline 5 & 49.4 & 10.5 & 65.4 & 7.6 \\
\hline 6 or more & 50.1 & 3.2 & 67.6 & 2.1 \\
\hline
\end{tabular}

Source: Author's caluclations based on ISTAT sample survey, 1994. 


\section{Enrica Chiappero-Martinetti}

amount of female household work can be attributed in part to the presence of young children and, in these circumstances, men's contribution to domestic responsibilities. Families with only one child (more than 4,000 cases in my sample) were selected and the distribution of domestic work between mother and father was analysed, both in relation to the child's age and to whether the mother was employed in work outside the home or was instead a housewife. The results of this analysis are shown in Table 5.10 and are quite interesting.

For the parents of children who are under 3 years old, the time spent on domestic work is fairly onerous for the mother (more than forty hours), but not substantially higher than the average ( 39.4 hours), while it is slightly higher than usual in the case of the father ( 7.4 hours compared to 6.7). Unpaid work decreases when the mother participates in the labour market (30.6 hours of unpaid work per week instead of 40.5), but this lower amount is compensated for by turning to domestic help or social structures and not by the intervention of the father, whose load increases but only marginally (under an hour per week). Finally, housewives with young children spend almost fifty hours a week in domestic activities; their husbands no more than six hours.

As children grow up, their mothers' burden decreases initially by several hours but then increases again until it exceeds forty hours per week in homes where there are adult sons and daughters. For mothers who are also employed outside the home, domestic activity seems to be unavoidable and the time commitment changes only marginally with the increase in age of the children. Housewives dedicate on average forty-seven hours per week to school-age children and can count on under five hours of help per week from the father. The hypothesis that women's unpaid work is devoted not only to young children but also, and above all, to the other adult members of the

Table 5.10 Fathers' and mothers' unpaid work by children's age (couple with a child; no. of cases 4,294)

\begin{tabular}{lllllll}
\hline & \multicolumn{2}{l}{ Total sample } & \multicolumn{2}{l}{ Mother employee } & \multicolumn{2}{l}{ Mother housewife } \\
\cline { 2 - 7 } Child's age & $\begin{array}{l}\text { Father's } \\
\text { unpaid } \\
\text { work }\end{array}$ & $\begin{array}{l}\text { Mother's } \\
\text { unpaid } \\
\text { work }\end{array}$ & $\begin{array}{l}\text { Father's } \\
\text { unpaid } \\
\text { work }\end{array}$ & $\begin{array}{l}\text { Mother's } \\
\text { unpaid } \\
\text { work }\end{array}$ & $\begin{array}{l}\text { Father's } \\
\text { unpaid } \\
\text { work }\end{array}$ & $\begin{array}{l}\text { Mother's } \\
\text { unpaid } \\
\text { work }\end{array}$ \\
\hline <3 years & 7.4 & 40.5 & 8.3 & 30.6 & 6.5 & 49.7 \\
3-5 years & 6.5 & 36.0 & 8.4 & 27.8 & 3.8 & 44.1 \\
6-10 years & 6.3 & 36.2 & 7.5 & 28.1 & 4.3 & 47.0 \\
11-13 years & 5.1 & 35.8 & 5.0 & 27.6 & 4.9 & 47.6 \\
14-18 years & 5.5 & 37.1 & 6.2 & 27.7 & 4.6 & 47.7 \\
18-25 years & 6.1 & 40.9 & 5.3 & 27.9 & 5.8 & 47.4 \\
$>$ 25 years & 8.3 & 41.6 & 7.3 & 26.1 & 7.5 & 45.5 \\
Total & 6.7 & 39.4 & 6.9 & 28.5 & 5.9 & 47.3 \\
\hline
\end{tabular}

Source: Author's calculations based on ISTAT sample survey, 1994. 
family has been already argued (see Chapter 1) and seems to find further confirmation here.

\section{Is there a relationship between well-being and unpaid work?}

In order to check whether or not there is a relationship between individual well-being and unpaid work, only families made up of couples without children $(3,709$ cases), or with one (4,294 cases) or two children (4,586 cases), were selected. In all of these cases, the aim was to investigate whether or not unpaid work carried out by women was correlated with the well-being of spouses and children. ${ }^{17}$ At a higher level of detail, attention focused on the fifteen basic indicators of well-being and the five dimensions they make up, as well as an aggregate well-being indicator represented by the simple average of the membership degrees referring to the five functionings. Using contingency tables and the corresponding association measures (chi-square test), the relationship between unpaid work and well-being was tested. Then, starting from linear regressions, more complex relations such as quadratic, logistic or sigmoidal functions were looked for to describe this relationship. In brief, the results obtained in this first preliminary and explorative analysis are as follows. The relationship between the well-being of spouses and children and the domestic work carried out by women appears fairly weak when we look at the overall indicator, but is strengthened if we look at several of the five dimensions and the fifteen basic indicators considered. In particular, statistically significant chi-square values are obtained with reference to the functionings relating to health, education and knowledge, and psychological state.

The estimated linear regressions gave significant results only for the indicator referring to health, with regard to both its objective value (the presence of chronic diseases) and the subjective perception of one's own state of health. However, for other dimensions of well-being the relationships seem to be more complex: for instance, the link between unpaid work and social relations is well approximated with a sigmoidal function, and a quadratic function seems to describe in an appropriate way the link between unpaid work and psychological state.

These results, as well as those discussed above, seem to suggest that a rich and complex set of links between well-being and unpaid work may be drawn and should be clarified. More detailed analyses are necessary to make these links clearer, but I believe that by following this complementary line of research, which focuses on the non-material dimension of well-being, we can throw light on the unique role that unpaid work plays in human life. 


\section{Enrica Chiappero-Martinetti}

\section{Conclusions}

The main aim of this chapter was to complement more traditional approaches to the economic evaluation of unpaid work with a broader conceptual scheme that enlarges the boundaries of individual well-being beyond a quantitative and monetary sphere. I have tried to show that the theoretical contribution suggested by Amartya Sen can provide a fruitful framework for this aim. Sen's approach allows unpaid work to be analysed as a main input in the household production process, something already made possible thanks to other economic theories, but which is actually the only approach that allows non-materialistic dimensions of well-being to be considered. Most importantly, it affords us the possibility to examine how the wellbeing process and intra-household distribution mechanisms can generate positive effects in terms of capabilities and achieved functionings, but also negative consequences in terms of gender inequalities in the distribution of well-being and use of time.

To have a comfortable and suitable house, to enjoy good health, to achieve a satisfactory level of education and to enlarge one's knowledge, to have rich and gratifying social and family relations, to be happy and satisfied in many dimensions of one's own life - from economic to relational, from professional to the dimension that refers to health and leisure time - are elements that are included in the list of those aspects that make life worth living (Nussbaum and Sen 1993; Nussbaum and Glover 1995). The analysis of how these well-being indicators are distributed among individuals has permitted us to outline positions of advantage and disadvantage, uniformity and inequality which are very different from those that arise from the more traditional studies of the monetary well-being of the family. It has allowed us, first of all, to highlight how women are still disadvantaged in many fundamental aspects of human life, the exception being knowledge and education, but only in the case of young women. It has brought to light the fact that, in certain respects, non-monetary well-being is distributed in a more equal way than commonly occurs with income: in this sense the results attained in some of the dimensions of well-being between the North and South of Italy appear relatively less unequal, above all in the field of health and for the functionings of a relational and psychological type. On the other hand, when the single individual instead of the whole family is taken as the reference unit, this allows the low level of well-being in which housewives live to be highlighted. Looking at the family's income obviously does not permit an assessment of this type of deprivation and inequality.

Very large gender inequalities in time allocation between paid and unpaid work emerge from our empirical analysis, and they do not seem to be related to economic, social and cultural factors such as geographical area, age, professional status or level of education. Nor can they be explained from a 'life-cycle' household perspective: as already argued in other chapters in this volume, the burden of women's domestic work does not depend in any 
significant way on the age of the children because it continues to exist even when they reach adulthood. In fact, the increase in women's participation in the labour market has simply translated into a greater total amount of work that is nothing but the corollary of the huge gender inequality to be found in the unpaid work space.

Finally, I tried to connect the two parts of our empirical analysis - the distribution of non-monetary well-being and the distribution of the use of time - with the aim of investigating whether a correlation exists. The results obtained move in the direction of a relatively weak relationship if the overall well-being is considered, a predictable result given the intrinsic complexity of the phenomenon and the heterogeneity of its components. However, a stronger relationship may be observed with regard to several specific functionings and/or basic indicators, mainly in the field of health, knowledge and the subjective perception of well-being. The attempts made to individuate the nature of the correlation between these elements further confirm the fact that the functional relationships, far from being expressible by simple linear functions, are rather more complex. 


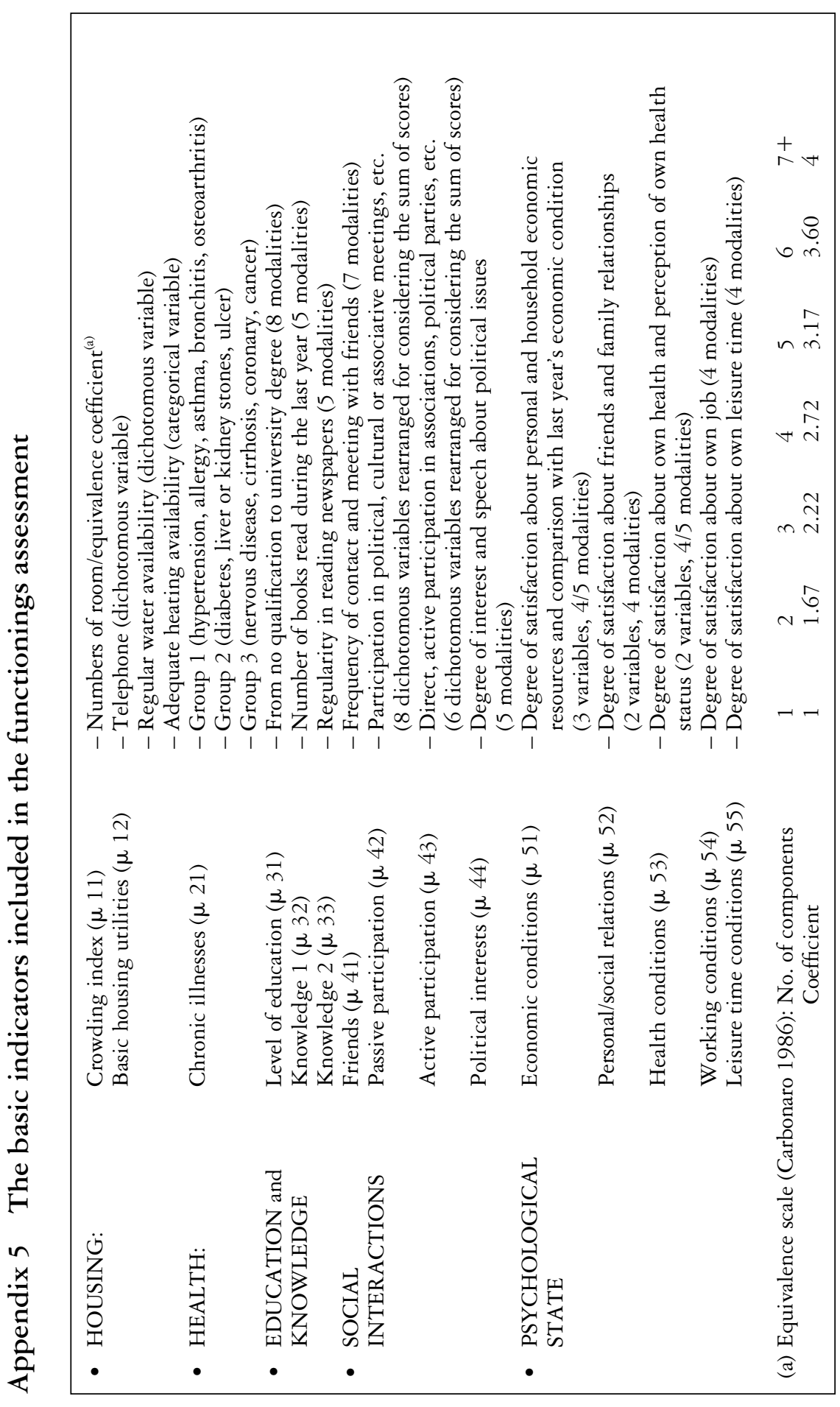




\section{Appendix 5B A few remarks about the fuzzy set theory}

In formal terms, if $\mathrm{X}$ denotes a universal set, then the membership function $\mu_{A}$, by which a fuzzy set $A$ is usually defined, has the form

$$
\mu_{\mathrm{A}}: \mathrm{X} \rightarrow[0,1]
$$

where $[0,1]$ is the interval of real numbers from 0 to 1 . Hence, $\mu_{A}(x)=0$ if the element $\mathrm{x} \in \mathrm{X}$ does not belong to $\mathrm{A}, \mu_{\mathrm{A}}(\mathrm{x})=1$ if $\mathrm{x}$ belongs completely to $A$ and $0<\mu_{A}(x)<1$ if $x$ belongs partially to $A$.

Let us assume that the subset $A$ defines the position of each individual according to the degree of achievement of a given functioning or refers to one of the indicators considered for the functioning assessment. In this case, membership values equal to 1 identify a condition of full achievement, a value equal to zero denotes the opposite situation of total failure, whereas intermediate values between 0 and 1 describe gradual positions within the arrangement. Generally speaking, it is necessary: (1) to define an appropriate arrangement of modalities (or values) on the basis of the different degrees of hardship/well-being; (2) to identify the two extreme conditions such that $\mu_{\mathrm{A}}(\mathrm{x})=1$ (full membership) and $\mu_{\mathrm{A}}(\mathrm{x})=0$ (non-membership); (3) to specify the membership functions for all the other intermediate positions.

The choice of the proper membership function depends on the application context and the kind of indicator we want to describe. For instance, in cases of variables with equi-distributed modalities along an ordinal scale, a linear function may be appropriate; a trapezoidal or a sigmoid function could be appropriate to describe quantitative and qualitative variables with modalities that are not equi-distributed and so on. In our work we have made wide use of membership functions derived directly from the distribution function of the $k$ indicators considered. That is, we have computed $\mu\left(x^{k}\right)$ in the following way:

$$
\mu\left(x^{k}\right)= \begin{cases}0 & \text { if } k=1 \\ \mu\left(x_{k-1}\right)+\frac{F\left(x_{k}\right)-F\left(x_{k-1}\right)}{1-F\left(x_{1}\right)} & \text { if } k>1\end{cases}
$$

where $\mathrm{F}(\mathrm{x})$ is the sampling distribution function of the variable $\mathrm{x}$ arranged in an increasing order according to $\mathrm{k}$. For each indicator related to a given functioning, membership grades equal to 0 and 1 are assigned respectively to the lowest and the highest position in the ranking, and intermediate values are reserved for all the other elements, relating to their position inside the distribution function. With this kind of specification any a priori and arbitrary choice is avoided and membership functions are the 'mirror' of the sample distributions: in this sense it may be considered as a 'totally relative' approach that fully reflects reality (see Cheli and Lemmi 1995: 124).

As outlined above, in the evaluative process measurement and representation are usually followed by an aggregation operation among (1) a subgroup 
of elementary indicators referring to a given functioning, and/or (2) the whole set of functionings. The former allows us to obtain a synthetic evaluation for each achieved functioning $f_{i}$, whereas the latter is related to an overall evaluation of well-being $w_{i}$. From a general point of view, both operations may be viewed as a suitable aggregation of each elementary fuzzy set with membership degree $\mu_{k f i}$ pertaining respectively to the $k$ indicators and the $f$ achievements examined, for each of the $i$ reference units.

The basic operations in crisp sets theory, i.e. union and intersection, have been generalised with reference to the fuzzy sets, so that for both of these operations there exists a broad class of function operations, each of which is characterised by a given set of property axioms. In our work we used very simple aggregation operations such as:

$$
\begin{array}{ll}
\text { standard intersection } & \mu_{A \cap B}=\min \left[\mu_{A}, \mu_{B}\right] \\
\text { standard union } & \mu_{A \cup B}=\max \left[\mu_{A}, \mu_{B}\right]
\end{array}
$$

Standard intersection and union operations focus, respectively, on the least and the most favourable position, so the membership grades to the composite set will be the lower value of $\mu$ to the elementary sets in the former case, and the highest values in the latter. They implicitly excluded the possibility that there may be any sort of compensation between indicators.

A different way to consider the aggregation operation on $n$ fuzzy sets (with $n \geq 2$ ) is through a generalised mean:

$$
\mathrm{h}_{\alpha}=\left(\mathrm{a}_{1}, \mathrm{a}_{2}, \ldots \mathrm{a}_{\mathrm{n}}\right)=\left[\left(\mathrm{a}_{1}^{\alpha}+\mathrm{a}_{2}^{\alpha}+\ldots+\mathrm{a}_{\mathrm{n}}^{\alpha}\right) / \mathrm{n}\right]^{\frac{1}{\alpha}}
$$

with $\alpha$ equal to 1 for the arithmetic mean, $\alpha=-1$ for the harmonic mean and $\alpha=0$ for the geometric mean; $a_{1}, a_{2}, \ldots, a_{n}$ denote the membership grades of each element belonging to sets $A_{1}, A_{2}, \ldots, A_{n}$.

In an analogous way, a class of weighted averaging operations may be derived:

$$
\mathrm{h}_{\alpha}=\mathrm{h}\left(\mathrm{a}_{1}, \mathrm{a}_{2}, \ldots \mathrm{a}_{\mathrm{n}} ; \mathrm{w}_{1}, \mathrm{w}_{2}, \ldots \mathrm{w}_{\mathrm{n}}\right)=\left[\sum_{\mathrm{w}_{\mathrm{i}}} \mathrm{a}_{\mathrm{i}}^{\alpha}\right]^{\frac{1}{\alpha}}
$$

where the weighting structure, expressed by $\mathrm{w}_{\mathrm{i}} \geq 0$ and $\Sigma_{\mathrm{w}_{\mathrm{i}}}=1$ specifies the relative importance assigned to each aggregate set.

The selection of a suitable weighting structure is an old and questionable issue. In a multidimensional approach, if each dimension of human wellbeing is considered as equally relevant, a neutral choice could be to assign an equal weight to all constitutive elements, as in [8] below: in this way we are not called upon to express uneasy judgements or to define a ranking among them. Alternatively, if we want to maintain an 'objective' approach to the measurement, a frequency-based weighting can be adopted. With regard to this a direct relation to the above membership function [2], $\mathrm{w}_{\mathrm{i}}$ has been defined 
as an inverse function of the frequency of the corresponding symptom of deprivation:

$$
\mathrm{w}_{\mathrm{i}}=\ln \left[\frac{1}{\mathrm{n}} \Sigma_{\mathrm{i}} \mu_{\mathrm{ij}}\right]
$$

and the choice of the logarithm is justified with the opportunity of not giving too much importance to the modalities showing a very low frequency (see Cheli and Lemmi 1995). 


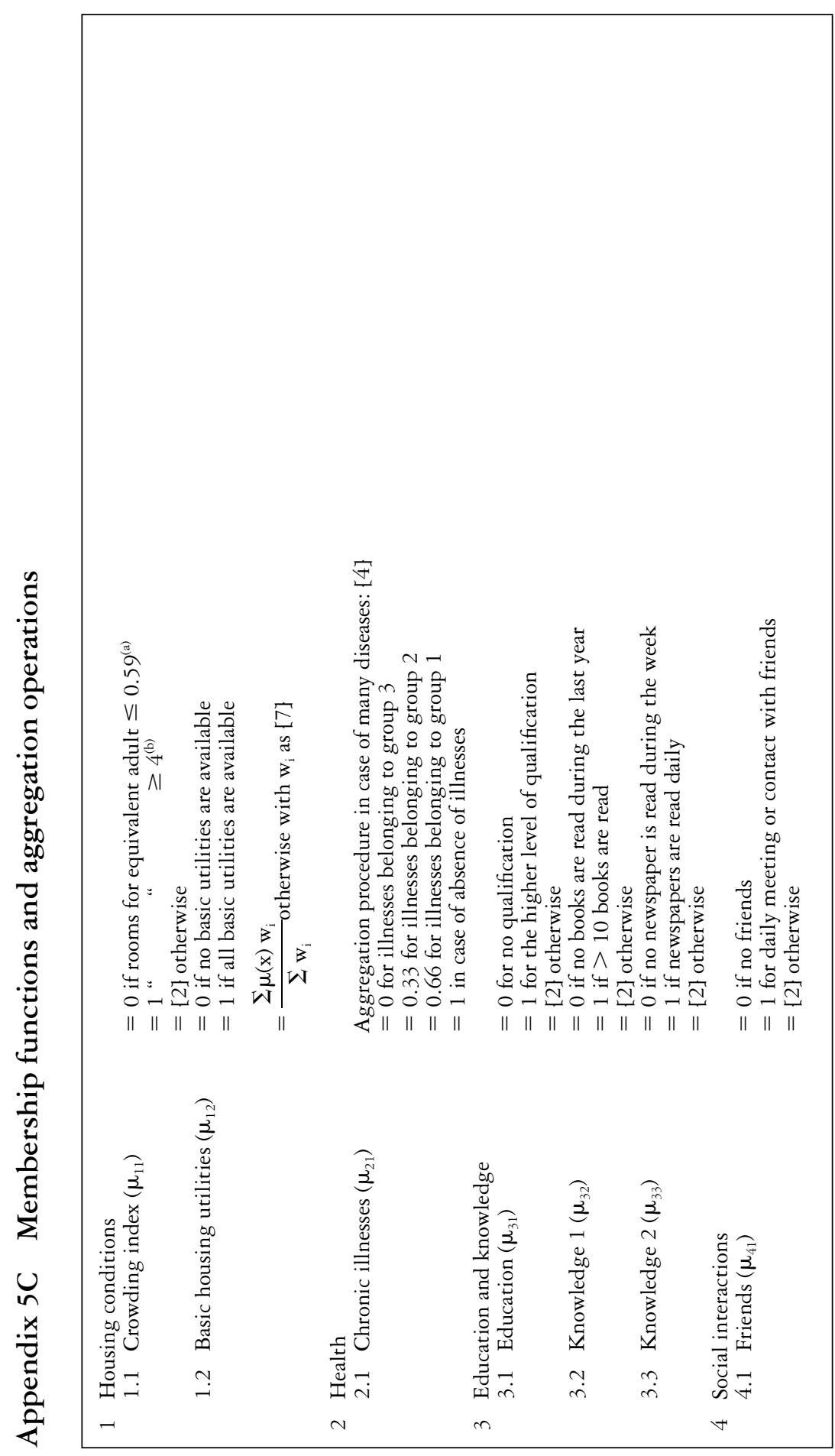




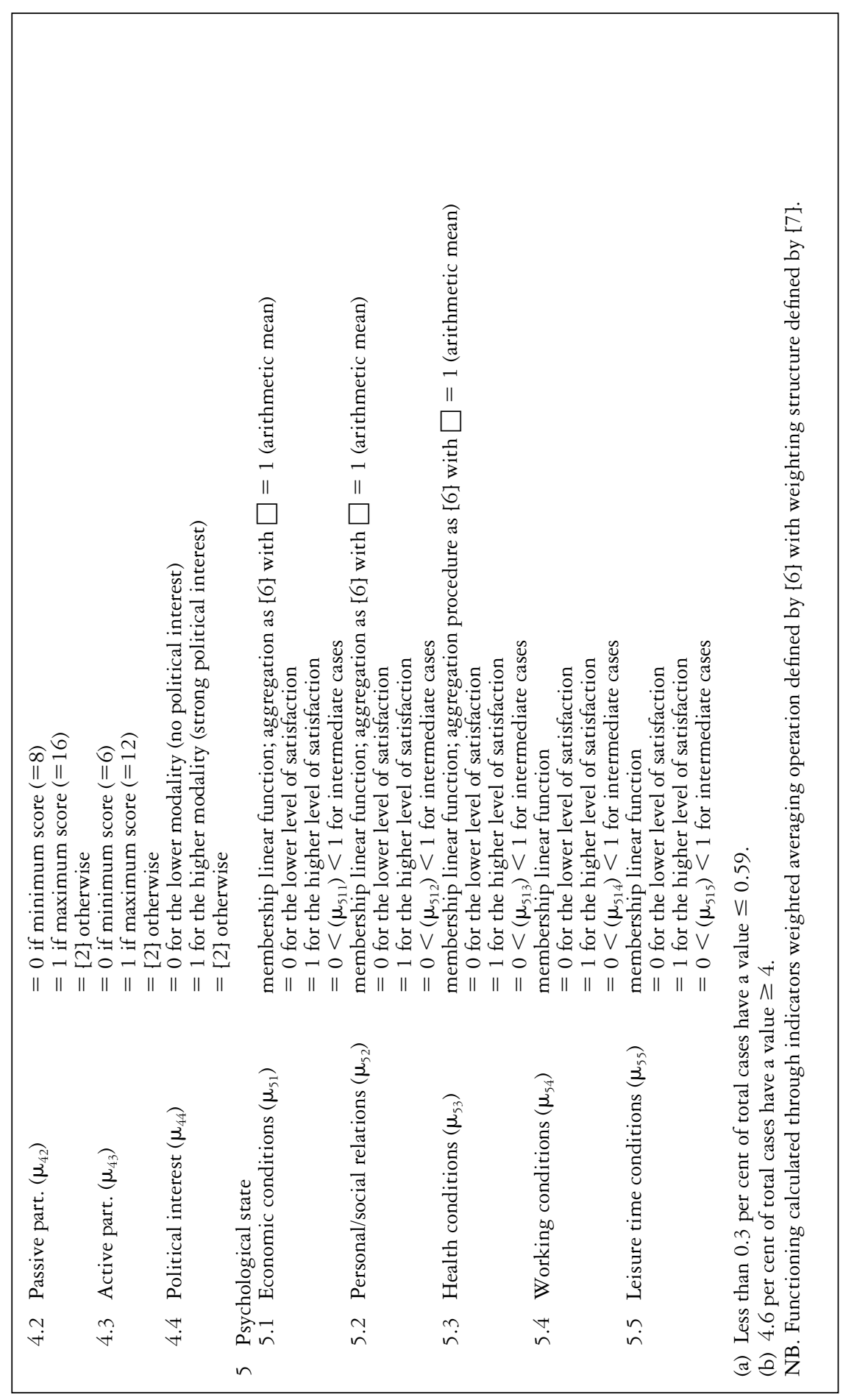




\section{Enrica Chiappero-Martinetti}

\section{Notes}

1 It has been estimated that in most industrialised countries the unrecorded economic activity is as large as the recorded activity in terms of hours of work, and the monetary value of domestic work is also supposed to be absolutely significant. See e.g. Addabbo and Caiumi 1998; Goldschmidt-Clermont 1994; Nyberg 2000. For an extended standard of living evaluation relating to Italy, see the econometric analysis carried out in Chapter 3, this volume.

2 With reference to Figure 5.1, this means limiting attention to the two extremes of the process of well-being.

3 On this argument, see e.g. Sen 1984, 1990; Tinker 1990.

4 See Becker 1981; Cigno 1991; Willis 1987. For a recent survey on household economic models, see also Grossbard-Shechtman 2001; Jefferson and King 2001; Mattila-Wiro 1999.

5 Among the few empirical analyses on the standard of living that refer to Sen's theoretical approach is that carried out by Schokkeart and Van Ootegem (1990) on a sample of unemployed people in Belgium, who were asked to answer questions about their economic, physical, psychological and relational well-being. An interesting result that emerges from this research is that all these aspects (which are deemed by the authors to be essential functionings in a person's life) are strongly affected by the family structure, with the result that those who lived alone suffered major difficulties, not only for obvious economic reasons but even more for physical, psychological and relational reasons.

6 For the empirical analysis discussed in the following sections, I will refer largely to a previous paper (see Chiappero-Martinetti 2000, 2002) concerning a multidimensional assessment of well-being; however, I enlarge this analysis here by investigating the gender inequalities in both well-being and time-use distribution as well as the relationship existing between them.

7 With regard to this, see e.g. Desai 1990; Nussbaum and Sen 1993, as well as Sen's already cited works.

8 A simple equivalence scale has been applied, proposed by Carbonaro (1986), and based only on the number of household components.

9 Information on chronic diseases collected by the survey has been organised into three groups: non-disabling pathologies (i.e. hypertension, allergies, asthma and bronchial problems), partially disabling illnesses that can nevertheless be treated (i.e. diabetes, ulcers and other similar pathologies) and, finally, disabling illnesses such as cancer, heart attacks, nervous disorders and so on.

10 This is what may be defined as social capital.

11 Concerning the correlation on each indicator and/or dimension, see Chiappero-Martinetti 2000.

12 The fact of knowing, for example, that an individual habitually consumes breakfast or meat less than once a week does not tell us if these eating habits are the result of free choice or of economic restrictions. This distinction is, however, central to Sen's approach in that it is what differentiates the area of capabilities from that of the effective realisations.

13 In the following pages, I shall describe just a few essential elements of the methodology used by referring to the Appendix and to my previous papers already quoted for more technical aspects.

14 The average values for the total sample coincide with the average values only in the case of the group divided by sex. For the other groups, the differences in the total average values arise because the dimension of the subgroups varies depending on the cases.

15 This part complements the empirical evidence described in Chapter 2, where unpaid work in Italy is analysed in great detail by Addabbo using another data source: the 1989 ISTAT time budget survey. 
16 The only exceptions being for the single parent with a child for whom the amount of domestic work almost doubles: this type of family is, however, statistically irrelevant because it represents less than 1 per cent of the sample.

17 The cases where the head of the family was female (very few, in fact) were not considered. I have also excluded the effect of unpaid work carried out by the male head of the family on the well-being of the other components (children and wife), given the small amount of male domestic work revealed in the previous section.

\section{References}

Addabbo, T. and Caiumi, A. (1998) 'Extended income and inequality by gender in Italy', paper presented to the 25th International Association Review of Income and Wealth Conference, Cambridge, August.

Becker, G.S. (1981) A Treatise on the Family, Cambridge, MA: Harvard University Press.

Carbonaro, G. (1986) 'Nota sulle scale di equivalenza', in Commissione di Indagine sulla Povertà in Italia, La povertà in Italia. Rapporto conclusivo, Rome: Presidenza del Consiglio dei Ministri.

Cheli, B. and Lemmi, A. (1995) 'A totally fuzzy and relative approach to the multidimensional analysis of poverty', in Economics Notes 24: 115-34.

Chiappero-Martinetti, E. (2000) 'A multidimensional assessment of well being based on Sen's functionings approach', Rivista Internazionale di Scienze Sociali, 108(2): 207-39.

Cigno, A. (1991) The Economics of the Family, Oxford: Clarendon Press.

Desai, M. (1990) 'Poverty and capability: towards an empirical implementable measure', Working Paper no. 27, Development Economics Research Programme, London School of Economics.

Goldschmidt-Clermont, L. (1994) 'Monetary valuation of unpaid work', in International Conference on the Measurement and Valuation of Unpaid Work: Proceedings, Ottawa: Statistics Canada.

Grossbard-Shechtman, S. (2001) 'The new Home Economics at Columbia and Chicago', in Feminist Economics, 7(3): 103-30.

Jefferson, T. and King, J.E. (2001) "Never intended to be a theory of everything": domestic labor in neoclassical and marxian economics', Feminist Economics, 7(3): 71-102.

Mattila-Wiro, P. (1999) 'Economic theories of the household: a critical review', Working Paper no. 159, World Institute for Development Economics Research.

Nussbaum, M. and Glover, J. (1995) Women, Culture and Development: A Study of Human Capabilities, Oxford: Clarendon Press.

Nussbaum, M. and Sen, A.K. (eds) (1993) The Quality of Life, Wider studies in development economics, Oxford: Clarendon Press.

Nyberg, A. (2000) 'Power, gender and GNP', paper presented to the 20th European Association of Evolutionary Economics Conference, Berlin, November.

Ringen, S. (1996) 'Households, goods and well-being', Review of Income and Wealth, 42(4): 421-31.

Schokkaert, E. and Van Ootegem, L. (1990) 'Sen's concept of the living standard applied to the Belgian unemployed', Recherches économiques de Louvain, 56(3-4): 429-50.

Sen, A.K. (1984) Resources, Value and Development, Oxford: Blackwell, and Cambridge, MA: Harvard University Press.

(1985) Commodities and Capabilities, Amsterdam: North Holland.

(1987) The Standard of Living, Cambridge: Cambridge University Press. 


\section{Enrica Chiappero-Martinetti}

(1990) 'Gender and cooperative conflict', in I. Tinker (ed.), Persistent Inequalities: Women and World Development, New York: Oxford University Press.

(1992) Inequality Reexamined, Oxford: Clarendon Press.

(1993) 'Capability and well-being', in M. Nussbaum and A.K. Sen, The Quality of Life, Wider studies in development economics, Oxford: Clarendon Press.

- (1994) 'Well-being, capability and public policy', Giornale degli economisti e annali di economia, 7-9: 333-48.

- (1996) 'Freedom, capabilities and public action: a response', in A. Balestrino and I. Carter (eds), Functionings and Capabilities: Normative and Policy Issues, Notizie di Politeia 12: 43-4.

- (1997) On Economic Inequality, Expanded edition with a substantial annexe by James Foster and Amartya Sen, Oxford: Clarendon Press.

(1999) Development as Freedom, New York: Knopf.

Tinker, I. (ed.) (1990) Persistent Inequalities: Women and World Development, New York: Oxford University Press.

Willis, R.J. (1987) 'What have you learned from the Economics of the Family?', American Economics Review, 77(2): 68-81. 


\title{
6 'Convenience consumption' and unpaid labour time
}

\section{Paradoxes or norms?}

\author{
Giuliana Campanelli
}

\section{Introduction}

This chapter analyses unpaid labour from a different perspective from the one often adopted in the literature on the subject and also from that of many contributions presented in this volume: we shall try to understand its relevance by looking at the demand side, and more precisely at consumption, rather than at the supply side.

In the light of the history of household consumption in the USA, the basic idea of our approach is that unpaid work represented and continues to represent an important field of investigation and 'manipulation' for both industrial and post-industrial economies always in search of markets for their production and reproduction. It represents, indeed, the 'household market' whose target group, initially composed of housewives only, has progressively changed to include women working outside the home and all the men undertaking unpaid work.

Focusing attention on the post-industrial societies, for which time seems to represent the scarcest resource, a simple scheme is proposed to explain the success of a particular group of products - within the household market defined as 'convenience consumption', the function of which seems to be to reduce unpaid labour time. ${ }^{1}$ By buying these products, indeed, consumers purchase not only the goods but time as well, and unpaid labour time in particular.

By looking carefully at the experience of the American economy, however, the relationship between convenience consumption and unpaid labour time (together with leisure time) produces much more complicated results than the ones economists and experts on marketing and business expected on the basis of their oversimplified models. Convenience consumption patterns were not adopted primarily by women working outside the home and, even more surprisingly, they did not reduce unpaid labour time. The time spent on unpaid work has remained fairly steady from 1920 to 1990, while for some housework activities it has even increased, in spite of convenience consumption. The scope of the chapter is to provide an explanation for such apparent paradoxes and to understand what new phenomena can be associated with the long-run stability of unpaid labour time. 


\section{Giuliana Campanelli}

\section{A methodological note}

In this chapter - as mentioned already - we refer mainly to the American experience, not only because the literature on convenience consumption started and developed there, but also because the figures for unpaid labour time in the American economy allow for a long-term perspective. We also hope that, given the high level of development attained by the USA, our investigation could, with the usual caveats, shed some light on the future of the household market and unpaid labour time in the Italian case too.

The difficulty of applying the above mentioned approach to the Italian economy arises for the following two reasons:

1 The absence of research on both convenience consumption and its relationship with unpaid labour. The only exception - considered in Section 3 of this chapter - is represented by some empirical investigation of a particular group of convenience consumption products defined as 'usa e getta' (use and throw them away), a fast-growing sector of the Italian economy.

2 The unavailability of time series on unpaid labour time; only in 1989 did the Italian Central Institute of Statistics start to provide figures on 'Bilanci del Tempo' (time balances) and for the time being they are limited to a few years. ${ }^{2}$

\section{The continuous search for markets: 'the household market' and its difficult creation}

An investigation of the functioning of industrial and post-industrial economies clearly shows the enormous efforts they made to acquire domestic and international markets for the production and reproduction of goods and services. The intensity of such efforts had to increase over time, due to the saturation phenomena that usually accompany rising incomes. To recall a well-known debate on capitalism, we can say that such a system always had to face the problems associated with possible 'crises of realisation', and these problems become more severe the longer the capitalist system survives. ${ }^{3}$ After the saturation of so-called mass consumption, which was crucial to the production and reproduction of the industrial system, it is usually argued that what will guarantee the market for post-industrial economies is the demand for services, in particular financial and personal services.

To look carefully at changes in consumption patterns, unpaid labour has always constituted a field of observation and 'manipulation', in view of the potential market for products that it could generate. The problem, indeed, was that such a market (from now on defined as the household market) was not always ready to buy products, but rather had to be constructed. Let us recall some of the main steps in this construction process.

If we take the USA during the 1920s, i.e. during Taylorism, we already 
see enormous efforts made by producers, economists, experts in marketing and advertising, to teach women how to become more efficient about housework (see Strasser 1982; Cowan 1989; Graham 1999). More precisely, through a very detailed study of the necessary movements and time associated with different housework activities, they wanted to suggest to housewives how to eliminate the waste of time, and energy in particular. These suggestions, apparently with the goal of improving the efficiency of housework, aimed ultimately to open up new markets for products, more specifically durable consumption goods such as refrigerators and washing machines. The producers of such durable consumption goods, indeed, knew very well that, in 1920, women - in particular, middle-class women - were responsible for 80 to 90 per cent of total household consumption and consequently they constituted a privileged target group. However, they had to be convinced to buy these particular goods and services.

The efforts to open up the household market were accompanied, if not preceded, by many publications aimed at preparing housewives to be more efficient about their housework. In a short time, indeed, a great number of books started to appear; e.g. Managing Home Efficiently, The New House Keeping, Scientific Management at Home, Household Engineering, The Efficient Kitchen, Efficiency in the Household. Needless to say, one should also add the enormous number of articles on the efficiency of household production which appeared in the Ladies Home Journal in the years between 1912 and 1919. ${ }^{4}$

All these considerations lead to a straightforward conclusion: the creation of the household market imposed a change in the form of household production. In this connection, one should recall that in the period usually defined as pre-industrial or agrarian, housework was fundamentally a production activity based on great physical effort without a definite timetable and with very little use of the marketplace. In the early phase of industrialisation, ${ }^{5}$ and particularly in the 1920s, entrepreneurs were trying to replace this kind of housework 'model' with one closer to the Taylorist firm, able to produce output by minimising effort and heavily dependent on the marketplace for its goods and services. Some scholars of the history of domestic work in the USA have seen in these phenomena of 'manipulation' of consumption patterns important efforts to achieve total industrialisation of domestic production. ${ }^{6}$ In addition, Strasser establishes a relationship between the phenomenon of opening up the market for domestic consumption and the end of community life of the previous period - community life based on a strong sense of solidarity. The new pattern of housework centred on the single consumer (in this case the housewife), who maximises her satisfaction by buying goods on the market, was expected to lead to her social isolation. ${ }^{7}$ At this point one may ask what will happen to domestic production and consumption today in the so-called post-industrial economies.

Once again, by looking at the experience of the American economy, one can see a strong relationship between changes in the productive structure 
and changes in the structure of domestic consumption, in the sense that as the productive structure moves towards the tertiary sector, the household market shows an increasing share of services bought in the marketplace as well (e.g. take-away meals and shopping by mail).

Once again, these processes reflect enormous efforts on the part of entrepreneurs, economists, experts in marketing and advertising to create an appropriate market for their products. It seems, however, that there are three main differences between industrial and post-industrial economies in the creation of the household market. First, in post-industrial societies, there is strong competition among sectors - mainly between industry and services to capture the household market. For example, with regard to the important market of goods and services for food, while the restaurateurs set lower and lower prices for restaurant and take-away meals, the food industry produces more and more cheap fast food to be consumed at home. Second, the household consumption target group has expanded over time and nowadays includes not only housewives, but also women working outside the home, as well as a growing number of men who do unpaid work (in several industrialised countries the proportion of such men seems to have increased in both absolute terms and hours spent). Third, while in industrial economies the main emphasis of advertising is on the reduction of physical effort, in the post-industrial economies it is mainly on time saving. ${ }^{8}$

This means that to understand some important changes which occurred in domestic consumption and production patterns in the post-industrial economies, one should analyse not only the product characteristics, but also the product functions, especially in relation to time and in particular to unpaid work time. There exists, indeed, a time dimension of consumption that should be considered explicitly, as will be shown below. This perspective will allow us to discover one additional difference between industrial and post-industrial economies and societies related to the different intensity of unpaid labour time that the literature does not seem to have acknowledged.

\section{Domestic consumption functions and unpaid labour time}

A vast area of the literature on post-industrial economies and societies argues that time represents the scarcest resource and that it imposes the greatest constraints on people (see Linder 1970; Robinson 1990). On this assumption, it would be easy to understand what has happened to some consumption items - in our case household consumption - by looking at their function in relation to unpaid labour time.

Our idea is that one should start by considering the time an individual has available in one day, in other words his or her total daily time, referring to a typical weekday and not a weekend. In this connection it is worth recalling that for a long time economic theory has broken down the working day into the following two main components: working time (WT) and 
leisure time (LT). Increasingly, however, at empirical and at theoretical levels the need has emerged to divide working time, too, into two main components, i.e. paid labour time (PLT) and unpaid labour time (ULT), where by unpaid labour time we mean that time spent primarily on housework and family care. ${ }^{9}$

On this basis, an average working day (WD) can be divided as follows:

$$
\mathrm{WD}=\mathrm{PLT}+\mathrm{ULT}+\mathrm{LT}
$$

Needless to say, in the case of housewives, the first component PLT is equal to zero, while for those who are not engaged in housework activities the second component ULT is equal to zero.

Taking post-industrial economies and assuming that it is not possible to reduce paid labour time, if people want to increase their leisure time - a growing desire that accompanies rising incomes ${ }^{10}$ - they have to shorten unpaid labour time. The problem is then how to achieve such a result. A possible strategy is to buy goods which, at least in their expectations (ex ante), will have the effect of reducing unpaid labour time. The idea of a distinction between ex ante and expost, from the point of view of the consumer, is important, since, as we shall argue below, the expected results can differ greatly from the actual ones.

Thus it will be possible to relax some of the time constraints by consuming specific goods and services, whose purpose is to save unpaid labour time. And it is on the basis of this simple approach that one can explain the enormous success of some goods and services - within the household market - the object of which is exactly that of 'buying working time in general', and unpaid working time in particular. Some of these goods could actually be very expensive since the relative price of saving time is very high.

In this connection it is worth emphasising that already at the end of the 1950 s in the USA, some contributions to the literature began to appear on the relationship between consumption and unpaid labour time (see Kelley 1958), and some of these issues reappeared at the end of the 1970s (see Voss 1967; Voss and Blackwell 1975, 1979; Berry 1979). These articles, even though they refer explicitly to the work of economists such as Gary Becker (Becker 1966) and Linder (Linder 1970), came mainly from experts in marketing and business. Their purpose, however, was not to recognise the importance of housework within post-industrial societies, but rather to understand the emerging markets for future production. ${ }^{11}$

A particular category was identified and defined as "convenience consumption' to indicate those goods and services - within domestic consumption - through which one can 'buy unpaid labour time'. ${ }^{12}$

Convenience consumption usually includes the following items:

- some durable consumption goods (e.g. microwave ovens, dishwashers, refrigerators, freezers, washers and driers, food processors); 


\section{Giuliana Campanelli}

- some non-durable consumption goods (e.g. frozen, canned, pre-cooked and instant foods, together with disposable products such as napkins, plates and nappies);

- some services (e.g. restaurants, purchased house cleaning, purchased dry cleaning and laundry and purchased childcare).

One should also add that, at the beginning, the literature on convenience consumption considered only the first group of goods, that is time-saving durable consumption goods, and emphasised the major role played by technical progress, incorporated into these goods, in reducing unpaid labour time. Later, this definition was extended to include time-saving foods and services mentioned above, so that the linkage with technical progress has become less important.

More interesting, however, are the expected results on the relationship between convenience consumption, unpaid labour time and leisure time. In particular, relative to convenience consumption, the experts on marketing and business expected the following two results:

- convenience consumption goods would be bought primarily by women working outside the home, since they have much less time available for housework and family care;

- the reduction of unpaid labour time due to the use of convenience consumption goods would increase leisure time, if paid labour time remains unchanged (or, as economists say, ceteris paribus).

The empirical investigations of labour time and convenience consumption did not seem to confirm these expectations; on the contrary, most produced very different, if not paradoxical results.

\section{The paradoxes of 'convenience consumption'}

Empirical investigations on convenience consumption have produced results that, as already mentioned, may be considered unexpected if not, in some cases, paradoxical. Let us recall them.

1 The relationship between convenience consumption and women's working conditions appears much more complicated than economists and experts in marketing and business expected. In the case of the American economy, a vast number of econometric studies did not find a significant relationship between convenience consumption and women working outside the home: other variables such as income, wealth, life cycles and changes in housing appeared more significant (see Strober 1977; Strober and Weinberg 1977, 1980; Weinberg and Winer 1983). In the case of Italy, a preliminary investigation of a fast-growing category of convenience consumption, i.e. 'Usa e getta' (use and throw 
them away), for the house ${ }^{13}$ during the 1990s shows that they are not bought primarily by women working outside the home, but by housewives and in particular by women from Southern Italy. They mentioned convenience and practicality as the main reasons for their behaviour, adding that these are important elements of that 'American way of life' which allows them to save time and energy. It is worth adding, however, that factors such as the number of children, of meals and of courses for each meal, together with the lack of water and good climate, can also play a crucial role in this result, and all these factors are greater in the case of Southern Italy (see Vesco 1998). One should also add that women working outside the home not only have less time, but perhaps are also less vulnerable to convenience consumption advertising and sales.

2 In spite of the expectations about convenience consumption, ${ }^{14}$ in the USA unpaid labour time does not seem to have fallen, but rather remained virtually unchanged between 1920 and 1990 (see Figure 6.1), particularly in the case of housewives. ${ }^{15}$

A disaggregated picture of unpaid labour time can, however, show interesting phenomena of time reallocation. Going back to the well-known study of Vanek (1974) for the American economy over the period 1926 to 1968, the following results emerged (see Figure 6.2): the time spent on preparing food has been reduced, whereas that devoted to shopping (including the time spent travelling from one shop to another) and managerial tasks, together

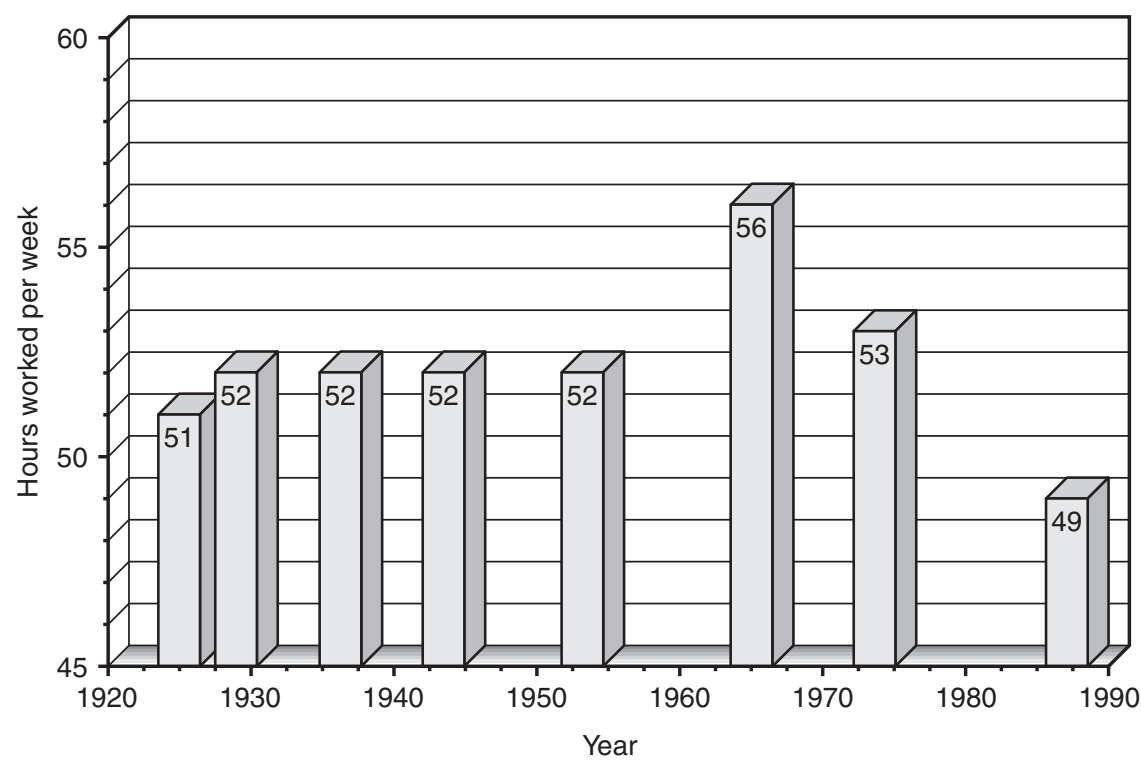

Figure 6.1 Housewives' weekly working hours. 


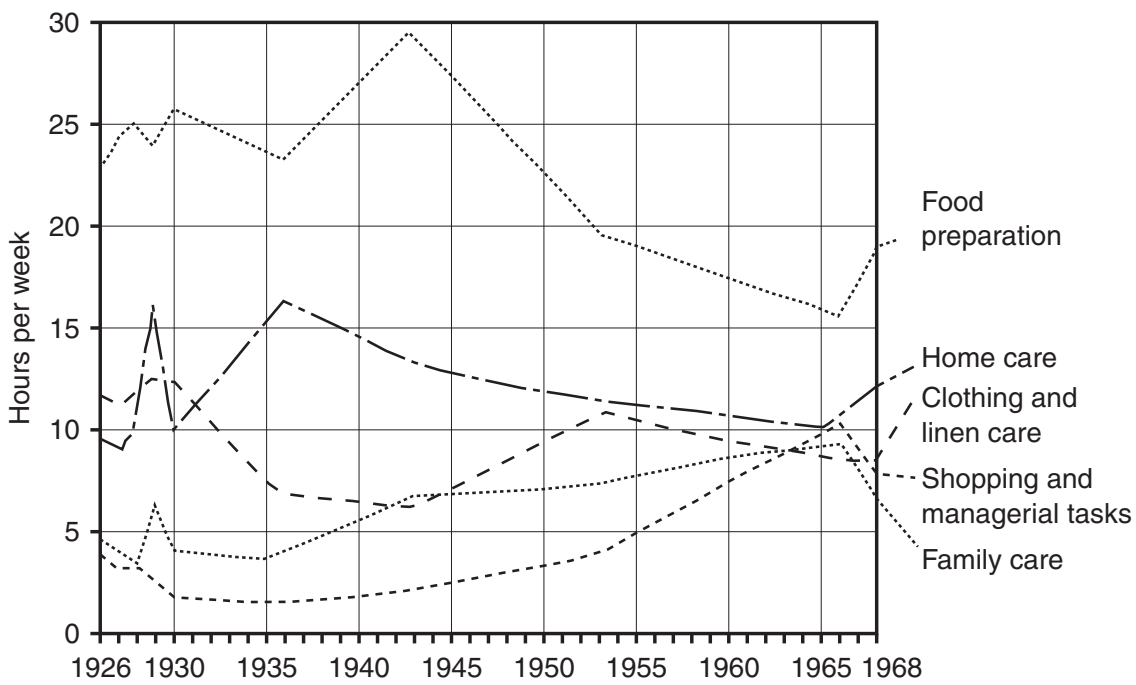

Figure 6.2 Distribution of time among various kinds of household work.

with home care and family care, has expanded. ${ }^{16}$ In particular, the time devoted to food preparation fell by about ten hours per week between 1920 and 1960, but it has been offset by an increase in the time spent shopping, and on managerial tasks and family care. The time devoted to laundry surprisingly increased (see Figure 6.3), in spite of convenience consumption use.

The explanation for this last, apparently paradoxical, result is quite simple: the standards of different housework activities (or tasks) can rise. An interesting example of this is the time devoted to laundry, since over time people have more clothes and want them to be cleaner. Thus one discovers that, for some convenience goods, the expected function (stressed by economists and business people) of saving unpaid labour time did not coincide with the reality since labour time did increase. Another case is that of family care, the standard of which, in spite of convenience consumption, has risen so much that a very large increase in time is required: to be a good mother (and, why not, a good father) nowadays encompasses not only material, but also psychological needs. Let us not forget, moreover, that even children's leisure requires greater expenditures of time and money on the parents' part, given all the different after-school activities in which children are involved.

Thus in this scenario technical progress incorporated into convenient consumption did not play the role that many economists and business people believed it would: to substitute leisure time for working time. This happened because, although, on the one hand, technical progress is able to save time relative to one housework activity, on the other hand, it contributes to 


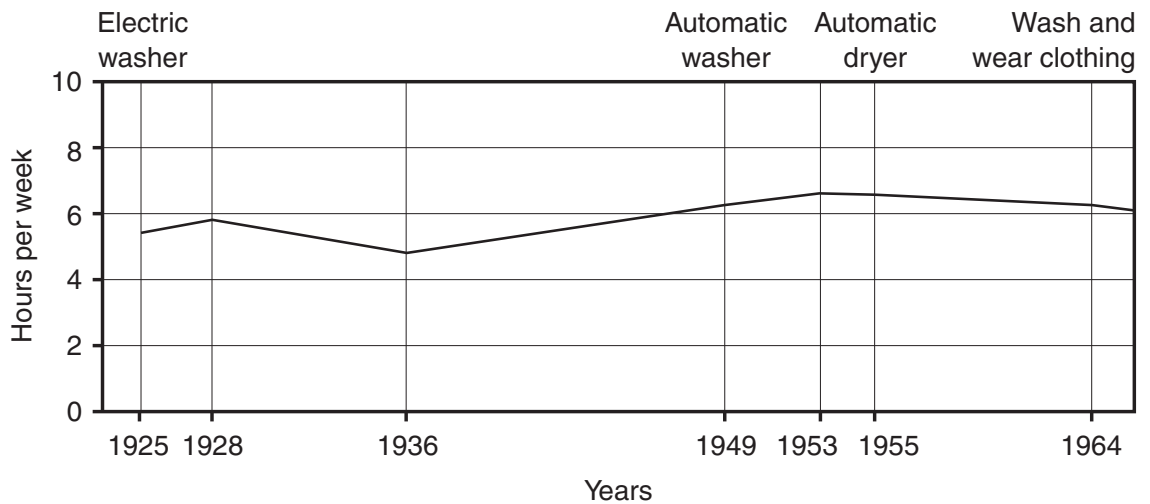

Figure 6.3 Time devoted to laundry.

generating new activities and new standards. This means that one should also include quality considerations of unpaid labour time since one may use the latest equipment to increase the quality of one's work without considering whether this is related to a reduction in working hours. ${ }^{17}$

Another example of these apparent paradoxical results of technical progress is represented by small home appliances, which seem to have extended rather than reduced tasks and work time for housewives, especially if one takes into account the time spent reading instructions, taking the appliances out of the cupboard and cleaning them after use. ${ }^{18}$ Sometimes the list of paradoxical results of technical progress incorporated into convenience consumption includes even the refrigerator: the reason is that it has contributed to an increase in the amount and variety of food stored in the home, with a consequent increase in the number of trips to supermarkets which are usually located at a distance from housing, and an increase in travelling time for shopping.

In conclusion it seems that, as Cowan argues, the 'modern labor-saving device eliminates drudgery, not labour'. ${ }^{19}$

\section{A crucial dimension of unpaid labour time: its intensity}

It seems that increased standards and new activities of unpaid labour, together with greater pressures generated by a leisure time that is more and more 'time consuming', ${ }^{20}$ can produce a relevant intensification of unpaid labour time. In other words, one hour of unpaid labour in a post-industrial society can differ greatly from 'the same hour' in an industrial or agrarian society in terms of numbers, in some cases standards too, of housework activities (or tasks) done per unit of time. One should not forget, indeed, 
that in a post-industrial society some of these activities may be done simultaneously thanks to technical progress which makes it possible to wash clothes and linen in the washing machine, while the microwave oven warms up foods, the dishwasher washes the dishes of the last meal, and so on. Thus the concept of unpaid labour has to be put in a historical perspective, since the two dimensions of total time devoted to it and the other, perhaps even more crucial one, of its intensity, defined as the number of housework activities per hour, can substantially change over the years.

Unfortunately, the literature on unpaid labour has devoted little attention to the second dimension, and the lack of data on the intensity of housework activities allows only speculation. However, we are convinced that the long-run stability of unpaid labour time in the USA between 1920 and 1990 is associated with an increase in the number of housework activities per hour, with a consequent rise in stress for the unpaid workers.

\section{Conclusions}

The scope of this final section is to summarise the main results of the chapter and to discuss them in the light of the whole research project.

Our investigation reveals the crucial role played by unpaid labour in creating additional demand in both industrial and post-industrial economies. The history of domestic consumption in the USA during the 1920s shows how the transformation of domestic production, and consequently of household consumption, was instrumental to the production and reproduction of the economic system as a whole.

In current post-industrial societies, in which time seems to be the scarcest resource, an understanding of the changes in consumption patterns necessitates an examination of the functions of goods and services in relation to time rather than of their characteristics. Taking the household market, we explained the enormous success of a particular group of goods and services defined as convenience consumption - by relating them to the possibility of reducing unpaid labour time.

Once again, however, as in other contributions to this project, ${ }^{21}$ it emerges that an investigation of convenience consumption and its relationship with unpaid labour requires a more comprehensive framework than the one often adopted in the literature. Our investigation shows, indeed, that oversimplified approaches based on quantitative variables alone (such as total time or quantity of physical effort), on single agents (such as consumers distinguished by working conditions) who maximise their welfare independently of social norms, and on technical progress that replaces labour time with leisure time in a fundamentally static scenario, may be misleading.

Every activity of unpaid labour has a standard that should be considered explicitly. In addition, these standards can be raised very rapidly thanks to technical progress that sometimes, instead of increasing leisure time, creates new standards and new activities. Our investigation reveals that, in the case 
of time devoted to laundry, technical progress incorporated into convenience consumption, instead of reducing unpaid labour, actually increased it. The explanation for this apparent paradox is simple: the standard of an activity can rise - in this case people have more clothes and want them to be cleaner. The standard of family care has also shown a dramatic increase over the years.

Thus increased standards and new activities of housework, together with the pressures of 'more time-consuming' leisure time, can change the 'rhythm' of unpaid work in post-industrial societies, in the sense that they can increase the number of housework activities per hour. This means that an investigation of unpaid labour time should consider both total time devoted to such labour and its intensity, defined as the number of activities (or tasks) per hour. Unpaid labour has, indeed, an historical dimension that should be explicitly taken into account; otherwise we shall not be able to understand the new phenomena related to post-industrial vis-à-vis previous societies.

Attention to the historical dimension may also be crucial in explaining shifts in the standards of consumption due not only to technical progress, but also to changes in consumption norms. ${ }^{22}$ Today, these norms seem less and less related to local and/or national contexts and more to global ones, thanks mainly to the effect of the media. In this different scenario, the working conditions of unpaid workers can be irrelevant. In fact, housewives may be much more receptive or vulnerable to those norms than women who work outside the home, and the empirical results for the use and throw it away' sector in Italy seem to support this idea. In this connection one should also add that the adjustment process of individuals to consumption norms requires the explicit introduction of qualitative variables such as the sense of suitability, the ethics of responsibility, or simply the spirit of emulation of those who do unpaid work; these factors can no longer be ignored. It is on the basis of the idea of the standard as the state of a material and symbolical process that one can understand that 'demonstration effect' ${ }^{23}$ or that 'image effect' of consumption which underpins new needs and new aspirations, sometimes independently of the resources possessed. ${ }^{24}$ Thus one can easily believe that convenience consumption is not only unable to reduce unpaid labour and increase leisure time, but can command a greater quantity of paid labour. ${ }^{25}$ If this is reasonable, then the assumption of ceteris paribus should also be abandoned, since we are implying that paid work, unpaid labour and leisure time (both for the single agent and society as a whole) are clearly interrelated and not distinct, as a vast part of the economic literature claims to be the case. ${ }^{26}$

\section{Acknowledgements}

The author would like to thank G. Gattei, A. Romagnoli and A. Picchio for their valuable suggestions. The views expressed as well as any remaining errors are solely the author's own. 


\section{Giuliana Campanelli}

\section{Notes}

1 As we shall see later, in Figure 6.2, unpaid labour time includes the time devoted to food preparation, home care, clothing and laundry, shopping and managerial tasks, and family care.

2 See the contributions of Addabbo (ch. 2), and Addabbo and Caiumi (Chapter 3). It is worth adding that the consumption figures provided by ISTAT are not very useful for the construction of an index of convenience consumption since the disaggregation used does not allow us to understand its relationship with unpaid labour time.

3 See Sweezy (1942), and in particular Baran and Sweezy (1966: Chapter 5). They argue that sales promotion is a very old phenomenon: it appeared in various forms in Antiquity, it increased its importance in mediaeval times and extended its action under capitalism.

4 See Graham 1999.

5 Between approximately 1860 and 1910.

6 See Strasser (1982: 7), in which she says, 'Food, shelter, and clothing became matters of social production, not private, created by profitable industrial manufacture'. See also Cowan (1989: 5), in which she defines this phenomenon as 'the industrialization of the home'.

7 See Strasser 1982: 9.

8 On this issue, see Gross and Sheth 1989

9 For a more detailed disaggregation of unpaid labour time, see n. 1 and Figure 6.2.

10 On this relationship, see Voss 1967.

11 Voss and Blackwell claim that they examine the implications of a theory of time resources 'for marketing strategy' (1979: 297).

12 For the single housewife, unpaid labour time may be 'bought' through convenience consumption or 'saved' through the actual work of other members of the family, particularly the partner or the children.

13 Includes disposable napkins, plates and glasses.

14 One should add that for many housewives this period represents the transition from living in the countryside to living in town and consequently factors other than convenience consumption contributed to reducing unpaid labour time, such as the availability of utilities (in particular electricity, running water and gas) and the reduction in the number of children.

15 Women working outside the home show instead a reduction in unpaid labour time.

16 A comparison of these results with the Italian case is not straightforward, not only because of the different disaggregation of unpaid work activities, but also because of the lack of time series for such activities. Addabbo's and Addabbo and Caiumi's contributions (Chapters 2 and 3, this volume) suggest that, in the case of Italy, the time devoted to food preparation represents a consistent share of the total time spent on domestic activities.

17 With regard to the technological systems that presently dominate our households, Cowan argues that they 'were built on the assumption that a full-time house-wife would be operating them, since very few people in the last one hundred years (when the foundations for these systems were being laid) wanted adult women to leave their homes in order to work in the labor market, or believed that adult women themselves would ever want to go out to work' (Cowan 1989: 211). Another very interesting issue analysed by Cowan is the different impact of technical progress on men's and women's household tasks; she concludes that industrialization served to eliminate the work that men (and children) had once been assigned to do, while at the same time leaving the work of women either untouched or even augmented'. See Cowan 1989: 63, 64.

18 See Bose et al. 1984.

19 See Cowan 1989: 100. 
20 It is worth adding that the nature of leisure time also changes over time: in postindustrial societies, not only does it assume a greater relevance, but it also involves more activities (e.g. sports, theatre, cinema, travelling and goods such as books and records), the characteristic of which is to be 'time consuming'. See Voss 1967.

21 See, in particular, the contributions of Picchio and Chiappero-Martinetti which stress the importance of the study of unpaid labour of a welfare concept defined in a multidimensional space.

22 On this issue, see Brown 1987.

23 On the importance of consumption as a symbol of respectability and power, one should recall the seminal work of Veblen (1912: ch. 4).

24 The object of many businesspeople was and continues to be to stimulate popular aspirations towards higher and higher levels of consumption in order to increase demand, without any consideration of the possible gap between consumption patterns and effective resources. This phenomenon could explain another interesting paradox related to consumption in the USA according to which 'Overall, half of the population of the richest country in the world say that they can not afford everything they really need' (Schor 1998: 6). Another interesting example of this paradox is represented by the following title of a newspaper article quoted by J. Schor: 'Feeling poor on 100,000 dollars a year' (Schor 1998: 12).

25 This might partly explain the constant increase of time devoted to paid labour time which - according to Schor - occurred in the USA during the 1980s. See Schor 1992 passim.

26 On this point see the Introduction to this volume.

\section{References}

Baran, P.A. and Sweezy, P.M. (1966) Monopoly Capital. An Essay on the American Economy and Social Order, New York: Monthly Review Press.

Bartos, R. (1978) 'What every marketer should know about women', Harvard Business Review, 56(2): 73-85.

Becker, G.S. (1966) 'A theory of the allocation of time', Economic Journal, 75(3): 493-517.

Bell, D. (1973) The Coming of Post-industrial Society: A Venture in Social Forecasting, New York: Basic Books.

Bellante, D. and Foster, A.C. (1984) 'Working wives and expenditure on services', Journal of Consumer Research, 11(4): 700-7.

Berkowitz, E.N., Walton, J.R. and Walker, O.C. (1979) 'In-home shopper: the market for an innovative distribution system', Journal of Retailing, 55(2): 15-33.

Berry, L.L. (1979) 'The time-buying consumer', Journal of Retailing, 55(4): 58-69.

Bose, C.E., Bereano, P.L. and Malloy, M. (1984) 'Household technology and the social construction of the household', Technology and Culture, 25(1): 53-82.

Brown, C. (1987) 'Consumption norms, work roles and economic growth, 1918-80', in C. Brown and J. Pechman (eds) Gender in the Work Place, Washington, DC: The Brookings Institution.

(1994) The Standard of Living, Cambridge, MA: Blackwell.

Bryant, K.W. (1988) 'Durables and wives' employment - yet again', Journal of Consumer Research, 15(3): 37-47.

Cowan, R. (1989) More Work for Mother, London: Free Association Books.

Cross, G. (1993) Time and Money: The Making of Consumer Culture, New York: Routledge. Gillett, P.L. (1976) 'In-home shopping: an overview', Journal of Marketing, 40(4): 81-8. 


\section{Giuliana Campanelli}

Graham, L.D. (1999) 'Domesticating efficiency: Lillian Gilbreth's scientific management of homemakers, 1924-1930', Sign, 24(3): 633-75.

Gross, B.L. and Sheth, J.N. (1989) 'Time oriented advertising: a content analysis of United States magazine advertising 1890-1982', Journal of Marketing, 53(4): 76-83.

Kelley, E.J. (1958) 'The importance of convenience in consumer purchasing', Journal of Marketing, 22(3): 32-8.

Linder, S. (1970) The Harried Leisure Class, New York: Columbia University Press.

McCall, S.H. (1977) 'Meet the workwife', Journal of Marketing, 41(3): 55-65.

Oropesa, R.S. (1993) 'Female labor force participation and time-saving household technology: a case study of the microwave from 1978 to 1989', Journal of Consumer Research, 19(2): 567-79.

Picchio, A. (1992) Social Reproduction, Cambridge: Cambridge University Press.

Reilly, M.D. (1982) 'Working wives and convenience consumption', Journal of Consumer Research, 8(2): 407-18.

Robinson, J.P. (1990) 'The time squeeze', American Demographics, 12(2): 30-3.

Rosenburg, L.J. and Hirschman, E.C. (1980) 'Retailing without store', Harvard Business Review, 58(4): 103-12.

Schaninger, C.M. and Allen, C.T. (1981) 'Wife's occupational status as a consumer behaviour construct', Journal of Consumer Research, 8(4): 189-96.

Schary, P.B. (1971) 'Consumption and the problem of time', Journal of Marketing, 35(2): $50-5$.

Schor, J.B. (1992) The Overworked American: The Unexpected Decline of Leisure, New York: Basic Books.

- (1998) The Overspent American, New York: Basic Books.

Sharony, N. and Fox, K.D. (1983) 'Buying time and saving time: strategies for managing household production?', Journal of Consumer Research, 10(4): 197-208.

Strasser, S. (1982) Never Done, New York: Pantheon Books.

Strober, M.H. (1977) 'Wives' labor force behaviour and family consumption patterns', American Economic Review, 67(2), Paper and Proceedings: 410-17.

Strober, M. and Weinberg, C.B. (1977) 'Working wives and major family expenditures', Journal of Consumer Research, 4(4): 141-7.

- (1980) 'Strategies used by working and non working wives to reduce time pressure', Journal of Consumer Research, 6(2): 338-48.

Sweezy, P.S. (1942) The Theory of Capitalist Development, New York: Monthly Review Press.

Vanek, J. (1974) 'Time spent in housework', Scientific American, 231(4): 116-20.

Veblen, T. (1912) The Theory of the Leisure Class, London: Macmillan.

Vesco, B. (1998) L'usa e getta per la tavola. Un settore ancora sconosciuto ma in forte espansione, Unpublished BA dissertation, University of Bologna.

Voss J. (1967) 'The definition of leisure', Journal of Economic Issues, 1(2): 91-106.

Voss, J.L. and Blackwell, R.D. (1975) 'Markets for leisure time', in Advances in Consumer Research, vol. 2, Chicago, IL: Schlinger. Association for Consumer Research.

- (1979) 'The role of time resources in consumer behaviour', in O.C. Ferrell, S.W. Brown and C.W. Lamb Jr. (eds) Conceptual and Theoretical Development in Marketing, Chicago, IL: American Marketing Association.

Weinberg, C.B. and Winer, R.S. (1983) 'Working wives and major family expenditures: replication and extension', Journal of Consumer Research, 10(4): 259-63.

Zyck, C., McCulloch, J. and Smith, K.R. (1996) 'Trade-offs between purchased services and time in single parent and two-parent families', The Journal of Consumer Affairs, 30(1): $1-23$. 


\title{
$7 \quad$ Young people living with their parents
}

\author{
The gender impact of co-residence \\ on labour supply and unpaid work
}

Gianna Claudia Giannelli and Chiara Monfardini

\section{Introduction}

In Southern Europe young adults leave home much later than they do in Northern Europe. This problem has implications both for the labour market and for the intra-household distribution of unpaid work. Although unpaid work remains almost exclusively a female duty, it is observed that the later young people leave home, the larger the burden of domestic work for older women compared to younger women.

Let us define co-residence as adult children living in the parental home. This chapter analyses young adults' decisions concerning family coresidence, study and work, with the objective of studying the implications for unpaid work. We investigate the behaviour of young people on the assumption that the decisions concerning human capital investment, labour market participation and family status are interrelated. The aim of the analysis is to focus on the determinants of the different pairs of combinations of the activity status (being a student, worker or neither of the two, e.g. housewife), and the family status (living with parents or with a partner away from parents).

The existing economic literature on this subject is not extensive. To our knowledge, only a few studies assume paid work and family status to be determined jointly. One of the few economic models of leaving the parental home is by McElroy (1985), who estimated a multivariate probit model of the joint determination of paid work and family status of young American men. Her model indicates that at a sufficiently low offered wage, a young man lives with his parents and does not work. When the offered wage rises, he works in the market but remains in his parents' household; finally, if the offered wage is sufficiently high, he works and quits the parental home. The conclusion is that parents insure their sons against poor market opportunities.

Another set of studies, leaving aside work decisions, focuses on coresidence as an implicit voluntary transfer of parents to their children. Rosenzweig and Wolpin (1993) introduce the decision on human capital investment while treating co-residence as a voluntary intergenerational 


\section{Gianna Claudia Giannelli and Chiara Monfardini}

transfer. Their article focuses on parents' decisions, but also has implications for the study of the decisions of the young men themselves. In particular, they find that young American men in school were more likely to receive contemporaneous parental support, particularly in the form of shared residence. In addition, Ermisch (1997) explores the issue of the support for human capital investment by young British adults from their parents' perspective. He finds that richer parents are more likely to support their sons' human capital investment through monetary transfers rather than through shared co-residence, but that shared co-residence is more likely to be offered to young working people.

We focus on Italy. Other studies for this country find a positive relation between unemployment of young co-resident people and family income (Belli 1997), or take a sociological perspective (Ongaro 1998). The question for policy-makers is whether this behaviour is related to the structure of the Italian labour market and welfare system: the former would tend to ensure a job for the middle-aged heads of household while the latter would be biased by a too generous pension system. A too rigid labour market together with the absence of subsidies for students would, moreover, constrain young people who decide to undertake further educational investment to live in their parental home until they complete their education. This system leads to obvious economic and social distortions such as, to mention a few examples, the delayed formation of new households which in turn leads to a decrease in fertility, an ageing population and an ever increasing pressure on the pension system (see e.g. Padoa Schioppa 1997).

We wish to measure the relative contribution of the individual, family and market characteristics to the probabilities in the choice made. Adopting a gender perspective, we distinguish between male and female behaviour, a fundamental distinction for the implications for unpaid work.

\section{Co-residence in Italy}

Italy is a country where the phenomenon of young people delaying their departure from the parental home even beyond the age of 30 is massive and increasing, even compared to other Mediterranean countries.

According to a multipurpose survey conducted by the Italian National Statistical Institute (ISTAT 1990, 1998), 52 per cent of Italians aged 18 to 34 lived with their parents in 1990 and the percentage rose to 59 per cent in 1998. Even young adults in their thirties tend to leave their parental home later: in 199018 per cent of males aged between 30 and 34 still lived with their parents, rising to 29 per cent in 1998. The corresponding percentages for females are 10 per cent and 15 per cent, respectively.

The data for our analysis are drawn from the Bank of Italy sample survey on family budgets of Italian households in 1995 . The survey, covering 8,135 households and 23,924 individuals, provides information on a number of relevant variables, some relating to the household, some to the individual. 
Table 7.1 Observed sample frequencies (and percentages) for males aged 18 to 32

\begin{tabular}{llll}
\hline & $\begin{array}{l}\text { Members of } \\
\text { parents' household }\end{array}$ & $\begin{array}{l}\text { Not members of } \\
\text { parents' housebold }\end{array}$ & Total \\
\hline Working & 377 & 135 & 512 \\
& $37 \%$ & $13 \%$ & $51 \%$ \\
Studying & 485 & 0 & 485 \\
& $48 \%$ & $0 \%$ & $48 \%$ \\
Out of the labour force & 12 & & \\
and not studying & $1 \%$ & $0 \%$ & 14 \\
& 874 & 137 & 1,011 \\
Total & $86 \%$ & $14 \%$ & $100 \%$ \\
& & &
\end{tabular}

Source: BI survey (1995).

We looked at young people aged 18 to 32, with a high school diploma, not unemployed (because of the assumption that young people choose their status). Tables 7.1 and 7.2 show the sample frequencies of the different pairs of outcomes by sex.

The status 'not member of parents' household' in practice means living with a partner, since the state of 'living alone' seems not to be chosen by young Italian people. In substance, the decision to leave the parents' household in Italy coincides with the decision to live with a partner.

The frequency distribution indicates the outcomes that are relevant for the analysis. Males may decide to work and live with their parents, study and live with their parents or work and form a new household. Females have an additional option, namely to become housewives. The most frequent state for both sexes is to be a student and co-reside with parents. Males choose to

Table 7.2 Observed sample frequencies (and percentages) for females aged 18 to 32

\begin{tabular}{llll}
\hline & $\begin{array}{l}\text { Members of } \\
\text { parents' household }\end{array}$ & $\begin{array}{l}\text { Not members of } \\
\text { parents' housebold }\end{array}$ & Total \\
\hline Working & 284 & 179 & 463 \\
& $26 \%$ & $16 \%$ & $43 \%$ \\
Studying & 490 & 10 & 500 \\
Out of the labour force & $45 \%$ & $1 \%$ & $46 \%$ \\
and not studying & 23 & & \\
& $2 \%$ & 101 & 124 \\
Total & 797 & $9 \%$ & 1,087 \\
& $73 \%$ & 290 & $100 \%$ \\
\hline
\end{tabular}

Source: BI survey (1995). 


\section{Gianna Claudia Giannelli and Chiara Monfardini}

work and co-reside with parents more than do females, and the difference is almost the same as the percentage of females who choose to form a new household and become housewives.

\section{Variables}

Our objective is to measure separately the effects on the choice of status of the individual's own human capital and of family background (human capital of the parental family). The first variable is approximated by the type of high school diploma while the second is approximated by the educational level of the father of the young person (either university degree or lower) and by his professional qualification (essentially a sectoral dummy for working in public administration and for holding a managerial position at the age of his adult children in 1995: see Appendix 7A). A dummy variable for fathers aged over 65 should capture the effect on adult children's decisions of having a retired father. Controls for mothers' human capital have turned out to create turbulence in the results on the effects of family background (e.g. the introduction of mothers' education reversed the sign of some of the coefficients of fathers' education). Family income is usually proxied by fathers' human capital and position in the labour market, and those are the variables to be used if one is convinced that the effect of parents' education on adult children's choices operates mainly through income (the lack of data on parents' income does not allow us test this hypothesis). Furthermore, the variable on mothers' participation in the labour market could not be used, since it relates to a point in time (at their adult children's age, for example) and the careers of the cohorts of mothers of adult children in our sample (if they participated) are very likely to be interrupted.

A demographic variable for the number of sons and daughters present in the parental family takes account of the size of the family of origin with the hypothesis that the number of children is correlated negatively with the income that parents allocate to raise each child.

The performances of the labour and housing markets are the two main constraints on young peoples' choices. ${ }^{1}$ It is assumed that a poor labour market performance, proxied by a high unemployment rate for young people, might oblige some young people to go on investing in education or to become inactive (through a discouraged worker effect). The current (1995) youth unemployment rate by sex and region controls for this effect on the hypothesis that the participation decision may be revised at any point in time.

High prices for housing is likely to cause some young people to delay leaving their parental home. Since the decision to leave the parental home, once taken, is assumed to be irreversible, prices for housing in the year of marriage (or the year of beginning to cohabit with a partner) is the relevant variable for the group of non-co-resident young people. ${ }^{2}$ Co-resident young people, instead, are assumed to be able to revise their decision at each point 
in time, and for them the current price of housing (in 1995) is the variable chosen to proxy this effect on their cohabitation decisions.

The Italian socio-economic system is split sharply between North and South: some regional dummies are therefore introduced to capture other unobserved characteristics of young people. This allows us to test more firmly some empirical evidence which states, for example, that working and cohabiting with parents is a widespread phenomenon in North-eastern Italy.

\section{Results}

We estimate a multinomial logit model of the relevant states. The coefficients and standard errors derived from the multinomial estimation procedure are reported in Appendix 7B. Tables 7.3 to 7.5 present the results in terms of marginal effects, elasticities and effects on probabilities of the categorical variables.

Table 7.3 shows the characteristics of the reference individual (i.e. the average values of the continuous variables and the modal value for the categorical variables in the sample). The reference male is about 25 years old, he has a technical high school diploma, he has one brother (or sister), lives in the South, his father is between 50 and 60 years old and has an elementary school diploma, he faces an average unemployment rate of about 20 per cent and a housing price index that is higher than the cost of living. The

Table 7.3 Reference individual characteristics

\begin{tabular}{lcc}
\hline & Man & Woman \\
\hline Età & 24.5934 & 24.4317 \\
Etas & 604.8353 & 596.9080 \\
Studprof & 0 & 0 \\
Studtec & 1 & 1 \\
Studmag & - & 0 \\
Studlic & 0 & 0 \\
Nw & 0 & 0 \\
Ne & 0 & 0 \\
C & 0 & 0 \\
Padpens & 0 & 0 \\
Coop1 & 0 & 0 \\
Coop2 & 1 & 1 \\
Laureap & 0 & 0 \\
Medsupp & 0 & 0 \\
Medinfp & 0 & 0 \\
Padamm & 0 & 0 \\
Padalt & 0 & 0 \\
Nfrattot & 1 & 1 \\
Dis1529 & 20.2390 & 32.7261 \\
Indabit & 1.0991 & 1.0817 \\
Const & 1 & 1 \\
\hline
\end{tabular}


176 Gianna Claudia Giannelli and Chiara Monfardini

Table $7.4 a$ Marginal effects and elasticities - women

\begin{tabular}{|c|c|c|c|c|c|c|}
\hline & \multicolumn{2}{|c|}{ Work and co-reside } & \multicolumn{2}{|c|}{ Work and married } & \multicolumn{2}{|c|}{ House and married } \\
\hline & m.e. & Elast. & m.e. & Elast. & m.e. & Elast. \\
\hline Eta & 0.0205 & 1.1163 & 0.0682 & 14.5714 & 0.0431 & 14.2594 \\
\hline DIS1528 & -0.0038 & -0.2764 & -0.0038 & -0.8671 & 0.0004 & 0.1890 \\
\hline Indabit & 0.8441 & 2.0325 & -0.7158 & -6.7675 & -0.4160 & -6.1192 \\
\hline
\end{tabular}

Table 7.4b Marginal effects and elasticities - men

\begin{tabular}{|c|c|c|c|c|}
\hline & \multicolumn{2}{|c|}{ Work and co-reside } & \multicolumn{2}{|c|}{ Work and married } \\
\hline & m.e. & Elast. & m.e. & Elast. \\
\hline Eta & 0.0827 & 3.8815 & 0.0220 & 15.2532 \\
\hline DIS1529 & -0.0028 & -0.1074 & -0.0013 & -0.7142 \\
\hline Indabit & 0.3567 & 0.7479 & -0.2344 & -7.2612 \\
\hline
\end{tabular}

reference female is slightly younger, but has the same characteristics as her male counterpart, with the exception of the unemployment rate, which is nearly 33 per cent.

Table 7.4 reports the estimated marginal effects and elasticities of the continuous variables. The high elasticity with respect to age of leaving the parental home reflects the fact that the reference individual is around 24 years old, an obviously critical starting age for the probability of getting married. More interestingly, it is found that if the unemployment rate increases by 1 per cent, the probability of working and getting married decreases by 86 per cent for women and by 71 per cent for men. By contrast with the reference state of being a student and living with parents, it is more probable to choose to be a student when the unemployment rate increases.

The price of housing has a substantial effect on the probability of getting married for both men and women: the probability falls by between 6 and 7 per cent for an increase of 1 per cent. Since the effects are very similar in the event of working and getting married and of not working and getting married (for women), it may be concluded that this variable influences only the decisions about family arrangements.

Turning to the categorical variables, Table 7.5 presents the effects on the predicted probabilities of variations in the categorical variables with respect to the reference individual. As already shown in Table 7.4, the probability of the different states varies with age (this becomes evident as the reference levels of age increase), but here it is interesting to note that while the probability of all the other states goes in the same direction for both sexes, the probability of working and co-residing decreases with age for females, 
Table 7.5 Effects on probabilities of variations in categorical variables

\begin{tabular}{|c|c|c|c|c|c|c|c|}
\hline & \multicolumn{4}{|l|}{ Women } & \multicolumn{3}{|l|}{ Men } \\
\hline & $\begin{array}{l}\text { Work } \\
\text { and } \\
\text { co-reside }\end{array}$ & $\begin{array}{l}\text { Work } \\
\text { and } \\
\text { married }\end{array}$ & $\begin{array}{l}\text { Study } \\
\text { and } \\
\text { co-reside }\end{array}$ & $\begin{array}{l}\text { House } \\
\text { and } \\
\text { married }\end{array}$ & $\begin{array}{l}\text { Work } \\
\text { and } \\
\text { co-reside }\end{array}$ & $\begin{array}{l}\text { Work } \\
\text { and } \\
\text { married }\end{array}$ & $\begin{array}{l}\text { Study } \\
\text { and } \\
\text { co-reside }\end{array}$ \\
\hline Average & 0.4493 & 0.1144 & 0.3624 & 0.0739 & 0.5242 & 0.0355 & 0.4403 \\
\hline Età $=26$ & 0.4301 & 0.2356 & 0.1866 & 0.1469 & 0.6192 & 0.0773 & 0.3035 \\
\hline Età $=28$ & 0.3434 & 0.3728 & 0.0713 & 0.2126 & 0.6651 & 0.1739 & 0.1611 \\
\hline Età = 30 & 0.2906 & 0.4535 & 0.0309 & 0.2249 & 0.6258 & 0.2937 & 0.0805 \\
\hline Studprof & 0.4772 & 0.1889 & 0.1711 & 0.1629 & 0.7330 & 0.0607 & 0.2063 \\
\hline Studmag & 0.4011 & 0.0980 & 0.4379 & 0.0629 & & & \\
\hline Studlic & 0.0870 & 0.0177 & 0.8768 & 0.0187 & 0.0901 & 0.0051 & 0.9048 \\
\hline Padpens & 0.5225 & 0.0879 & 0.3511 & 0.0385 & 0.6796 & 0.0427 & 0.2777 \\
\hline Coop1 & 0.3616 & 0.0871 & 0.4930 & 0.0583 & 0.5798 & 0.0492 & 0.3711 \\
\hline Medinfp & 0.4724 & 0.1135 & 0.3645 & 0.0496 & 0.4820 & 0.0272 & 0.4908 \\
\hline Medsupp & 0.4480 & 0.0602 & 0.4717 & 0.0201 & 0.3637 & 0.0313 & 0.6050 \\
\hline Laureap & 0.3754 & 0.0398 & 0.5772 & 0.0076 & 0.2005 & 0.0022 & 0.7873 \\
\hline Padamm & 0.4688 & 0.0670 & 0.3624 & 0.0739 & 0.4190 & 0.0298 & 0.5512 \\
\hline Padalt & 0.3462 & 0.0882 & 0.4856 & 0.0800 & 0.4977 & 0.0128 & 0.4894 \\
\hline 2 frat & 0.3383 & 0.2491 & 0.2235 & 0.1891 & 0.5193 & 0.1148 & 0.3650 \\
\hline 3 frat & 0.1796 & 0.3823 & 0.0971 & 0.3410 & 0.4323 & 0.3123 & 0.2553 \\
\hline
\end{tabular}

whereas for males it increases from the age of 24 to the age of 28 , and then starts to decrease again.

The main objective of the analysis is to compare the relative variation in probabilities of individual and family background variables. Starting with the variables that approximate parental family income, it is found that if the father has a university degree, the probability of being a student and living with parents nearly doubles for men and increases by 20 per cent for women. A father with a university degree reduces the probability of working and coresiding, but even more the probability of getting married (especially of becoming a housewife). A father whose job involves managerial tasks increases the probability of studying. The probability of studying diminishes steadily if the father has lower educational levels. If the father is retired, the probability of co-residing and working increases (more for women).

If the number of children in the family of origin is believed to be correlated negatively with the share of parental income allocated to each child, the result concerning the number of brothers and sisters of the young person shows that family size is negatively correlated with the state of co-residing, either working or studying, for both sexes.

These results may be compared with those concerning the predictor of expected own income, i.e. the type of high school diploma attained by the young person. A vocational school diploma decreases the probability of coresiding and studying, and increases the probability of working and 
178 Gianna Claudia Giannelli and Chiara Monfardini

Table 7.6 Average probabilities by region of residence

\begin{tabular}{lllll}
\hline & $\begin{array}{l}\text { Work and } \\
\text { co-reside }\end{array}$ & $\begin{array}{l}\text { Work and } \\
\text { married }\end{array}$ & $\begin{array}{l}\text { Study and } \\
\text { co-reside }\end{array}$ & $\begin{array}{l}\text { House and } \\
\text { married }\end{array}$ \\
\hline Men & & & & \\
South & 0.4749 & 0.0205 & 0.5046 & \\
North-west & 0.5496 & 0.0368 & 0.4134 & \\
North-east & 0.5676 & 0.0434 & 0.3890 & \\
Centre & 0.5099 & 0.0545 & 0.4357 & \\
Women & & & & 0.0860 \\
South & 0.3512 & 0.0680 & 0.4939 & 0.0576 \\
North-west & 0.5156 & 0.1250 & 0.3020 & 0.0918 \\
North-east & 0.5288 & 0.1416 & 0.2737 & \\
Centre & 0.4185 & 0.1576 & 0.3321 & \\
\hline
\end{tabular}

co-residing, especially for males. A lyceum diploma (academic high school, which predicts the highest expected income level) has the highest positive effect on the probability of studying and co-residing with parents.

Table 7.6 presents the average probabilities by region of residence. These have been calculated by associating the corresponding regional average unemployment rate and housing cost index to the reference individual of each region.

Young people living in the South have the highest probability of studying (the lowest of working and co-residing) and young people living in the North-west the lowest (but the highest of working and co-residing). It is interesting to compare the probabilities for the South with the averages of Table 7.4: the probability of co-residing and studying increases from 36 per cent to 49 per cent for females, and from 44 per cent to 50 per cent for males. This effect is driven entirely by the unemployment rate, which reaches dramatic levels in the South ( 53 per cent for females and 36 per cent for males). ${ }^{3}$ A simple simulation sheds more light on the dimension of the discouraged worker effect. If young females in the South experienced the unemployment rate of the North-east (around 17 per cent), their probability of studying and co-residing would drop to 26 per cent. If young males in the South experienced the unemployment rate of the North-east (around 8 per cent), their probability of studying and co-residing would drop to 39 per cent.

Traditionally, young people in the South used to marry earlier than in the other Italian regions. In the context of this analysis, our results show instead that young women in the South have the lowest probability of marrying and working, and that result does not change much, even when the probabilities of being a worker or a housewife are added. The same result applies to young men. In sum, unemployment discourages not only participation but also new household formation, and our model allows us to measure these effects in terms of probabilities. 


\section{Conclusions and implications for unpaid work}

The above analysis has shown that parental income has a major role in determining young people's choices. Even compared to the effects of the predicted own income of the young, these factors are extremely relevant. In particular, high parental income increases the probability of being a student, i.e. undertaking further educational investment and co-residing with parents. Lower parental income tends to increase the probability of coresiding and working, working and getting married for both sexes, and also of getting married and becoming a housewife for females. High levels of youth unemployment and increasing house prices tend to discourage labour force participation and departure from the parental home.

What are the implications for unpaid work? Using the 'Multipurpose survey on domestic work' (ISTAT 1993), we derive the distribution of unpaid work for a sample of young adults selected with the same criteria as Tables 7.1 and 7.2. Table 7.7 shows this distribution.

Co-residing young women do about three times the amount of domestic work compared with men of the same age. Married working women do more than three times the amount of domestic work done by unmarried women, and five times that of married men. Married males do only two hours more domestic work than unmarried co-residing young adult males.

Co-residing young adults imply a number of hours of unpaid work which may be compared to that implied by younger children: the results show, in fact, that young adults with two siblings have the highest probability of marrying (we interpret this as a result of an income effect, but also as evidence of an excessive burden of domestic work for the mothers).

We also tested for the hypothesis that working mothers imply a lower probability of co-residing for young adult children than non-working mothers: the dummies for the mother's state, however, do not turn out to be significant. Working mothers and non-working mothers of adult co-residing children do the same amount of unpaid work.

Finally, high unemployment (especially in the South) and high housing costs tend to delay departure from the parental home. The discouraged worker' effect that transforms potential workers into poorly motivated students helps to keep the burden of domestic work high for mothers well into old age.

Table 7.7 Domestic hours of work - people aged 18 to 32 with a high school diploma: weekly average hours

\begin{tabular}{llll}
\hline & Work and co-reside & Study and co-reside & Work and married \\
\hline Females & 8.16 & 8.93 & 27.4 \\
Males & 2.72 & 3.79 & 5.54 \\
\hline
\end{tabular}




\section{Appendix 7A Description of the variables}

\section{Individual variables}

ETA: age

ETAS: age squared

STUDPROF: vocational school diploma

STUDTEC: technical school diploma

STUDLIC: lyceum diploma

NW, NE, C: regional dummies; North-west, North-east, Central Italy.

South is the base.

\section{Family background variables}

PADPENS: father retired (born before 1931)

COOP1, COOP2: cohort of the father; up to 1936, 1936 to 1946

LAUREAP: father with a university degree

MEDSUPP: father with a high school diploma

MEDINFP: father with middle school diploma

PADAMM:* father working in the public administration

PADALT:* father with a managerial job (any position with a managerial

content, i.e. manager, executive, professional, entrepreneur; the base is unskilled, skilled and clerical workers)

*These two variables are not fully comparable for both co-resident and non-co-resident young people. This is because fathers' position in the labour market for: (1) co-resident young people refers to the time of the interview, since it is derived from the matching of fathers and adult children in the same family (so that this piece of information is reported by fathers themselves as members of the sample survey); (2) non-co-resident young people refers to fathers' position at the age of their adult children in the year of the interview (so that this piece of information is reported by young people living in a newly formed household in the section devoted to their family background). For some members of the sample, therefore, these variables record fathers' current position, and for others fathers' position at the age of their adult children.

Given this inconsistency, it has not been possible to exploit the available information on fathers' sector of employment. As far as the father's professional position is concerned, however, one could exploit the information on the managerial content of the job collapsing all positions with some managerial content in the dummy PADALT. The measurement error mentioned above is reduced under the assumption that, since non-co-resident young people are on average older than their co-resident counterparts, if their fathers are managers at the date of the interview (which is not known), their position at their children's age (which is known) should already have some managerial content (it is likely that the transition from blue collar to manager, for example, has low probability). The same line of reasoning applies to PADAMM, with the justification that in Italy it is usually observed that a person who has started a career in public administration tends to remain in that sector for the rest of his working life (see Bardasi and Monfardini 1997). Entering any kind of public administrative $\mathrm{job}$, in fact, requires passing a public competitive examination which involves an investment in human capital. Therefore, if fathers of non-co-resident young adults were employed in the 
public administration when they were fairly young, it is conceivable to assume that they are still there at the date of the interview. On the other hand, if they had started a career in the private sector, it is conceivable to assume that they have not switched to the public sector later on.

NFRATTOT: total number of siblings in the parental home. This variable may be gendered, i.e. disaggregated into number of brothers and sisters. Since the estimated coefficients of the gendered variables were not significantly different, the total number of siblings has been used instead.

It should be noted that the way the sample has been constructed has the drawback of over-representing siblings among co-resident young adults with respect to non-co-resident ones, since co-resident siblings, being members of a surveyed family, are all members of the sample; the number of siblings of non-co-resident young adults, instead, not being members of the sample, is derived from the dedicated section on family background. This has the unfortunate consequence of reducing the variability of family background variables for co-resident young people (siblings have the same family background).

\section{Market-specific variables}

These are constructed using official statistics provided by the Italian Statistical Office (ISTAT).

DIS1529: the unemployment rate by region and sex of people aged 15 to 29 (Source: 'Rilevazione delle forze di lavoro - media 1995', ISTAT). Unemployed people in the rate are: strictly unemployed, looking for their first job, other people looking for a job (see Eurostat definitions).

INDABIT: the ratio of the housing cost index over the total consumption price index. The housing cost index is included in the group for the calculation of the general consumption price index. It is therefore a relative measure of housing costs over total consumption costs. The housing cost index takes account of the following: rent, water, maintenance and repair of domestic equipment (see Metodi e Norme, Consumption prices, base $85=$ 100, Series A, no. 23, ISTAT). The time series used cover the years 1981 to 1995 and refer to the main town in each Italian region.

The construction of this variable comprises several steps.

1 Distinction by region, in order to approximate the housing costs by region of residence. This is an approximation because the ISTAT index is calculated only for the main town in the region (i.e. Florence for Tuscany).

2 It is assumed that co-resident young people may revise their decision to form a new household at each point in time. The relative housing costs variable for them is therefore measured in the year of the interview.

3 For non-co-resident young people who have already formed a new 


\section{Gianna Claudia Giannelli and Chiara Monfardini}

household, it is assumed that the relevant housing costs measure is that of the year of their marriage or union (in other words, their cohabitation decision after having left the parental home is assumed to be irreversible at least until they reach the age of 32). Since the year of marriage is not recorded in the survey, the non-co-resident sample has been divided into two groups: married with children and married without children.

Married with children: the year of marriage is derived assuming that they had the first child two years after their marriage i.e. 1995 (year of the interview) - age of first child (available in the survey) - 2;

Married without children: the year of marriage is derived imputing to each individual the modal age at marriage of his or her age cohort by region of residence. This has required the collection of the following official statistics: number of marriages by sex, age cohort at marriage and by region for the years 1981 to 1995 (Source: 'Annuario di statistiche demografiche', years 1981 to 1983 and 'Annuario matrimoni, separazioni e divorzi', years 1985, 1987 to 1995 , ISTAT). The time series was needed in order to take account of all possibilities ranging from being 32 in 1995 and having married at 18 (year of marriage 1981) to being 18 and having married in 1995. 


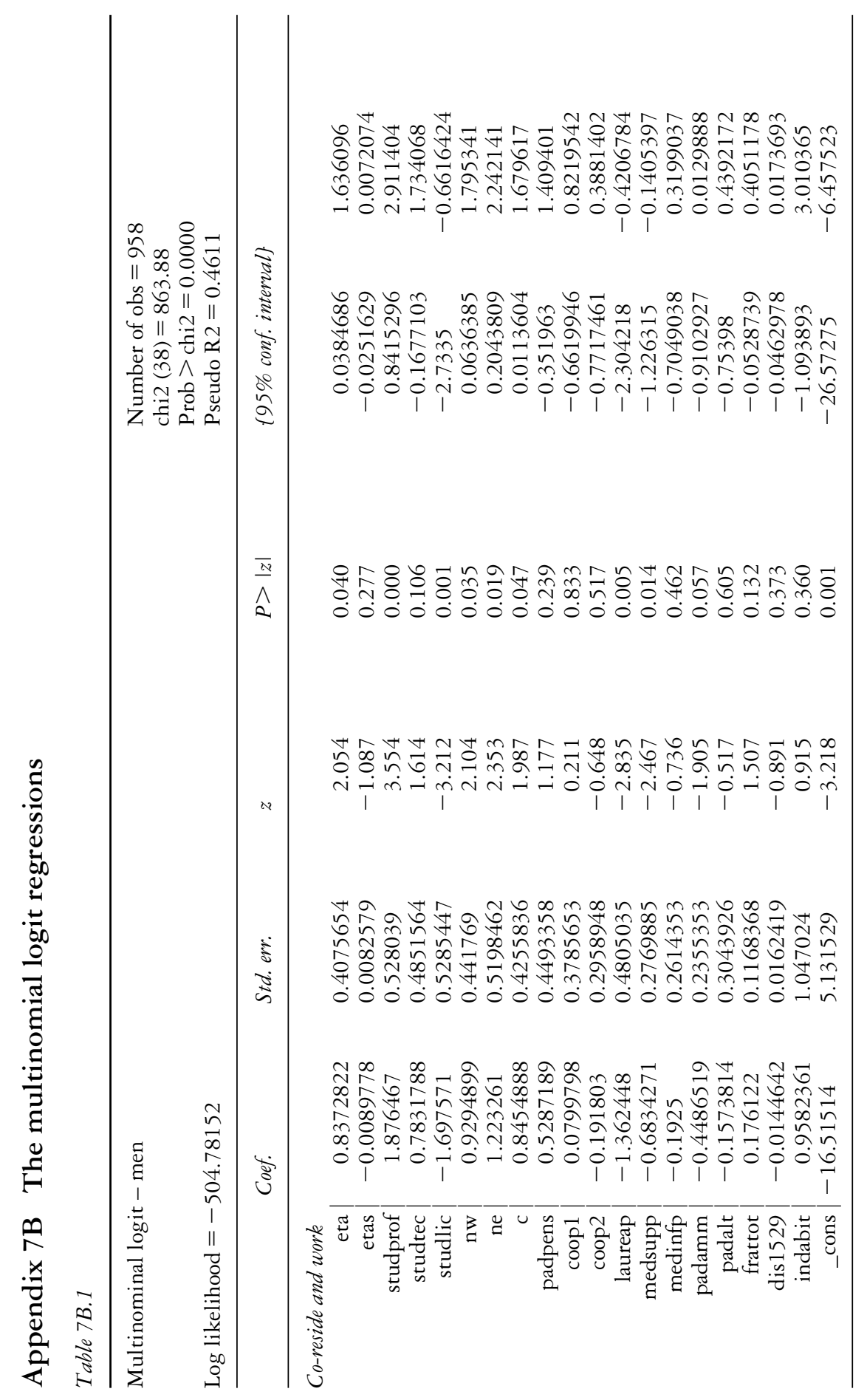




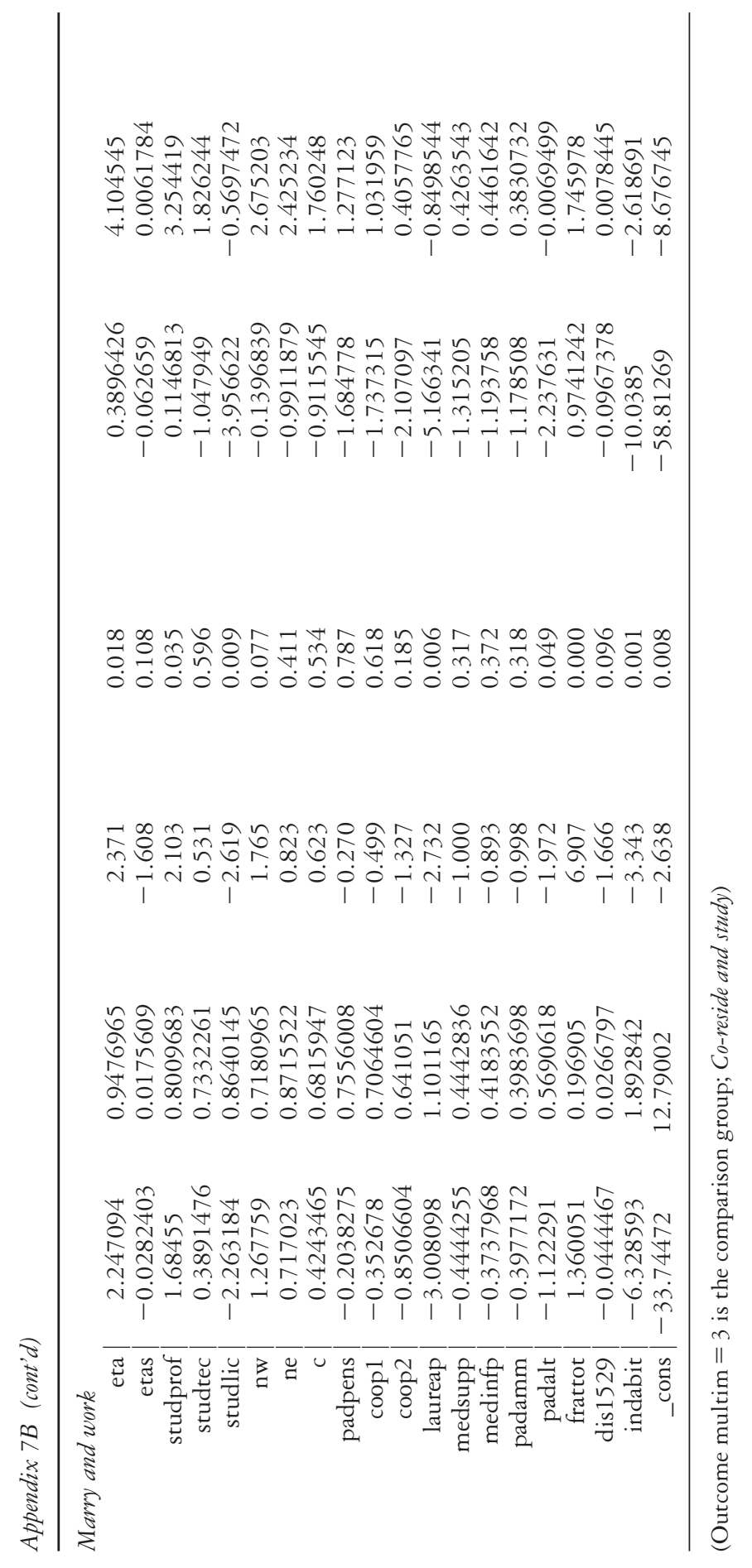




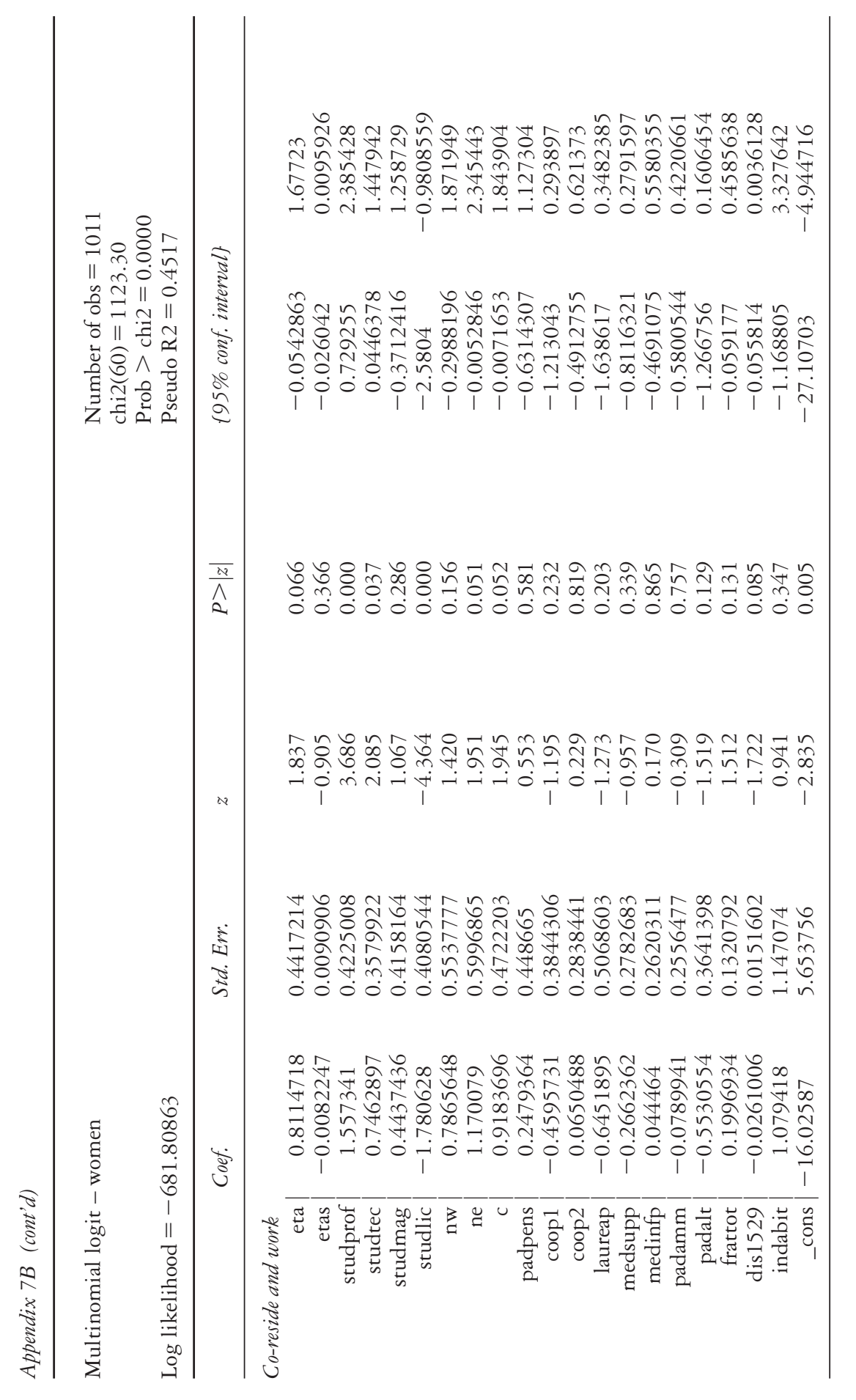




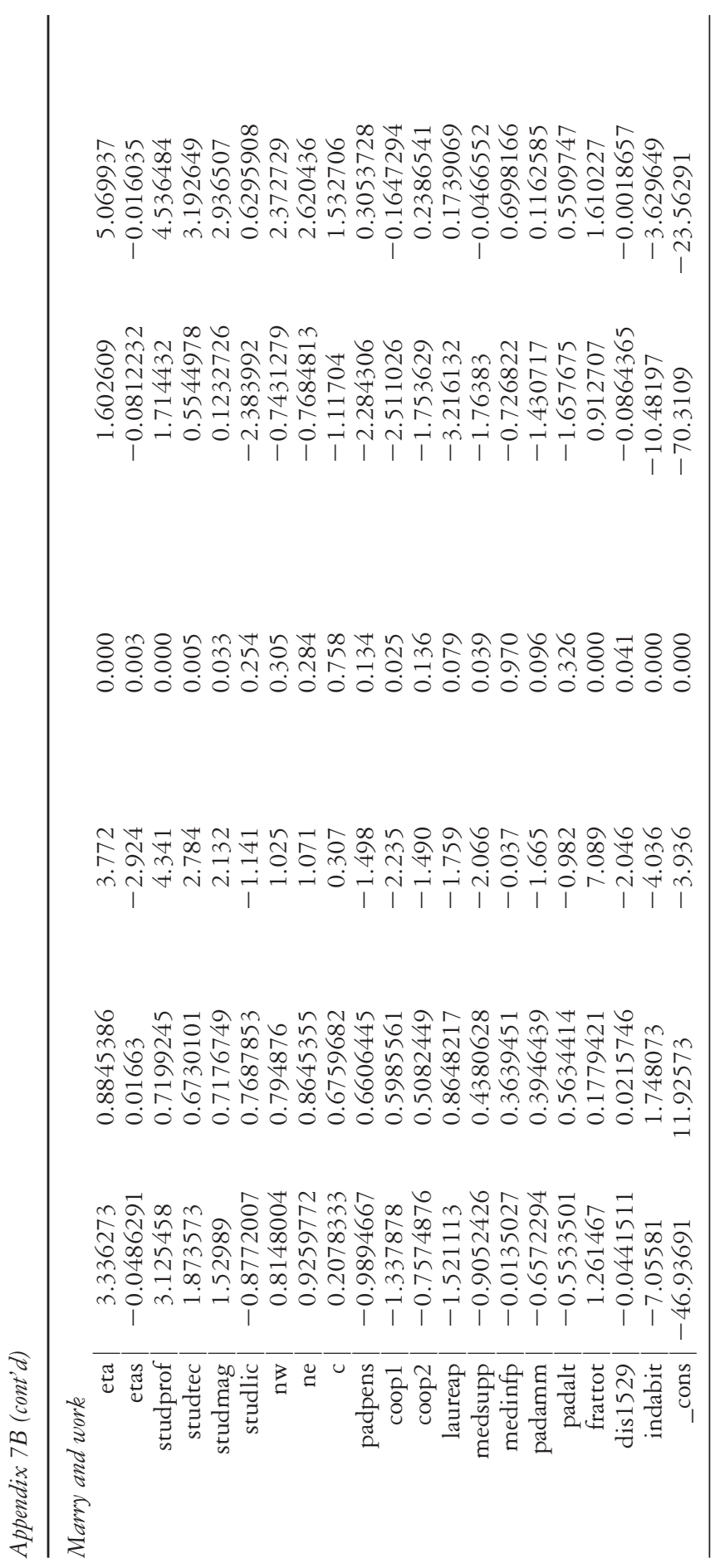




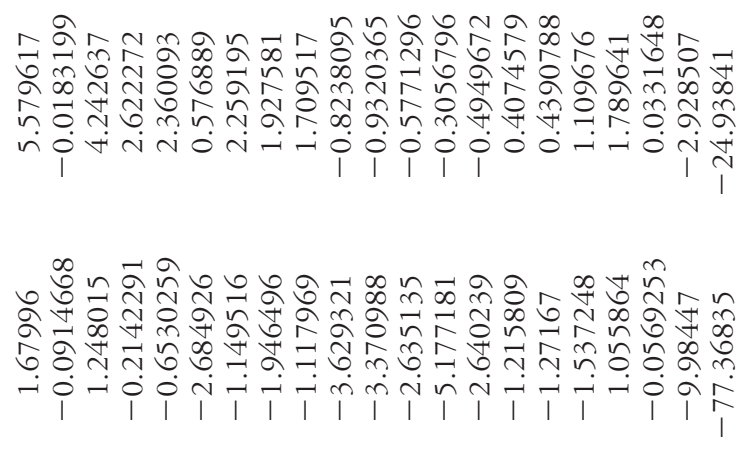

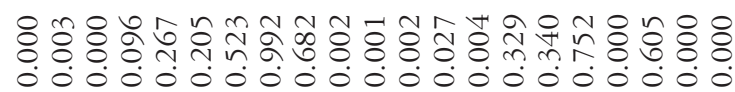

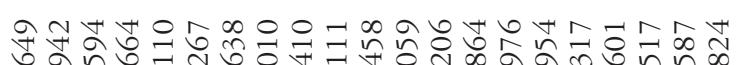

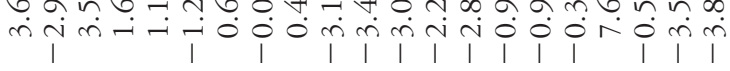

कo

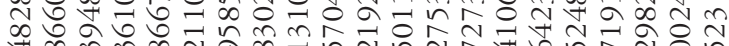
+

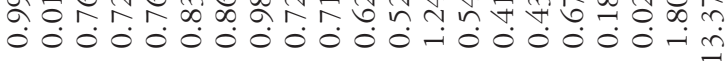

क

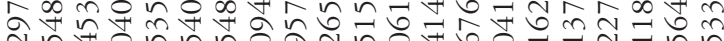

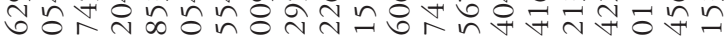

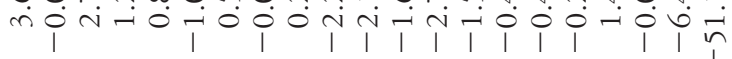

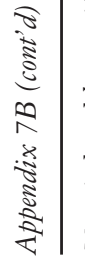

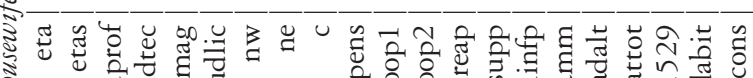

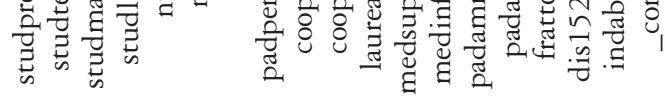




\section{Gianna Claudia Giannelli and Chiara Monfardini}

\section{Notes}

1 See Appendix 7A for the description of these two variables.

2 The information on the year of marriage or beginning of cohabitation is not available in the survey and had to be predicted. See Appendix 7A for details.

3 The probabilities for the South are derived by substituting the average level of unemployment and housing cost index for the Southern regions for the overall Italian average reported in Table 7.3. If only the regional unemployment rate is replaced, the result does not change.

\section{References}

Bank of Italy (1997) 'I bilanci delle famiglie italiane nell'anno 1995', Supplementi al bollettino statistico, 14: 1-114.

Bardasi, E. and Monfardini, C. (1997), 'La scelta del settore occupazionale in Italia: un'analisi probit trivariata' in Ricerche Quantitative per la Politica Economica, Bank of Italy (eds).

Belli, E.E. (1997) 'Struttura familiare, partecipazione alla forza lavoro e disoccupazione. La famiglia come ammortizzatore sociale?', Lavoro e relazioni idustriali, 2 (July to December): $103-50$.

Ermisch, J. (1997) 'Parental support for human capital investment by young adults', Institute for Labour Research, 10: 1-24.

ISTAT (1990, 1993, 1998) 'Famiglia, soggetti sociali e condizione dell'infanzia', in Indagine Multiscopo, Rome: ISTAT.

McElroy, M.B. (1985) 'The joint determination of household membership and market work: the case of young men', Journal of Labor Economics, 3: 293-316.

McElroy, M.B. and Horney, M.J. (1981) 'Nash bargained household decisions: towards a generalization of the theory of demand', International Economic Review, 22: 333-49.

Ongaro, F. (1998) 'Coresidenza di genitori e figli adulti nell'Italia di oggi', CNEL, Commissione di Politica Economica (I), Seminario sulla Distribuzione del reddito tra le famiglie e nelle famiglie.

Padoa Schioppa, K.F. (1997) 'Giovani e occupazione, vecchi e pensionamento: il nostro welfare state a confronto con quello europeo', Istituto Programmazione Economica, Working Paper no. 67.

Rosenzweig, M.R. and Wolpin, K.I. (1993) 'Intergenerational support and the life-cycle incomes of young men and their parents: human capital investments, coresidence, and intergenerational financial transfers', Journal of Labour Economics 1: 84-112. 


\title{
8 Unpaid and paid caring work in the reform of welfare states
}

\author{
Elisabetta Addis
}

\section{Symmetric and asymmetric welfare regimes}

The standard of living each person can enjoy depends on the sum total of available resources of time and money that she or he can control independently. The set of practices and institutions that we call the welfare state has a key role in reallocating money and time between people of different ages, wealth and sex, thus allowing them to achieve a given standard. It does this either by providing cash transfers or by providing public services, thus affecting the proportion of paid versus unpaid care work. By such redistribution the welfare state has contributed to reshaping women's roles, to changing the traditional division of labour within and outside of the family, and has affected gender relations between men and women in a variety of ways. The social notions of gender have changed as a result of these processes. ${ }^{1} \mathrm{We}$ may therefore discuss not just a 'welfare state', but a 'welfare regime', i.e. the configuration of practices producing care, including care produced in the home and by the market, as relevant for standards of living.

Redistribution between the rich and poor is a classic topic of debate on welfare systems. ${ }^{2}$ The original purpose of the welfare state was to create a safety net, an insurance against the risk of becoming poor due to illness, accident or old age. Redistribution between generations, both young and old people, is a more recent and less fully debated topic which emerged among economists when some financial pitfalls of existing pension regimes were subject to analysis by means of overlapping generations of identical 'representative agents'. ${ }^{3}$

In this chapter I shall leave aside these two topics. I shall focus instead on redistribution of time and money among people of different sexes, a topic that has still not been fully explored. In order to understand it, we need an analytical framework that explicitly takes into account the economic value of the services produced within the household, mostly by women, and how this redistribution influences gender roles and relations. Transfers of resources by the welfare state may be in cash or in the form of services. Cash may be used to purchase care, and public services may be substituted for domestically produced ones. In both cases, caregivers are hired to provide care and paid 
work is a substitute for unpaid work. Thus the size and form of public transfers determine gender relations. This produces a particular configuration in the distribution of work, between paid and unpaid labour, between public employment and private employment. It determines how much care will be provided domestically, purchased on the market, or provided by public services. It will therefore influence the status, economic independence and relative power of men and women.

Issues of redistribution between the sexes and its effects on gender may be obscured in many ways. ${ }^{4}$ First, there is a long tradition of measuring poverty and of redistributing wealth using the family, as opposed to the individual, as the relevant reference unit. This implies that within each family resource allocation is, by definition, equitable and not an object of policy intervention. Resources accruing to individual members are not even measured. This 'patriarchal' assumption has been challenged in economic literature. ${ }^{5}$ Second, often only money and goods are taken into account when measuring welfare: time is not. An equal sharing of money and goods could still mask an uneven distribution of welfare due to an uneven distribution of free versus working time, and time spent in domestic work is not counted as time spent working. ${ }^{6}$ Third, welfare provisions often make reference to one particular model of family, taking it as the norm, and, by doing so, assigning it normative value. Families and gender relations that do not correspond to this norm are not supported, while behaviour corresponding to the model is rewarded. Often, but not always, this model is the traditional family: a heterosexual family where the parents are married, the father is the exclusive breadwinner and the mother the exclusive housekeeper. Gearing provisions to this particular model of the family, as is done in Italy, means that those who break with this model, in particular women wishing to enjoy a 'double presence' as mothers and caregivers at home and as workers in the market, end up carrying a 'double burden'.

In the past decade, a growing body of literature examined the most important aspects of the relationship between gender and welfare policies, helping to penetrate this obscurity. ${ }^{8}$ My discussion below draws on that literature, summarising some of the findings in a general scheme in order to provide tools for the evaluation of public policies from this point of view.

Redistribution by wealth and by gender is very different in each of the three main models of welfare state (i.e. 'Liberal', 'Nordic' and 'Bismarckian'), identified in sociology and political science following the seminal work of Esping-Andersen (1990, 1996). These models differ in terms of main sources of financing for care (private purchase, income taxation, pay-roll taxation), main places where care takes place (private services, public services, the family) and the amount and channels of resources directed to the needy (cash transfers or transfers in kind by the state, private intra-family transfers). ${ }^{9}$

Each model has to provide the basic functions that constitute care, once produced entirely within families. These include the provision of food, 
clothing and clean shelter for all members of the family, care for the children, education, care for the sick, care for the frail elderly and resource transfers in the event of lack of income. This care may be produced by the home, the state or the market, and substitution among the three modes of care provision happens all the time. ${ }^{10}$ The chosen mix determines the condition of the caregiver: he or she may be a public employee, a private employee, or a relative with no formal employment ties.

Each model has a chosen, but never unique, way to provide for care, and each operates under a chosen 'mix'. A model is only a basic scheme, but each country uses all three ways of funding, all three channels of redistribution and all three places of care, each in different proportions. The 'Liberal' model is centred upon the market: care may be purchased, thus funding is private and care is provided in private, but not domestic, premises. Transfers of resources to the needy may be private (charities) and when public, they are in cash rather than in the form of services. The 'Nordic' model is centred on the state, uses income taxation to provide care, which is provided in public premises, and transfers by the state are in kind. The Bismarckian model is centred on the family, care is provided in the home and may use public or private sources or finances, because public transfers are in cash rather than in kind.

Italy, for example, fits best in the Bismarckian (Continental) model, with some particular Southern European characteristics, mostly absence of what Ferrera calls 'statualità' (roughly translated as respect for the state). That is, Italians do not trust the state (perhaps with good reason) and lack respect for rules (Ferrera 1998). Each model is developed with and within a corresponding political culture: liberalism, social democracy and Catholic social thinking (social-market economics), respectively. Each model is a 'regime', i.e. a set of coherent practices, fitting together in different ways to satisfy care needs.

The concept of 'welfare regime' is useful in that it underlines the fact that in each regime the parts fit together in a coherent way to satisfy care needs. This has strong implications for the possibilities of reform. It means that it is not always possible to copy 'best practices', to import single welfare programmes from other countries. When doing this, policy-makers should consider spill-over effects on the entire regime. Such spill-overs shift the burden of adjustment to policy reforms from one subset of citizens to another. When budget cuts decrease cash and services available to families, adjustment also involves the substitution of market- or state-produced care for home-produced care.

'Nordic' and 'liberal' welfare regimes, albeit very different in size and in other dimensions of equity, are similar in one way: they are relatively more 'symmetric', while Bismarckian regimes are 'asymmetric'. By 'symmetric' I mean that they treat men and women alike - differently in each regime, but both sexes in the same way. Bismarckian regimes are asymmetric in that they try to induce men and women towards different work: domestic unpaid work for women, paid work in the labour market for men. 


\section{Elisabetta Addis}

Major pathologies of the Southern European welfare systems arise from this asymmetry. On the other hand, this asymmetry has some positive byproducts that produce strong resistance towards reform. Moreover, attempts to reform the Bismarckian welfare regimes by mimicking reforms enacted in symmetric welfare regimes may worsen the asymmetry of the Bismarckian regimes, with unwelcome results in terms of equity, efficiency and financial soundness.

To make clear what I mean by symmetric, I shall resort to a graphic presentation of the flows of economic resources. However, the reader should bear in mind that diagrams necessarily simplify the complexity of an argument. The first diagram represents traditional social reproduction, after industrialisation but before the introduction of welfare provisions. We may think of the rural household in pre-industrial times as a place where people of both genders provided goods and services in kind to other family members and sold some of the family's surplus products. Industrialisation and urbanisation changed work and care arrangements. Young people and men sold their labour for a wage, and women of reproductive age specialised in domestic production of care in exchange for an informal intra-family transfer of resources, which we label 'unpaid work'. This arrangement is portrayed in Figure 8.1.

This arrangement became sufficiently widespread in industrial societies in the past two centuries to shape the notion of what we now call 'traditional', even though it reflects a situation that prevailed for a relatively short period of time in a relatively small part of the world and which, in its pure form, may have never actually existed. Young working-class women always worked for money, and men always provided some of the care. Yet its archetypal form lives in the minds of most people and is a very powerful mental attractor, even to people who reject it as a normative model.

The diagram focuses on unpaid care work and use of time of men and

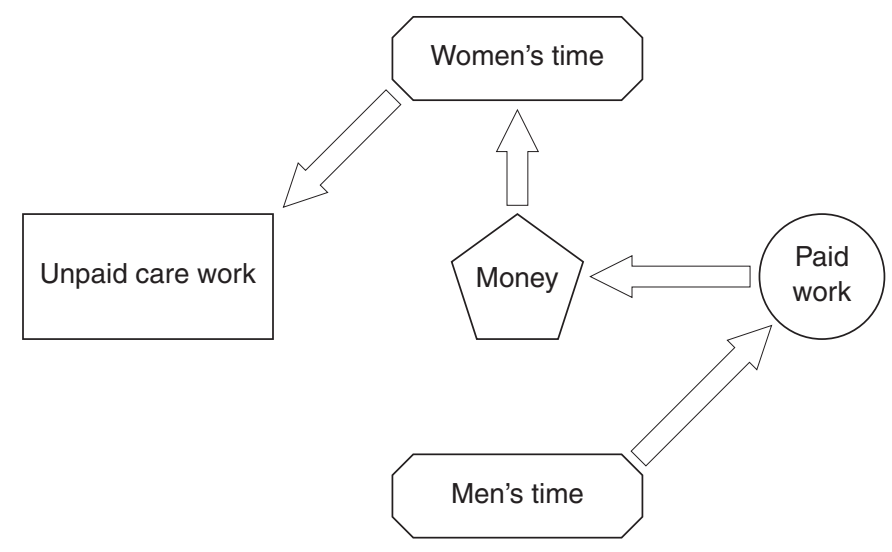

Figure 8.1 No welfare state. 
women. 'Unpaid care work' is defined loosely so as to include all those activities needed to keep people fed, clean, and looked after both physically and psychologically according to a commonly accepted standard. It is the activity that is needed to transform goods into well-being, production into consumption. In this arrangement, care is produced within the family, using, as input, women's time and men's money. Men's time is used in the labour market to earn money to purchase the goods that are then used by the women to produce actual welfare, for the children, for the adults and for anybody who needs care. There is no welfare state. This arrangement is called 'familist', because care is produced within the family. It is also 'patriarchal', because men earn all the money and therefore have greater power than other members to decide how resources are allocated. Within the family there is bargaining and exchange. Money, earned by the men in paid work, is exchanged for time devoted by women to unpaid work, by combining their time and goods purchased in the market. ${ }^{11}$ Children and the frail elderly, who cannot provide for themselves, are the recipients of care, as are the adult men who provide the household with the money.

The arrangement is completely asymmetric: women perform all the unpaid work, men all of the paid work. Only men earn money, and therefore they may have more say as to how it is spent. However, not much care is available outside the household. The situation is one of co-dependency: women are very dependent on family men for money resources and men are very dependent on family women for care provision. In the past, for the average male worker who wanted his children and himself to be fed and clothed day in day out, a good wife could probably offer the best price/quality deal in town, if not the only one available. Women and men were very different social and economic actors; each specialised in one kind of work.

This arrangement has been changed dramatically by the introduction and expansion of public expenditure devoted to the satisfaction of care needs and by the parallel development of a private marketable personal services sector. Part of the unpaid work once performed by women within the household is now performed by women and men who are either public or private employees. Women have entered paid employment in the public or private sector. Their labour force participation rates have become almost equal to men's in some countries.

The second diagram (Figure 8.2) represents a welfare regime where reproduction and care are produced by unpaid work of men and women, public services (provided by men or women who are public employees), or bought on the market. Money earned by family members of both sexes in paid employment is used to purchase private services (provided by men and women who are private employees).

The diagram shows how the arrangement for care provision changed dramatically with the parallel developments of market-provided personal services and the expansion of public expenditure devoted to the satisfaction of care needs. In the diagram, the square shape ('services') represents public 


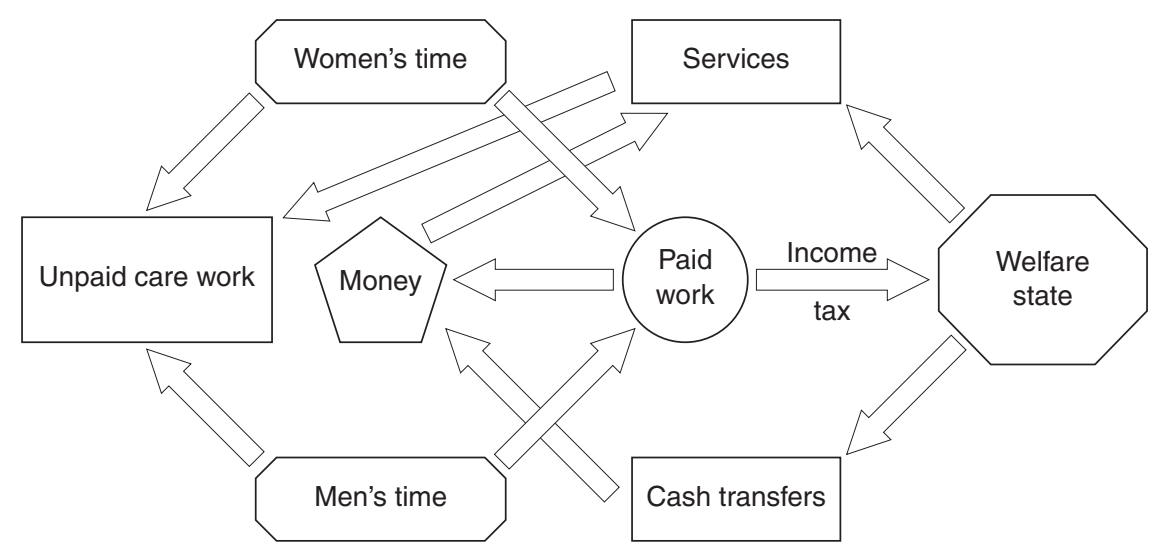

Figure 8.2 Symmetry in welfare states.

or private services. The welfare state (a hexagon) can finance itself by income taxes or pay-roll taxes, and can deliver either cash or services. Part of the unpaid work once performed by women within the household is now performed by women and men who are either public or private employees. Care is provided within the public and private market spheres, institutions regulated by law open to any citizen either as buyer or seller according to agreed norms, as opposed to the private family sphere. Women enter paid employment in the public or private market sector. Their labour force participation rates climb to become almost equal to men's in some countries. They have some independent access to money through their own earnings or through cash transfers. The economic exchange of money for care that once happened within the household has also moved to the public sphere, and the economic value of time spent in household production becomes more evident.

Nordic and liberal welfare states are undoubtedly very different from each other in many respects. One of the most evident is size, especially in terms of relative size of market-provided versus public service-provided care. Yet they are very similar in one respect: they can both be represented by Figure 8.2 simply by altering the relative size of the welfare state, the two shapes representing services and cash transfers.

When personal services, no matter whether public or private, are available as an alternative to domestically produced care, the position of men and women becomes more symmetric: they both perform paid work, they both earn money and they can both purchase part of the care. The time of both has an economic value, and so both may be required to perform domestic production. Both can choose not to perform unpaid care work themselves. Children and the frail elderly still require money that they cannot earn, which has to come either from the state or from adults of either sex. The intergenerational arrangements may be very different depending on how this 
is done. But the economic reason for the internal exchange of money for care between adult men and women weakens. The road is open for a more diversified set of personal choices, by people of both sexes. Care can be shifted out of domestic production. The specific productive skills of the housekeeper, such as how to clean and cook, go the same way as the skills of spinning and embroidering. The core of the care work, namely responsibility for the wellbeing of somebody else, can be requested more easily and performed independently of the sex of the caregiver. The 'single' lifestyle, where a single person is capable of earning enough and providing enough care for her or himself, is one of the products of this new arrangement, as are public and private nursery schools and dual career couples with a nanny. Data on the use of time show most clearly the difference. In symmetric countries, time spent in unpaid work by women decreases and time spent in unpaid care work by men increases, even though they never converge completely (Gershuny 1995).

When there is family formation, unpaid care work does not disappear. First of all, as Giuliana Campanelli shows in her contribution to this book (Chapter 6), the standards of care change. What is commonly understood as being properly fed, clean and so on moves with technological and social change. Second, there is a managerial aspect of care that cannot be avoided totally, even by the more advanced professional two-income family which has all the laundry taken care of outside of the home and buys prepared meals in gourmet shops every night. Somebody has to make sure that things are done properly and take responsibility for the final outcome of the process of caring for other people who cannot do it by themselves. The need to care and the need to be cared for are strong needs by themselves. Personal relations are also exchanges of reciprocal care, and of the time taken to care. And the time must be directly delivered, not completely transformed into goods or money.

How much care will remain within domestic production, and how much will be allocated respectively to the market and to the state, depends on the details of the institutional arrangements. This mainly involves the method of financing of public provisions (income taxes, pay-roll taxes levied on earnings, fee-for-service), the method of disbursement (cash or in kind) and entitlement to the benefits.

Methods of financing are important. Mandatory contributions levied on earnings (pay-roll taxes), in particular, have two important features. First, they constitute a tax on the use of labour, increasing labour costs and reducing employment. Take two economies with the same features, the first of which finances public expenditure from general income taxation, the second from pay-roll taxes. In the second economy, the same amount of money must be raised on a narrower base, from workers only, rather than from the economy as a whole. Labour costs are made up of net wages in the pocket of the worker, plus pay-roll taxes. So labour costs will be higher in the second country and therefore, in that country, only jobs with higher productivity 


\section{Elisabetta Addis}

will be undertaken. This means that fewer people, overall, will be employed, activity rates of the overall population will be lower and fewer women will be attracted into the labour force. It also means that low productivity jobs, as care jobs are perceived to be, will not be undertaken. Thus employment opportunities will be fewer for all, and in particular for women.

Second, with pay-roll taxes, it is the worker, rather than the citizen, who is entitled to welfare, usually the male head of the household, whose wife and children are designated as 'dependants'. Whether or not distribution within the family is then fair and whether the care needs of all the members are met becomes a private family matter which does not concern the state. On the one hand, this regime fosters family unity. Italian out-of-wedlock birth rates are extremely low in comparison with those prevailing in liberal and Nordic countries. On the other hand, if the family is dysfunctional, there is no security whatsoever. The weak members of dysfunctional families, namely battered spouses, abused or neglected children, have nowhere to go.

Methods of disbursement also matter. If transfers are in cash, they may be used either to finance the women in the family to be full-time or part-time housekeepers or to purchase care outside of the home to substitute for domestically provided care. So, the person who will ultimately provide the care, wipe the nose of the child, empty the bedpan of the frail elderly relative, will probably still be a woman. She will be either a housewife, entitled to benefits either directly or through her husband, or a private employee, subject to whatever employment protection exists in her country and the prevailing wage rates, which may be high or low depending on the care work provided and the labour market situation. If the transfers are in kind, i.e. a public service is provided free of charge to the user or at subsidised, below-cost rates, then the person providing care will most likely still be a woman, a public employee subject to employment protection and wages prevailing in the public sector, where protection is usually higher and wages have a more compact distribution than in the private sector. The condition of the caregiver, and therefore her social status, is likely to be most secure and better rewarded in the Nordic regimes and next best in a liberal regime. In Bismarckian regimes, the amount of monetary resources and the status of the caregiver depend on the functionality of her family and, in practice, may be very high or very low.

Other institutional details count. First of all, we have what economists call 'traps': ${ }^{12}$ particular features of both taxation and disbursement designed with the traditional arrangement in mind create particular 'traps' which reproduce that same arrangement and foster women's dependency. Tax allowances for those who have a non-earning spouse create incentives for spouses to remain non-earning. Income thresholds for access to benefits calculated in terms of joint earnings of the family, which means the family loses the benefit when, with the additional income of the second earner, that threshold is reached, also cause women to exit the labour market. Many 
econometric studies in different countries documented the presence of these effects, which Tindara Addabbo and Massimo Baldini measure for Italy in Chapter 9, this volume.

Under the heading of 'family policies', different provisions transfer resources for families with children. Relevant in evaluating these policies from a gender point of view is the concept of 'vulnerability' to poverty, developed by Ann Orloff. The idea here is that people may enjoy a given level of material well-being using resources provided by the welfare state without having direct entitlement to them. Thus young unemployed people who live off their parents' high pension are not poor. In Italy they may even be quite rich if we look at consumption standards, as Gianna Giannelli documents in her contribution to this book (Chapter 7). Yet they are vulnerable to poverty should the parents decide to cut the funding. Family policies may be quite effective in transferring resources to the family, yet they may still be quite ineffective in making the caregivers in the family less vulnerable to poverty if the entitlement of the benefit belongs to the male breadwinner. Recent research suggests that it does matter, from the point of view of expenditure patterns, whether cash benefits for poor families are given directly to one or to the other parent (Woolley 2001). Family policies under which the caregiver depends for cash on the male breadwinner reconstruct that inner link of care in exchange for money characteristic of traditional arrangements. They lift the family as a whole out of poverty, but do not make the caregiver feel safe and non-vulnerable to poverty. This concept of vulnerability to poverty is extremely important in relation to fertility.

Labour market policies also matter, as they influence the length of time that is spent in paid work and how much money is obtained by it. If the standard labour contract calls for a weekly working time of nearly forty hours and no part-time or other 'friendly' flexibility is available, mothers may drop out of the labour force more easily. If mandatory retirement is too early, they may never re-enter. ${ }^{13}$ Even administrative arrangements about opening hours of shops and offices matter: if they are strictly regulated they may make it impossible for men and women to reconcile working life and family life.

Thus, by a particular mix of institutional details, Bismarckian and Southern European welfare regimes have tried to preserve and superimpose traditional arrangements for care provisions on modern ones. Using pay-roll taxes rather than income taxation, cash disbursement rather than in-kind provisions and other policies riddled with traps, or provisions that eliminate poverty but leave vulnerability to poverty fully in place, they create an incentive to adopt an arrangement that may be represented by Figure 8.3. The old, asymmetric structure is artificially preserved, including the exchange of care for money internal to the family. There is an evident attempt to recreate the specialisation of women in unpaid care work and men in paid work, as in the traditional arrangement.

The 'structures of constraint', as Nancy Folbre (1994) brilliantly defines 


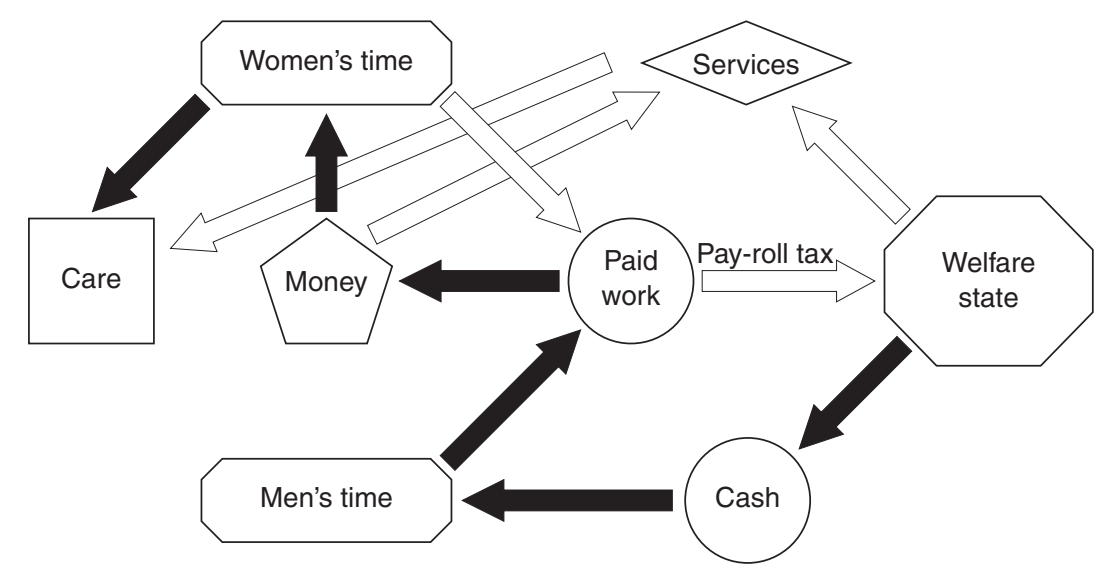

Figure 8.3 Pathologies of the continental welfare state.

them, are very different in each of the three models of welfare. Men and women make daily choices about how to spend their time and money. These choices are made under a complex set of constraints, created by available resources and by the alternatives that are effectively in place. The constraints are a result, among other things, of the political choices made by men and women about the amount of public spending and how it should be allocated. Today they are very different in Sweden, in Italy and in the USA. In symmetric regimes women and men are, to some extent, more at liberty not to provide care. If they have enough money and/or are willing to pay enough taxes, they need not perform care directly and personally. In asymmetric regimes, the market for care is not broad enough. If you do not care personally for your relatives, nobody else will.

The symmetriclasymmetric distinction is most relevant from the gender viewpoint. Gender is a set of physical and mental characteristics. It includes the proper, normal behaviour that each culture attributes to people on the basis of their biological sex, which we know varies widely between cultures and over time. Gender, in advanced industrialised democracies today, is the result of political choices on how much to tax, how much to spend and the institutional details of how to spend it. There is very little that is 'natural' or 'traditional' in how much unpaid work women do in relation to men. It is a matter not only of individual choice, but also of how constraints are set by public policy and how they operate for men and women. ${ }^{14}$

Though different symmetric regimes put different structures of constraint on people, a symmetric regime puts the same set of constraints on men and women, within which they are then 'free to choose'. Only in symmetric regimes do men and women similarly located in terms of income, age and so on benefit from the same opportunities. A prerequisite of symmetry in welfare arrangements is the existence in society of equal opportunities for men and women. 


\section{Italy as an example of welfare asymmetry}

In a previously published work (Addis 1999), I gave an institutional description of how Italian welfare works with respect to gender. The general framework of Italian welfare penalises women's paid work and gives recognition to women's unpaid work only if it is an exclusive choice made as a 'dependant' of a man. Benefits are linked to the job, but only to the job of one earner. ${ }^{15}$ Family policies, pension policies, unemployment policies and newly introduced means-testing combine to depress activity rates, give incentives to dependent housekeeping as a lifelong choice, shift care on to the family and force traditional roles in an otherwise 'mature' society. The majority of women who still perform unpaid care work within their family set the standards of care, such as how clean and well kept a house should be, how well dressed members of the family should be and how tasty the meals should be. In functioning families with average family income, these standards are extremely high. This demand for high standards of living was one of the ingredients for Italian success in producing fashionable clothing, furniture and interior decoration.

Italy is an extreme case of women's low participation, high unemployment, dependency on work or marriage for access to welfare benefits and low fertility. Compared to other countries with similar per capita income, women's participation in the labour market is much lower (see Table 8A.1) and there is greater women's unemployment and difference between men's and women's unemployment rates (Table 8A.2). Notwithstanding the abnormally high public debt, the Italian state does not spend more on welfare than the European average (Table 8A.3). What is above average is the ratio between cash transfers (especially pensions, which are higher than in the rest of Europe) and services, which are fewer and of lower quality (Tables 8A.4). Participation in the labour market is low due to lack of services substituting for women's traditional caregiving work, which means that women, and in particular mothers, work at a high personal and family cost. In addition, some of the direct transfers are regulated so as to give incentives for non-participation. Unemployment and the unemployment difference between the sexes are high because both private and public service sectors, which in most countries are the main source of women's employment, are underdeveloped: Bettio and Villa (1996) estimate the missing jobs in services at over 2,500,000.

In addition, there are specific labour market policies in place, which I call 'handicap privileges', which very effectively prevent hiring and promoting women in the private sector. They include:

- Long mandatory maternity leave (a total of five months before and after the birth at 80 per cent pay, plus there is the option, if taken within the first two years, of another six months at 20 per cent of the wage), which discourages the hiring of young married or marriageable women. Recent 
changes have introduced a non-mandatory parental leave for the father as well, making this provision less asymmetric.

- Mandatory retirement age was set at 55 for women in the private sector, which prevented employment of older women willing to re-enter the labour force after child-bearing age. This provision was changed later by the Dini reforms, but there is some remaining asymmetry.

- The fact that the weekly working hours mandated by national labour contracts in the private sector are long and other forms of shorter time commitment to employment are strongly penalised, so that family life and childcare for a couple where both are employed is severely curtailed. This has been changing slowly with the introduction of non-standard work (lavori atipici): in addition to standard contracts (lavoratori protetti) there are non-standard contracts with more flexible schedules, pay and working conditions that have eroded these rigidities, although at a cost. Recent research by Addabbo shows that the flow of people of both sexes into non-standard jobs is about the same, but many more men than women go on to a standard type of employment (Addabbo 2000).

Thus, in terms of labour market policies, the asymmetry has been eroded somewhat in recent years, introducing aspects of a liberal labour market model. This means that more women will be able to enter the labour force and to have independent access to money, but at the price of lower on-thejob protection.

However, the asymmetry has changed very little in terms of transfers. The imbalance in favour of cash transfers rather than services is compounded by the fact that direct monetary transfers in the Italian welfare state are highly job-based. They are basically of three kinds:

1 Family allowances, which may be based either on pay-roll taxes (such as the assegni familiari) or on relief from income taxation (detrazioni), paid to workers for their spouse and children.

2 Unemployment transfers, divided into three main categories: 'Cassa Integrazione Guadagni' (CIG, redundancy), 'Mobilità' (mobility), which companies with more than ten employees may request for their workers, and ordinary individual unemployment benefit, which is very low. CIG is so job-based that in Italy those affected are still notionally employed, albeit in CIG, whereas in other countries they would be considered as temporarily unemployed. ${ }^{16}$

3 Pensions, with the exception of the 'social pension' analysed below, are strictly work-based. They are paid either to people who cannot work (disability pensions) or survivors of workers (widow and widower benefits) or those who worked and paid pay-roll taxes for a sufficient number of years (seniority and retirement pensions).

These transfers are described in detail below. I will discuss the extent to 
which they induce traditional patterns and indicate what change, or lack of it, took place in the 1990s.

\section{Family allowances}

In Italy there are two policies which may be classified as family-related cash transfers. The first applies to any citizen who presents an income declaration and has a 'dependant'. The second holds for those who are employed and have a 'dependant'. 'Dependant' is defined as a spouse or other family member living in the same household with an income of less than 5,500,000 lire $(£ 2,840)$ per year, and children below 18 years of age or below age 26 if they are at school.

The first is a tax credit: people have a right to deductions from tax due otherwise for the 'dependent' spouse and for each child or other dependant. The 1996 budget set the amount of this deduction to 336,000 lire (£174) per child or other dependants and a maximum of 1,057,552 (£546) (for the income bracket below $30,000,000(£ 15,500)$ and a minimum of 817,552 lire (£422) (for the income bracket over 100,000,000 (£51,650)).

The second are known as 'assegni familiari' (family allowances). They are paid out by a special fund of the INPS, the National Institute for Social Provision, which is funded from pay-roll taxes paid by all employees in prescribed amounts linked to the wage, except of course in the 'underground' economy. 'Assegni familiari' are given to workers, included in their monthly pay cheque, but they are means-tested and based on a family income threshold. There are sixteen brackets. The threshold of the upper bracket, at 92,500 million lire ( $£ 48$ million) per year, is rather high. An amount is given for the dependent spouse and an amount is given for each child. The amount given varies with the income bracket of the worker and with the number of dependants. The amount given for each dependant changes with the order number of the dependant. Table 8A.5 shows the entire scale as of July 1998.

The programme of the Olive Tree (Centre-Left) coalition called for an increase in the 'assegni familiari' because they were presented as a good 'family policy' to deal with the demographic crisis of an ageing population and a falling birth rate, in particular by one group in the coalition, the 'Social Christians'. They were increased markedly in 1994 and in 1995 (20,000 lire (£10.30) per month per child after the first, 84,000 lire (£43.40) after the second). The 1996 budget increased the expenditure on the 'assegni' by 1,900 billion lire ( $£ 0.98$ billion). In the case of a disabled person, the income brackets have been shifted so that the thresholds are higher but they are still calculated on the joint income. Most of the increase in expenditure is due to a 25 per cent increase in the sums given to single parents. Given that most single parents are mothers, the latter is a small step in favour of single working mothers, which goes towards the recognition of women's work. 


\section{Elisabetta Addis}

With the exception of the recent increase of benefits to single parents who are workers, the pattern of the 'assegni' mirrors the gender relations in the family and in the society of the 1950s and 1960s. Being means-tested on the joint income of the family, the 'assegni' are lost if the wife's earnings take the family income above the thresholds. Thus they discourage women from seeking paid employment and may constitute a form of 'poverty trap'.

There are many problems with the 'assegni' as a way of fighting poverty. They would work as a means to achieve a more equitable distribution of income between rich and poor people if most families were bi-parental, with a continuously employed man and a housekeeping woman, and if the worker were willing to redistribute his earnings fairly to wife and children. But unemployment is high, especially among young men and women in childbearing years; therefore linking provision for poor children to the job of the head of the family is not an ideal solution, since children of the unemployed receive nothing. Furthermore, the 'assegni' cannot assist labour market transitions from one job to the next, with short spells of unemployment in between which characterise the youth labour market and the labour market of an economy undergoing continuous technological change.

Besides being job-centred, the 'assegni' are patriarchal, in that they assume that whatever is given to the head of the family will be redistributed fairly to the wife and to other members of the family - which is not always the case. Moreover, because of this patriarchal bias, they are inadequate to deal with a situation of family instability, separation and divorce. If the couple splits up, the unemployed spouse of a worker has no independent right to them. In the event of family breakdown, they may accrue to the father who has a job, even if, in over 90 per cent of cases, courts give custody to the mother. Even though a woman also has a legal right to them when she works, she will lose them for the entire family if she pushes family earnings above a certain threshold. There is no programme designed to help the children of people who divorce or become single parents and who do not have a job. The 'Olive Tree' coalition government attempted to create an experimental programme of family guaranteed income in a few cities, but the five-year term of government ended before the results of the experiment were even officially accounted for. It is clearly a case of flow of money going directly from the state to the male breadwinner, so that the internal exchange money/care can be perpetuated, with an added incentive for women to stay out of the labour force, thus remaining in need of such an exchange.

\section{Unemployment benefits}

The regime is based on a host of schemes. In the past, the centre-piece was CIG, 'Cassa Integrazione Guadagni' (redundancy benefits), divided into Ordinary and Special. The CIG remains the largest scheme. Introduced in 1968, 'CIG Ordinaria' (CIGO) is a mandatory contribution fund (i.e. 
financed with a pay-roll tax), provided by INPS, to finance labour hoarding by firms facing temporary declines in demand. The request for CIGO must be made by the company and must be accepted by the local job inspectors. CIGO pays 80 per cent of the wage, for a period from between three to twenty-four months. The employment relation between the firm and the worker is never broken; at the end of the period in CIGO, supposedly when the temporary problems of the company are solved, the worker goes back to work at the same firm.

'CIG Speciale' (CIGS) was intended for firms with over 200 employees, purportedly to deal with those cases in which problems were long term, such as restructuring of plants. It was intended to last for up to four years, but it has been known to last, with legal and bureaucratic pretexts, for up to ten years. Since 1988 it has been financed directly by the Treasury. In fact, it was, and still is, a very generous programme for collectively dismissed workers, who are, however, still formally employed and therefore prevented from looking for a new job.

In 1991 Law no. 233 introduced some changes, reducing the duration of the benefit, introducing the 'indennità di mobilità' (mobility benefit) and a programme of early retirement for people at the end of CIG. Mobility benefit is similar to CIG, except that it applies officially to firms with more than fifteen employees, lasts twelve months and it is paid in cases where it is acknowledged that the firm will not rehire the workers. It is also paid after the end of CIG benefits for firms with more than 200 employees.

Other forms of collective benefits recently introduced are special benefits for construction workers, who used to rely heavily on CIG for the winter months and are now under a separate programme. The ordinary benefit for individual lay-offs, for people who do not belong to the collective, firmmanaged programmes, pays only 30 per cent of the last wage for six months; the worker must have worked legally and paid pay-roll taxes for two years before qualifying.

By subsidising labour hoarding, CIG boosts Italian firms' productivity and biases competition with other European firms. It is therefore under attack by the European Union. CIG is a job-based, age- and gender-biased scheme. It favours those who have a job against those who have never held a stable job. In practice it favours the old against the young. CIG favours people who work in large firms against people who work in small firms or individually, such as domestic helpers. Since women are on average younger, may never have held a stable job and are on average employed in smaller firms, it is biased against women. A study by Trifiletti (1996) shows that the changes introduced in 1991 further decreased women's access to CIG benefits. It is a clear example of a reform that, while improving the overall quality of public intervention in the labour market, worsened its bias against women.

Proposals to eliminate CIG altogether and the 'mobility' benefit associated with it, in favour of an individually based, rather than collectively 


\section{Elisabetta Addis}

based, unemployment subsidy, or in favour of some form of minimum guaranteed income, are opposed both by employers and trade unions. An unemployment subsidy programme would provide general improvements for women through measures based on citizenship and having universal coverage. Such measures acknowledge a citizen's rights to a security net independently from their performance in paid employment and, therefore, implicitly acknowledge unpaid domestic and caregiving work. Conversely, fragmented careers, shorter hours, withdrawal from participation due to unpaid caregiving work and reentry into a different job, which once characterised the female labour market, is now becoming more widespread for both sexes. Retraining is a constant necessity in times of fast technological change.

Men are insured against unemployment more than women are. Therefore, in hard economic times, they have the money to exchange for care. Women's unemployment insurance lies in the fact that they perform unpaid care for the family in exchange for family money. The absence of a universal unemployment subsidy strengthens the money/care exchange within the family. Overcoming the job-centred model would make the welfare regime more symmetric and, at the same time, it would adjust public intervention to the needs of a changed labour market.

\section{Pensions}

Until the early 1990s, this familist, patriarchal welfare state, stingy in family assistance and unemployment benefits, was quite generous in its pension regimes. The ratio between pay-roll taxes and benefits was very low with respect to the European average. It was very generous to workers and, as a consequence, also to their dependent wives. Survivors' benefits were high with respect to the European average. The work performed by women in the household was never recognised explicitly as a source of citizens' rights. However, the benefits devised for workers have been stretched, sometimes beyond legality, to subsidise women's work in the household, by providing them with semi-fake disability pensions, very early retirement, voluntary contributions to pension schemes after work interruptions and so on. Early retirement was the peculiar way in which the Italian state coped with (men's) unemployment problems and the need to provide (women's) care work to the family.

Before the recent wave of reforms, the Italian regime provided for the end of the working life through two programmes: voluntary seniority pensions ('anzianità), linked to the number of years the employee paid pay-roll taxes, and mandatory old age pensions ('vecchiaia') for all at a prescribed age. It was a 'pay-as-you-go' regime: today's pensions are paid out of the pay-roll taxes that today's workers pay; when these are not sufficient the Treasury makes up the difference. The regime was acknowledged to be financially unsustainable in the medium term before reforms were introduced. Arguments about its sustainability continue today. 
Before the reforms, the seniority pension allowed retirement on request as early as after fifteen years, six months and one day of contributions in the public sector, while twenty-five years of contributions were needed in the private sector. The amount of benefits ceased to increase after forty years of contributions, even if the worker kept working beyond forty years until mandatory retirement age. Those who drew seniority benefits could get a second job before mandatory retirement age. Early retirement was in fact the security core over which a number of elderly women provided free services to their family and a number of elderly men provided cheap labour, working with no pay-roll taxes in the underground economy of small firms or in selfemployment.

In the private sector mandatory retirement age was set at 55 for women and 60 for men, and in the public sector at 60 for both sexes, although in some careers it was possible to obtain an extension to 65 . To obtain the maximum benefit in the private sector a woman would have had to work from the age of 15 . This obvious bias was offset partially by the fact that women, but not men, could pay voluntary contributions, in addition to the normal amount, to cover one year for each child and thus obtain slightly larger benefits. It still resulted in a distribution of pensions in which most women received pensions of 1,000,000 lire (£516) per month, while men's pensions ranged from $1,000,000$ to over $5,000,000$ lire $(£ 2,583)$ per month.

The labour market effects of the mandatory retirement age at 55 were heavy. In the few instances when a woman in the private sector was considered for the higher echelons of a career, she would be obviously passed over because she was about to retire. The cost of hiring and training a woman of 45 coming back to work after child-bearing age was not recoverable in the ten years before retirement; thus women were not hired in middle age. However, with a typical insider/outsider effect, trade unions traditionally opposed increasing women's mandatory retirement age, even voluntarily, and notwithstanding the fact that if women wanted to retire before the mandatory age, they could, of course, get seniority benefits.

Reforms were enacted in waves, by the governments of Amato (1992 to 1993), Ciampi (1993 to 1994) and Dini (1995 to 1996). The final reform is gradually phasing in a new regime, which will be fully operational only for those who are newly hired. In the new regime, benefits will not be earningsrelated but contribution-related. Rules defining retirement age have been changed to make the regime financially viable: age of retirement may vary, but the mandatory character of retirement at age 65 has been retained. This is common practice in Europe, as opposed to the USA.

Under the new law, approved under the Dini government, the mandatory retirement age is set at 65 , allowing retirement from the age of 57 with a penalty of 3 per cent of the pension per anticipated year. The years of contributions required for seniority benefits increased to thirty-five. Early retirement in one form or another is therefore eliminated. People who had made more than eighteen years of contributions could retire according to the old 


\section{Elisabetta Addis}

rules. People hired for the first time after the reform were subject to the new rules. People who had been working and contributing for less than eighteen years would have their pension calculated in accordance partly with the old rules and partly with the new rules. In order not to penalise people who were about to retire and who had made plans and choices based on that expectation, the recent reforms created a gradual regime, in which the age of mandatory retirement and the number of years of contribution required move forward one year at a time.

For the part that is at present earnings-related, benefits have been reduced. They are now calculated over the entire working life, rather than on the last five years of working life. They will be lowered progressively from 80 per cent to a lower percentage. The possibility of most voluntary contributions was eliminated. In addition, survivors' benefits have been curtailed subject to means-testing. It used to be that a widow or widower received 80 per cent of the benefits accruing to the worker. Now, if a widow/widower's income from any source, including work or retirement pension, is above $26,755,950$ lire $(£ 13,820)$, the survivors' benefits are cut by 25 per cent; if the income is above $35,674,600$ lire $(£ 18,427)$, they are cut by 40 per cent; above $44,593,250$ lire $(£ 23,034)$, they are cut by 50 per cent. As an exception to the general rule of no change for people who had already begun to enjoy the benefits, benefits for survivors who were already receiving them, and whose income was over the level of 26,755,950 lire mentioned above, were frozen at the present level.

From the gender point of view, equalisation of the mandatory retirement age for the two sexes, while a positive labour market measure, leaves an open problem. Who will now provide the childcare services that elderly women have been providing until now, and who will deal with the typical bureaucratic quagmire of the public services in Italy? Minding grandchildren and queuing in various offices is typically the grandmother's task at present. The lack of an available retired grandmother, in addition to the lack of affordable good-quality nursery schools, may squeeze further young working mothers' already tight time resources and therefore hamper further young women's fertility or their participation rate.

Lengthening the years of contributions required for seniority pensions is gender-biased, because women tend to have shorter contribution histories with gaps in their working careers due to family-related events. This should be balanced by the fact that the regime will become entirely contributionbased, allowing people with as few as five years of contributions to draw old age pensions.

Reductions in survivors' benefits are of course particularly adverse to women, since women have a longer life expectancy than men, marry men who are older and are the beneficiaries of most survivors' pensions. It is, in addition, a blatant violation of equity between women who work for a wage and women who are full-time housekeepers. A woman who still works and therefore has a wage, or who has a substantial pension from her own job, will 
be penalised and will see her survivors' benefits cut. As a limiting case, a working widow with children should notionally subtract from her wage the cost of whatever services she uses to replace her own domestic work, the benefits she loses because of means-testing and the amount of survivor's pension that she loses by going to work. It may well be that she is better off by choosing to stay at home, because her extra-domestic work adds very little to the wealth of her family. The fruits of her work will be literally taken back by the state.

Means-testing survivors' benefits may be construed as equitable between people with different incomes, because it cuts benefits to elderly widows/widowers who are already sufficiently well-off; but it may also be construed as inequitable in failing to distinguish between women who worked only inside the home and women who both worked inside the home and earned a wage income. Women's earned income is treated as if it was unearned rent from property; no allowance is made for the fact that in order to earn it, women have to make an alternative use of their time, taking it from other socially productive uses in their home.

There is a clear example of double standards at work. In the case of survivors' pensions, the consensus is that the duty of the welfare state is to provide only a decent minimum. Women who work and earn are already quite well-off; therefore it is fair and legitimate to cut survivors' benefits, even if this breaks the equity between work effort and social recompense, and between contributions made into the pension funds and receipts accruing from those contributions. In the case of high seniority pensions accruing to relatively young men, the same reasoning did not apply; the argument that the welfare state should provide only a decent minimum was rejected. Proposals to apply a cap on higher pensions, in the form of a proportional cut to be applied after means-testing, never gained any support, on the grounds that they would break the relationship between contribution history and pension, which the policy regime aimed to preserve. Yet these are pensions that accrue to elderly men who are already well-off. Contributions by a man whose wife does not hold a job are thus worth more than for a man whose wife does work. These provisions concerning survivors, so blatantly unfair to women workers, went almost unnoticed in the public debate over the pension regime. Elderly women and women who work have very little public voice, or, perhaps, women are the only ones who may be persuaded to accept sacrifices for the common good.

The underlying logic for this double standard is again related to persistence of the traditional circuit. Men's work is the source of money for the family, so high pensions of elderly men should not be cut, for they are needed by him to pay for himself and his wife. Women receive money from the male breadwinner in exchange for care. Survivors do not have a husband in need of care, so the money they receive from the state can be cut. 


\section{Elisabetta Addis}

\section{Minimum pension and 'social benefit'}

In the past, people who, at the mandatory retirement age, did not have a long enough contribution history had the right to a minimum pension. The same minimum pension accrued to people who worked for fifteen years ('minimo') or under ('integrata al minimo'). After the fifteenth year the pension increased with job seniority. In 1996 minimum benefit was equal to 659,000 lire (£340) per month. It was means-tested: if there was no other income, the INPS paid the full amount; if there was other income from any other source (excluding severance pay) greater than twice this minimum, the right to this benefit was lost.

A wave of reforms introduced by Amato's first government brought some changes: the number of years after which benefits began to rise was changed from fifteen to twenty years and the means test was changed from personal income to family income. The rule was that a single person should not have an income of double the benefit and a couple three times as high as the benefit, in order to maintain the right to the benefit.

These moves were again clearly gender-biased: it is women who tend to have short contribution histories and therefore to be claimants of these pensions. Means-testing based on the couple's income eliminated the pensions of those women who had worked for a short period of time and whose husbands were still working or had a modestly high pension.

The second wave of reforms, under the Dini government in 1995, eliminated altogether the right to minimum integration for those with fewer than eighteen years of contributions. People who had worked fewer than eighteen years by 1995 , reaching retirement age before twenty years of contributions, would not get the 'minimum pension'. They would have the right only to social benefit ('assegno sociale'), which in 1998 was equal to $6,593,000$ lire $(£ 3,405)$ per year. This is not classified legally as a pension but as 'assistance'.

Dini partly adjusted back the threshold for those already receiving the 'minimum pension'. It kept the reference to joint rather than single income, but the threshold for the couple receiving the minimum benefit was set to four times the minimum benefit, i.e. double the threshold for single pensioners. This was an improvement from women's point of view.

People who, at the age of 65 , had no contribution history whatsoever because they did not pay any contributions, either because they did not work or because they had always been employed illegally, had the right to this 'social pension'. It was the only form of guaranteed minimum income existing in Italy. The amount is lower than that of the 'minimum pension'. In 1995 it was set at 357,000 lire (£184) per month. In the past twenty years the number of recipients of these benefits decreased, from 840,000 in 1974 to 718,000 in 1995 , as women began to make enough contributions to receive the 'minimum'. Seventy-eight out of 1,000 elderly citizens receive it, 80 per cent of them women. Forty-one per cent of recipients live in the 
South, 22.3 per cent in the Centre and 36.2 per cent in the North. As shown by Monacelli (1996), the threshold for this 'social pension' was set in a rather peculiar way. The target set for a couple was more than three times the target set for a single person. Couples or families with many members received enough to live near the poverty line; single, divorced and widowed people were heavily penalised. For a couple where both partners have a social pension, the death of one of the spouses could mean sudden further impoverishment for the survivor. It appeared that the state preserved the family unit as long as two elderly people were living together. Once an elderly person remained alone, she - since most 'social pensioners' were women - had no option but to join another family, typically her children's.

As of 1996, the 'social pension', too, was replaced by the 'social benefit', which then became the single measure by which the Italian state deals with the poorest part of the elderly population. In 1998, the yearly amount of 'social benefit' was $6,593,600$ lire $(£ 3,406)(507,200$ lire $(£ 626)$ per month over thirteen months), for single people over 65 with zero income. If income was between 0 and 6,593,600 lire, people had the right to integration up to an income of 6,593,600 lire. Above that amount they had no right to the benefit. If people were married, then a joint income threshold exactly double that amount applied. If person $\mathrm{X}$ earned 0 and the spouse less than $6,593,600$, person $\mathrm{X}$ received the benefit. If the spouse earned between $6,593,600$ and $13,187,200$ lire, person $\mathrm{X}$ received a reduced amount to make up an income of 13,187,200 for the couple; if the spouse earned more than 13,187,200, person X received nothing. Again, the logic of the traditional circuit is more than evident. The money/care exchange is upheld and made into an institution. The source of money for the person in this situation, usually a woman, is the care she provides. The Centre-Right government in power since 2001 promised during the electoral campaign to increase this pension to $1,000,000$ lire (£516) per month. If enacted, this measure would be an improvement for poor families, but would reinforce the underlying traditional circle.

The incentive effects of this measure are not easily evaluated and they are not particularly important from the point of view of increased efficiency of the regime. Yet fairness is still a value in society, even when the consequences of unfairness will be borne only by those who suffer it. Because of the difference in the average age of marriage between men and women, husbands reach 65 before wives. At that age, if a wife has a small wage income, this may make the husband lose the benefit. When both spouses are over 65, then the fact that one of the two, usually the husband, qualified for a low pension implies that he has lost the benefits for the spouse and is now as well-off as the person who did not work at all. He must be willing to share his already low income evenly with his spouse and she cannot in any way make sure that this happens. Moreover, a couple where nobody ever worked is as well-off as a couple where each worked with low wages for as many as nineteen years before reaching retirement. One may argue that if we want to 


\section{Elisabetta Addis}

lift the very lowest end of an income distribution to a given minimum level, we will always be unfair to those who had reached that level by themselves. Yet, in my opinion, this is one of the clearest cases in which it would not have been at all unfair to allow some couples be slightly better off than others. Here, at the poorest end of the income distribution, treating each individual, married or not, as single is the only way to avoid leaving elderly married women in a position of total dependency on their husbands.

The last item in the pension reform is the institution at INPS in 1997 of a voluntary fund for home-makers ('casalinghe'). People who had no other job and were therefore full-time home-makers, or anybody else, were given the possibility of insuring themselves against job accidents and earning the right to a pension at the age of 65 by paying voluntary contributions into this fund. The symbolic value of this act is certainly highly positive, because it affirms the citizenship of women who are full-time housekeepers and, taken in perspective, may weaken the money/care exchange. However, the financial value of starting such insurance may be questionable for women who are married, given that survivors' benefits are then means-tested. Thus those contributions may ultimately be lost.

\section{Means-testing}

Italy has recently witnessed the gradual expansion of a variety of local means tests for access to many services, ranging from some medical procedures to nursery schools. Testing at the local level has often been quite crude; the unit chosen for means-testing was the nuclear family, with no consideration of possible alternatives, no allowance for the number of people who have to live on the income, its source, or the kind of service requested. All families earning more than a certain amount per month pay; all below do not.

The Ministry of Finance proposed a general 'means-test' scheme to be used nationally by local administration, with or without modifications, to regulate access to services. The scheme was presented by the media as 'riccometro' ('wealth indicator'), but it is known more formally as ISE, 'Indicatore della Situazione Economica' (economic situation indicator), which became law in March 1998. According to ISE, a family requiring social services or exemptions, such as nursery school, exemption from co-payments for physicians' care, drugs, or medical tests, should answer a questionnaire that includes an income declaration and information on other aspects of family composition and wealth. The scheme uses an equivalency scale based on income reported in the questionnaire, taking into account the number of people living on that income, whether the parent is single and whether there is any handicapped person in the family. A small allowance is made if both parents with children under 3 work, in the form of a slight increase in the parameters of the equivalency scale.

This is probably an improvement over the rough means-testing mentioned above. In a related paper (Addis 1998) I discussed the gender effects 
of means-testing and the use of different techniques to address the issue of women's poverty trap. In general, the means-test fails to take into account the number of earners, other than for children under 3 , and therefore does not include a higher threshold for families with two wage earners and no 'housekeeper'. The need for care is denied, as is the value of the unpaid work performed. Thus women's work outside the household is penalised and nonparticipation by the wife becomes a more attractive option.

Again, as in the case of the threshold for the 'assegni familiari', ISE takes into account only the number of people who have to live on a given income, not the source of that income. It thus gives incentives for non-participation and assumes that the money for care exchange within the family takes place. Again, it artificially imposes the traditional circuit.

It must also be noted that, from an economic point of view, the increase in the parameters of the equivalency scale for families where both parents have a job works in the opposite direction to tax deduction for a dependent spouse mentioned above. The deduction is given to all families where the wife does not have a job; the second is given to low-income families where the wife does have a job. Excluded are women who work in families where income is not too low.

How much care work is shifted to the market and the state is a matter of political choice, as is the amount that remains within the family as unpaid work. There is nothing natural and no 'backwardness' in terms of natural progress towards market-provided or state-provided care in the arrangement that has prevailed in Bismarckian regimes. Only one element emerged unexpectedly in the last decade of the twentieth century and helped, by chance and not by choice, to preserve the central role of domestically produced care in the Italian regime: the inflow of cheap domestic labour from the former Soviet bloc. By the 1980s the shortcomings of market and state care induced rich households with two working spouses to import domestic labour from the Philippines and Cape Verde. The opening of the Eastern European frontier created an abundant supply of babysitters and cleaning ladies, cheap and affordable even by lower-middle-class families, thus weakening the demand for high-quality public services. ${ }^{17}$ By shifting some of her and the breadwinner's money to the cleaning lady, the Italian working woman can hope to preserve for her family, adult men included, the high standards of care mandated in a regime where the majority of women still perform only unpaid care work. ${ }^{18}$

\section{A comparison of welfare regimes: is there a trade-off between symmetry and person-specificity?}

While we can imagine an archetypal world in which the family provides all the care, it is very hard to envisage a world where all the care is provided either by the market or the state. Some form of free private care among people, who may or may not be blood relatives, will probably be chosen 


\section{Elisabetta Addis}

freely by most people. Human relations also involve reciprocal unpaid care, and care that is given freely by people who have time and money tends to be of very high quality. There is an element here that is under-researched, what I call the need for 'person-specificity' of some care. ${ }^{19}$ For many people, to receive care from a specific person has a higher value than to receive the same care from a public or private employee who is not that specific person. Care may be given professionally by a public or private employee, but tender, loving care is that which is given freely because of affection, or love, that runs reciprocally between people.

The wish for 'person-specific' services may be different for the caregiver and the care recipient. Asymmetric regimes enforce a particular kind of personspecific care by the woman of the house towards everybody else. This, in some cases, may be a gentle or not so gentle coercion of the will both of the care receiver and of the caregiver. In other cases it corresponds to what the care receiver wants, even if the requested caregiver, the woman of the house, does not. In other cases, it corresponds to a reciprocal, person-specific need: the need for a child to be looked after by his or her own parents and of the parents to look after their own child, or of a frail elderly person to be looked after by his or her own children.

In the traditional model, the women of the house provided person-specific care and spent all of their working time, unpaid, in doing so. The men specialised in paid work and spent all their working time performing it. If both men and women spend all their working time in doing paid work, personspecific care shrinks and eventually disappears. Most or all care work will be done by professionals in a precise exchange of time for money. The opportunity cost of person-specific care becomes too high for people to indulge in it. There is no more time to care.

This fact is of some relevance from the gender point of view. To be the free care provider was a characteristic feminine attribute. Being properly female was being the unpaid caregiver of one's family. If unpaid care shrinks or disappears, one characteristic considered formerly as feminine disappears. The lives of men and women become more similar; both are as men's lives used to be. All their working time is spent in paid employment, often in a competitive working environment where the values and the skills that are rewarded are those traditionally associated with the male. Gender roles converge, but they do not converge to an average, in which both genders perform some unpaid and some paid work, in equal proportions. They converge towards the old male gender figure. Assimilation, understood as women fitting in with the male model, is a process underway in other sections of society as well, such as female soldiers and policewomen, which represents welcome and positive advancement for women. However, so far, it does not appear to correspond with parallel assimilation of men to female models and values. ${ }^{20}$ Society as a whole becomes more 'masculine'. ${ }^{21}$ The real world evolves towards the old model of neoclassical economic theory, a world and a model where there is only paid work and leisure, and no productive care work. 
Unpaid working time produces person-specific services, services that are of higher quality because of the special relationship existing between two human beings. In this framework, higher standards of care, some of it still provided by unpaid women, may be interpreted as the result of the need for person-specific care by the care receiver, combined with women's desire to continue to maintain an identity that is somewhat different from men's and to create, maintain and restore personal relations.

Person-specificity, if chosen willingly by care receiver and caregiver, is a positive characteristic of a welfare arrangement and produces care of extremely high quality. Leaving time available for person-specific unpaid care is a positive characteristic of a welfare regime, from a feminist point of view. The traditional arrangement, bad as it is and was for women's independence, may be preferred by many women to a symmetric arrangement where personspecificity and the availability of time for care are squeezed out.

In the end, a welfare regime must be judged by its financial soundness, by the various dimensions of equity, by how well caregivers fare and by how well people who receive care fare. How do the different prevailing modes of providing care - market, family and public services - compare in terms of quality of care?

Quality of care provided in both rich and poor households is likely to be very different, as care is a combination of time, skills and goods, and the rich obtain better goods. In addition, if they like person-specific care, the rich can always choose to perform more unpaid work and give up some income. The poor do not have this choice. Their time must be spent in paid work to earn the money to purchase the goods. Quality of care is very different in functional families and in dysfunctional families. The quality of personal relationships matters. In well-to-do, loving families, the quality of care provided may be extremely high. Otherwise it may be very low. In regimes that are asymmetric, low-quality family care is the only available alternative. Thus care provided through unpaid work is of uneven quality, touching the extremes of very high and very low. The condition of the caregivers in the family depends on the symmetry of the regime. If the regime is symmetric, they can opt out of caregiving and buy the care outside of the home or resort to public services.

Care that is given outside of the household is by definition not personspecific, although one may choose one's restaurant, one's physician, or the school for one's children, and it is usually more likely to be through the market than through the state. The quality of care provided in welfare regimes that act principally through the market depends on the wealth of the purchaser. It is very high for the rich and very low for the poor, so it is also very uneven. The condition of the caregivers who sell care through the market as employees of a care-providing firm depends on the conditions of the labour market. In tight labour markets where they can obtain a higher wage it will be better than when there is high unemployment. In highly regulated labour markets, workers can enjoy excellent working conditions, 


\section{Elisabetta Addis}

as long as the labour market does not split into insiders versus outsiders, where the outsiders may end up in a position even worse than the average condition in unregulated labour markets. The condition of caregivers who act independently, such as maids, at-home nurses and so on, is usually at the lowest end of the scale of desirable jobs in terms of earnings and job protection.

The quality of care provided by public services generally does not depend on the wealth of the care receiver, but is uniform along the wealth dimension. However, this quality may be very good, average or bad. Believers in competition claim that lack of it in the long term would undermine the quality of public services. Although there is certainly a grain of truth in this claim, the quality of care in some Nordic countries and in parts of the Bismarckian regime ${ }^{22}$ is such that one may believe that, with proper administrative policies and political pressure at local level, an excellent quality of care may be achieved.

The condition of caregivers who are public employees is usually good in terms of salary, job protection and working conditions. Excess protection of caregivers in some situations may interfere negatively with the quality of care. In this respect, providing care through public services creates the need for an efficient regime of checks and balances between the status of the caregiver and the quality of care. Cultural factors may play an important role, but perhaps an overestimated one.

Whether through lack of either appropriate culture or appropriate administrative procedures, one of the distinguishing features of the Southern European version of the Bismarckian model is what Ferrera (1998) labelled lack of 'statualità'. What is lacking is a consciousness that public services belong to all and should be performed according to the wishes of the care receivers. Lack of 'respect for the state' makes public employees slack in doing their duty and lowers the quality of care provided. Thus Southern European regimes in a time of financial crisis have a built-in tendency to move away from public services and towards family or market care, in search of quality care. If the quality of public services is uniform for rich and poor at about the same standards that the market can provide for the rich, all is well. If the quality of care in public services deteriorates for all, then letting the rich have better care becomes Pareto optimal, demand for family- or marketprovided care grows and the welfare regime moves away from the Nordic and towards one of the other models. The very high quality of home-provided care becomes an element of resistance to the introduction of a prevailing public or market-oriented regime.

What we have discussed so far may be used to build a grid of parameters that characterise different models of the welfare state. Although bearing in mind that such a grid cannot contain many nuances of a complex reality, I believe it is useful to evaluate the performance of different welfare regimes and to focus on needed changes. Table 8.1, representing such a grid, classifies the three models of welfare, plus the Southern European variant. Con- 
sider initially the first four columns of Table 8.1. These represent the existing models of welfare. The first three rows (Financing, Disbursement, and Where and who cares) are purely descriptive. The subsequent columns are my evaluation of these regimes relative to a series of relevant parameters. The condition of the caregivers is evaluated according to the prevailing mode in each regime, level of autonomy, earnings and job protection. Where the family prevails as a mode of giving care, autonomy of women is low. Earnings are uneven: high for wives of rich husbands and low otherwise. Job protection is nil. Earnings, autonomy and job protection are best in Nordic regimes. Quality of non-domestic care depends on wealth in market regimes and is high both in the Nordic and Bismarckian regimes. The difference between the Bismarckian and the Southern European models emerges only in the quality of non-domestic care. The lack of 'statualità' (respect for the state), characteristic of these models, implies that the quality of public services tends to be uniformly bad for the rich and the poor, rather than uniformly good, while the market regime remains underdeveloped.

Nordic and liberal regimes score high in symmetry, while Bismarckian and Southern European regimes give incentives to asymmetry. The latter two, however, score high on person-specificity, while, especially in liberal regimes, people of both sexes spend a very large amount of time in paid employment, making person-specific care expensive and hard to get, especially for the poor. ${ }^{23}$ Liberal and Bismarckian regimes leave more people vulnerable to poverty, although for different reasons: the liberal regime because it is stingy in benefits and fearful of poverty traps; the Bismarckian and Southern European regimes because the security net is for families: women and young people are left vulnerable.

Freedom not to provide care is high in symmetric regimes and low in others. Freedom to care is high in Bismarckian and Southern European regimes, but only if people choose to devote their entire working time to unpaid care, or retire early. It is very low for women who choose to enter paid employment and who have to carry a 'double burden', so it is unevenly distributed between people of different sex, age and gender. ${ }^{24}$

The exercise shown in Table 8.1 may be useful because it allows us to focus on the characteristics of a welfare regime that is equitable from the gender point of view. Such a regime should respect both women's equal rights and women's 'differences', i.e. those values that in the traditional gender division of attributes were associated with the female role. It should therefore be simultaneously symmetric and person-specific. The characteristics of such a regime would be, roughly speaking, those described in column 5 .

Even though existing welfare regimes are either too asymmetric or too lacking in person-specificity, there is no reason for this to be the case. There is no necessary trade-off between person-specificity and symmetry. Imagine a suitably large welfare regime based on income taxation rather than pay-roll taxes, redistributing a proper mix of cash and kind, with a competitive framework of market and public services. It should moreover avoid the 


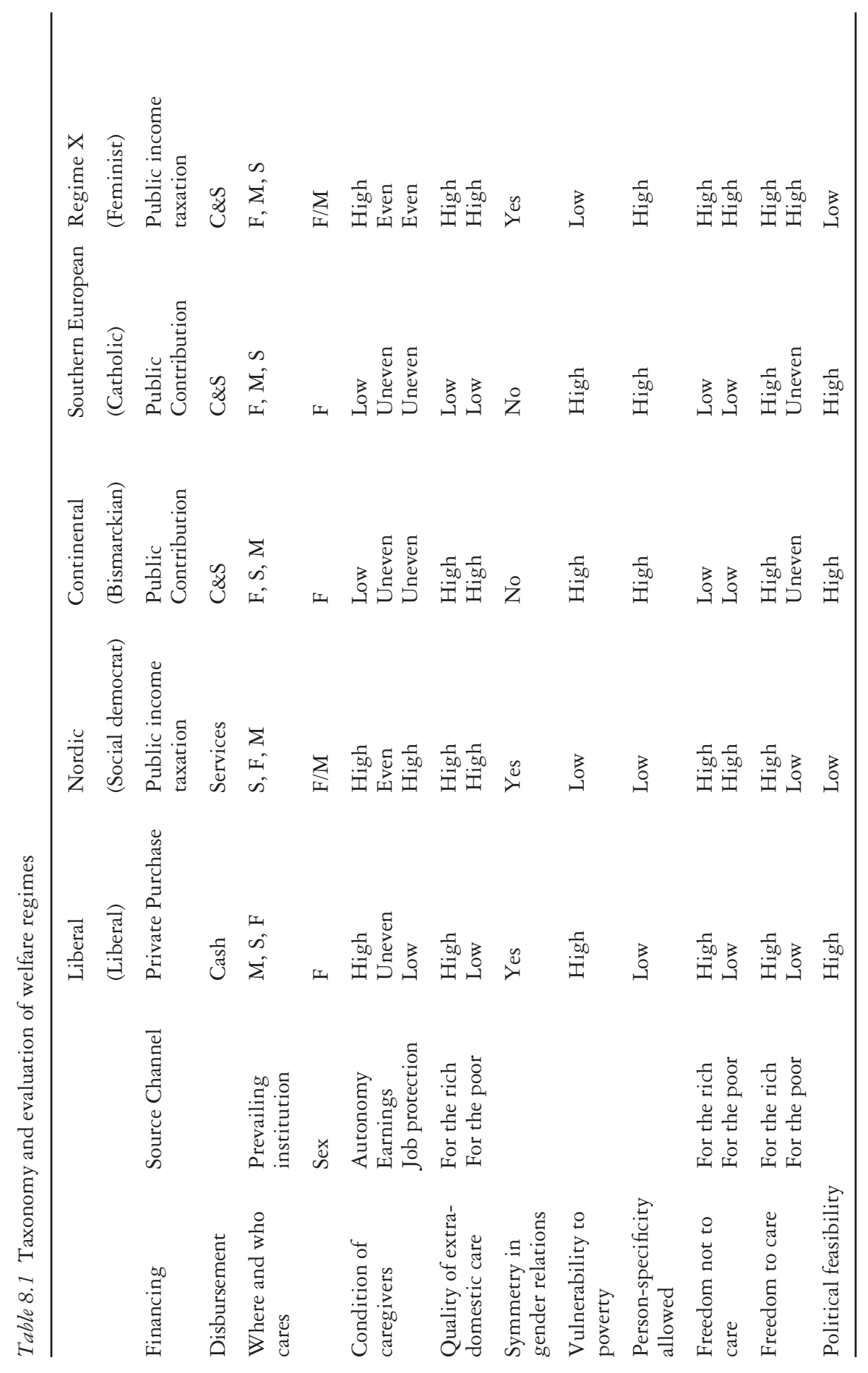


perverse incentives that induce asymmetry, disadvantages for women, lack of autonomy, vulnerability to poverty and so on. Such a model need not have any internal imbalance. Existing welfare regimes offer women either assimilation with the male model or continuing civil inferiority, but this is not a necessary evil. Welfare regimes may be designed which include the need for person-specificity and give incentives to time spent in caregiving by people of both sexes. This regime, however, must be symmetric; otherwise the attempt to induce person-specificity will reinforce traditional patterns with their related problems.

This type of welfare regime has a coherent structure that could be functional. However, its political feasibility, nowadays, is not very high. For many reasons which lie beyond the scope of this chapter, the political climate works strongly against it. ${ }^{25}$ One of the reasons, in my opinion, is a lack of clarity on the issues that are at stake. I hope this chapter may have contributed to this clarification. 


\section{Elisabetta Addis}

\section{Appendix}

Table 8A.1 Participation rates by sex, selected years

\begin{tabular}{|c|c|c|c|c|c|c|c|c|c|c|c|}
\hline & \multicolumn{3}{|l|}{1973} & \multicolumn{3}{|l|}{1983} & \multicolumn{3}{|l|}{1993} & \multicolumn{2}{|l|}{1996} \\
\hline & $F$ & $M$ & Total & $F$ & $M$ & Total & $F$ & $M$ & Total & $F$ & $M$ \\
\hline Australia & 47.7 & 91.1 & & 52.1 & & 69.3 & 62.3 & 85.0 & 73.7 & 64.9 & 85.4 \\
\hline Austria & 48.5 & 83.0 & 65.1 & 49.7 & 82.2 & 65.6 & 58.9 & 80.8 & 9.9 & 62.1 & 1.0 \\
\hline Belgium & 41.3 & 83.2 & 62.2 & 48.7 & & 62.8 & $54.1 *$ & $72.6 *$ & 63.8 & 56.1 & 72.1 \\
\hline Canada & 47.2 & 86.1 & 66.7 & 60.0 & 84.7 & 72.3 & 65.3 & 78.3 & 71.8 & 67.9 & 81.7 \\
\hline Denmark & 61.9 & 89.6 & 75.9 & 74.2 & 87.6 & 80.9 & 78.3 & 86.9 & 82.6 & 74.1 & 85.1 \\
\hline Finland & 63.6 & 80.0 & 71.7 & & 82 & 77.4 & 70.0 & 77.6 & 3.6 & 70.5 & 7.5 \\
\hline France & 50.1 & 85.2 & 67.8 & 54.3 & & 66.4 & 59.0 & 74.5 & 66.7 & 59.9 & 74.3 \\
\hline Germany & 50.3 & 89.6 & 69.4 & 52.5 & 82.6 & 67.5 & 61.4 & 78.6 & 70.2 & 61.0 & 80.0 \\
\hline Greece & 32.1 & 83.2 & 57.1 & 40.4 & 80.0 & 59.9 & 43.6 & 73.7 & 58.6 & 45.9 & 74.4 \\
\hline Ireland & 34.1 & 92.3 & 63.5 & 37.8 & 87.1 & 62.7 & $39.9 *$ & $81.9^{*}$ & $61.2 *$ & 49.4 & 78.1 \\
\hline Italy & & 85.1 & 58.7 & 40.3 & 80.7 & 60.1 & 43.3 & 74.8 & 58.9 & 43.2 & 75.1 \\
\hline Japa & 54.0 & 90.1 & 71.7 & 57.2 & 89.1 & 73.0 & 61.8 & 90.2 & 76.1 & 62.2 & 90.7 \\
\hline Luxembourg & 35.9 & 93.1 & 64.8 & 41.7 & 85.1 & 63.3 & $44.8 *$ & $77.7 *$ & $61.5 *$ & - & - \\
\hline Netherlands & 29.2 & 85.6 & 57.6 & 40.3 & 77.3 & 59.0 & $55.5 *$ & $80.8 *$ & 69.4 & 58.3 & 84.2 \\
\hline New Zealand & 39.2 & 89.2 & 64.5 & 45.7 & 84.7 & 65.3 & 63.2 & 83.3 & 73.2 & 67.1 & 84.2 \\
\hline Norway & 50.6 & 86.5 & 68.7 & 65.5 & 87.2 & 76.5 & 70.8 & 82.0 & 76.5 & 74.3 & 84.8 \\
\hline Portugal & $57.3 \#$ & \# 90.9\# & 64.0 & 56.7 & 86.9 & 71.4 & 61.3 & 82.5 & 71.7 & 64.1 & 81.5 \\
\hline Spain & 33.4 & 92.9 & 62.7 & 33.2 & 80.2 & 56.6 & 42.8 & 74.5 & 58.6 & 46.2 & 74.4 \\
\hline Sweden & 62.6 & 88.1 & 75.5 & 76.6 & 85.9 & 81.3 & 75.7 & 79.3 & 77.5 & 73.7 & 78.0 \\
\hline Switzerland & 54.1 & $94.6 \#$ & 77.7 & 55.2 & 93.5 & 74.5 & 57.9 & 92.5 & 75.3 & 67.1 & 96.8 \\
\hline U. Kingdom & 53.2 & 93.0 & 73.0 & 57.2 & 87.5 & 72.4 & 64.7 & 83.3 & 74.1 & 66.4 & 83.1 \\
\hline United States & 51.1 & 86.2 & 68.4 & 61.8 & 84.6 & 73.1 & 69.0 & 84.9 & 76.9 & 71.0 & 84.5 \\
\hline North America & 50.7 & 86.2 & 68.2 & 61.1 & 84.6 & 73.0 & 68.7 & 84.2 & 76.4 & - & - \\
\hline OECD Europe & 44.7 & 88.7 & 67.1 & 49.8 & 82.3 & 65.8 & 60.6 & 80.1 & 69.0 & - & - \\
\hline OECD Total & 48.3 & 88.2 & 68.2 & 55.1 & 84.3 & 69.3 & 61.6 & 81.3 & 70.3 & - & - \\
\hline
\end{tabular}

Source: OECD Employment Outlook 1996; OECD Main Economic Indicators, July 1998.

Notes

* Last available 1992.

\# First available 1979. 
Table 8A.2 Unemployment rates by sex, selected years

\begin{tabular}{|c|c|c|c|c|c|c|}
\hline & \multicolumn{2}{|l|}{1983} & \multicolumn{2}{|l|}{1993} & \multicolumn{2}{|l|}{1997} \\
\hline & Women & Men & Women & Men & Women & Men \\
\hline Belgium & 19.0 & 8.6 & 12.7 & 6.9 & 11.9 & 7.9 \\
\hline Canada & 11.1 & 11.2 & 10.6 & 11.7 & - & - \\
\hline Denmark & 10.5 & 8.2 & 13.7 & 11.3 & 7.8 & 7.3 \\
\hline Finland & - & - & 15.7 & 19.5 & 14.9 & 13.2 \\
\hline France & 10.8 & 6.3 & 13.8 & 9.9 & 14.4 & 10.7 \\
\hline Germany (W.) & $(8.0)$ & $(8.7)$ & $(8.4)$ & $(8.0)$ & 10.6 & 9.0 \\
\hline Greece & 11.7 & 5.8 & 14.2 & 5.4 & 14.9 & 6.2 \\
\hline Ireland & 16.5 & 14.6 & 12.1 & 17.3 & 10.4 & 10.1 \\
\hline Italy & 14.4 & 5.8 & 17.3 & 8.1 & 16.6 & 9.3 \\
\hline Japan & 2.6 & 2.7 & 2.6 & 2.4 & 3.4 & 3.4 \\
\hline Luxembourg & 5.3 & 2.6 & 1.9 & 1.5 & 5.2 & 2.7 \\
\hline Netherlands & 14.7 & 11.1 & 10.5 & 5.7 & 6.9 & 3.9 \\
\hline New Zealand & - & - & 8.9 & 10.0 & - & - \\
\hline Norway & 3.8 & 3.2 & 5.2 & 6.6 & - & - \\
\hline Portugal & 11.8 & 5.3 & 6.5 & 4.6 & 7.8 & 6.0 \\
\hline Spain & 20.8 & 16.5 & 29.2 & 19.0 & 28.3 & 16.0 \\
\hline Sweden & 3.6 & 3.4 & 6.6 & 9.7 & 9.7 & 10.6 \\
\hline Switzerland & - & - & 4.7 & 3.0 & - & - \\
\hline United Kingdom & 9.9 & 11.9 & 7.5 & 12.4 & 6.0 & 7.9 \\
\hline USA & 7.4 & 7.0 & 6.5 & 7.0 & 5.0 & 4.9 \\
\hline
\end{tabular}

Source: Bonke (1995); Eurostat Labour Force Survey (1994, 1997).

Table 8A.3 Social expenditure in the EU countries as a percentage of GNP

\begin{tabular}{lccc}
\hline Country & 1980 & 1986 & 1992 \\
\hline Belgium & 28.0 & 29.4 & 27.8 \\
Denmark & 28.7 & 26.7 & 31.4 \\
Germany & 28.7 & 28.1 & 26.6 \\
France & 25.4 & 28.5 & 29.2 \\
Ireland & 21.6 & 24.1 & 21.6 \\
Luxembourg & 26.5 & 24.8 & 28.0 \\
Netherlands & 30.8 & 30.9 & 33.0 \\
UK & 21.5 & 24.3 & 27.2 \\
EU 12 & 24.4 & 26.0 & 27.1 \\
Greece & 12.2 & 19.4 & 19.3 \\
Italy & 19.4 & 22.4 & 25.6 \\
Portugal & 14.7 & 16.3 & 17.6 \\
Spain & 18.1 & 19.5 & 22.5 \\
\hline
\end{tabular}

Source: Eurostat (1993). 


\section{Elisabetta Addis}

Table 8A.4 Main categories of social protection expenditure in EU 12

\begin{tabular}{llllll}
\hline Country & $\begin{array}{l}\text { Old age and } \\
\text { survivors' pensions }\end{array}$ & Health & Unemployment & Disability & Family \\
\hline Belgium & 11.9 & 6.0 & 2.6 & 2.9 & 1.9 \\
Denmark & 11.0 & 6.0 & 4.1 & 3.0 & 3.3 \\
Germany & 12.7 & 7.7 & 2.0 & 2.2 & 2.0 \\
France & 12.1 & 8.0 & 2.0 & 3.5 & 2.2 \\
Ireland & 5.7 & 6.1 & 3.0 & 1.5 & 2.2 \\
Luxembourg & 11.2 & 5.9 & 0.2 & 3.5 & 2.7 \\
Netherlands & 11.9 & 7.1 & 2.9 & 7.2 & 1.6 \\
UK & 10.8 & 5.1 & 1.6 & 3.1 & 2.6 \\
EU 12 & 11.9 & 6.5 & 1.9 & 2.4 & 1.8 \\
Greece & 10.2 & 2.3 & 0.5 & 1.5 & 0.1 \\
Italy & 15.4 & 5.4 & 0.5 & 2.2 & 0.8 \\
Portugal & 7.0 & 5.3 & 0.8 & 2.4 & 0.8 \\
Spain & 9.4 & 5.9 & 4.8 & 2.3 & 0.2 \\
\hline
\end{tabular}

Source: European Commission 1995.

\section{Notes}

1 I use 'gender' to indicate the set of physical and mental characteristics, and the proper, normal behaviour that each culture attributes to people on the basis of their biological sex. Gender therefore changes widely in time and space, through history and in different cultures and civilisations. For a thorough discussion of the concept of 'gender', see Nelson 1996.

2 There are, of course, many other dimensions of redistribution, between the healthy and the sick, between the lucky and the unlucky, between regions, or ethnic groups and so on that need to be considered in a full evaluation of the performance of a welfare system. For a classic discussion of the various dimensions of equity, see Sen 1992.

3 In Italy, see the very influential work by Rossi 1997.

4 For a discussion of this phenomenon, see Orloff 1996.

5 See Ferber and Nelson 1993; Addis 1997.

6 See Bonke 1993.

7 See Saraceno 1997; Bimbi 1997.

8 Of the main contributions to this literature, see Borchorst 1994; Brocas et al. 1990; De Leonardis 1998; Fraser 1997; Gordon and Fraser 1994; Hobson 1990; Jenson 1986; Knijn and Ungerson 1997; Lewis 1992; O'Connor 1993; O'Connor et al. 1999; Ostner and Lewis 1995; Sainsbury 1993, 1996; Ungerson 1997.

9 In order to classify models, that of industrial relations is also relevant, with centralised or decentralised wage-setting, and with co-operation or conflict as the prevailing wage-setting mode. We choose not to deal with these differences because they are not relevant to our theme.

10 By market-provided care I mean the purchase of a service that was formerly available within the household, such as childcare, a hot meal and laundry.

11 Purchasing the time of a domestic worker is a short cut whereby home-produced services are purchased in the market.

12 Traps are perverse incentives due to the 'moral hazard' that may be created by insurance schemes. An often-used example is that of a person who has unemployment insurance and so will not look for a job as long as the insurance payment lasts. 
13 On these issues, see also Gornick et al. 1997.

14 This implies that analyses based on rational choice theories, albeit useful, have clear limitations for comparative and evaluation purposes, since they take the structures of constraints as given.

15 On linking welfare provisions to employment, see Castles 1994; Flora and Albers 1991.

16 See Dell'Aringa and Samek Ludovici 1996.

17 To my knowledge, nobody has analysed the effects, in terms of gender politics in Western Europe, of the sudden availability of cheap domestic labour and sexual services by immigrant women that took place in the 1990s.

18 Evaluating as a whole the provisions taken since 1992 by Centre-Left governments, I think it is fair to comment that, although the welfare state was preserved, as opposed to what might have been an attempt at severe retrenching by the rightwing coalition, the asymmetry of the Italian welfare state was strengthened, rather than weakened. The Left in power failed to grasp that this artificial attempt to preserve/reproduce the traditional arrangement, with its patriarchal, familistic and jobcentred character, was the source of many of the pathologies of the Italian welfare state.

19 An item is called 'personalised' when it is built to custom, unique and suited specifically to one person's needs, though it does not matter who builds it. I tried to find a word indicating the opposite, the fact that a service, not unique but similar no matter who performs it, is valued more by the person who receives the care or by the one who gives it. For a child it is not the same to be fed by a parent or by a teacher; for a frail elderly person it is not the same to be washed by a nurse or by one's own child.

20 See Gershuny 1995.

21 A 'neutral but male' society emerges, competitive, hierarchical, aggressive and rigid, turning away from the values of which women have historically been the depositories. Solidarity, meekness, mediation and caring abilities lose value and become ever rarer both in men and women.

22 In Italy, the region of Emilia Romagna is known internationally for its excellent public childcare.

23 The tendency towards long working hours, documented by Schor (1992), has been reinforced by the workfare provisions of welfare reform at the end of the 1990s.

24 See Plantenga (1998) for an excellent discussion of the terms of the double burden.

25 On the political setting of recent European welfare reforms, see also Addis 2000.

\section{References}

Addabbo, T. (2000) 'I lavori atipici', in I differenziali salariali per sesso in Italia, Rome: Ministero del Lavoro, ch. 5.

Addabbo, T. and Baldini, M. (2000) 'Il lavoro non pagato e le politiche: una applicazione al reddito minimo di inserimento', in A. Picchio (ed.) Lavoro non pagato e condizioni di vita, Rome: CNEL.

Addis, E. (1997) Economia e differenze di genere, Bologna: Clueb. (1999) 'Gender in the Italian welfare state reforms', Southern European Society and Politics, 1: 122-49.

- (2000) 'La riforma dello Stato sociale nell'Europa della democrazia illuminata', Europa Europe, 1: 53-65.

Bettio, F. and Villa, P. (1996) 'Un modello al bivio', Donna, Woman, Femme (DWF), 4: 44-62.

Bimbi, F. (1997) 'Lone mothers in Italy: a hidden and embarrassing issue in a familist 


\section{Elisabetta Addis}

welfare regime', in J. Lewis (ed.) Lone Mothers in European Welfare Regimes, London: Jessica Kingsley, pp. 171-202.

Bonke, J. (1993) 'The distribution of time and money in the family', in S. Carlsen and J.L. Lansen (eds) The Equality Dilemma, Copenhagen: The Danish Equal Status Council.

Borchorst, A. (1994) 'The Scandinavian welfare states - patriarchal, gender neutral or woman-friendly?', International Journal of Contemporary Sociology, 31: 1-23.

Brocas, A-M., Cailloux, A-M. and Oget, V. (1990) Women and Social Security, Geneva: International Labour Office.

Campanelli, G. (2000) 'Convenience consumption e tempo di lavoro non pagato: paradossi o norme?', in A. Picchio (ed.) Lavoro non pagato e condizioni di vita, Rome: CNEL.

Castles, F. (1994) 'The wage-earners' welfare state revisited', Just Policies (May): 12-15.

De Leonardis, O. (1998) In un diverso Welfare, Bologna: Il Mulino.

Dell'Aringa, C. and Samek Ludovici, M. (1996) 'Gli ammortizzatori della disoccupazione: l'esperienza italiana', Qualità Equità, 3: 35-47.

Esping-Andersen, G. (1990) The Three Worlds of Welfare Capitalism, Princeton, NJ: Princeton University Press.

- (1996) Welfare States in Transition, London: Sage.

Ferber, M.A. and Nelson, J.A. (eds) (1993) Beyond Economic Man: Feminist Theory and Economics, Chicago, IL: University of Chicago Press.

Ferrera, M. (1998) Le trappole del Welfare, Bologna: Il Mulino.

Ferrera, M. and Gualmini, E. (1999) Salvati dall'Europa, Bologna: Il Mulino.

Flora, P. and Albers, J. (1981) 'Modernization, democratization and the development of welfare states in Western Europe', in P. Flora and A. Heidenheimer (eds) The Development of Welfare States in Europe and America, New Brunswick, NJ: Transaction Books, pp. 37-80.

Folbre, N. (1994) Who Pays for the Kids?, New York: Routledge.

Fraser, N. (1997) Justice Interruptus: Critical Reflections on the Postsocialist Condition, New York and London: Routledge.

Gershuny, J. (1995) 'Gender convergence and public regulation', Paper presented at the Forum on Gender and the Use of Time, Florence: European University Institute.

Goldschmidt-Clermont, L. and Pagnossin-Aligisakis, E. (1996) 'Measures of unrecorded economic activities in fourteeen countries', UNDP Human Development Report Office, Occasional Papers.

Gordon, L. and Fraser, N. (1994) “"Dependency” demystified: inscriptions of power in a keyword of the welfare state', Social Politics, 1: 14-31.

Gornick, J., Meyers, M. and Ross, K. (1997) 'Supporting the employment of mothers: policy variation across fourteen welfare states', Journal of European Social Policy, 7: 45-70.

Gustavsson, S. and Stafford, F. (1994) 'Three regimes of childcare: the U.S., the Netherlands and Sweden', in R. Blank (ed.) Social Protection versus Economic Flexibility, Chicago, IL: Chicago University Press, pp. 333-62.

Hobson, B. (1990) 'No Exit, No Voice: women's economic dependency and the welfare state', Acta Sociologica, 33: 235-50.

Jenson, J. (1986) 'Gender and reproduction: or, babies and the state', Studies in Political Economy, 20: 9-45.

Knijn, T. and Ungerson, C. (1997) 'Introduction: Care work and gender in welfare regimes', Social Politics, 4: 323-7. 
Lewis, J. (1992) 'Gender and the development of welfare regimes', Journal of European Social Policy, 3: 159-73.

Monacelli, D. (1996) 'Assessing public action in Italy: elderly assistance and the social pension scheme', Mimeo, Bank of Italy.

Nelson, J. (1996) Feminism, Objectivity, and Economics, London: Routledge.

O'Connor, J.S. (1993) 'Gender, class and citizenship in the comparative analysis of welfare state regimes: theoretical and methodological issues', British Journal of Sociology, 44: 501-18.

O'Connor, J.S., Orloff, A.S. and Shaver, S. (1999) States, Markets, Families: Gender, Liberalism and Social Policy in Australia, Canada, Great Britain and the United States, Cambridge: Cambridge University Press.

Orloff, A.S. (1996) 'Gender in the welfare state', Annual Review of Sociology, 22: 51-70.

Ostner, I. and Lewis, J. (1995) 'Gender and the evolution of European social policies', in S. Liebfried and P. Pierson (eds) European Social Policy: Between Fragmentation and Integration, Washington, DC: Brookings, pp. 159-93.

Platenga, J. (1998) 'Double lives: labour market participation, citizenship and gender', in J. Bussemaker and R. Voet (eds) Gender, Participation and Citizenship in the Netherlands, Aldershot: Ashgate, pp. 51-64.

Rossi, N. (1997) Meno ai padri e più ai figli, Bologna: Il Mulino.

Sainsbury, D. (1993) 'Dual welfare and sex segregation of access to social benefits: income maintenance policies in the UK, the US, the Netherlands and Sweden', Journal of Social Policy, 22: 69-98.

- (1996) Gender, Equality and Welfare States, Cambridge: Cambridge University Press.

Saraceno, C. (1994) 'The ambivalent familism of the Italian welfare state', Social Politics, 1: 60-82.

(1997) 'Family change, family policies and the restructuring of welfare', in OECD Social Policy Studies, 21, Family, Market and Community, Paris: OECD, pp. 81-100.

Schor, J.B. (1992) The Overworked American: The Unexpected Decline of Leisure, New York: Basic Books.

Sen, A. (1990) 'Gender and cooperative conflicts', in I. Tinker (ed.) Persistent Inequalities, New York: Oxford University Press. (1992) Inequality Reexamined, Oxford: Oxford University Press.

Trifiletti, R. (1996) 'Mediterranean welfare regimes and the worsening position of women', paper presented at the Interdisciplinary Women's Studies Seminar, European University Institute, Florence.

Ungerson, C. (1997) 'Social politics and the commodification of care', Social Politics, 4 (3): 362-81.

Woolley, F. (2001) Why pay child benefits to mothers? Mimeo presented to the annual IAFFE conference, Oslo. 


\title{
9 The gender impact of workfare policies in Italy and the effect of unpaid work
}

\author{
Tindara Addabbo and Massimo Baldini
}

\section{Introduction}

The analysis carried out in this chapter may be set alongside the literature which analyses the effect of public policy by gender, such as the research conducted since the beginning of the 1990s by the UK Women's Budget Group, ${ }^{1}$ or by Budlender et al. (1998) in South Africa and Australia. Himmelweit (1998) discusses how the different employment conditions and working profiles over the life cycle of men and women can affect the impact of the same public policy by gender, and states that ignoring these differences can noticeably reduce the efficacy of the policy itself. After acknowledging the economic relevance of unpaid work, ${ }^{2}$ the effects of public policies on its distribution and size need to be evaluated:

If the effect of budgetary policy is to move women's time from unpaid care economy to other sectors of the economy, the full ramifications have to be recognized, planned and budgeted for.... This is not to argue that women's (or men's) labour time should not be transferred between sectors, but that the costs and benefits to society should be looked at overall.

(Himmelweit 1998: 10)

The importance of acknowledging the gender impact of welfare policies is addressed in Addis (1999), who stresses the discouraging effect on women's labour supply of the Italian welfare state system.

This chapter analyses the impact of a policy recently introduced in Italy which is still in an experimental phase: minimum insertion income (hereafter MI). MI is aimed at very poor families and combines a cash transfer with policies aimed at encouraging labour market participation by at least one family member of working age. Section 1 describes the characteristics of this policy and contains a simulation on how many households can benefit from it. Section 2 evaluates how, by extending income to include unpaid work, family labour supply decisions can change. This evaluation relates to a sample with couples of working age, with or without children, from the 
1995 Bank of Italy Survey on Household Income and Wealth (hereafter SHIW). The 1995 SHIW data-set contains useful information on the household socio-demographic structure and on household income but does not report information on unpaid work. $^{3}$ It is therefore necessary to use a matched data-set obtained by combining SHIW records with unpaid work information estimated from the last available ISTAT time budget survey in 1989. ${ }^{4}$

\section{The minimum insertion income}

An experimental form of minimum insertion income (MI) has recently been introduced in Italy, and the aim of this research is to evaluate the effects it could have on the propensity of the women currently outside the labour force to search actively for a job.

The receipt of minimum income is indeed conditional on joining an insertion programme with the objective of reintroducing the beneficiary into the labour market, through the acceptance of any job proposals, attendance at training courses or involvement in socially useful activities. Women belonging to households with incomes so low as to be eligible for MI, however, are generally characterised by a low educational level, and the low wages that they could probably earn once in the labour market are extremely unlikely to compensate for the reduction in the component of extended income produced by their unpaid work.

In general, the introduction of MI seeks to remedy the lack, in Italy, of a last-resort safety net that may guarantee a minimum standard of living to all needy households. ${ }^{5}$ Many local authorities provide some form of minimum income, but in a totally uncoordinated and discretionary way.

In a first and experimental phase of three years, starting in 1999, MI has been introduced into only thirty-nine local areas (among them Naples, Catania, Genoa, Reggio Calabria), chosen according to a complex set of social and economic characteristics, and concentrated mainly in Southern Italy - the poorest region. The amount of minimum income for 2002 is set at 0.55 million lire ( $€ 284$ ) per month for a single person, while for other households the levels are calculated by applying an equivalence scale simply defined as the number of components raised to the power 0.65 (the elasticity of the scale). ${ }^{6}$ Thus the household is the reference unit to evaluate the welfare of an individual. The transfer is set so as to cover the difference between minimum income itself and total disposable household income (including other forms of social assistance); only 75 per cent of total earnings are counted in total household income, to diminish the poverty trap, so that the scheme reproduces a negative income tax with a marginal tax rate of 0.75 , covering a constant share of the poverty gap (the difference between minimum income and household income). Any amount of financial assets, however small, is a sufficient condition for losing eligibility, a requirement perhaps imposed by the nature of the scheme, aimed at alleviating situations 
of particularly harsh poverty and social exclusion; as for real assets, only the ownership of the house where one lives is allowed, any other real asset causing loss of benefit.

This scheme has been devised, following the French example fairly closely, not only as a protection against poverty but also as an instrument to promote the reintroduction of the poor into active social life: its receipt is conditional on joining an insertion programme, through acceptance of any job proposals, attendance at training courses, or involvement in socially useful activities by one of the household's members of working age. This participation condition does not apply to households with children younger than 3 or with seriously disabled members. If this measure is extended to the whole population, some simulations on the SHIW sample have shown that it will cost about 4,000 billion lire $(€ 2,000$ billion) per year. MI should represent, at the end of the experimental phase, the third step of a system of benefits aimed at contrasting situations of economic difficulty: if a person loses his or her job, he or she may receive benefit from the wage supplementation fund (Cassa Integrazione Guadagni, CIG), equal to a substantial percentage of the previous wage, for not more than one year, then a mobility allowance giving a lower share of the wage, and finally, if he or she still fails to find a new job, the MI, a universal safety net open to all citizens, not only to members of the labour force. MI, however, will be the only transfer available to non-dependent workers, which in Italy represent a substantial share (nearly 30 per cent) of the labour force, and to people who have never been employed.

For an analysis of the process which led to the experimental introduction of MI in Italy, see Negri (1998) and Alti and Maino (1999), who discuss the problems emerging during the first stages of the experimentation in a small town in Northern Italy; too rigid formal requirements and the presence of irregular workers who may find the amount of MI too low to apply for are, according to the authors, the two most important reasons for the relatively limited number of applications received so far by local authorities.

The introduction of MI is an important part of a wider reform process of the Italian system of social assistance currently taking place, which is undergoing a complete revision of the targeting system: from an uncoordinated and often irrational set of means-testing instruments, based largely on taxable income, towards a single criterion to ascertain the economic conditions of those wishing to apply for cash transfers or benefits in kind. A new indicator of the economic circumstances of a household, called ISE (Indicatore della Situazione Economica), has recently been introduced and consists in a straightforward combination of the values of incomes and assets of the family. The adoption of a new targeting system is seen as a necessary precondition for the shift from a category-based to a universal welfare state, since only with a reliable and efficient means test can a welfare system be based on universal schemes open to all individuals, satisfying only the conditions of citizenship and need. MI should actually represent the most 
significant move towards universalism in the pool of potential beneficiaries. The normative aspect of ISE has been adopted only partially in the case of MI: the definition of the family is the same, as well as the equivalence scale, while the means test is different and more severe, since it excludes from the set of potential beneficiaries those owning assets other than the house in which they live, a point to which we shall return below.

Many obstacles can jeopardise the success of the new system, of which ISE and MI are the first steps (provided, of course, that the resources necessary to finance MI at the end of the experimental period are found); in particular, all the criticisms raised against means-testing apply here (Atkinson 1996): the risk of placing a substantial share of households in a poverty trap, the problem of low take-up levels, the distortionary effects of the informal economy, the inefficiency of public administration which should ascertain the actual economic conditions of the applicants and organise the insertion programmes for MI recipients. This latter problem seems to be the most relevant for Italy, especially in the case of the local authorities of the South, where most of the poor are concentrated. As for the disincentive effects, little can be said for this particular case, but the literature has concluded so far that disincentive effects from safety net schemes are certainly present, although of limited quantitative significance (Atkinson and Mogesen 1993).

\section{Extended standard of living and minimum insertion income}

In this section, using the microdata of the Bank of Italy survey for 1995, we simulate the possible effects of MI on the division of labour within a couple, considering how extended household income changes when at least one member of the couple modifies his or her work status if the household wants to satisfy the prerequisites for MI eligibility.

\section{Characteristics of housebolds eligible for MI}

Table 9.1 shows the percentage distribution of two-partner households whose male member is between 21 and 64 years old, with or without children, into three groups: the first includes those households which, according to their composition and their total income, would have had the right to receive MI in 1995; the second includes those households with equivalent income greater than the MI threshold, but by less than 10 per cent of its value, and therefore singles out those households who run the risk of falling into a situation of severe poverty; all other households are in the third group. The last row converts the column totals into the actual number of households in each group. Tables 9.2 and 9.3 contain the same information, but focus on households with and without children, respectively.

According to our simulations, about 195,000 two-partner households would be eligible for MI (for the whole Italian population, the number 


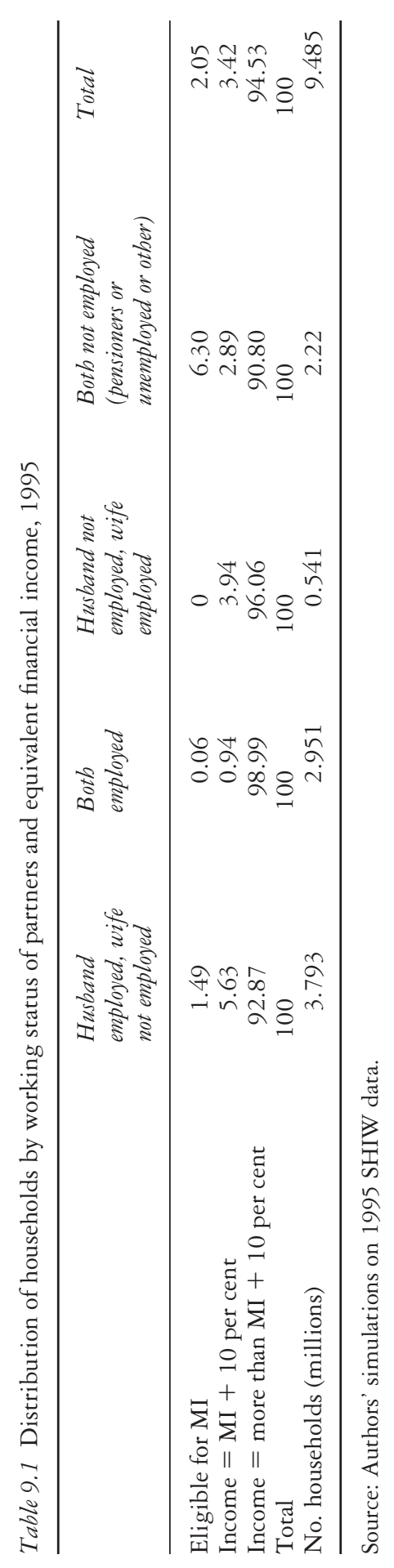




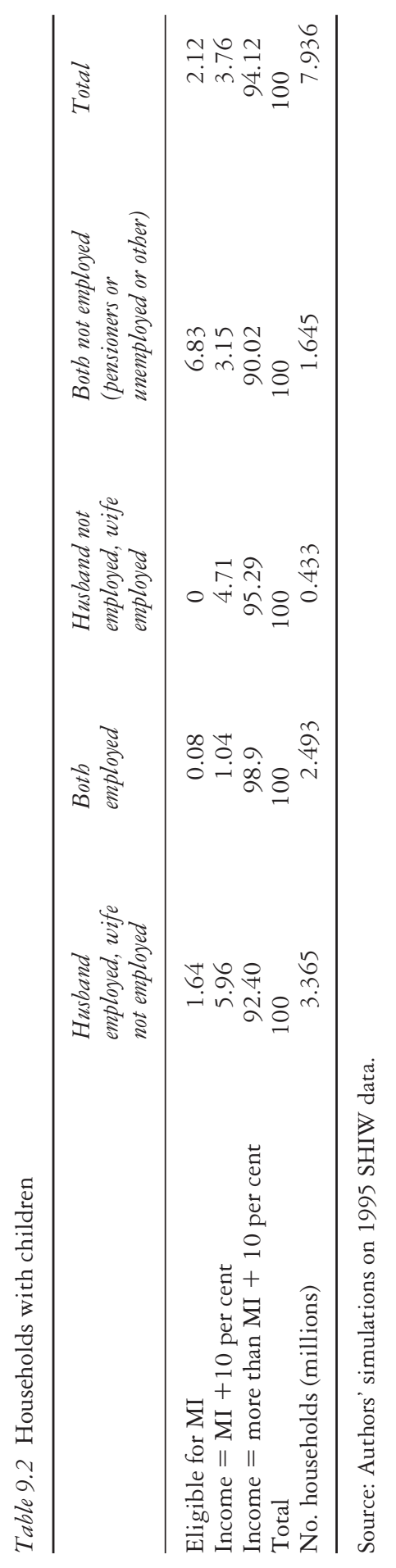


would increase to around 500,000 households), and 324,000 other households would not present a significantly greater equivalent disposable income. If at least one of the partners is employed, the probability of earning a low income falls significantly, though if only the man works, about half a million households would still have incomes not much greater than the MI threshold. If both partners work, the probability of receiving MI actually falls to zero.

Table 9.4 confirms the great concentration of poor households in Southern Italy, in particular in the South-west (which also includes, in our classification, Sicily and Sardinia), while the number of households potentially involved in the MI scheme is very low in the North-west. If those households that are close to the threshold are also included, about 145,000 households with both partners present would in any case be in a difficult economic situation. ${ }^{8}$

Women living in the most difficult economic circumstances have low levels of education (Table 9.5), and it is very likely that this will also be the case for their partners. The reduced endowment of human capital implicit in these low educational levels could represent a serious obstacle to the possibility of finding jobs with satisfactory wages.

On the basis of Table 9.6, the probability of living in poverty decreases steadily with respect to the age of the wife; this could be due to the greater incidence of unemployment in the first stages of the life cycle, and to the lower level of protection granted by the current structure of the welfare system to households without pensioners.

\section{Unpaid work and minimum insertion income}

The average unpaid work of women who live in households eligible for MI, or in households whose equivalent income is no higher than 10 per cent of the income level required to enjoy MI, totals fifty-five hours a week, ten hours more than the unpaid work of women living in households whose income is at least 10 per cent higher than the MI level. This section contains a simulation of the effects in terms of welfare changes of MI on different family types, again looking at those who are eligible for MI.

\section{Households with children aged under 3}

The first group of households eligible for MI is made up of those with children aged under 3. These households are eligible for MI without being required to join training schemes or accept job offers. They can enjoy cash transfers and, if the wife did not work in the market before MI, extended income can increase without any change in unpaid work. However, one can see how for the double-earner households closer to MI level (whose household income is no more than 10 per cent above MI, the MI cut-off) and with children aged under 3, women may be encouraged to leave the labour 


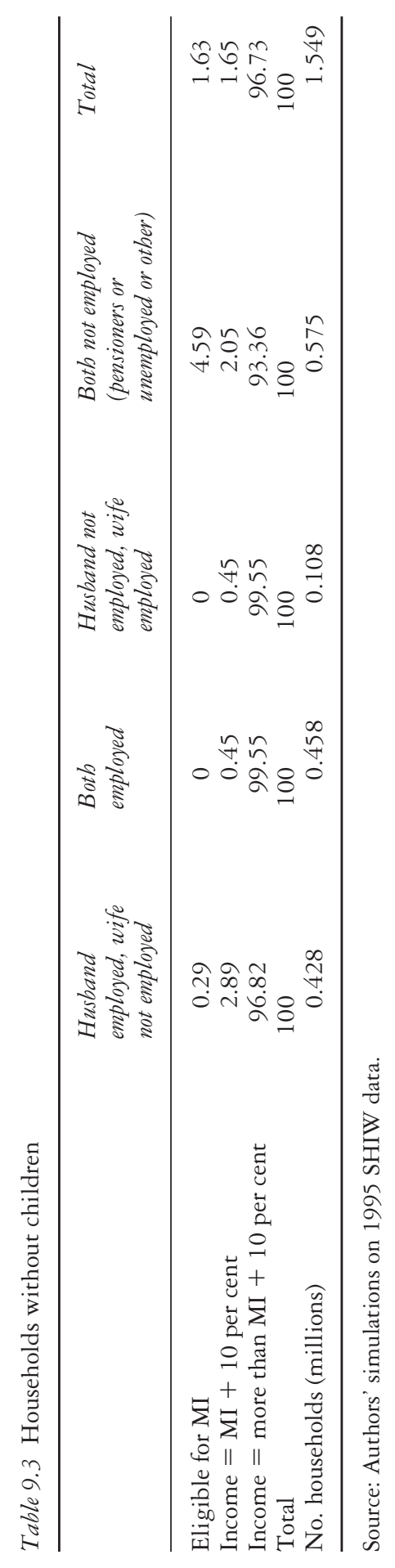




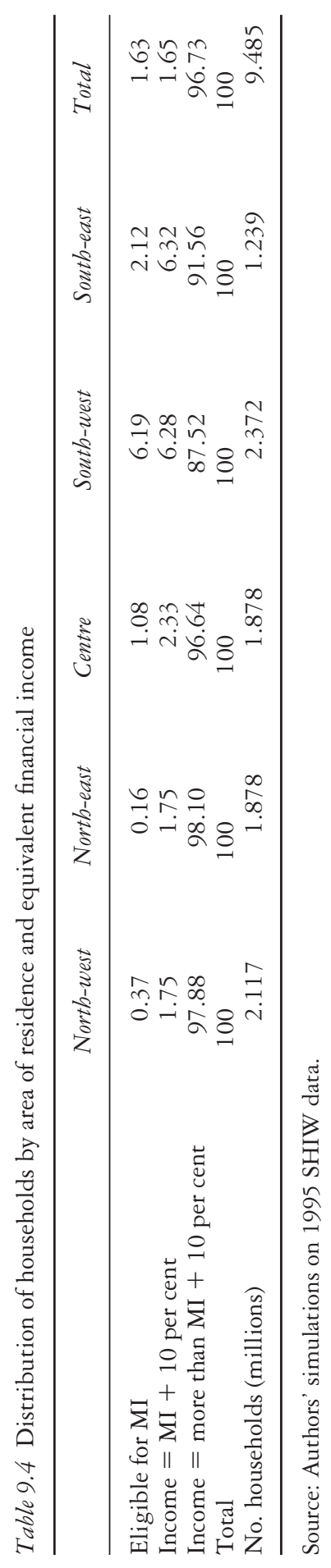




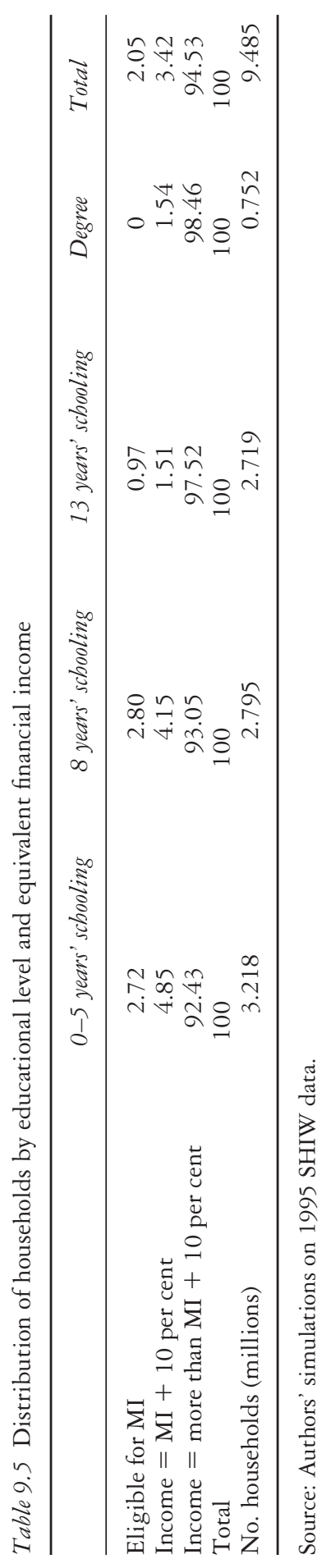




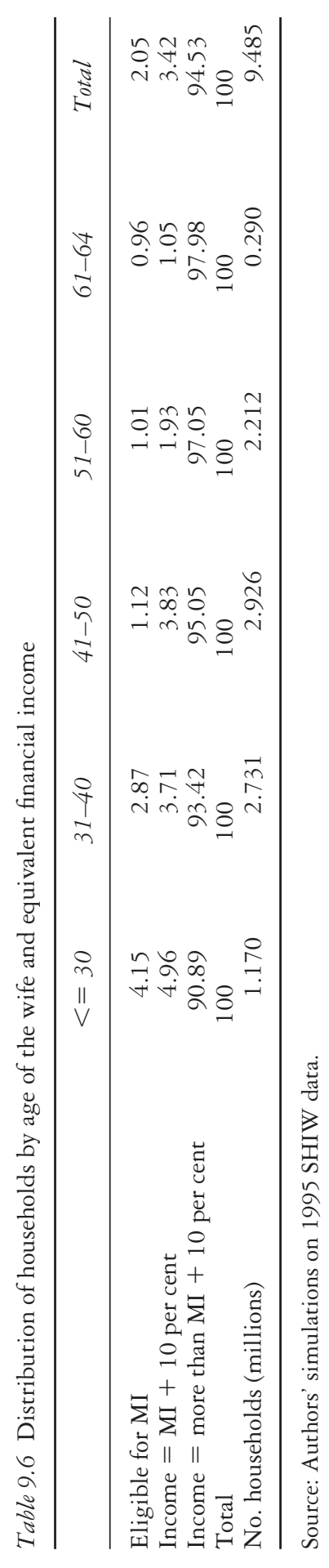


market. Given the lower level of education of these women with respect to other women, and the higher discontinuity in their working profile (Addabbo 1999; Bettio and Villa 1999), the probability that they will exit the labour market is particularly high. The introduction of MI, together with the low level of wages they can enjoy by working and the improvement in extended welfare that the household can enjoy if the mother left the labour market (and supplied more unpaid work), can therefore produce a discouraging labour supply effect for the mother. In fact, their exit in the presence of young children is very likely to be definitive rather than temporary. Even if they had a continuous work profile it is probable that their wages and career prospects would not noticeably improve, and when re-entering the labour market they could not discount the years they spent outside of it. However, one should note that these women are more likely to leave the labour market completely once they exit for child-rearing reasons (Bettio and Villa 1999) and therefore they are more subject to the risk of social exclusion. The literature on the fixed costs connected with working (Addabbo 1996) shows how the costs linked to the presence of young children are higher when the individual is out of the labour market than when she is employed. The former has to look for care services and the costs of searching will add to the money costs of the service itself. One can surmise that couples in this group of households will take the following steps:

- Women will exit the labour market in order to enjoy MI without having to work in the labour market and also to devote more time to the care of their children in a particularly delicate phase of the family cycle (as is also shown by the data on unpaid work). ${ }^{9}$

- When their child is older than 3 they may not return to the labour market since the costs of market childcare could be too high, or because the labour market situation could discourage the labour supply by a potential worker whose weakness in the labour market has been worsened by her being out of it for three years.

In order to avoid the risk of social exclusion the following policies could be adopted:

- Increase childcare availability at low cost in order to reduce the problem of constraints connected with the high fixed costs which could discourage women from returning to paid employment. This can be done either directly (by increasing the availability of full-time public schools for children over age 3) or by encouraging the provision of childcare services by non-profit institutions and by arranging for low-income families to use these services.

- Provide training programmes to help women to re-enter the labour market. 


\section{Tindara Addabbo and Massimo Baldini}

Households without children younger than age 3 and where neither partner is employed

In most of the households which are eligible for MI, both partners are unemployed (Table 9.1). If they received MI their extended income would increase because of the cash transfer they would receive. However, in order to enjoy MI, at least one of the household's members of working age must join training courses or must be available to accept a job if it is offered.

In order to check whether any discouraging effect on the labour supply of one of the family members could arise, one can simulate the impact on households' welfare of the acceptance of a job (we assume a full-time job in the service sector) by each one of the formerly non-employed partners. In this case:

- Money income would increase because of the employed partner's earnings (which one can evaluate by multiplying the imputed wage obtained by estimating a human capital wage equation with labour demand variables by thirty-seven hours, the average number of working hours of people in this sample who are employed in the service sector). ${ }^{10}$ Where labour earnings are not enough to reach the MI cut-off, the amount necessary to bring the family income to the MI level should be added to that income.

- The assumption is made that the non-employed partner will substitute for the unpaid work of the employed partner by also providing the necessary childcare. The money costs necessary to buy childcare services in the market are not deducted here from the household welfare.

- Extended income changes depending on the unpaid work imputed by using the equations estimated in Chapter 3 (this volume) ${ }^{11}$ and by changing the characteristics of the partners. ${ }^{12}$

Table 9.7 shows the changes in money and extended income in the case where the woman accepted a proposal of a white-collar job in the service sector. As may be seen, in some cases the wife's earnings do not even reach the MI level, and in this case a cash transfer to the labour earnings had to be added in order to reach the MI level.

As Table 9.7 shows, the increase in money income is on average $3,517,184$ lire ( $€ 1,817)$, but the loss in welfare connected with the reduction in the wife's unpaid work is $4,284,554$ lire ( $€ 2,213$ ), so the net loss for this type of household if the wife accepted the job proposal would be 767,359 lire (€396). This may discourage the wife from accepting the job offer. This result is connected with the low hourly wage of women who belong to this group of households and also to the reduction in women's unpaid work.

These computations do not take account of the long-term effects of a woman's decision to work, assuming either that there are only low returns of 


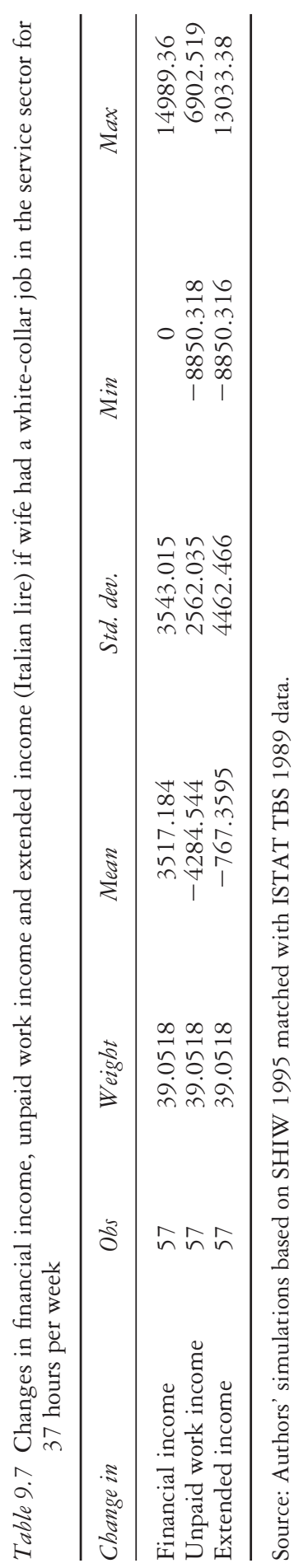




\section{Tindara Addabbo and Massimo Baldini}

work experience on forward wages and on the working career of women with a relatively low level of education (as in the case of women belonging to this group of households) or short-sighted behaviour that prevents them from evaluating the dynamic effects of their current choice.

If the husband entered the labour market while his wife continued to provide unpaid work, the household's welfare would increase on average by $14,118,690$ lire $(€ 7,293)$ per year. This is because money income will on average increase more than in the case where the wife would have accepted the job proposal and given that the reduction in unpaid work income is not as great as in the previous case. If one compares the welfare losses and gains connected with the choice regarding labour market participation, one can see how it would be more likely that the husband will become employed.

If one adds the loss of self-esteem by the unemployed husband to these evaluations based on the computations of money and extended income, which has been found by researchers investigating the lower labour supply by the wives of unemployed men (Barrère et al. 1985), it is even more likely that the intensity of the husband's job search will be greater than the wife's propensity to supply her labour. On the one hand, the employment choice made by the family on the basis of the increase in the household's welfare may lead the husband to become employed, and on the other hand the husband's job search may be encouraged, given that the likely labour income will be well above the MI level and there will be no need for further cash transfers.

In this case one should adopt policies to increase women's human capital to promote the economic independence of family members (an aim that is stated by the MI Decree Law itself).

One-earner households without children younger than age 3

Turning to one-earner households which are eligible for MI, if the wife were to accept a white-collar job in the services sector, one may observe:

- An increase in money income by 5,404,220 lire $(€ 2,791)$ if one disregards the money costs connected with the care of children in such households. However, unlike the case where both partners were unemployed, in this household group one must compute a money cost for care of children below age 10, which we have imputed on the basis of 10,000 lire ( $€ 5.16)$ per hour for 37 hours a week if the family contains children from 3 to 5 years old, and on the basis of 10,000 lire ( $€ 5.16$ ) per hour for twenty hours a week if the family contains children from 6 to 10 years old. We surmise the use of a market service to substitute for women's care instead of the cost of a public service by assuming that children under 6 do not attend a state school and that the education for children over 6 is not full-time. ${ }^{13}$ If one also considers these costs, the money income would decrease by $2,476,812$ lire (€1,279) (Table 9.10). 


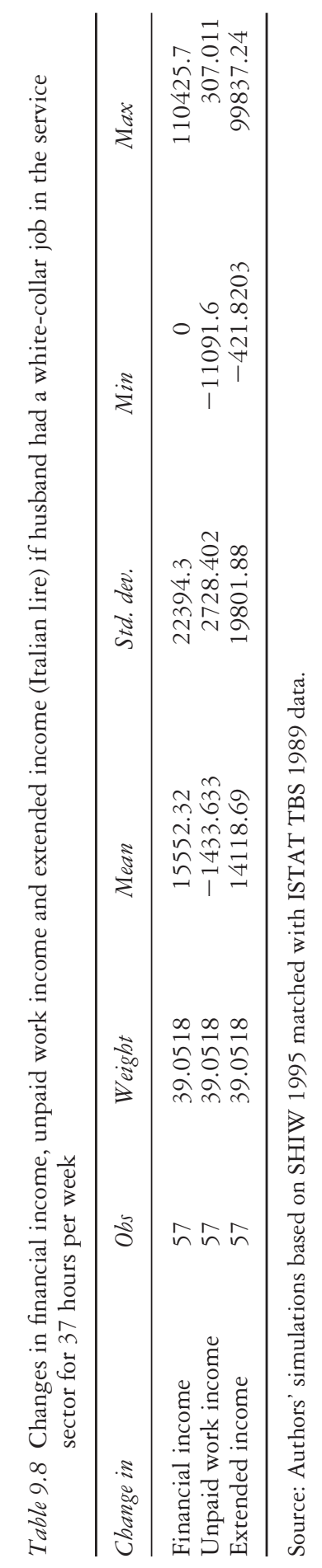


- Unpaid work income evaluated at its opportunity cost will decrease by $6,075,152$ lire $(€ 3,138)$.

- The net decrease in extended income totals 670,932 lire (€346) (if one excludes childcare additional costs; see Table 9.9) and 8,551,965 lire $(€ 4,417)$ (if one also considers the financial costs of childcare; see Table 9.10).

From these computations one may deduce a highly discouraging effect on women's participation in paid employment in poor one-earner households, as a result of which women may either not engage in active job hunting or refuse a job offer.

\section{Conclusions}

This chapter shows how, by considering extended income, households can change their labour market behaviour in the presence of public policies, with reference to a scheme (currently in an experimental phase in Italy) to supplement the financial income of the poorest households.

The inclusion of unpaid work in household welfare highlights the potentially discouraging effects on women's labour supply in very low-income households (households that are potentially eligible for MI). By means of a computation based on the expected change in a household's extended income, this chapter shows how low-income households may prefer the wife not to accept a job offer or to engage in job hunting. This can lead to a low take-up of MI or to continuing social exclusion of women belonging to the poorest households, who are already in a weak position as far as their labour market work is concerned. ${ }^{14}$ Short-sighted behaviour (which may lead to neglecting the long-term effects of the labour supply choice) together with low education levels (which can reduce the possibility of being in a job with good career prospects) may cause women to exit from the labour market or not to accept MI if this involves accepting a job, and this can increase their economic dependence either on the state or on their partners, with very bad effects in cases of marriage breakdown. ${ }^{15}$ Moreover, the analysis of the loss in unpaid work connected with the acceptance by women of a job shows how, at very low levels of household income, women's unpaid work is needed particularly to sustain a household's standard of living.

The knowledge of the effect on individuals' choices of family constraints should induce the public officers entrusted with the application of MI to pay particular attention to the tensions and needs inside the households which entered into the MI experimental phase, and to increase the incentives for training of the weakest household members and for childcare provision. ${ }^{16}$ More information on the long-term effects of being out of the labour market should also be provided. ${ }^{17}$

The data on unpaid work reveal the high total workload of women and the unequal distribution of total work by gender inside the family. In house- 


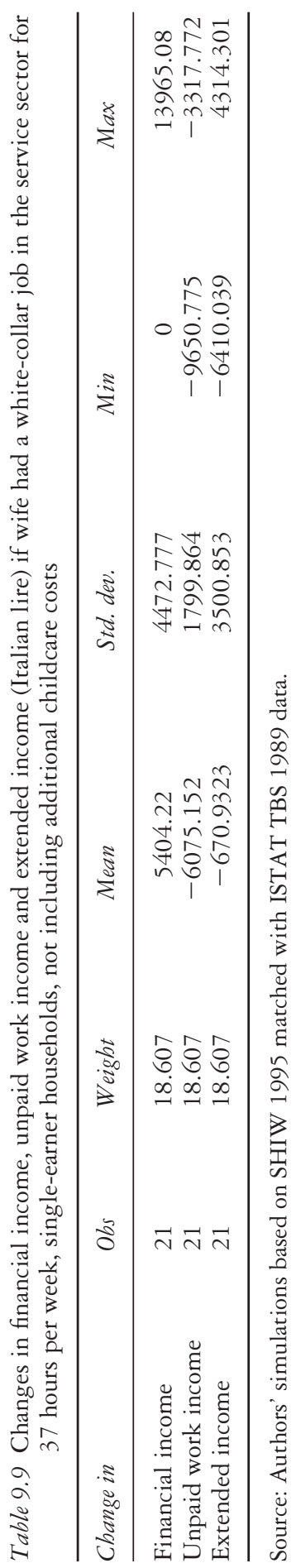




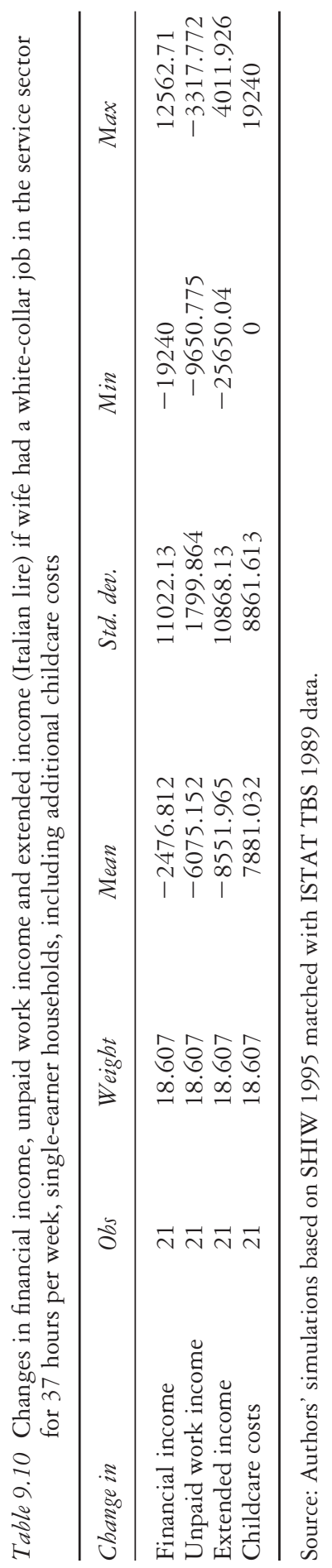


holds which manage not to fall into poverty by means of paid work by both partners, women have to pay in terms of a high total workload and of the difficulties of finding affordable substitutes in the market for their inputs of time or home-produced goods.

This analysis deals with a very low-income group of households. However, the problem of making choices with regard to labour market participation when there are young children or elderly family members requiring care at home is also present for women in households with higher incomes, and particularly with average income and with members who are not employed: these households are more likely to be excluded from public services or included by paying high tariffs. A subsequent extension of this research will consider how access to childcare and public care services for the elderly would be changed by using ISE, and how the discouraging effect on women's labour supply can be reduced by changing the parameters of the ISE equivalence scale. 
244 Tindara Addabbo and Massimo Baldini

Appendix

Unpaid work by gender, type of work and days of the week $k^{18}$

Table 9A.1 Equations on married women's housework on different days of the week (OLS-Dep. Var.: logarithm of housework hours)

\begin{tabular}{|c|c|c|c|c|c|c|}
\hline & \multicolumn{2}{|l|}{ Weekdays } & \multicolumn{2}{|l|}{ Saturdays } & \multicolumn{2}{|l|}{ Sundays } \\
\hline & coefficient & $t$ & coefficient & $t$ & coefficient & $t$ \\
\hline Constant & 1.017 & 5.581 & 1.200 & 7.739 & 1.072 & 7.564 \\
\hline North-west & 0.092 & 2.193 & & & & \\
\hline South & 0.053 & 1.408 & 0.053 & 1.423 & 0.079 & 1.917 \\
\hline Wife's age & 0.008 & 1.699 & & & 0.010 & 4.013 \\
\hline Wife's education & -0.019 & -2.703 & -0.006 & -0.984 & -0.020 & -3.266 \\
\hline Wife not in labour force & 0.806 & 5.593 & 0.139 & 1.747 & & \\
\hline Wife part-time & 0.283 & 4.053 & 0.068 & 0.964 & -0.320 & -1.636 \\
\hline Wife self-employed & -0.195 & -2.337 & -0.200 & -1.994 & & \\
\hline Wife managerial & & & -0.248 & -1.503 & & \\
\hline Wife in agriculture & 0.670 & 4.24 & 0.237 & 2.030 & 0.190 & 2.573 \\
\hline Wife in service sector & 0.343 & 2.585 & -0.197 & -2.084 & & \\
\hline Husband's age & -0.004 & -0.858 & 0.008 & 2.739 & & \\
\hline Husband's education & 0.016 & 2.766 & -0.006 & -1.145 & & \\
\hline Husband not in labour force & -0.063 & -1.183 & -0.049 & -0.737 & 0.062 & 1.144 \\
\hline Husband part-time & 0.082 & 1.422 & 0.127 & 3.267 & 0.147 & 2.036 \\
\hline Husband managerial & -0.196 & -1.582 & & & & \\
\hline Husband service sector & 0.037 & 0.926 & & & & \\
\hline Children $0-2$ years & & & & & 0.083 & 1.283 \\
\hline Children $15-17$ years & & & 0.051 & 1.070 & & \\
\hline Children $18-24$ years & & & 0.077 & 1.753 & & \\
\hline Children aged over 18 & & & 0.073 & 1.289 & & \\
\hline $\begin{array}{l}\text { Employee with low } \\
\text { education }\end{array}$ & 0.114 & 1.233 & & & -0.132 & -2.076 \\
\hline $\begin{array}{l}\text { Number of minority age } \\
\text { children }\end{array}$ & 0.079 & 4.005 & 0.051 & 2.049 & 0.053 & 2.298 \\
\hline $\begin{array}{l}\text { Number of majority age } \\
\text { children }\end{array}$ & 0.063 & 2.94 & & & 0.044 & 1.597 \\
\hline
\end{tabular}




\section{Wage equations by gender}

Table 9B.1 Employment probability (Heckman first step)

\begin{tabular}{|c|c|c|c|c|c|c|}
\hline \multirow[b]{2}{*}{ Variables } & \multicolumn{3}{|l|}{ Women } & \multicolumn{3}{|l|}{ Men } \\
\hline & Coefficient & Std. error & t-ratio & Coefficient & Std. error & t-ratio \\
\hline Constant & -5.177 & 0.538 & -9.621 & -4.800 & 0.632 & -7.599 \\
\hline Household's income & -0.001 & 0.002 & -0.625 & -0.014 & 0.002 & -8.248 \\
\hline Age & 0.238 & 0.028 & 8.638 & 0.308 & 0.030 & 10.364 \\
\hline Age squared & -0.003 & 0.000 & -9.095 & -0.004 & 0.000 & -11.927 \\
\hline Education & 0.134 & 0.007 & 18.407 & 0.082 & 0.008 & 10.302 \\
\hline $\begin{array}{l}\text { Children aged } \\
\text { under } 3\end{array}$ & -0.343 & 0.088 & -3.905 & 0.107 & 0.111 & 0.958 \\
\hline Children aged & & & & & & \\
\hline $3-5$ & -0.231 & 0.064 & -3.602 & 0.019 & 0.080 & 0.234 \\
\hline $\begin{array}{l}\text { Children aged } \\
6-17\end{array}$ & -0.183 & 0.036 & -5.136 & -0.141 & 0.038 & -3.681 \\
\hline $\begin{array}{l}\text { Children aged } \\
18-24\end{array}$ & -0.157 & 0.044 & -3.550 & 0.088 & 0.045 & 1.951 \\
\hline $\begin{array}{l}\text { Regional } \\
\text { unemployment rate } \\
\text { Chronic disease } \\
\text { Partner not employed }\end{array}$ & $\begin{array}{r}-0.049 \\
-0.270 \\
0.156\end{array}$ & $\begin{array}{l}0.006 \\
0.087 \\
0.106\end{array}$ & $\begin{array}{r}-8.735 \\
-3.103 \\
1.465\end{array}$ & $\begin{array}{l}-0.040 \\
-0.119 \\
-0.159\end{array}$ & $\begin{array}{l}0.006 \\
0.084 \\
0.170\end{array}$ & $\begin{array}{l}-6.601 \\
-1.423 \\
-0.934\end{array}$ \\
\hline
\end{tabular}

Table 9B.2 Wage equations: second step, potential wage

\begin{tabular}{lrlrrrrrr}
\hline & \multicolumn{7}{l}{ Women } & \multicolumn{7}{c}{ Men } \\
\cline { 2 - 3 } Variables & Coefficient & Std. error & t-ratio & & Coefficient & Std. error & t-ratio \\
\hline Constant & 0.504 & 0.470 & 1.072 & -0.237 & 0.302 & -0.783 \\
Education level & 0.084 & 0.009 & 9.411 & 0.072 & 0.003 & 24.272 \\
Age & 0.030 & 0.019 & 1.556 & 0.089 & 0.014 & 6.249 \\
Age squared & -0.000 & 0.000 & -0.982 & -0.001 & 0.000 & -6.042 \\
Past work experience & 0.064 & 0.019 & 3.373 & 0.078 & 0.011 & 6.824 \\
South-east & -0.103 & 0.057 & -1.812 & -0.152 & 0.026 & -5.792 \\
South-west & -0.164 & 0.057 & -2.855 & -0.155 & 0.029 & -5.287 \\
Centre & -0.109 & 0.038 & -2.880 & -0.043 & 0.023 & -1.848 \\
Heckman's lambda & 0.175 & 0.106 & 1.649 & 0.449 & 0.073 & 6.111 \\
Obs. & 1290 & & & 2455 & & \\
$\mathrm{R}^{2}$ & 0.27 & & & 0.30 & & \\
\hline
\end{tabular}

Source: Authors' calculations based on SHIW 1995 data. 


\section{Tindara Addabbo and Massimo Baldini}

\section{Acknowledgements}

We would like to thank the research group on unpaid work and standard of living directed by Professor Antonella Picchio for useful comments on a previous version of this chapter. The usual disclaimers apply. Financial support from CNEL is gratefully acknowledged.

\section{Notes}

1 See Chapter 1 (this volume) above for an analysis and survey of women's budget studies, and Himmelweit (1999) for a report on the UK Women's Budget Group activities.

2 See Picchio (1996) and Chapter 1 (this volume).

3 Only in the 2000 SHIW survey has information on the average weekly number of unpaid hours of work been included for a subsample of households (see Bank of Italy (2002) for first results of this survey, and Chapter 2 (this volume) for comparison with ISTAT 1989 time budget data).

4 See Chapter 3 (this volume) for details on the matching procedure.

5 Minimum income should not be confused with basic income (or citizen's wage): the latter is an unconditional and universal money transfer, provided for all citizens without any means test, whereas minimum income is reserved for those who can prove that they earn less than a threshold corresponding to a minimally decent standard of living. It is therefore a conditional and selective transfer, even if it is universal in the sense that it is potentially available to all households, and does not depend on belonging to specific categories, occupational or otherwise.

6 Plus some corrections aimed at identifying particularly critical situations: the scale is increased by 0.2 points if the head is a single parent, by 0.2 points if both parents work and there are children younger than age 18 living in the household, and by 0.5 points for each seriously physically disabled member.

7 Briefly, ISE = Income +0.2 Wealth. See Baldini et al. (2002) for an analysis of the institutional characteristics and distributive implications of ISE.

8 The geographical disaggregation is similar to that proposed, on the basis of many socio-economic indicators, by Attanasio and Padoa Schioppa (1991): South-east (Puglie, Abruzzo and Molise); South-west (Calabria, Basilicata, Sicily, Sardinia, Campania); North-west (Piedmont, Lombardy, Liguria, Valle d'Aosta); North-east (Veneto, Friuli-Venezia Giulia, Trentino-Alto Adige); Centre (Emilia Romagna, Tuscany, Umbria, Marche, Lazio).

9 See Chapter 3 (this volume).

10 See Appendix for wage equations.

11 These equations are also reported in the Appendix.

12 Only the values of the variables on each partner's characteristics will change, not the parameters of the model.

13 There are obviously alternatives to a market service, such as family or state schools. However, the data-set did not contain sufficient information to estimate the provision of childcare by other relatives, and as far as public childcare is concerned, it must be borne in mind that the choice of private baby-sitting is consistent with the fact that when the job offer arrives, it may be difficult for the family to find a place for the child or to place him or her in school. One should also add the costs connected with childcare search. Moreover, we have assumed that the hourly cost of childcare would not change with the number of children in the family.

14 Apart from social exclusion, one should also consider (Robeyns 1998) the implications for the link between decision-making power and personal income in the family (Ott 1995; Robeyns 1998), and the loss of social connections and identity that 
might be entailed by exiting from the labour market (in this connection see Robeyns 1998).

15 On the effect of work experience on the work profile and on forward wages, see Addabbo 1996. See Joshi and Davies (1994) and Robeyns (1998) on the effects of a discontinuous work profile in terms of the loss of potential wages and on the low rights in terms of retirement.

16 See Ward et al. (1996) and Robeyns (1998) on the effect of childcare services in encouraging women's paid work.

17 See Robeyns (1998) for an analysis of the factors affecting the 'choice' between paid and unpaid work, and on the importance of analysing the effect on the introduction of basic income by different groups of women characterised by a different labour market work attachment and by a different level of potential labour income.

18 Here we report only the results of estimation of housework equations for married women. Equations on different types of unpaid work, by gender and by day of the week, have been run by using Heckman's selection models in order to impute total unpaid work. The complete set of equations run to impute unpaid work for men and women in our sample may be found in Chapter 3 (this volume).

\section{References}

Addabbo, T. (1996) L'offerta di lavoro: un'analisi dinamica, Bologna: CLUEB.

(1999) 'Labour supply and employment probabilities in Italy: a gender analysis in a regional perspective', Economia E Lavoro, 33(3-4).

Addis, E. (1999) 'Gender in the Italian welfare state reforms', South European Society and Politics, 4(2), special issue on 'Gender Inequalities in Southern Europe: Women, Work and Welfare in the 1990s'.

Alti, T. and Maino, F. (1999) 'La sperimentazione del reddito minimo di inserimento in Italia: primi spunti per una valutazione', paper presented at the conference 'Sicurezza Sociale, Mercato e Politiche del Lavoro', Pavia, 17-18 June (mimeo).

Atkinson, A.B. (1996) Incomes and the Welfare State, Cambridge: Cambridge University Press.

Atkinson, A.B. and Mogesen, G.V. (eds) (1993) Welfare and Work Incentives, Oxford: Clarendon Press.

Attanasio, O.P. and Padoa Schioppa, F. (1991) 'Regional inequalities, migration and mismatch in Italy, 1960-1986', in F. Padoa Schioppa (ed.) Mismatch and Labour Mobility, Cambridge: Cambridge University Press.

Baldini, M., Bosi, P. and Toso, S. (2002) 'Targeting welfare in Italy, old problems and perspectives of reform', Fiscal Studies, March, 23(1): 51-75.

Bank of Italy (2002) 'I bilanci delle famiglie italiane nell'anno 2000', Supplementi al Bollettino Statistico, nos 6-18 (January).

Barrère-Maurisson, M., Battagliola, F. and Daune-Richard, A. (1985) 'The course of women's careers and family life', in B. Roberts, R. Finnegan and D. Gallie (eds) New Approaches to Economic Life, Manchester: Manchester University Press, pp. 431-58.

Bettio, F. and Villa, P. (1999) 'To what extent does it pay to be better educated? Education and market work for women in Italy', South European Society and Politics, 4(2), special issue on 'Gender Inequalities in Southern Europe: Women, Work and Welfare in the 1990s'.

Budlender, D., Sharp, R. and Allen, K. (1998) 'How to do a gender-sensitive budget analysis: contemporary research and analysis', Australian Agency for International Development, Canberra and the Commonwealth Secretariat, London (mimeo). 


\section{Tindara Addabbo and Massimo Baldini}

Himmelweit, S. (1998) 'Care and the budgetary process', paper presented at 'Out of the Margin 2' Feminist approaches to economics, European session on Care, University of Amsterdam, 2-5 June.

(1999) 'The UK Women's Budget Group: trying to make macroeconomic policy more women friendly and gender aware', paper prepared for the Pro-Poor, Genderand Environment-sensitive Budgets workshop participant forum, UNICEF House, New York, 28-30 June.

Joshi, H. and Davies, H. (1994) 'The paid and unpaid roles of women: how should social security adapt?', in S. Baldwin and J. Falkingham (eds) Social Security and Social Change. New Challenges to the Beveridge Model, London: Harvester Wheatsheaf.

Moffitt, R. (1992) 'Incentive effects of the U.S. welfare system: a review', Journal of Economic Literature, 30(1): 1-61.

Negri, N. (1998) 'Italia. Le intenzioni del reddito minimo garantito', Assistenza Sociale, 1: 61-73.

Ott, N. (1995) 'Fertility and the division of work in the family', in E. Kuiper and J. Sap (eds) Out of the Margin. Feminist Perspectives on Economics, London: Routledge.

Paugam, S. (1998) 'Francia: gli effetti del Reddito Minimo di Inserimento', Assistenza Sociale, 1: 41-59.

Picchio, A. (1996) 'The analytical and political visibility of the work of social reproduction', in UNDP Background Papers, Human Development Report 1995, New York.

Prometeia (1998) Rapporto di Previsione, Bologna.

Robeyns, I. (1998) 'An emancipation fee or hush money? The advantages and disadvantages of a basic income for women's emancipation and well-being', paper presented at the Seventh Conference on Basic Income, Amsterdam, 1-12 September.

Ward, C., Dale, A. and Joshi, H. (1996) 'Combining employment with childcare: an escape from dependence?', Journal of Social Policy, 25(2): 223-47. 


\section{Index}

Note: page numbers in italics refer to figures or tables separated from their textual references

Addabbo, T. 7, 8, 235

Addis, E. 8, 199, 210-11, 224

advertising 163

age factors: childcare 62 ; co-residence

176-7; marriage 178, 182; time

allocation 31, 42, 97; unpaid domestic

work 62, 139, 179; women 207

Alti, T. 226

Amato government 205, 208

Anderson, M. 21

Angrist, J. 66

Apps, P.F. 104, 112, 113, 116, 117

Arellano, M. 66

Arosson, T. 113

Atkinson, A.B. 227

Australia 224

average membership degrees 131-2, 133, 135-6, 137

Baldini, M. 8

Bank of Italy: family budget survey 172-3; Survey on Household Income and Wealth $44,46,60-1,64,65,77,91-2,225,226$, 227-30, 246n3

Barbagli, M. 44

bargaining theory 112,114

Battistin, E. 66

Becker, G. 112, 126-7, 161

Beijing Platform 25, 59

Belgium 154n5

Belli, E.E. 172

Bettio, F. 199, 235

Bismarckian welfare regime 190-2, 196, 197, 214, 215

Blackorby, C. 105

Blundell, R. 106

Bonke, J. 68, 70
Borzaga, C. 45

Bourguignon, F. 114, 115

Britain, Women's Budget Group 224

Browning, M. 114, 115

Bruyn-Hundt, M. 67

Bryant, K.W. 68, 70

budget share function 108

Budlender, D. 25, 224

Caiumi, A. 7-8, 116

Campanelli, G. 8, 195

Canadian Statistical Institute 4

capabilities and functioning concept 8,9n3 capability approach 124

Capellari, S. 30

capital 26-7n8

capitalism: labour 17-18; modes of production 22-3

care work: family 45, 62, 211, 215;

financing 195-6; gender differences 1 , 122, 196; generational factors 194-5; labour market 194, 211, 243; personspecificity 211-12, 213, 215, 217 , 220n19; private/public 193, 214; singleperson households 195; social

reproduction 122; standards 195, 213-14; statistics 3, 11, 32, 127; women in labour market 194

caregivers: professionals 189-90, 211-12; responsibilities 20; working conditions 213-14

cash transfers: family members 196,197 ; minimum insertion income 224, 225-7; welfare regimes 189-90, 200

Centro di Analisi delle Politiche Pubbliche (CAPP) 46

Chiappero-Martinetti, E. 8 


\section{Index}

Chiappori, P.A. 104, 112, 113, 114

childcare 246n13; age of child 62; costs 236; fathers 4 , 31; grandparents 45, 206; nonprofit institutions 235; regional differences 4

children: costs of $7-8,68,106,108,116$, 235; leisure time 164; living standards 103; time allocation 30, 33, 35, 37, 39; unpaid domestic work for 144-5; vulnerable family members $194-5$

Ciampi government 205

CIG (Cassa Integrazione Guadagni) 200, 202-3, 226

CIG Speciale 203

Cigno, A. 106

CIGO 203

citizen's wage $246 \mathrm{n} 5$

civil society 25

civil status 134

class: state 21; unpaid domestic work 192; waged labour 13

classical political economy: production 17 , 22-3; social reproduction $1-2,17$; structural dynamics $9 \mathrm{n} 4$

co-dependency 193

collective approach 113, 114, 115

Colombino, U. 45

commodities: households 113; labour 17-18, $27 \mathrm{n} 8$; social reproduction 13

construction workers 203

consumption 167 ; convenience 8,157 ,

161-5; extended 100n3, 108-11; housewives 159; income 129-30; scale economies 110; United States of America $157,159,166$; use and throw away 162-3, 167; waged labour 21; see also household consumption

conversion mapping 124

co-operation: family 125 ; households 112 ; social reproduction $125-6$

co-residence: age factors 176-7; education 177-8; family 177, 180-1; gender differences 176-7, 179; Italy 172-4; market-specific variables $181-2$; multinomial logit regressions 183-7; parents 171-2, 173, 179; partners 173 ; reference individual 175-8; regional differences 171, 175-8; students 173-4; unemployed people 172; wage levels 171-2

Cowan, R. 165, 168n17

cross-country comparisons: labour market 218; social expenditure 219, 220; unemployment 219 daily life survey, ISTAT 95-8, 128-30

Deaton, A.S. 115

decision-making: family $246-7 \mathrm{n} 14$;

households 116, 126-7

dependants 201

dependency 14

Dini government 200, 205, 208-9

disadvantaged people $127-8$

domestic labour/immigrants 211

Donaldson, D. 105

double burden 190, 215

double standards 207

durable consumption goods 159

early retirement 205

education 148; co-residence 177-8; gender differences 31, 66, 235; human capital 174, 230; identity 2; ISTAT 148;

minimum insertion income 225; parents 174, 177; time allocation 42; unpaid domestic work 31, 62; wage levels 68, 225; well-being 134; women 42

Ekert-Jaffe, O. 114

elderly 194-5; see also age factors

eligibility: income support 60; minimum insertion income 226, 227-30, 231, 232,

233, 234, 235

Elson, D. 25

Emilia Romagna 4

employment: opportunity cost 196; parents 180

employment probability 245

Engel's approach 104, 108-9

equal opportunity 4, 23

equivalence scales: cost function 106; household 105-7; household production 7-8, 103-4; income 60, 232, 233, 234

Ermisch, J. 172

Esping-Andersen, G. 190

EURISKO data 30, 44

European Commission 21, 25, 26

European Community Household Panel (ECHP) 13-14

European Time Use Study (ETUS) 29

EUROSTAT 29

expenditure/income 25

extended income 1; circular flow 18-22; distribution 68-72; gender differences 60, 73; marriage 68-9; opportunity cost 240; social reproduction 20; unpaid domestic work 22, 224-5, 236; well-being 103

fairness, welfare regime 209-10

familism 193 
family: care work 45, 62, 211, 215; cash transfers 196, 197; co-operation 125; coresidence $177,180-1$; decision-making 246-7n14; dysfunctional 196, 213; firms 14-15, 16-17, 19; heads of household 155n17; human capital 174; identity formation 246-7n14; income distribution 23; ISE 226; labour divisions 23; living standards 199; public policies 106-7, 197; scale economies 125; size of 139 , $163,177,181$; social interactions 246-7n14; time allocation 31, 45; unpaid domestic work 1, 5; vulnerable members 128, 193, 194-5; welfare regimes 190; well-being 127, 154n5; see also households

family allowances (assegni familiari) 200, 201-2, 211

family budget survey, Bank of Italy 172-3 family incomes 14,17

fathers 4, 31, 200

Feminist Economics 26

Ferrera, M. 191-2, 214

fertility choices 106

firms/family 14-15, 16-17, 19

flexibility in labour market 197, 200

Folbre, Nancy 197-8

food industry 160

Fordism 21

fuzzy set theory $8,130,149-51$

gender 220n1

gender differences: assimilation 211-12; care work 1, 122, 196; co-residence 176-7, 179; education 31, 66, 235; extended income $60,63,73,247 \mathrm{n} 18$; heads of household 155n17; income 26, 60; life cycle 224; marriage $247 \mathrm{n} 18$; pensions 205; public policies 25-6, 60; redistribution of resources 60, 190; social exclusion 240; social interactions 134; Sweden 4; time allocation 12, 31-44, 48-51, 62-3, 95-6, 138; unemployment 199; unemployment insurance 204; unpaid domestic work 29-31, 41, 44, 140-3, 244; welfare regimes 25, 189 , 198, 224; work 44; working hours 63-5 gender inequalities 1; pensions 206, 208; time allocation 134-45, 146-7; wage levels 61, 73-4, 75; well-being 130-4 generational factors $115-16,194-5$

Gershuny, J. 195

Giannelli, G.C. 45, 197

Glover, J. 146 grandparents 45, 206

Gronau, R. 67

handicap privileges 199

handicaps, people with 128

heads of household $155 \mathrm{n} 17$

health factors $128,129,148,154 \mathrm{n} 9$

Heckman, J. 61-2, 68

Himmelweit, S. 224

homemakers' fund (casalinghe) 210

house administration 32

household consumption: ISTAT $57 \mathrm{n} 8,60$, 65, 118; SHIW 60; United States of

America 157, 166; unpaid domestic work 160-2; value added 103

household market 157, 158-60, 166

households 41, 108; bargaining theory 112 , 114; collective approach 113, 114, 115; commodities 113; co-operation 112; decision-making 116, 126-7; equivalence scales 105-7; heads of $155 \mathrm{n} 17$; income distribution 60, 72, 114; income inequality 69-70, 71-2; ISTAT 31; living standards 59, 72; minimum insertion income 227-30, 238, 240; production 7-8, 103-4, 125; resource allocation 104-5, 111-13, 115-16, 126; social reproduction 125; sociodemographics 66 ; time allocation 33-40, 48-51, 60, 96-7, 117; unpaid domestic work 46, 52-6; welfare benefits 115 ; working status 228 ; see also family

housewives 134, 159, 168n14

housework 3, 32, 62, 82-3, 159; see also unpaid domestic work

housing conditions 129, 148

housing market 174-5

human capital 18, 19, 171-2, 174, 230

human development 18, 20, 24

husbands 63

identity formation 2, 246-7n14

immigrants 211

income: changes 237, 238, 239, 240, 241, 242; consumption 129-30; equivalence scales 60, 232, 233, 234; expenditure 25; family 14, 17; firms 17; gender differences 26, 60; household inequality 69-70, 71-2; per capita 60; welfare entitlement 60, 196-7; well-being 13; see also extended income

income distribution: family 23; gender differences 26, 60; gender inequalities 1 ; households $60,72,114$ 


\section{Index}

income tax 194

individuals: living standards 69; state 24; utility functions 116

informal economy 23

INPS 201, 203

interdependence 14-15, 22

International Association for Feminist Economics 26

ISE (Indicatore della Situazione Economica) 210-11, 226

ISTAT (Italian Statistical Service): daily life survey 95-8, 128-30; education 129; household 31; household consumption $57 \mathrm{n} 8,60,65,118$; multipurpose survey 172; SHIW 60-1, 91-2; Time Budget Survey 4-5, 6, 7, 10n9, 29, 31-2, 42, $44-5,47,60-1,77,91-2$

Italian Central Institute of Statistics 158

Italy 1; co-residence 172-4; labour market 172; time use/gender differences 12, 139; unpaid domestic work 139, 158; use and throw away consumption 162-3, 167; welfare regime 172, 191-2, 198, 199-201

Jenkins, S.P. 68,70

Kennedy, P. 66

Krueger, A. 66

labour: capitalism 17-18; commodities 17-18, 27n8; costs 195-6; see also waged labour

labour divisions 14-15, 19, 23

labour hoarding 203

labour market: access to 13-14, 20-1; care work 194, 211, 243; cross-country comparisons 218; equity/efficiency 23 ; flexibility 197, 200; gender inequalities 1; Italy 172; minimum insertion income 224, 225-7; public policies 197 ; re-entry 235; retirement 197, 200, 205-6; social reproduction 11-12; young people 174; see also unpaid domestic work; waged labour; women in labour market

labour-saving devices 165, 166

labour time: technology 166-7, 168n17; unpaid domestic work 157, 160-2, 163-4; see also working hours

Ladies Home Journal 159

laundry 167

leisure time 161, 164, 169n20

Leser, C. 108

Lewbel, A. 105, 106 liberal welfare regime 190-1, 194, 215

life cycle 4, 224

Linder, S. 161

living conditions 1 ; economists 21 ; social exclusion 25; waged labour 24; wages fund 17 ; working conditions 22 ; working population 3, 4-5

living standards 2,8 ; extended 7, 60, 74, 227; family 199; households 59, 72; housing conditions 129; individuals 69; number of children 103; regional differences 130, 134; Sen 154n5; social reproduction 12-13; welfare regimes 189; well-being 7, 123; working population 18,19

Lucifora, C. 14, 21

McElroy, M.B. 171

macroeconomic approach 13

Maino, F. 226

male breadwinner model 197, 202, 207

marriage: age factors 178,182 ; extended income 68-9; gender differences 60, 63, 73, 247n18; housework 82-3; regional differences 178 ; unpaid domestic work 31, 44, 57n7, 247n18; working hours 81

Marx, Karl 27n8

maternity leave 199-200

means testing 59-60, 201, 207, 210-11

Meek, R.L. 18

Meghir, C. 66

membership functions 152-3

men: fathers 4, 31, 200; husbands 63;

total working hours 32, 42; unpaid

domestic work 139, 160; welfare

losses/gains 238

microeconometric analysis 61-5

minimum insertion income 224, 225-7,

246n5; cash transfers 224, 225-7; education 225; eligibility 226, 227-30, 230, 231, 232, 233, 234, 235; equivalent financial income 232, 233, 234; households 227-30, 238, 240; labour market 224, 225-7; SHIW 226; take-up rate 240; training 226, 236; unpaid

domestic work 230-40

minimum wage 115

Mobilità 200

mobility allowance 203, 226

Mogesen, S.V. 227

Monacelli, D. 209

Muellbauer, J. 115

multipurpose survey, ISTAT 172 
National Institute for Social Provision (INPS) 201, 203

Negri, N. 226

non-profit firms 22

non-profit institutions 235

non-standard work 200

Nordic welfare regime 190-1, 194, 214

Nussbaum, M. 2, 13, 27n9, 146

\section{OECD 21}

O'Leary, N.G. 68, 70

Olive Tree coalition 201, 202

Olivier, Francesca 64

Ongaro, F. 172

opportunity cost 7, 67-8, 127, 196, 240

Orloff, A. 197

overemployment 45

Padoa Schioppa, K.F. 172

Palomba, R. 30, 31

parents: co-residence 171-2, 173, 179; education 174, 177; employment 180; pensions 197; single 155n16, 201-2

part-time work 63

paternity leave 200

patriarchy 190, 202

pay-roll tax: entitlement 196; family allowances 200; pensions 204; welfare regimes $194,195,197$

pensions 200, 204-7; Dini government 208-9; gender differences 205; gender inequalities 206, 208; minimum 208-10; parents 197

Perali, F. 30, 44, 116

person-specific services 211-12, 213, 215, 217, 220n19

personal relationships 213

Phipps, S.A. 114

Picard, N. 114

Picchio, A. 2, 17, 23, 100n2

Pollak, R.A. 106

post-industrial societies $157,160,161$

poverty: regional differences 230; social exclusion 226; vulnerability 197; wage levels 14, 21; welfare state 230

poverty trap $202,211,225$

prices of housing $174-5$

production: classical political economy 17 ,

22-3; households 7-8, 103-4, 125; social reproduction 17

psychological well-being 129,148

public policies: equal opportunity 23 ; family 107-8, 197; gender differences 25-6, 60; labour market 197; social exclusion 235; unpaid domestic work 6, 8; well-being 25

public services 59-60, 189-90, 214

public voice of women 207

quality of life 23

redistribution of resources $60,189,190$, 220n2

re-entry to labour market 235

Rees, R. 104, 112, 113, 116, 117

regional differences: childcare 4 , 31; coresidence 171, 175-8; gender/unpaid work 31; living standards 130, 134; marriage 178 ; poverty 230 ; unemployment 179 ; use and throw away consumption 163; women in labour market 4,45

replacement costs 67

reproductive labour: see social reproduction resource allocation, households 104-5,

111-13, 115-16, 126

responsibilities $15,20,25$

retirement: early 205; mandatory 197, 200, 205-6

retraining 204

Rettore, E. 66

Ricardo, David 26-7n8

Ringen, S. 125

Robeyns, I. 247n17

Rosenzweig, M.R. 171

Sabbadini, L.L. 30, 31

Samuelson, P.A. 111

scale economies 110,125

Schokkeart, E. 154n5

Scottish Enlightenment 18

self-employment 63

self-esteem 238

Sen, A. 2, 8, 13, 122, 123, 127, 128, 146, $154 \mathrm{n} 5$

service prices $7,67,68$

service sector 160

shopping 32, 165

Shor, J. 21

short-termism 240

single parents $155 \mathrm{n} 16,201-2$

single-person households: care 195; time allocation 32; unpaid domestic work 42 , $43,63,88-90$

Smith, Adam 18

social assistance 226

social benefit 208-10, 226; see also welfare benefits 


\section{Index}

Social Christians 201

social compact 21, 23

social exclusion: gender differences 240;

living conditions 25 ; poverty 226; public

policies 235

social expenditure 219, 220

social interactions $129,134,148,246-7 \mathrm{n} 14$

social national accounting data 59, 122

social pension 209

social reproduction 1; care 122; classical political economy $1-2,17$; commodities

13; co-operation 125-6; holistic approach

127; households 125 ; interactions 16 ;

labour market 11-12; living standards

12-13; production 17; unpaid domestic

work $6-7$; working population 13

social wealth flow 16-18, 22-3

socialisation 2,127

Socialist bloc 21

sociodemographics 66, 225

South Africa 224

standard contracts 200

state 21, 22, 24; see also welfare regimes

Statistics Canada, Total Work 25

statualità (respect for state) 191, 214, 215

Strasser, S. 159

structures of constraint 197-8

students $173-4$

subsistence 18, 22, 26n2

Survey on Household Income and Wealth

(SHIW) 65, 77; and ISTAT 60-1, 91-2;

minimum insertion income 226;

sociodemographics 225 ; unpaid working hours $64,246 \mathrm{n} 3$

survivor's benefits 204, 206, 210

Sweden 4, 198

Swedish Institute of Statistics 9n6

tax credit 201

Taylorism 158-9

technology: labour time 166-7, 168n17; unpaid domestic work 164-5

time allocation: age factors $31,42,97$;

children in family $30,33,35,37,39$;

education 42; family 31 , 45 ; gender

differences 12, 31-44, 48-51, 62-3,

95-6, 138, 139; gender inequalities

134-45, 146-7; household production

126; households 33-40, 48-51, 60, 96-7,

117; ISTAT 30-1, 44; single-person

households 32; unpaid domestic work

63-5, 112-13, 134, 139; waged labour

134, 139; weekdays/weekends 31-2,

$35-40,63,77-90$ time balances 158

Time Budget Survey, ISTAT 4-5, 6, 7, 10n9, 29, 31-2, 42, 44-5, 47, 60-1, 77, 91-2

time constraints 62

Total Work, Statistics Canada 25

total working hours $1,32,42$

training 226, 235, 236

traps $196-7,202,220$ n 12 ; poverty 202 , 211,225

Trifiletti, R. 203

two-step estimation method 61-2

underemployment 45

UNDP 29, 65, 97-8; Human Development

Reports 4, 15, 24

unemployment: Belgium 154n5; coresidence 172; cross-country comparisons 219; gender differences 199; households 236; incentives 196-7; regional differences 179; self-esteem 238

unemployment benefits 200, 202-4

unemployment insurance 204

United States of America: consumption patterns 159; household consumption 157, 166; Taylorism 158-9; unpaid domestic work 158; welfare regime 198 universalism 227

unpaid domestic work 3, 31, 32, 59, 244; age factors 62, 139, 179; for children 144-5; class 192; economic value 5 . 19-20, 59, 192-3; education 31, 62; equation estimation 78-80; evaluation 67-8; extended income 22, 224-5; family 1, 5; gender differences 29-31, 41, 44, 140-3, 244; gender inequalities 1 ; household consumption 160-2; households 46, 52-6; Italy 139, 158; labour time 157, 160-2, 163-6; marriage 31, 44, 57n7, 247n18; men 63, 139, 160; microeconometric analysis 61-5; minimum insertion income 230-40; public policies 6 , 8; SHIW 64, 246n3; single-person households 42, 43, 63, 88-90; social reproduction 6-7; standards 164-5; statistics 3, 11, 100n2, 154n1; Taylorism 159; technology 164-5; time allocation 63-5, 112-13, 134, 139; UNDP 29; United States of America 158; weekdays/weekends 63, 244; well-being 123-8, 145; work type 244

use and throw away consumption 162-3, 167 utilitarian theory 123

utility functions 116 
Van Ootegem, L. 154n5

Vanek, J. 163

Villa, P. 199, 235

voluntary sector 22

vulnerable members of family 128,193 , 194-5

wage equations $68,93-4,245$

wage levels: co-residence 171-2; education 68,225 ; gender inequalities $61,73-4,75$; poverty 14,21 ; women in labour market 235, 236; work experience 68; see also minimum wage

waged labour 7; class 13; consumption 21; dependency 14; gender differences 41 ; living conditions 24 ; single-person households 42, 43; subsistence 22; time allocation 134, 139

wages fund 17,19

Wales, T. J. 106

weekdays: time allocation 31-2, 35, 36, 63, 77-88; unpaid domestic work 63, 244

weekends: time allocation 31-2, 37-40, 63, 77-90; unpaid domestic work 63, 244

welfare benefits: double standards 207; entitlement 60, 196-7; gender differences 25; households 115; losses/gains 238; traps 196-7; universalism 227; widows 206-7

welfare economics $123,124-5$

welfare losses 236

welfare regimes 8,224 ; cash transfers 189-90, 200; comparisons 104, 211-17, 216; fairness 209-10; family 190; gender differences 25, 189, 198, 224; income tax 194; Italy 172, 191-2, 198, 199-201; living standards 189; pay-roll tax 194, 195, 197; poverty 230; public services 189-90; redistribution of resources 189; symmetric/asymmetric 191-2, 193-4, 197, 215-17; see also Bismarckian/Liberal/ Nordic welfare regimes well-being 2, 5; capability approach 124 ; extended income 103; family 127, 154n5; gender inequalities 130-4; housewives

134; human development 20, 24; income 13; living standards 7, 123;

macroeconomic approach 13; nonmonetary 146; psychological 129, 148; public policies 25; unpaid domestic work 123-8, 145

widows 134, 206-7, 210

Wolpin, K.I. 171

women: age factors 207; double burden 190, 215 ; education 42 ; overemployment 45 ; poverty trap 211; public voice 207 ; single 134; underemployment 45; unemployed husbands 238; see also gender differences; gender inequalities

women in labour market 9-10n7; care services 194; with children 32; costs of working 199, 235; loss of welfare 236; maternity leave 199-200; regional differences 4, 45; sectoral differences 63; unpaid domestic work 3-4, 199; wage levels 235, 236

Women's Budget Group, Britain 224

Woolley, F. 197

work: choices 247n17; costs of 199, 235; gender 44; standard/non-standard 200; see also labour market; unpaid domestic work

Working, H. 109

working conditions 22, 213-14

working hours $63-5,73,74,76,81,161$, 197; total 1, 32, 42; see also labour time working population $9 \mathrm{n} 2$; living conditions 3, 4-5; living standards 18, 19; social reproduction 13

young people 174, 197; see also co-residence

Zyck, C.D. 68, 70 


